\title{
Zweiter Beratungsgegenstand: \\ Gesetzesgestaltung und Gesetzesanwendung im Leistungsrecht
}

\section{Bericht von Prof. Dr. Reinhard Mußgnug, Heidelberg}

\section{Inhalt}

\begin{abstract}
Seite
I. Begriff und Eigenart des Leistungsrechts . . . . . . . . . . . . . . 114

1. Die Kennzeichen des Leistungsrechts . . . . . . . . . . . . . 114

a) Die Unschärfe des Begriffs ,Leistung“ . . . . . . . . . . . 114

b) Das Kriterium der freien Gestaltbarkeit . . . . . . . . . . 115

c) Das Kriterium der Finanzabhängigkeit . . . . . . . . . 116

d) Rechtsdogmatische Systematisierbarkeit? . . . . . . . . 117
\end{abstract}

2. Das Leistungsrecht der parlamentarischen Demokratie . . . . . 117

a) Die politische Prävalenz des Leistungsrechts . . . . . . . . 117

b) Der Integrationseffekt des Leistungsrechts . . . . . . . . . . . 119

II. Gesetzliche Gestaltung des Leistungsrechts . . . . . . . . . . . . 120

1. Vermeidung der Leistungsvergabe . . . . . . . . . . . . 120

a) Ersatz der Leistung durch Verschonung . . . . . . . . . . 120

b) Abwälzung der Leistungspflicht auf außerstaatliche

Leistungsträger .................... 120

2. Gestaltung des Leistungsrechts durch Verzicht auf gesetzliche

Regelung . . . . . . . . . . . . . . . . 122

a) Leistungssteuerung über den Haushaltsplan . . . . . . . . . 122

b) Definition des Leistungszwecks durch den Haushaltsplan . . . 124

3. Leistungsrechtlicher Gesetzgebungszwang . . . . . . . . . . . 125

4. Leistungsrechtliches Übermaßverbot? . . . . . . . . . . . . . . 126

a) Das haushaltsrechtliche Úbermaßverbot . . . . . . . . . 126

b) Verfassungsrechtliches Übermaßverbot? . . . . . . . . . . . . 127

c) Finanzverfassungsrechtliches Übermaßverbot? . . . . . . . . 128

d) Verbot der Leistungsfinanzierung durch Kreditaufnahme . . . 129

III. Rechtsanwendung im Leistungsrecht ... . . . . . . . . 132

1. Objektives Leistungsrecht und subjektiver Leistungsanspruch . . 132

a) Das Leistungsrecht im System des verwaltungsgerichtlichen

Rechtsschutzes ........................ 132

b) Leistungsvergabe nach Ermessen . . . . . . . . . . . . . . 133

c) Leistungsvergabe nach typisierenden Vorschriften . . . . . . 134

2. Leistungsrecht und Verwaltungsverfahren . . . . . . . . . 136

a) Sachverhaltsermittlung . . . . . . . . . . . 136

b) Spezialgesetzliche Verfahrensvorschriften . . . . . . . . . 137 
Herr Hill, Herr Hufen und ich haben es mit unserem Thema leicht. Es bedarf keiner Rechtfertigung. Es rechtfertigt sich von selbst. Wir können also ohne Umschweife zur Sache kommen.

Das tut auch not. Denn das Leistungsrecht ist ein weites Feld. Um der Fülle seiner Probleme wenigstens einigermaßen Herr zu werden, müssen wir das europäische Leistungsrecht beiseite lassen; wir gehen davon aus, daß es in der Diskussion von berufeneren Sachkennern zur Sprache gebracht werden wird. Den leistungsrechtlichen Vorbehalt des Gesetzes können wir nur streifen, aber nicht in den Mittelpunkt rücken; er ist 1981 in Trier hinreichend miterörtert worden ${ }^{1}$. Auch die münchner Beratungen von 1986 über die „Rechtsverhältnisse in der Leistungsverwaltung " 2 tragen zu unserer Entlastung bei.

Untereinander haben wir abgesprochen, daß sich Herr Hill primär der sozialen Verwaltungsleistungen annehmen wird. Herr Hufen wird seine Beispiele vorwiegend aus der Daseinsvorsorge beziehen und sich auf die Gesetzesgestaltung konzentrieren. Ich werde mit einem gewissen Schwerpunkt bei den Subventionen auf die allgemeinen Probleme des Leistungsrechts eingehen. $\mathrm{Da}$ das eine Verständigung darüber voraussetzt, was unter dem Leistungsrecht zu verstehen ist, sind einige definitorische Vorbemerkungen angezeigt.

\section{Begriff und Eigenart des Leistungsrechts}

\section{Die Kennzeichen des Leistungsrechts}

\section{a) Die Unschärfe des Begriffs ,"Leistung“}

Inhalt und Gegenstand des Leistungsrechts lassen sich nicht kurz und bündig umreißen. Daran trägt die Unschärfe des Begriffs ,Leistung“" die Schuld ${ }^{3}$. Mit seiner Hilfe ist der Eigenart des Leistungs-

${ }^{1}$ Unter dem Thema „Gesetzgebung im Rechtsstaat“, VVDStRL 40 (1982), S. 7 ff.

2 VVDStRL 45 (1987), S. $152 \mathrm{ff}$.

${ }^{3}$ Einen Eindruck von der kaum zu bändigenden Vielfalt dessen, was der allgemeine und der juristische Sprachgebrauch als ,Leistung“ bezeichnen, vermitteln die Beiträge von Krings und Hollerbach zu diesem Stichwort im Staatslexikon der Görresgesellschaft, Bd. 3, 7. Aufl. 1987. Es kommt daher nicht von ungefähr, wenn von Unruh, DVBl 1972, S. 469ff., selbst die polizeiliche Gefahrenabwehr der Leistungsverwaltung zurechnet; in der Garantie des sicheren Lebens unter dem Schutz der Gesetze, der Behörden und der Gerichte liegt schließlich die raison d'être des Staates. Aber die Begriffe ,Leistungsrecht" und ,Leistungsverwaltung" verlieren ihren Erkenntniswert, wenn man sie mit der Gefahrenabwehr verquickt; vgl. Forsthoff, Rechtsfragen der leistenden Verwaltung, 1959, S. 13. 
rechts nicht beizukommen ${ }^{4}$, und ein anderer tauglicherer Begriff ist nicht in Sicht. Denn das Leistungsrecht ist ein inhomogenes mixtum compositum $^{5}$, das für abstrakte Definitionen keinen Ansatz bietet ${ }^{6}$.

Wo die Abstraktion versagt, bleibt nur die Enumeration übrig. Sie muß auflisten, was die Gleichartigkeit seiner Ziele und Probleme zum Leistungsrecht vereint ${ }^{7}$. Dabei handelt es sich um dreierlei:

1. Um das Recht der öffentlichen Daseinsvorsorge.

2. Um das in das Sozialhilfe- und Sozialversicherungsrecht aufgespaltene Sozialrecht.

3. Um das Recht der Subventionsvergabe.

Diese drei Gebiete verbindet, daß sie mit Geld-, Sach- und Dienstleistungen der Unfähigkeit des Einzelnen, der Wirtschaft und der Gesellschaft abhelfen, aus eigener Kraft aufzubringen, was sie zur Sicherung ihrer Existenz benötigen.

\section{b) Das Kriterium der freien Gestaltbarkeit}

Existenzsichernde Geld-, Sach- und Dienstleistungen erbringt die Verwaltung freilich auch außerhalb der Daseinsvorsorge, des Sozialund des Subventionsrechts.

Die Gehalts- und sonstigen Zahlungen an Beamte, Abgeordnete, ehrenamtlich Tätige, Wehr- und Ersatzdienstpflichtige, Zeugen und Sachverständige etc. haben mit dem Leistungsrecht jedoch nichts zu schaffen $^{8}$. Sie werden als erdiente Leistungen nach andern Regeln vergeben und bemessen als die Geldleistungen des Sozial- und Subventionsrechts. Das gleiche gilt für die Entschädigungsleistungen. Sie erfaßt das Leistungsrecht nur, wenn ihnen die verfassungsrechtliche Absicherung fehlt. So verhält es sich z.B. mit der Entschädigung für

4 Auch dann nicht, wenn man vom Leistungsbegriff des Zivilrechts ausgeht. In der Sichtweise der $\S \S 241$ und 812 BGB sind auch die Erteilung der Fahrerlaubnis, die Einbürgerung, die Aushändigung des amtlichen $\mathrm{Kfz}-\mathrm{Kennzeichens}$ und die Befreiung vom Wehrdienst Leistungen. Ginge es nach dem Zivilrecht, so schmölze der Unterschied zwischen dem Eingriffs- und dem Leistungsrecht also auf die Differenzierung zwischen dem begünstigenden und dem belastenden Verwaltungshandeln zusammen. Auch das hat Forsthoff nicht gemeint, als er der Leistungsverwaltung in seiner bahnbrechenden Schrift „Die Verwaltung als Leistungsträger" aus dem Jahre 1938 ihren Namen gab.

5 So auch Schulze-Fielitz, DÖV 1988, S. 758ff., 760; Hennecke, DÖV 1988, S. $768 \mathrm{ff}$., 769; Tzong-li Hsu, Verfassungsrechtliche Schranken der Leistungsgesetzgebung im Sozialstaat, 1986, S. 25ff.

- In den von Krause, VVDStRL 45 (1987), S. 213-215 aufgelisteten Beispielen leistungsrechtlicher Verwaltungstätigkeiten tritt das besonders anschaulich zutage.

7 Das war auch Forsthoffs (Fn. 4, S. 9f., 27) Methode.

- Dazu und zum folgenden Tzong-li Hsu (Fn. 5, S. 27ff.). 
die seuchenpolizeiliche Tötung von Haustieren, die das TierseuchenG den Landwirten zuspricht ${ }^{9}$. Da Art. 14 Abs. 3 GG sie nicht gebietet ${ }^{10}$, ist sie bei Lichte besehen eine Subvention. Die Enteignungs- und Aufopferungsentschädigung indessen ist an verfassungsrechtliche Vorgaben gebunden, die ihrer freien Gestaltung nach den Prinzipien des Leistungsrechts einen festen Riegel vorschieben ${ }^{11}$. Das trennt sie vom Leistungsrecht $\mathrm{ab}$.

Das Leistungsrecht erfaßt also nicht alles, was die Verwaltung an Geld-, Sach- und Dienstleistungen vergibt. $\mathrm{Ihm}$ sind allein die Leistungen zuzuschlagen, über die der Gesetzgeber frei disponieren kann. Das reduziert das Leistungsrecht auf die Trias von Daseinsvorsorge, Sozialund Subventionsrecht. Allein bei ihr genießt der Gesetzgeber den breiten Spielraum, der das eine Charakteristikum des Leistungsrechts ausmacht $^{12}$.

\section{c) Das Kriterium der Finanzabhängigkeit}

Das andere Kennzeichen des Leistungsrechts liegt in seiner Finanzabhängigkeit ${ }^{13}$. Denn das Leistungsrecht kann nur leisten, was die öffentlichen Haushalte hergeben. Darin steckt das Kernproblem, mit dem der Gesetzgeber bei der Gestaltung und die Verwaltung bei der Anwendung des Leistungsrechts fertig werden müssen. Ein in diesen Tagen veröffentlichtes Urteil des VGH Mannheim ${ }^{14}$ belegt, daß auch die Justiz mit ihm zu ringen hat. Es betrifft die Klage zweier Sozialhilfeempfänger, die für ihre 3 und 5 Jahre alten Kinder eine einmalige Beihilfe für den Kauf eines Dreirads und eines Puppenhauses begehrten. Der VGH hat ihre Klage zum größten Teil abgewiesen. Zwischen

9 Weitere Beispiele liefern der Ausgleichsanspruch des $\S 38$ AtomG für Schäden, die durch grenzüberschreitende Auswirkungen nuklearer Unfälle im Ausland verursacht werden (dazu neuerdings VG Köln NJW 1988, S. 1995f. und S. $1596 \mathrm{ff}$ ), sowie die Entschädigung für Opfer von Gewalttaten, die $\S 7$ OEG folgerichtig auf den sozialgerichtlichen Rechtsweg verweist.

10 BVerfGE 20, S. $351 \mathrm{ff}$.

11 Aus diesem Grunde sind auch die Wahlkampfkostenerstattung, die Förderung des politischen Bildungswesens (BVerfGE 73, S. 1ff.) und die Subventionierung der Privatschulen (BVerfGE 75, S. 40ff.) aus dem Leistungsrecht auszuscheiden.

12 Das Sozialstaatsprinzip engt diesen Spielraum zwar ein; denn es gebietet ein bestimmtes Minimum an Daseinsvorsorge-, Unterstützungs- und Versicherungsleistungen. Aber den Ausschlag gibt, daß das Leistungsrecht mehr vergeben kann, als es vergeben muß. Begrenzt ist es nur ,, nach unten“; , nach oben “ bleibt es offen; vgl. Zacher, in: Isensee/Kirchhof (Hrsg.), Handbuch des Staatsrechts I, 1987, \& 25 Rdn. 63ff.; Stark, DVBl 1978, S. 937 ff., 938.

${ }_{13} \mathrm{Zu}$ ihr Stern, Das Staatsrecht der Bundesrepublik Deutschland I, 2. Aufl., 1984, S. 918 ff.

14 Vom 18.1.1988, ESVGH 38, S. $130 \mathrm{ff}$. 
den Zeilen der Entscheidungsgründe klingt jedoch deutlich an, daß er ihr gerne in vollem Umfang stattgegeben hätte. Aber damit hätte das Gericht einen Präzedenzfall geschaffen, der zu einer Vermehrung der einmaligen Beihilfen um $8 \%$ (bei derzeit jährlich 1,2 Milliarden ${ }^{15}$ also um 96 Millionen DM) gezwungen hätte. Das verbot es dem VGH, großmütig zu entscheiden. Er mußte die Belange des Steuerstaats im Auge behalten ${ }^{16}$.

\section{d) Rechtsdogmatische Systematisierbarkeit?}

In der Diskrepanz zwischen staatlicher Leistungsbereitschaft und staatlicher Leistungsfähigkeit sehe ich das prägende Merkmal des Leistungsrechts. In allem übrigen unterscheiden sich die Daseinsvorsorge-, Sozial- und Subventionsleistungen zu sehr von einander, als daß sie sich über einen Leisten schlagen ließen. Wenn sich die Verwaltungsrechtslehre dem Leistungsrecht gegenüber kraftlos gezeigt hat ${ }^{17}$, so ist das nicht der Insuffizienz ihrer Bemühungen um dieses Gebiet, sondern dem Widerstand zuzuschreiben, den das Leistungsrecht seiner rechtsdogmatischen Vereinheitlichung entgegensetzt. Der gemeinsame Nenner des Leistungsrechts, die Vergabe von finanzwirksamen Geld-, Sach- und Dienstleistungen, ist als Grundlage für eine verwaltungsrechtliche Sonderdogmatik zu klein. Für seine zusammenfassende Betrachtung eignen sich allein die Probleme, die von dem Aufeinanderprallen des sozialpolitischen Drucks zur fortwährenden Steigerung der Daseinsvorsorge-, Sozial- und Subventionsleistungen mit dem finanzpolitischen Zwang zu ihrer Begrenzung auf das Maß des Bezahlbaren herrühren.

\section{Das Leistungsrecht der parlamentarischen Demokratie}

\section{a) Die politische Prävalenz des Leistungsrechts}

Der Trend zur permanenten Vermehrung der Verwaltungsleistungen wird gemeinhin auf ökonomische und soziale Ursachen zurückgeführt. Die wirtschaftlichen, gesellschaftlichen und technischen Veränderungen der letzten $100 \mathrm{Jahre}^{18}$, erklären jedoch lediglich das Entstehen und allmähliche Anwachsen des Leistungsrechts. Seine seit der

\footnotetext{
15 Statistisches Jahrbuch 1987, S. 416.

16 Zur Begrenzung der richterlichen Rechtsfortbildung durch die finanziellen Bindungen des Leistungsrechts Starck, VVDStRL 34 (1976), S. 83.

17 So Zacher, VVDStRL 25 (1967) S. 310.

${ }^{18} \mathrm{Zu}$ ihnen Forsthoff, (Fn. 3), S. 23 ff.; ders., Der Staat der Industriegesellschaft, 1971, S. 42ff.; ders., Lehrbuch des Verwaltungsrechts, 10. Auflage 1973, S. 61ff.; Häberle VVDStRL 30 (1972), S. $55 \mathrm{ff}$.
} 
Mitte der 50'er Jahre in der Bundesrepublik zu beobachtende Tendenz zum Überborden indessen beruht auf anderen, nämlich verfassungsrechtlichen Gründen.

Auf den stimulierenden Einfluß der Grundrechte hat Häberle 1972 in Regensburg hingewiesen ${ }^{19}$. Die Umdeutung der Grundrechte in Teilhaberechte ist zwar juristisch umstritten geblieben. Als politisches Postulat hat sie sich jedoch durchgesetzt. Das Leistungsrecht hat ihr in jeder seiner drei Sparten Tribut zollen müssen, in der Daseinsvorsorge mit dem Ausbau der Hochschulen, im Subventionsrecht mit der Theaterund Filmförderung, im Sozialrecht mit der Ausbildungsförderung, um nur die markantesten Beispiele zu nennen.

Noch stimulierender hat sich, wenn ich es richtig sehe, die feste Anbindung der Regierung an das Parlament ausgewirkt, die sich aus den Regeln des Grundgesetzes über die Kanzlerwahl und die Kabinettsbildung ergibt. Mit ihr hat das Grundgesetz die parlamentarische Demokratie in ihrer reinen Form verwirklicht ${ }^{20}$, die nicht nur den Erhalt der Regierungsmacht ${ }^{21}$, sondern auch den Zugang zu ihr vom Vertrauen der Parlamentsmehrheit und damit vom Ausgang der Wahlen abhängig macht $^{22}$.

Daß der Regent abtreten muß, wenn er vor seinem Volk ,mit leeren Händen dasteht", wußte schon Macchiavelli ${ }^{23}$. Sein Rat, dem Volk mit der Peitsche in der Hand gegenüberzutreten, weil das Verteilen von Geschenken nur den Appetit auf mehr Geschenke weckt, verfängt allerdings nicht mehr. Eine Regierung, die dem Bürger Furcht einflößt, erlebt bestenfalls das Ende der laufenden Legislaturperiode. Will sie es überleben, so muß sie im gemeinsamen Zusammenwirken mit ihrer Parlamentsmehrheit das Leistungsrecht ausbauen und dem Wunsch der Bevölkerung auf fortwährend opulentere Leistungen bis an die Grenzen des noch eben Möglichen nachgeben. Denn in der parlamentarischen Demokratie ist mit dem Eingriffsrecht ,,kein Staat zu machen “24.

19 VVDStRL 30 (1972), S. 45ff.

20 Vgl. Herzog in: Mounz/Dürig/Herzog, GG, Art. 53, Rdnr. 2.

21 So noch die Weimarer RV, die der Reichsregierung beim Reichspräsidenten mehr Rückhalt bot als beim Reichstag; dazu Mußgnug, in: Jeserich/Pohl/von Unruh (Hrg.) Deutsche Verwaltungsgeschichte IV, 1985, S. $308 \mathrm{ff} ., 312$ und V, 1987 , S. 100 ff., 101.

${ }^{22}$ Das unterstreicht die der WRV noch fremde Synchronisation der Regierungs- mit der Wahlperiode (Art. 69 Abs. 2 GG).

${ }^{23}$ Zitiert nach der von Carlo Schmid besorgten Auswahl aus "Il Principe", 1956, S. 57, Nr. 35.

${ }^{24}$ Die Weimarer Republik konnte die Tuberkulose noch mit Zwangsbehandlungen und Reihenuntersuchungen bekämpfen. Den Gesundheitspolitikern der Bundesrepublik indessen fällt nur die kostenlose Verteilung von Einwegspritzen ein, wenn es gilt, die unter den Rauschgiftsüchtigen grassierenden Infektionskrankheiten einzudämmen. 
Ihr Verfassungsrecht rückt das Leistungsrecht in den Mittelpunkt der Politik.

Es verwundert daher nicht weiter, daß der steile Aufschwung des Leistungsrechts erst nach 1949 einsetzte ${ }^{25}$. Er ist das notwendige Attribut der parlamentarischen Regierungsform. Die parlamentarische Demokratie ebnet dem Streben nach dem Optimum an Staatsleistungen den Weg. Seiner Verwechslung mit dem Maximum hat sie nur den anachronistischen und daher gänzlich unwirksamen Art. 113 GG $^{26}$ entgegenzusetzen.

\section{b) Der Integrationseffekt des Leistungsrechts}

Es wäre allerdings kurzsichtig, das breite Vordringen des Leistungsrechts als das Negativum der parlamentarischen Demokratie zu betrachten. Denn vom Leistungsrecht geht ein nicht zu unterschätzender Integrationseffekt aus. Das hat die Weimarer Republik vernachlässigt. Sie hat es ihren Gegnem leicht gemacht, sie zu diffamieren, weil sie mit ihrem Leistungsrecht zu sparsam und mit ihrem Eingriffsrecht zu unbeholfen umgegangen ist. Die Bundesrepublik hat sich nicht zuletzt deshalb als stabil erwiesen, weil sie ihren Bürgern mit ihrem breit aufgefächerten Leistungsangebot das Gefühl sozialer Geborgenheit und gouvernementaler Fürsorge vermittelt.

Eine Reduktion des Leistungsrechts auf das unerläßliche Minimum wäre daher verfehlt. Der Staat muß als Leistungsgeber präsent bleiben. Die Subsidiaritätslehre ${ }^{27}$ sollte er nicht zur alleinigen Richtschnur seiner Leistungsgesetzgebung erheben. Großzügigkeit bei der Leistungsvergabe steht ihm jedenfalls besser an, als kleinkariertes Sparen um des Sparens willen. Der Staat darf sich mit seinem Leistungsrecht nicht übernehmen. Aber was er sich ohne Gefahr für seine finanzwirtschaftliche Ordnung leisten kann, sollte er nicht nur im Interesse seiner Bürger, sondern auch in seinem eigenen Interesse leisten.

${ }^{25}$ Signifikant war vor allem die Entwicklung des Subventionsrechts. Die Weimarer Republik setzte die Subventionen zur Krisenbewältigung ein (vgl. E.R.Huber, Deutsche Verfassungsgeschichte VI, 1981, S. 1040f.). Zum allgegenwärtigen Instrument der staatlichen Einflußnahme auf das Wirtschaftsleben hat sie erst die Bundesrepublik erhoben.

${ }^{26}$ Zur Untauglichkeit des Art. 112 GG Tomuschat, Der Staat, 19 (1980), S. 1ff., 12 m.w.N.; zu seiner anachronistischen Systemwidrigkeit Mußgnug, Der Haushaltsplan als Gesetz, 1976, S. 203.

${ }_{27} \mathrm{Zu}$ ihr Isensee, Subsidiaritätsprinzip und Verfassung, 1968; Rupp, in: Isensee/Kirchhof (Hrsg.), Handbuch des Staatsrechts I, 1987, § 28 Rdnr. 51ff. 


\section{Gesetzliche Gestaltung des Leistungsrechts}

\section{Vermeidung der Leistungsvergabe}

Was das Leistungsrecht verteilen kann, hängt von den öffentlichen Einnahmen ab. Aber es gibt Wege, die daran vorbei führen.

\section{a) Ersatz der Leistung durch Verschonung}

Der bekannteste, die Steuersubvention, ist allerdings ein Irrweg. Was der Staat auf ihm an Ausgaben spart, geht ihm bei den Einnahmen verloren. Die Steuersubventionen setzen das Steuerrecht zudem für einen Zweck ein, für den es nicht bestimmt ist ${ }^{28}$. Die Gebührenbefreiungen und ermäßigungen, die sozial Benachteiligten im Bereich der Daseinsvorsorge gewährt werden, wirken prima facie unbedenklicher. Aber sie werfen die intrikate Rechtsfrage auf, ob es angeht, Gebühren statt nach dem Wert der gebührenpflichtigen Leistung, nach dem Einkommen der Gebührenschuldner zu bemessen ${ }^{29}$. Das ist jedoch ein abgabenrechtliches, kein leistungsrechtliches Problem.

\section{b) Abwälzung der Leistungspflicht auf außerstaatliche Leistungsträger}

In engerer Verbindung mit dem Leistungsrecht steht die Technik, Leistungspflichten von der Verwaltung auf die private Wirtschaft zu verlagern. Sie entlastet die öffentlichen Haushalte dadurch, daß sie den gegen die Verwaltung gerichteten Leistungsanspruch durch einen solchen gegen einen verwaltungsfremden Schuldner ersetzt und auf diese Weise die Leistungspflicht mitsamt ihren Kosten vom Staat auf andere Leistungsträger, vorzugsweise die Arbeitgeber, abwälzt ${ }^{30}$.

Aufgrund des LohnfortzahlungsG erhalten so z.B. diejenigen Versicherten, die in einem Betrieb mit mehr als 20 Mitarbeitern beschäftigt sind, das Krankengeld während der ersten sechs Wochen ihrer Arbeitsunfähigkeit seit 1969 nicht mehr von der Krankenkasse, sondern von ihrem Arbeitgeber ${ }^{31}$. Das zweite VermögensbildungsG ${ }^{32}$ ebnete der tarifvertraglichen Inpflichtnahme der Arbeitgeber zu vermögensbildenden Leistungen an ihre Belegschaft den Weg. In Nordrhein-Westfalen und Hessen steht den Arbeitnehmern ferner ein gesetzlich garan-

${ }^{28}$ Dazu Tipke, Steuerrecht, 11. Aufl. 1987, S. 570ff.; Paul Kirchhof, Verwalten durch ,mittelbares" Einwirken, 1977, S. 380ff.

${ }^{29}$ Dazu einerseits VGH Kassel, NJW 1977, S. 452ff. m. Anm. von Klaus Vogel und andererseits Zacher, aaO. (Fn. 12), Rdn. 59f.

${ }^{30}$ Dazu ausführlicher Mußgnug, FS für Forsthoff, 1972, S. $259 \mathrm{ff} ., 283$.

$31 \S 10$ LohnfortzahlungsG i.Verb.m. §182 Abs. 4 RVO.

${ }^{32}$ Vom 1.7.1965 (BGBl. I, S. 585); zu ihm Forsthoff, BB 1965, S. $381 \mathrm{ff}$. 
tierter Bildungsurlaub von alljährlich 5 Tagen zu, den die Arbeitgeber durch die Weitergewährung des Arbeitslohns zu finanzieren haben ${ }^{33}$.

Mit alledem sichert das Arbeitsrecht den Arbeitnehmern Leistungen, die ihnen der Staat zu Lasten der Arbeitgeber verschafft. Der mietrechtliche Kündigungsschutz, die gesetzliche Limitierung der Mieten und das Wohnraum-Zweckentfremdungsverbot laufen auf das Gleiche hinaus. Auch sie schlagen bei der Sozialhilfe und beim Wohngeld mit gewichtigen Einsparungen zu Buche.

Derartige Entlastungen des Leistungsrechts durch gesetzliche Belastungen der privaten Wirtschaft sind im Prinzip legitim. Das Sozialstaatsprinzip muß nicht durch Staatsleistungen verwirklicht werden. Der Gesetzgeber kann ihm ebenso gut auch durch eine soziale Gestaltung des Arbeits- und des Mietrechts Rechnung tragen. In einer vom Sozialstaatsprinzip geprägten Privatrechtsordnung ist die Verwaltung weniger gefordert, als in einer solchen, die der Vertragsautonomie freien Lauf läßt. Es ist das gute Recht des Staates, sich das zunutze zu machen ${ }^{34}$.

Die Leistungsverlagerung vom Staat auf private Schuldner kommt freilich nur in Betracht, wenn sie an manifeste soziale Verantwortlichkeiten anknüpfen kann. Die Fürsorgepflicht des Arbeitgebers und die Sozialbindung des Vermieter-Eigentums rechtfertigen sie. Aber derartige Fürsorgepflichten und Sozialbindungen kann der Gesetzgeber nicht aus freier Hand zurechtkonstruieren ${ }^{35}$. Es gelten hier die gleichen Schranken, die das Verfassungsrecht auch der Leistungsfinanzierung durch Sonderabgaben zieht ${ }^{36}$. Diese Art der „Flucht ins Privatrecht" gehört zwar zum gesicherten Instrumentarium der leistungsrechtlichen Gesetzesgestaltung. Aber sie verdient das besondere Augenmerk der Jurisprudenz. Es ist vor allem an der Zeit, ihre Grenzen schärfer zu konturieren.

Dies hat das BVerfG vor kurzem ${ }^{37}$ hervorgehoben. Es hat den Arbeitnehmer-Bildungsurlaub wegen seiner Beschränkung auf 5 Tage pro Jahr als eine ,zumutbare“ Belastung der Arbeitgeber angesehen, den

${ }^{33} \mathrm{Zu}$ den Einzelheiten BVerfGE 77, S. 308ff.

${ }^{34} \mathrm{Da}$ dies schon seit langem geschieht, zeigt der Vollstreckungsschutz der ZPO. Bei ihm spielte von Anbeginn die Überlegung mit, daß das Kahlpfänden der Schuldner ein verkappter Griff der Gläubiger in die öffentlichen Armenkassen ist.

${ }^{35}$ Die Verpflichtung der kommunalen und privaten Verkehrsbetriebe zur unentgeltlichen Beförderung der Schwerbehinderten ging z.B. zu weit (so BVerwGE 14, S. $160 \mathrm{ff}$.). Die $\$ \S 59 \mathrm{ff}$. SchwerbehindertenG haben daraus die Konsequenz gezogen. Sie halten zwar an dem Anspruch der Behinderten auf Fahrgeldbefreiung fest, sprechen den Verkehrsbetrieben aber einen gegen den Staat gerichteten Anspruch auf Erstattung ihrer Ausfälle zu.

${ }^{36}$ Sie sind in BVerfGE 55, S. 274ff., 305-308 näher definiert.

${ }^{37}$ BVerfGE 77, S. 334 und 336f. 
bezahlten Urlaub, den Hessen auch den Arbeitnehmern zugestanden hat, die als Lehrkräfte an Bildungsveranstaltungen mitwirken wollen, aber als ,unzumutbar" beanstandet. Mit dem Kriterium der ,Zumutbarkeit " hat das BVerfG die Leistungsabwälzung auf private Leistungsträger aber noch nicht sicher genug im Griff ${ }^{38}$.

\section{Gestaltung des Leistungsrechts durch Verzicht auf gesetzliche Regelung}

\section{a) Leistungssteuerung über den Haushaltsplan}

Ist die Leistungsfinanzierung aus Haushaltsmitteln nicht zu umgehen, so behält sie der Gesetzgeber am zuverlässigsten unter seiner Kontrolle, wenn er auf eine gesetzliche Regelung der Leistungsvergabe verzichtet. Damit vermeidet er die rechtlichen Bindungen, die er der Verwaltung mit der gesetzlichen Normierung ihrer Leistungen auferlegt. Dafuir aber unterwirft er die Behörden einer umso festeren budgetären Bindung. Denn das Leistungsermessen trägt paradoxe Züge. Je freier es im Außenverhältnis zwischen Bürger und Verwaltung schalten kann, desto enger sind die Schranken, die ihm der Haushaltsplan im Innenbereich auferlegt. Gesetzlich fixierte Leistungspflichten müssen die Behörden auch dann erfuillen, wenn ihnen der Haushaltsplan die dafür erforderlichen Gelder vorenthält ${ }^{39}$. Ihr Ermessen dagegen reicht nur soweit, wie ihr Etat reicht. Auch wenn das Leistungsermessen durch kein Gesetz beengt wird, so zieht ihm der Haushaltsplan dennoch ein in Mark und Pfennig genau beziffertes, unübersteigbares Limit.

Dieses Limit macht sich auch im Außenverhältnis bemerkbar. Denn die Gerichte können es schwerlich als ermessensfehlerhaft beanstanden, wenn die Behörden Leistungen verweigern müssen, weil ihr Etat erschöpft ist ${ }^{40}$. Art. 3 Abs. $1 \mathrm{GG}$ entkräftet den haushaltsrechtlichen Erschöpfungseinwand lediglich, wenn die Verwaltung ihre Mittel plan-

38 Das Kriterium der Zumutbarkeit leistet dem Irrtum Vorschub, es komme auf den Umfang der Leistungen an, die der privaten Wirtschaft aufgebürdet werden. Entscheidend ist jedoch ihre Qualität. § 1 Abs. 2 Satz 2 LohnfortzahlungsG, der die Arbeitgeber auch bei der sozial indizierten Abtreibung zur Lohnfortzahlung verpflichtet, ist, wenn überhaupt, so jedenfalls nicht damit zu retten, daß die Lohnfortzahlung im Abtreibungsfall nur einen Bruchteil von dem kostet, was der Arbeitgeber für den Mutterschutz aufwenden müßte.

${ }^{39}$ Dazu Mußgnug, Der Haushaltsplan als Gesetz, 1976, S. 307ff.

$40 \mathrm{Vgl}$. BVerwGE 7, S. $180 \mathrm{ff}$., 184 sowie das in DVB1. 1988, S. 1062f. veröffentlichte Urteil des BVerwG vom 19.5.1988, das freilich zu kurz greift, wenn es sagt, daß ein aus haushaltsrechtlichen Gründen unerfüllbarer Antrag ermessensfehlerfrei abgelehnt werden ,dürfe"; ein solcher Antrag muß abgelehnt werden. 
los verschleudert ${ }^{41}$. Geht sie nach sachgerechten Kriterien vor, so ist der Verweis auf die Dürftigkeit des Etats ein stichhaltiger, nachgerade klassischer Ablehnungsgrund. Denn die Bindung der Exekutive an den Haushaltsplan läßt sich nicht mit der Brechstange des Art. 3 Abs. 1 GG aushebeln ${ }^{42}$.

Gegen die Leistungssteuerung allein durch den Haushaltsplan sind nur dann Bedenken anzumelden, wenn sich der Gesetzgeber auf sie auch dort zurückzieht, wo ihm der Vorbehalt des Gesetzes eine Regelungspflicht auferlegt ${ }^{43}$. Aber der Vorbehalt des Gesetzes erfaßt nicht jede Verwaltungsleistung. Im Leistungsrecht stößt er zudem an seine Grenzen. Denn er kann die gesetzliche Regelung der wesentlichen Leistungen lediglich fordern, sie aber nicht durch das Verbot ihrer Vergabe ohne gesetzliche Grundlage erzwingen. Die Ausbildungsförderung beweist das. Obwohl sie zum harten Kern des sozialpolitisch Wesentlichen zählt, haben sie der Bund und die Länder über ein Jahrzehnt ausschließlich durch die Verwaltungsvereinbarungen des Honnefer Modells geregelt ${ }^{44}$. Die Frage, wie sich das mit dem Vorbehalt des Gesetzes zusammenreimt, hat sich das Bundesverwaltungsgericht vorsichtshalber gar nicht erst gestellt ${ }^{45}$. Es wäre mit ihr in eine Sackgasse geraten, die nur zu vermeiden ist, wenn man den Vorbehalt des Gesetzes im Leistungsrecht zu einer verfassungsrechtlichen Naturalobligation ${ }^{46}$ degradiert. Der totale Parlamentsvorbehalt, dem das Leistungsrecht aufgrund des Art. $110 \mathrm{GG}$ unterliegt, erleichtert es, sich damit ebenso abzufinden, wie dies das BVerwG tut, das sich mit der ,parlamentarischen Willensäußerung “ begnügt, mit der das Haushaltsgesetz und der Haushaltsplan jede Verwaltungsleistung absegnen ${ }^{47}$.

Das Leistungsrecht schärfer an den Vorbehalt des Gesetzes zu ketten, wäre verfehlt. Denn der Leistungsstaat muß auf seine budgetäre Beweglichkeit bedacht blieben. Die Leistungssteuerung über den Haushaltsplan sichert sie ihm. Die lückenlose Durchnormierung des Leistungsrechts indessen macht den Leistungsstaat finanziell manövrierunfähig. Sie führt zum Abdriften des Leistungsrechts in den Sog der Haushaltssicherungsgesetze, die es mit weit grobschlächtigeren Metho-

${ }^{41}$ Z.B. also, wenn sie ihre Subventionsmittel nach dem "Windhundprinzip“ an die verteilt, die sie als Erste beantragen, und diejenigen abweist, die sich ,verspätet" mit besser begründeten Anträgen melden.

${ }_{42}$ Dazu eingehender Paul Kirchhof. NVwZ 1983, S. 505ff., 511 und Mußgnug, aaO. (Fn. 39), S. 335f.

43 Vgl. Mußgnug (Fn. 39), S. 315.

44 Vgl. Stephany, Das Honnefer Modell, 1968.

${ }^{45}$ BVerwGE 18, S. $352 \mathrm{ff} ., 353$.

46 So Wolfgang Martens, FS für J.J. Wolff, 1973, S. 435.

${ }^{47}$ Seit BVerwGE 6, S. $282 \mathrm{ff}$., 287 st. Rspr.; zu ihrer Würdigung Jarass, NVwZ 1984 , S. $473 \mathrm{ff} ., 478$. 
den im Zaum halten müssen, als dies seine von Jahr zu Jahr durch den Haushaltsplan neu zu begründende Ordnung ermöglicht.

\section{b) Definition des Leistungszwecks durch den Haushaltsplan}

Zur Regelung der Leistungsvergabe eignet sich der Haushaltsplan jedenfalls dann weit besser als das Leistungsgesetz, wenn es um die Verteilung vergleichsweise bescheidener Summen an einen überschaubaren Empfängerkreis geht. In diesem Fall bedarf es keiner breit ausholenden Vorschriften. Es genügt im Haushaltsplan zu regeln, welche Beträge für welchen Zweck zur Verfügung stehen, ein Verfahren, das sich für die Subventionen geradezu aufdrängt und bei ihnen vom $\mathrm{Ge}$ setzgeber auch bevorzugt angewandt wird. Die Kritik, die daran in der Literatur geübt wird, überzeugt mich nicht.

Das gilt auch für Haverkates ${ }^{48}$ These, die Vergabe einer jeden Leistung setze die gesetzliche Definition ihres Zwecks voraus ${ }^{49}$, weil sie andernfalls der verwaltungsgerichtlichen Kontrolle entgleite. Diese These vermengt die Frage, wer den Subventionszweck festzulegen hat, mit der ganz anderen Frage, in welcher Form dies geschehen muß.

Von Wichtigkeit ist allein, daß neben der Entscheidung über das Leistungsvolumen auch die Entscheidung über den Leistungszweck vom Parlament getroffen wird; ob im Haushaltsplan oder in einem ergänzend zu ihm hinzutretenden Gesetz, spielt keine Rolle. Die Zweckbestimmungen des Haushaltsplans binden die Verwaltung nämlich ebenso wie ein förmliches Gesetz. Wird ein Subventionsantrag mit der irrigen Begründung abgelehnt, er entspräche nicht dem im Haushaltsplan festgelegten Subventionszweck, so ist das ermessensfehlerhaft. Bewilligungen, die der Zweckbestimmung des Haushaltsplans zuwiderlaufen, sind umgekehrt rechtswidrig; sie können also gemäß § 48 VwVfG zurückgenommen werden ${ }^{50}$. Beides unterliegt der verwaltungsgerichtlichen Prüfung. $\mathrm{Ob}$ die Verwaltungsgerichte bei ihr von einem förmlichen Gesetz oder von der Innenbindung des Haushaltsplans ausgehen

48 Rechtsfragen des Leistungsstaats, 1983, S. $196 \mathrm{ff}$, ders. NVwZ 1988, S. 769 ff., 770.

49 Ähnlich der 55. Deutsche Juristentag 1984 (Verhandlungen II, Sitzungsberichte M, S. 199f. Nr. 4 und 5), der die Subventionsvergabe von einer vorherigen Bestimmung des Subventionszwecks durch Rechtsverordnung abhängig machen will.

so $\S 48$ Abs. 1 VwVfG hebt auf die objektive Rechtswidrigkeit ab, an der auch der haushaltswidrige VA leidet; vgl. Kopp, VwVfG, 4. Aufl. 1986, § 48 Rdn. 28. Der VGH Mannheim (NVwZ 1983, S. 552ff., 555) geht sogar noch weiter. Er entnimmt dem Haushaltsrecht eine Pflicht zur Rücknahme der haushaltswidrigen Leistung. 
müssen, fällt nicht ins Gewicht ${ }^{51}$. Es gibt also keine Lücke, die durch gesetzliche Definitionen des Subventionszwecks geschlossen werden müßte ${ }^{52}$.

\section{Leistungsrechtlicher Gesetzgebungszwang}

Der kurze Weg der Leistungssteuerung über den Haushaltsplan führt allerdings nur im Recht der Daseinsvorsorge und im Subventionsrecht zum Ziel. Dem Sozialrecht ist er versperrt. Denn das Sozialrecht kann nicht auf Ermessensleistungen aufbauen. Es muß gesetzlich fixierte Ansprüche garantieren, die der Haushaltsplan nicht summenmäßig limitieren kann. Das verleiht dem Sozialrecht eine finanzpolitisch bedrohliche Sprengkraft. Wenn der Gesetzgeber die Ansprüche auf die sozialen Leistungen nicht sorgfältig begrenzt, droht die Gefahr, daß für ihre Erfüllung erheblich mehr aufgewendet werden muß, als die Finanzlage hergibt. Die leistungsrechtliche Gesetzesgestaltung darf daher bei der Begründung von Rechtsansprüchen nicht stehen bleiben. Thre eigentliche Aufgabe besteht darin, diese Ansprüche auf das Maß des Bezahlbaren einzudämmen ${ }^{53}$. Das anspruchsbegründende Gesetz muß die Verwaltung an den doppelten Imperativ binden: Nicht weniger, aber auch nicht mehr!

Wie das gesetzgebungstechnisch $\mathrm{zu}$ bewerkstelligen ist, hängt von der Art der jeweiligen Leistung ab. Der Gesetzgeber muß sich an den Beträgen orientieren, die mittelfristig für sie zur Verfügung stehen. Verengt er den Kreis ihrer Destinatäre, so kann er die individuelle Leistung erhöhen. Reduziert er die im Einzelfall zu vergebende Lei-

51 Die gesetzliche Bestimmung des Leistungszwecks unterscheidet sich lediglich darin von der des Haushaltsplans, daß die Verwaltungsgerichte sie dem BVerfG zur Prüfung im Verfahren des Art. 100 Abs. $1 \mathrm{GG}$ vorlegen müssen, während sie sich über verfassungswidrige Zweckdefinitionen des Haushaltsplans eigenmächtig hinwegsetzen dürfen (BVerfGE 38, S. $201 \mathrm{ff}$.). Aber das ändert nichts daran, daß z.B. das Marionettentheater, dem die Teilhabe an der Theaterförderung verweigert wird, allemal eine gerichtliche Prüfung seines Begehrens herbeiführen kann. Ob es ein von der „Theater"-Förderung ausgeschlossenes aliud ist, hängt davon $a b$, was unter einem ,Theater" zu verstehen ist, nicht davon, ob der Haushaltsplan oder ein förmliches Gesetz diesen Begriff zum ausschlaggebenden Kriterium erheben. Es bleibt sich auch gleich, ob ihn der Haushaltsplan oder ein Gesetz durch den Zusatz „Puppenbühnen ausgeschlossen" näher konkretisieren; das schlägt nur im Hinblick auf Art. 100 Abs. 1 GG zu Buch, hindert die Verwaltungsgerichte aber nicht, auch den Haushaltsplan zu beanstanden; im Gegenteil: Halten sie den von ihm angeordneten Ausschluß der Puppenbühnen für verfassungswidrig, so können sie ohne den Umweg über das BVerfG zur Sache entscheiden.

${ }^{52}$ So auch v. Arnim, Wirtschaftlichkeit als Rechtsprinzip, 1988, S. 102.

53 Vgl. dazu Starck, VVDStRL 34 (1976) S. 83f. 
stung, so kann er einen entsprechend größeren Empfängerkreis berücksichtigen. Es geht darum diese beiden Alternativen miteinander ins rechte Lot $\mathrm{zu}$ bringen, also entweder wenigen viel oder vielen wenig $\mathrm{zu}$ geben und dabei so nahe als möglich an die ideale Lösung heranzukommen, die allen exakt das gibt, was sie brauchen, ohne damit die Finanzkraft von Staat, Wirtschaft und Gesellschaft zu überfordern.

Um dieses Ideal geht es bei der leistungsrechtlichen Gesetzesgestaltung. Daß es die zentrale politische Pflicht der Leistungsgesetzgebung definiert, steht außer Frage. Unklar ist jedoch, ob der Gesetzgeber auch rechtlich zur Begrenzung der Staatsleistungen auf das Idealmaß des sozial Sinnvollen und finanziell Tragbaren verpflichtet ist, mit anderen Worten: $\mathrm{Ob}$ ihn ein leistungsrechtliches Übermaßverbot zu mehr Standfestigkeit gegenüber den Leistungsbegehren von Gesellschaft und Wirtschaft $z$ wingt, als er es bislang im Vertrauen auf das trügerische Motto „Kommt Zeit, kommt Geld“ an den Tag gelegt hat. ${ }^{54}$

\section{Leistungsrechtliches Übermaßverbot?}

\section{a) Das haushaltsrechtliche Übermaßverbot}

Das Ubermaßverbot untersagt freilich nur, „mit Kanonen auf Spatzen zu schießen". Spatzen mit Kaviar zu füttern gilt als erlaubt. Das spricht gegen ein leistungsrechtliches Ubermaßverbot. Das Ubermaßverbot gehört in das Eingriffsrecht. Im Leistungsrecht wirkt es eher deplaziert. Dem Gebot des geringsten Eingriffs ein Gebot der geringsten Begünstigung gegenüberzustellen, wäre abwegig. Auch das Prinzip der Erforderlichkeit schießt im Leistungsrecht über sein Ziel hinaus. Gemessen an ihm wäre die Ausbildungsförderung durch Zuschüsse noch im Nachhinein zu verurteilen, weil sich mittlerweile herausgestellt hat, daß auch Darlehen genügen. Für das Leistungsrecht taugt daher nur das abgemilderte Ubermaßverbot, das in der Form des Wirtschaftlichkeits- und Sparsamkeitsgebots ${ }^{55}$ in den $\S \S 5,6$ und 19 HGrG sowie in den Gemeindeordnungen ${ }^{56}$ und der $\mathrm{RVO}^{57}$ seinen Niederschlag gefunden hat. Aber das Wirtschaftlichkeits- und Sparsamkeitsgebot bietet lediglich eine Handhabe gegen behördliche Leistungsex-

${ }^{54} \mathrm{Zu}$ dieser Frage v.Arnim, aaO. (Fn. 52), S. 67ff.; Starck, DVBl 1978, S. 937ff., 938; Tzong-li Hsu, Verfassungsrechtliche Schranken der Leistungsgesetzgebung im Sozialrecht, 1986, S. 77ff.

ss Zu ihm neuerdings v. Arnim, aaO. (Fn. 52).

56 Vgl. $\$ 77$ Abs. 2 bw. GemO.

s7 $\S 383$ e, 383 n Abs. 8. 
zesse $^{58}$. Gegen Gesetze, die allzu großzügige Leistungen ausdrücklich gestatten oder gar zwingend vorschreiben, fruchtet es nicht. Was die leges speciales des Leistungsrechts erlauben, kann die lex generalis des Haushaltsrechts nicht verbieten. Um auch die Leistungsgesetzgebung zu zügeln, bedarf es daher eines auch an sie adressierten verfassungsrechtlichen Übermaßverbots.

\section{b) Verfassungsrechtliches Übermaßverbot?}

Für ein solches verfassungsrechtliches Verbot der Leistung im ÜbermaB gibt das GG allerdings wenig her. Art. 114 Abs. 2 spricht zwar von der „Wirtschaftlichkeit der Haushalts- und Wirtschaftsführung“; er regelt jedoch nur die Kontrollkompetenz des Bundesrechnungshofs; ein den Gesetzgeber bindendes Ge- oder Verbot ist ihm nicht zu entnehmen ${ }^{59}$. Art. 109 Abs. 2 GG hilft ebenfalls nicht weiter. Er richtet sich nicht gegen die übermäßige Leistungsvergabe als solche, sondern nur gegen ihren das gesamtwirtschaftliche Gleichgewicht störenden Einsatz zur falschen Zeit und an der falschen Stelle.

Auch die Ableitung des leistungsrechtlichen Ubermaßverbots aus ungeschriebenen verfassungsrechtlichen Grundsätzen zeitigt kein überzeugendes Resultat. Denn es verträgt sich nicht mit der demokratischen Struktur des Grundgesetzes, Leistungen, die das Parlament ausdrücklich gebilligt hat, mit dem Verdikt des Ubermäßigen und daher per se Verfassungswidrigen zu belegen. In der Demokratie setzt der durch das Gesetz verkörperte Wille der Volksvertretung das Maß der Dinge. Demokratische Verfassungen müssen daher von der Vernunft der Gesetze ausgehen. Ihrem Umschlagen in die Unvernunft beugt das Gesetzgebungsverfahren vor, das dem Parlament die gewissenhafte Prüfung des Für und Wider eines jeden Gesetzes, wenn nicht gebietet, so jedenfalls ermöglicht. Ließe das demokratische Verfassungsrecht es zu, Staatsleistungen, die dieses Verfahren unbeanstandet passiert haben, wegen ihres Ubermaßes zu unterbinden, so würde es sich selbst untreu. Das demokratische Verfassungsrecht muß dem Augenmaß des Gesetzgebers vertrauen. Mit einem an seine Adresse gerichteten leistungsrechtlichen Ubermaßverbot brächte es zum Ausdruck, daß es der Volksvertretung und ihren Wählern mißtraut. Das aber wäre mit der Idee von der Souveränität des Volkes schlechterdings unvereinbar ${ }^{60}$.

\footnotetext{
so Ein markanter, allerdings schon lange zurückliegender Fall dieser Art hat den BGH in BGHZ 36, S. 395ff. beschäftigt.

s9 So auch von Arnim, aaO. (Fn. 52), S. 71f., 82ff. m.w.N.

${ }^{60}$ Zur rechtsphilosophischen und historischen Begründung dieser These Badura, Die parteienstaatliche Demokratie und die Gesetzgebung, 1986, S. 6f., $15 f f$.
} 
Die Frage nach dem rechten Maß der Staatsleistungen ist somit eine politische, keine Rechtsfrage. Sie kann nur vom Parlament beantwortet werden. Dessen leistungsrechtliche Entscheidungen mögen fragwürdig erscheinen. Aber das Parlament eicht mit ihnen die Skala, an der die Verwaltungsleistungen zu messen $\operatorname{sind}^{61}$.

\section{c) Finanzverfassungsrechtliches Übermaßverbot?}

Leistung im Ubermaß bedingt jedoch Besteuerung im Ubermaß. Das weist der Suche nach einer verfassungsrechtlichen Begründung des leistungsrechtlichen Utbermaßverbotes die Richtung. Sie kann nicht bei der Leistungsvergabe ansetzen. Sie muß bei der Leistungsfinanzierung einhaken.

Soweit die Verwaltungsleistungen aus dem allgemeinen Steueraufkommen finanziert werden, führt aber auch das nur weiter, wenn die Quote, die der Staat vom individuellen Einkommen und Vermögen als seinen Steueranteil in Anspruch nehmen darf, verfassungsrechtlich limitiert ist. Uber diese Frage haben wir uns 1980 in Innsbrück gestritten. Kirchhof hat die Ansicht vertreten, die Einkommensteuer dürfe in den unteren und mittleren Einkommensbereichen die 50\%Grenze nicht und auch bei den Spitzeneinkommen nur mäßig überschreiten $^{62}$. Dem habe ich in der Diskussion widersprochen ${ }^{63}$. An dem, was ich damals gesagt habe, halte ich fest. Aber ich will die innsbrucker Auseinandersetzung nicht erneut in Gang bringen. Deshalb nur so viel:

Darf die staatliche Steuerlast eine bestimmte Obergrenze nicht überschreiten, so steht dem Leistungsrecht nur die Summe zur Verfügung, die der Staat insgesamt an Steuern erheben darf. Diese Summe bildet gleichsam das Konto, das die Leistungsgesetzgebung nicht überziehen, wohl aber bis zur Neige ausschöpfen kann. Das schützt vor überhöhten Steuern, jedoch nicht vor einem Leistungsrecht, das die Steuern bis an den Rand des Zulässigen hochtreibt.

61 Das sieht der VfGH Rheinland-Pfalz, DVBl. 1969, S. 709ff. richtig. Er entnimmt Art. 1 Abs. 3 der rhl.-pf. LVerf. (,Die Rechte und Pflichten der öffentlichen Gewalt werden durch die naturrechtlich bestimmten Erfordernisse des $\mathrm{Ge}-$ meinwohls begründet und begrenzt") zwar eine Gemeinwohlbindung auch der Gesetze, hält aber ihre richterliche Beanstandung als gemeinwohlunverträglich nur in extrem gelagerten Fällen für vorstellbar. In dieser Beschränkung schiebt das Übermaßverbot nur absurden Fehlleistungen einen Riegel vor, wie sie sich die Phantasie leicht ausmalen kann, wie sie in der Praxis aber nicht vorkommen. Die Fragen, um die es in der konkreten Wirklichkeit des Leistungsrechts geht, kann es nicht bewältigen, weil es all das, was ernsthaft erwogen wird, gar nicht erst erfaßt.

62 VVDStRL 39 (1981), S. 272.

63 VVDStRL 39 (1981), S. 381 f. und $391 \mathrm{f}$. 
Von Arnims innsbrucker These, die Besteuerung dürfe nur soweit gehen, wie dies der staatliche Ausgabenbedarf erfordert ${ }^{64}$, kommt dem leistungsrechtlichen Übermaßverbot näher. Ihr zufolge setzt das Steuererhebungsrecht des Staates voraus, daß der Steuerertrag ausschließlich für gemeinwohlförderliche Ausgaben verwendet wird. Staatsleistungen ohne manifesten Bezug zum Gemeinwohl haben daher $\mathrm{zu}$ unterbleiben. Sie sind verfassungswidrig, weil es verfassungswidrig ist, für sie Steuern zu erheben ${ }^{65}$.

Aber auch das führt nur zu der Ausgangsfrage zurück, wer bestimmt, was dem Gemeinwohl dient. Das Verhältnismäßigkeitsprinzip, auf das von Arnim $^{66}$ verweist, vermag sie nicht zu beantworten. Denn es liegt im Dunkeln, womit die Staatsleistungen ins rechte Verhältnis zu bringen sind. Der Leistungszweck hilft jedenfalls nur begrenzt. Ob die Ausbildungsförderung als Zuschuß oder als Darlehen zu gewähren ist, läßt sich an ihm nicht ablesen. Davon abgesehen läßt sich nicht nur die Leistung ihrem Zweck, sondern umgekehrt auch die Definition ihres Zwecks der Leistung anpassen. Die einkommensunabhängige Ausbildungsförderung wäre sicher des Guten zu viel; aber als ,Ausgleich für ausbildungsbedingte Einkommensausfalle“ gewinnt auch ein ,Studentengehalt" wenigstens so viel Plausibilität, daß es mit dem Verhältnismäßigkeitsprinzip nicht mehr zu packen ist. Die Binsenweisheit, nach der die Unvernunft des Gesetzes für sich allein nicht zu seiner Verfassungswidrigkeit führt, würde es gegen alle juristischen Angriffe $a b$ schirmen ${ }^{67}$.

Uber die Tautologie des „Was zu viel ist, ist zu viel“ dringt also auch der Ansatz beim Steuerrecht nicht hinaus. Die Suche nach dem leistungsrechtlichen Übermaßverbot endet stets bei dem „quis iudicabit", auf das die Demokratie nur eine Antwort weiß: Zwischen dem Maß und dem Übermaß des Leistungsrechts unterscheidet das Parlament durch seine Gesetzgebung und seine Haushaltsbewilligungen.

\section{d) Verbot der Leistungsfinanzierung durch Kreditaufnahme}

Die Dinge sehen jedoch anders aus, wenn die Kosten des Leistungsrechts durch Kreditaufnahmen abgedeckt werden müssen. Die Kreditaufnahme begegnet nur dann keinen Bedenken, wenn sie zu-

64 VVDStRL 39 (1981), S. 311 ff., 316.

65 Ähnlich Mußgnug, FS für Forsthoff, 1972, S. 259ff., 276-278.

66 AaO., (Fn. 64), S. 310.

${ }^{67}$ Und zwar selbst dann, wenn das „Studentengehalt“ dem Eingangsgehalt des höheren Dienstes entspräche. Ebenso nahe wie die Annahme, eine derart spendable Ausbildungsförderung sei unverhältnismäßig hoch, liegt die umgekehrte, die Eingangsgehälter des höheren Dienstes seien unverhältnismäßig niedrig, wenn jeder Student das Gleiche erhält. 
gunsten der Investitionsleistungen der öffentlichen Daseinsvorsorge erfolgt. Diese Investitionen schaffen bleibende Werte. Das rechtfertigt es, die Steuerzahlergenerationen, die sie nutzen werden, über die Schuldentilgung an ihren Kosten zu beteiligen ${ }^{68}$. Subventions- und Sozialleistungen, die durch Kreditaufnahmen finanziert werden müssen, sprengen indessen die Grenzen des verfassungsrechtlich Erlaubten. In ihnen wird manifest, daß der Staat mehr leistet, als er sich leisten kann.

Art. 115 Abs. 1 Satz 2 GG verbietet das zwar nicht expressis verbis. Denn seine Neufassung durch das Finanzreformgesetz 1969 hat die alte Zweckbindung der Kreditmittel für den ,außerordentlichen Bedarf" durch eine Limitierung der Kreditaufnahme auf ,die Summe der im Haushaltsplan veranschlagten Investitionen " begrenzt ${ }^{69}$. Seither können auch nicht investive Ausgaben mit Krediten gedeckt werden, sofern ihnen investive Ausgaben in gleicher Höhe gegenüberstehen. Dieses Limit darf außerdem ,zur Abwehr einer Störung des gesamtwirtschaftlichen Gleichgewichts" überschritten werden ${ }^{70}$.

Aus Art. 115 GG zu folgern, daß dem Leistungsrecht ein Kreditplafond in der Größenordnung der jeweiligen Investitionsausgaben zur Verfügung stünde, wäre gleichwohl voreilig. Art.115 GG muß im Zusammenhang mit dem Gebot des Haushaltsausgleichs gesehen werden. Art. 110 Abs. 1 Satz 2 GG gestattet zwar Defizite durch Kreditaufnahmen auszugleichen. Ein langfristiges Wirtschaften auf Pump indessen erlaubt er nicht. Denn mit der Wirtschaft auf Pump überschreiten Parlament und Regierung die temporären Schranken ihres Mandats. Ihr Auftrag zur Gestaltung des Leistungsrechts gilt für die jeweilige Wahlperiode. Mit der Leistungsfinanzierung durch Kredit greifen sie über diese Zeitspanne hinaus. Sie verbrauchen heute, was morgen benötigt wird. Statt die Zukunft zu gestalten, schränken sie ihr Leistungsvermögen ein. Denn das nächste Parlament und seine Regierung müssen vorab die Schulden begleichen, die ihnen ihre Vorgänger hinterlassen. Je üppiger das Leistungsrecht der Gegenwart den Staat verschuldet, desto enger schrumpft daher der Spielraum des künftigen Leistungsrechts. Es kann dazu kommen, daß Leistungen, die in der Vergangenheit mit Krediten finanziert worden sind, justament dann eingestellt

${ }^{68}$ Bei Püttner, Staatsverschuldung als Rechtsproblem, 1980, S. 14ff. kommt das zu kurz. Püttner übersieht vor allem, daß die von ihm propagierte Investitionsfinanzierung aus den laufenden Einnahmen auf eine Besteuerung der Gegenwart für den Bedarf der Zukunft hinausläuft. Die Kreditaufnahme vermeidet das durch eine gerechtere Verteilung des Investitionsaufwands über die Jahre.

${ }^{69}$ Zur Auslegung des Art. 115 Abs. 1 Satz 2 GG v. Arnim/Weinberg, Staatsverschuldung in der Bundesrepublik Deutschland, 1986; Henseler, AöR 108 (1983), S. 490ff., 513; Heun, Die Verwaltung 18 (1985), S. 1ff.; Fricke, DVBl. 1977, S. 26ff.; Brenner/Haury/Lipp, FinArch. 38 (1980), S. 236ff.

70 Dazu v.Amim/Weinberg, aaO. (Fn. 69), S. 107ff. 
werden müssen, wenn das Steueraufkommen für sie ausreichen würde, aber primär zur Bezahlung dessen verwendet werden muß, was sich frühere Steuerzahlergenerationen gegönnt haben ${ }^{71}$.

Das belegt, daß die langfristige Abdeckung des Leistungsrechts durch Kreditaufnahmen verfassungswidrig ist. Art. 115 Abs. 2 Satz 2 GG nimmt die Verschuldung zugunsten nichtinvestiver Ausgaben hin, wenn Konjunkturkrisen und der mit ihnen einhergehende Steuerrückgang sie erzwingen. Aber das vermag ein Leistungsrecht, das auf lange Sicht zur Kreditaufnahme nötigt, nicht zu rechtfertigen. Ein solches Leistungsrecht fuihrt zu einer verfassungswidrigen strukturellen Verschuldung ${ }^{72}$, die sich nicht durch die Ausrufung einer Dauerkrise rechtfertigen läßt.

Allein daran kann das leistungsrechtliche Ubermaßverbot anknüpfen. Aber es richtet sich nicht gegen einzelne Leistungen. Es zielt auf das Leistungsrecht in seiner Gesamtheit ab. Organ- und Normenkontrollklagen, die ein bestimmtes Leistungsgesetz angreifen, können daher nicht auf das leistungsrechtliche Ubermaßverbot gestützt werden. Dieses Verbot trägt nur solche Klagen, die bei der Staatsverschuldung einhaken. Eine derartige Klage ist seit 1982 beim BVerfG anhängig. Sie richtet sich gegen das Haushaltsgesetz 1981 und die von ihm vorgesehene Schuldenaufnahme. Die Entscheidung des BVerfG steht noch aus. Gleichgültig wie sie ausfällt, sie wird mit Sicherheit auch für das Leistungsrecht und seine gesetzliche Gestaltung richtungsweisende Bedeutung entfalten.

Damit möchte ich meine Ausführungen zur leistungsrechtlichen Gesetzesgestaltung abbrechen. Ich wende mich nun abschließend der Gesetzesanwendung im Leistungsrecht zu. Da vieles von dem, was zur

7 Das kommt bei Heun aaO. (Fn. 69), S. 24ff. zu kurz. Er hebt zwar zu Recht auf die demokratische Bestimmungsmacht des Parlaments ab, bedenkt aber zu wenig, daß Art. 115 GG der Entscheidung über die Staatsverschuldung Grenzen zieht. Was Heun in diesem Zusammenhang vorträgt, rechtfertigt die Besteuerungshoheit, nicht jedoch auch die Verschuldungshoheit des Gesetzgebers, die sich auch und gerade in der Demokratie nicht zu einem Recht zum beliebigen Vorgriff auf künftige Einnahmen ausweiten läßt. Das geht selbst dann nicht an, wenn mit hinreichender Gewißheit mit einem Anwachsen des Steuerertrags zu rechnen ist. Denn das erhöhte Steueraufkommen der Zukunft steht zur Disposition derer, die es aufbringen, nicht zur Disposition derer, die vorerst nur hoffen, daß es in der zur Deckung ihres Konsums erforderlichen Höhe anfallen wird. Die Formel ,pay as you use“ trägt die Investitionsfinanzierung aus Kreditmitteln. Wer konsumtive Staatsleistungen mit Krediten bestreitet, verfälscht sie zu der Parole der Kreditunwürdigen ,let our children pay for our living“, der Art. 115 GG mit gutem Grund eine deutliche Absage erteilt.

${ }_{22} \mathrm{Zu}$ der Differenzierung zwischen der unbedenkiichen konjunkturellen und der verfassungsrechtlich dubiosen strukturellen Staatsverschuldung v.Arnim/ Weinberg, aaO. (Fn. 69), S. $25 \mathrm{ff}$. 
Rechtsanwendung im Leistungsrecht anzumerken ist, bereits 1986 in München erörtert wurde, kann ich mich - wie eingangs bereits gesagt bei ihr kürzer fassen.

\section{Rechtsanwendung im Leistungsrecht}

\section{Objektives Leistungsrecht und subjektiver Leistungsanspruch}

\section{a) Das Leistungsrecht im System des verwaltungsgerichtlichen Rechtsschutzes}

Mit der Anwendung des Leistungsrechts hat es seine besondere Bewandtnis, weil die Gerichte mit ihr nur befaßt werden, wenn die Behörden Leistungsbegehren ablehnen. Die Leistungsbewilligung indessen ist der gerichtlichen Kontrolle entzogen. Es gibt keinen Kläger, der sie angreifen und infolgedessen keinen Richter, der sie prüfen kann. Die Leistungsbewilligung bleibt daher ungerügt und ungeprüft. Daran mußten die Versuche scheitern, die Schwangerschaftsunterbrechung auf Krankenschein vor Gericht zu bringen ${ }^{3}$. Hätten die Krankenkassen sie dem $\S 200 \mathrm{f}$ RVO zuwider verweigert, so hätten wir nicht lange auf die klärenden Entscheidungen aus Kassel und Karlsruhe zu warten brauchen. Thre Bewilligung indessen entpuppt sich als gerichtsfreier Hoheitsakt.

Das hat seine Folgen. Das Leistungsrecht ist kompliziert. Darin steht es dem Steuerrecht in nichts nach ${ }^{74}$. Seine Anwendung setzt ebenso wie die des Steuerrechts meist umfangreiche Sachverhaltsaufklärungen voraus, die das Leistungsrecht - anders als das Steuerrecht nicht im Griff hat. Die Erhebung der Sozialversicherungsbeiträge klappt. Die Vergabe der Sozialversicherungsleistungen indessen stößt auf Schwierigkeiten ${ }^{75}$. An die Regel ,im Zweifel gegen die Leistung“, können sich die Behörden zudem nur bei der Subventionsvergabe halten; im Sozialrecht müssen sie umgekehrt nach dem Prinzip ,im Zweifel für die Hilfeleistung" schalten.

$\mathrm{Da}$ bei der Leistungsvergabe viele Fehler unterlaufen, verwundert daher nicht weiter. Die Dunkelziffer scheint beunruhigend hoch zu sein. Wagener hat das 1979 in Bonn eindrucksvoll begründet ${ }^{76}$. Er be-

33 BVerfGE 67, S. 26ff. und neuerdings NJW 1988, S. 2289.

74 Dazu unter dem Stichwort „Bürokratisierung des Leistungsrechts" SchulzeFielitz, DöV 1988, S. 767.

${ }^{75}$ Vgl. z.B. Möhlenbruch, NJW 1988, S. 1894, der schildert, wie schwer es fällt, für die pünktliche Einstellung der Rentenzahlungen beim Ableben des Berechtigten zu sorgen.

${ }^{76}$ VVDStRL 37 (1979), S. 248. 
richtete von einem Amtmann, der getadelt wurde, weil sich bei einer internen Prüfung 9\% der von ihm erlassenen BAFöG-Bescheide als fehlerhaft erwiesen hatten, der aber wenig später ein Lob erhielt, als sich herausstellte, daß er weit unter der durchschnittlichen Fehlerquote von $21 \%$ lag. Das bestätigt den Verdacht, daß die Leistungsverwaltung weit mehr Geld verteilt, als sie von Rechts wegen verteilen dürfte. Es ist an der Zeit, nach Wegen Ausschau zu halten, die dem abhelfen.

\section{b) Leistungsvergabe nach Ermessen}

Die Verwaltungslehre steht jedoch ganz im Bann des subjektiven Anspruchs auf Teilhabe an den Staatsleistungen. Die objektiv rechtswidrige Leistungsbewilligung dagegen beschäftigt sie nur im Zusammenhang mit der subventionsrechtlichen Konkurrentenklage ${ }^{77}$. Vor der prozessual nicht zu fassenden Leistung ohne Januskopf zieht sie sich auf $\$ 42$ Abs. 2 VwGO zurück. Dafür ringt sie umso nachhaltiger mit den Ermessensleistungen. Sie packt die Verwaltung bei ihren Richtlinien und ständigen Ubungen, um aus ihnen über das Vehikel des Gleichheitsgrundsatzes den Anspruch auf die richtlinienkonforme Leistungsvergabe und als seine Kehrseite die Rücknehmbarkeit des richtlinienwidrigen Bewilligungsbescheids abzuleiten. Das eine ist nur im Ansatz richtig, das andere schon im Ansatz falsch.

\section{aa) Durchbrechbarkeit der Vergaberichtlinien}

Art. 3 Abs. 1 GG gebietet, Ermessensleistungen gleichförmig zu vergeben. Aber er verlangt nur Gleichheit vor dem Gesetz, und für die Ermessensleistung besagt das Gesetz: „Ein Rechtsanspruch besteht nicht" "78. Art. 3 Abs. 1 GG verbietet daher nur willkürliche Abweichungen von den bisherigen Vergabepraktiken. Wo sachliche Gründe Ausnahmen rechtfertigen, läßt er ihnen Raum ${ }^{79}$.

Es gibt viele Gründe, die im konkreten Einzelfall solche Ausnahmen nahelegen. Insbesondere ist es keineswegs per se willkürlich, wenn die Verwaltung richtlinienkonforme Anträge ablehnt, weil die Erschöpfung ihres Etats sie dazu zwingt. Die Verwaltung genießt die Freiheit zum Entscheiden nach Ermessen schließlich nicht zuletzt deshalb, um ihrer Bindung an den Haushaltsplan gerecht werden zu können.

$"$ Vgl. Zuleeg, Subventionskontrolle durch Konkurrentenklage, 1973; ders. DöV 1984, S. 733ff., 738.

78 Die Richtlinien, mit denen die Verwaltung die Subventionsvergabe reguliert, versäumen es so gut wie nie, darauf ausdrücklich hinzuweisen. Vgl. z.B. Nr. 20 Abs. 3 der Bestimmungen des bad.-württ. Innenministeriums über die Förderung des sozialen Wohnungsbaus vom 30.6.1977, GemABl. S. $965 \mathrm{ff}$.

79 Dazu Oldiges, NJW 1984, S. $1927 \mathrm{ff} ., 1931$. 


\section{bb) Rechtswidrigkeit der richtlinienwidrigen Leistung?}

Ebenso wenig wie die richtlinienwidrige Subventionsverweigerung ist die richtlinienwidrige Subventionsbewilligung per se rechtswidrig. Das haben die Verwaltungsgerichte aus den Augen verloren. Sie halten jede Subventionsbewilligung für rücknehmbar, die von einer Verwaltungsvorschrift oder einer ständigen Úbung abweicht ${ }^{80}$. Damit befreien sie die Behörden von der Peinlichkeit, sich selbst der Willkür bezichtigen zu müssen, wenn sie eine zunächst für vertretbar erachtete Ausnahmebewilligung nachträglich reut ${ }^{81}$.

Auch das gibt der Gleichheitsgrundsatz nicht her. Denn den Verwaltungsrichtlinien geht die leistungsbegrenzende Verbindlichkeit des Gesetzes ab. Die Ermächtigung zur Leistungsvergabe fließt nicht aus ihnen. Sie findet ihre Grundlage in Rechtsnormen und in den Bewilligungen des Haushaltsplans. Es gilt, was das Gesetz und der Haushaltsplan besagen. Leistungen, die durch sie gedeckt werden, gehen auch dann rechtlich in Ordnung, wenn ihnen das paralegale Regelwerk der Richtlinien und Dienstanweisungen entgegensteht. Rechtswidrig ist die richtlinienwidrige Leistungsvergabe daher nur, wenn zu ihrer Richtlinienwidrigkeit weitere Mängel hinzutreten, die sie als willkürlich ausweisen $^{82}$. Alles andere ebnet den Unterschied zwischen der Bindung der Verwaltung an das Gesetz und ihrer Bindung an die von ihr selbst gesetzten Vorgaben ihres Handelns ein. Es gilt diesen Unterschied zu verteidigen. Wer ihn zu überwinden versucht, argumentiert am Verfasssungsrecht vorbei.

\section{c) Leistungsvergabe nach typisierenden Vorschriften}

Die durch zwingende gesetzliche Vorschriften geregelten Leistungen hat die Verwaltung freilich so zu bewilligen und zu verweigern, wie das Gesetz es befiehlt. Die Härten, zu denen das in atypisch gelagerten Sonderfällen führen kann, entschärft das Leistungsrecht durch Härteklauseln. Eine solche Klausel enthält z.B. $§ 602$ RVO. Er hilft

${ }^{\text {Bo }}$ So zuletzt OVG Bremen, NVwZ 1988, S. 447ff. m.w.N.; ebenso Götz, NVwZ 1984, S. 480 ff., 481.

${ }^{81}$ Geht es nach dieser Rechtsprechung, so kann die Bewilligung öffentlicher Mittel für den Bau eines Einfamilienhauses von mehr als $130 \mathrm{~m}^{2}$, die $\S 39$ Abs. 2 II. WohnungsbauG unter bestimmten Voraussetzungen ausdrücklich zuläßt, trotz ihrer Gesetzmäßigkeit zurückgenommen werden, wenn sie entgegen einer Richtlinie erfolgt, die bestimmt, daß von der Ermächtigung des $§ 39$ Abs. 2 II. WohnungsbauG kein Gebrauch zu machen ist. Ob die Abweichung von der Richtlinie sachlich einleuchtet, spielt bei dieser Sicht der Dinge keine Rolle.

${ }_{82}$ So auch Maurer, Allgemeines Verwaltungsrecht, 5. Aufl. 1986, § $24 \mathrm{Rdn}$. 23; Berg, GewArch. 1987, S. 1 ff., 2. 
den Hinterbliebenen der Arbeitnehmer, die frühzeitig wegen eines Arbeitsunfalls aus dem Erwerbsleben ausscheiden mußten und nach mehr als 10jährigem Bezug der Unfallrente an einer mit dem Arbeitsunfall nicht zusammenhängenden Krankheit versterben. Thre Angehörigen erhalten keine Unfallrente; denn ihr Ernährer ist nicht an den Folgen eines Arbeitsunfalls gestorben. Die Hinterbliebenenrente aus der Rentenversicherung steht ihnen zwar zu; aber bei den Versicherten, die schon in jungen Jahren erwerbsunfähig wurden, bleibt sie bescheiden. Die Hinterbliebenen früh verunglückter Arbeitnehmer fallen daher in eine Lücke zwischen der Unfall-und der Rentenversicherung. §602 RVO erlaubt es jedoch diese Lücke durch eine Beihilfe zu überbrücken, die den Hinterbliebenen ,in Härtefällen" gewährt werden kann, wenn sie nach dem Tod des Versicherten und dem Wegfall seiner Unterhaltsleistungen ohne eigene Einkünfte dastehen.

Der typisierende Charakter der Leistungsgesetze führt jedoch nicht nur zu Härten. Daß die Voraussetzungen gesetzlich garantierter Leistungsansprüche von Antragstellern erfüllt werden, denen sie an sich nicht zugedacht sind, ist ein nicht minder weit verbreitetes Phänomen. Das liegt teils daran, daß die gesetzlichen Anspruchsvoraussetzungen zu weitmaschig formuliert sind, teils daran, daß sie zu manipulativen Tatbestandsverwirklichungen einladen.

$\mathrm{Zu}$ weitmaschig gestrickt ist z.B. § 21 Abs. 1 BAFöG, der das Elterneinkommen mit den steuerpflichtigen Einkünften gleichsetzt und damit die Kinder der Landwirte privilegiert. Das hat erst der 1983 in $\S 21$ BAFöG neu eingefügte Absatz 1 a bereinigt. Seither ist auch das Einkommen der Landwirte, ,in wirklichkeitsnaher Weise auf den Bedarf" anzurechnen. Die Formulierung dieser Vorschrift läßt erahnen, wie ,wirklichkeitsnah" es bis dahin bei der BAFöG-Bewilligung an Bauernkinder nicht nur zugegangen ist, sondern von Gesetzes wegen zugehen mußte. Manipulationen ermöglicht $\S 21$ Abs. 3 Nr. 4 BAFöG. Nach ihm müssen sich die Studenten neben dem Einkommen ihrer Eltern und ihres Ehegatten auch anrechnen lassen, was andere zu ihrem Lebensbedarf zuschießen. Aber das ist nach dem Motto „Das Studium zahlt der Staat; das Auto und das Reitpferd stellt der Großvater" leicht zu umgehen. Seit der Umstellung der Ausbildungsförderung von $\mathrm{Zu}$ schüssen auf Darlehen hat das zwar viel von seinem ursprünglichen Reiz verloren. Aber es gibt noch immer Studenten, die auch den Wert eines zinslosen, nur bedingt rückzahlbaren Darlehens zu schätzen wissen. Wenn sie es richtig anstellen, so steht ihnen das BAFöG-Darlehen zu, selbst wenn sie auf Kosten reicher Verwandter mit dem Porsche beim Studentenwerk vorfahren und mit dem Jet-Set Ferien machen.

Aber das muß nicht so sein. Das Leistungsrecht braucht bei seinen Härteklauseln nicht stehen zu bleiben. Es kann auch mit Mißbrauchsklauseln ausgestattet werden, die der Verwaltung gestatten, gesetzlich 
zwingend vorgeschriebene Leistungen zu verweigern, wenn sie ohne zureichenden Grund in Anspruch genommen werden. Diese Klauseln so $\mathrm{zu}$ formulieren, daß sie rechtsstaatlichen Anforderungen Stand halten, fällt nicht weiter schwer. Die Zeit drängt leider zu sehr, als daß ich näher darlegen könnte, wie ich mir den Wortlaut einer solchen Mißbrauchsklausel vorstelle. Ich habe aber eine Formulierung zur Hand, die ich in der Diskussion gerne verlesen und näher erläutern werde, falls das gewünscht wird ${ }^{83}$.

\section{Leistungsrecht und Verwaltungsverfahren}

\section{a) Sachverhaltsermittlung}

Mehr noch als Mißbrauchsklauseln braucht das Leistungsrecht allerdings Verfahrensvorschriften, die seinen besonderen Bedürfnissen Rechnung tragen. Für sie hat, was das Sozialrecht angeht, das SGB-X gesorgt. Um das Subventionsrecht indessen ist es schlechter bestellt. Die ominösen $\S \S 44$ a der Bundes- und der Landeshaushaltsordnungen haben mittlerweile zwar eine der leistungsrechtlichen Schwachstellen des VwVfG beseitigt. Aber im VwVfG kommt nach wie vor zu kurz, daß die Leistungsvergabe andere Anforderungen an die Sachverhaltsaufklärung stellt als die Entscheidung über Verbotsverfügungen und eingriffsrechtliche Genehmigungen. Denn die Leistungsvergabe setzt in aller Regel eine Prüfung der Einkommens- und Vermögensverhältnisse des Antragstellers und vielfach auch seiner Angehörigen und $\mathrm{Ge}$ schäftspartner voraus.

In $\S 21$ Abs. 4 SGB-X hat der Gesetzgeber das bedacht. Diese Vorschrift verpflichtet die Finanzämter, den Sozialbehörden Auskunft über die Vermögens- und Einkommensverhältnisse sämtlicher Personen zu erteilen, die sie bei ihren Entscheidungen zu berïcksichtigen haben. Die Sozialbehörden können ferner Zeugen und Sachverständige zur Aussage zwingen ( $\$ 21$ Abs. 3 Satz 2 SGB-X); sie können sie notfalls auch gerichtlich vernehmen und vereidigen lassen ( $\$ 22$ SGB-X). Aber dies alles gilt nicht im Verfahren der Subventionsvergabe. Weil hier nach dem VwVfG vorzugehen ist, erteilen die Finanzämter den Behörden nur Auskunft, wenn der Betroffene sie vom Steuergeheimnis entbindet ${ }^{84}$. Zeugen und Sachverständige können zwar vorgeladen,

${ }^{83}$ Für das BAFöG kommt folgende Fassung in Betracht: „Ausbildungshilfe wird nicht gewährt, wenn der Auszubildende sie zur Bestreitung seines Lebensunterhalts und seiner Ausbildung offenkundig nicht benötigt. Dies ist insbesondere der Fall, wenn sich aus seiner Lebensführung ergibt, daß ihm Mittel im Wert von mehr als $120 \%$ des Bedarfs i.S. des $\$ 13$ dieses Gesetzes zur Verfügung stehen". 
aber nicht zur Auskunft gezwungen werden. Die Behörden verstehen es zwar, gleichwohl zu ermitteln, was sie wissen müssen. Denn sie bewilligen keine Subvention, wenn ihnen die gewünschten Angaben und Unterlagen vorenthalten werden. Die Grundlagen für die Kontrolle der Subventionsverwendung verschaffen sie sich durch Auflagen, die sie ihren Bewilligungsbescheiden beifügen. Aber sie hätten es mit beidem leichter, wenn das VwVfG sie mit den gleichen Ermittlungsbefugnissen ausstatten würde, die das SGB-X den Sozialbehörden einräumt. Das würde die Subventionsverwaltung zum einen vor dem Vorwurf bewahren, sie gehe mit ihren Auskunftsersuchen und Kontrollen zu weit. Zum anderen würde es dort Klarheit schaffen, wo ein und dieselbe Behörde Subventionen und Sozialhilfen zugleich vergibt. Darf z.B. die Gemeinde dem Handwerker, der um Förderung seines Betriebs bittet, vorhalten, was sie über sein Einkommen im Zusammenhang mit dem Sozialhilfeantrag seiner geschiedenen Ehefrau von Finanzamt erfahren hat? Oder muß sie sich so unwissend stellen, wie § 35 SGB-I ihr das unter der Überschrift „Sozialgeheimnis“ befiehlt? Eine Erweiterung des sozialrechtlichen zum leistungsrechtlichen Verwaltungsverfahren würde diese Frage nicht nur beantworten, sondern weit besser noch: Es würde sie erübrigen.

\section{b) Spezialgesetzliche Verfahrensvorschriften}

Auch mit den Spezialvorschriften, die der Gesetzgeber dem Verfahren der Leistungsvergabe widmet, beweist er nicht immer eine glückliche Hand. Ein besonders abschreckendes Beispiel dafür bieten die $\S \S 9$ und 48 BAFöG. § 9 Abs. 2 BAFöG macht die Ausbildungsförderung vom Nachweis der ,den Ausbildungs- und Prüfungsordnungen entsprechenden Studienfortschritte" abhängig. Hätte es der Gesetzgeber dabei bewenden lassen, so hieße das: Wer Ausbildungsförderung bezieht, hat am Ende eines jeden Semesters durch die Vorlage seiner Ubungs-, Seminar- oder Praktikumsscheine nachzuweisen, daß er ordnungsgemäß studiert hat. Aber $\S 48$ BAFöG sagt es anders. Ihm zufolge müssen die "Studienfortschritte", auf die es gemäß $\S 9$ Abs. 2 ankommt, erst im 5 . Semester durch das Zwischenprüfungszeugnis oder eine ihm gleichwertige Bescheinigung nachgewiesen werden. Wer Ausbildungsförderung bezieht, dem ist sie also zwei Jahre lang sicher, weil § 48 BAFöG für die ersten zwei Jahre des Studiums jede Leistungskontrolle ausschließt ${ }^{85}$.

\footnotetext{
$84 \S 30$ Abs. 4 Nr. 3 AO.

85 Anders nur in den Fällen, in denen bereits vor dem 3. Semester Zwischenprüfungen stattfinden. Bei ihnen verkürzt $\S 48 \mathrm{Abs}$. 1 Satz 2 die viersemestrige Schonzeit auf ein Jahr.
} 
Das erklärt, wie es zu dem kuriosen Urteil des $\mathrm{BGH}^{86}$ kommen konnte, das im vergangenen Jahr Aufsehen erregt hat. Es ging um einen Studenten, der Ausbildungsförderung bezogen hat, weil sich sein Vater geweigert hatte, für sein Studium aufzukommen. Die vom Studentenwerk gegen den Vater erhobene Klage aus dem gemäß § 37 BAFöG übergeleiteten Unterhaltsanspruch des Sohnes gab dem OLG Anlaß, diesen nach seinen Studienleistungen zu befragen. Sie scheinen sich auf eine bloße Kontaktaufnahme mit dem Studentenwerk beschränkt zu haben. Denn der Sohn wußte noch nicht einmal die Namen der Dozenten zu nennen, deren Lehrveranstaltung er angeblich frequentiert hat. Das half seinem Vater zum Sieg. Der BGH hielt ihm zugute, daß er für ein derartiges „Studium“ keinen Unterhalt schulde. Das hat die zivilrechtliche Seite des Falles in Ordnung gebracht. Die Unterhaltspflichtigen brauchen Bummelstudien nicht zu finanzieren. Aber das BAFöG finanziert sie vier Semester lang unkontrolliert mit öffentlichen Geldern!

Ohne den sonderbaren $\S 48$ BAFöG hätten die Studentenwerke die mißbräuchliche Inanspruchnahme der Ausbildungsförderung unschwer unterbinden können. Die Existenz dieser Vorschrift indessen macht es ihnen sogar schwer, ihre Bewilligungen zurückzunehmen, wenn sie entdecken, daß sie das parasitäre far niente einer Sozialdrohne gefördert haben.

Aber das möchte ich nicht weiterspinnen. Ich könnte sonst an dem irre werden, was ich Ihnen zur Begründung meiner Skepsis gegen das leistungsrechtliche Utbermaßverbot vorgetragen habe. Um mir meinen Glauben an meinen Leitsatz $11 \mathrm{zu}$ erhalten und weil meine Zeit abgelaufen ist, breche ich hiermit ab. Ich danke Ihnen für Thre Aufmerksamkeit.

${ }^{86}$ NJW 1987, S. $1557 \mathrm{ff}$. 
Leitsätze des Berichterstatters über:

\section{Gesetzesgestaltung und Gesetzesanwendung im Leistungsrecht}

\section{Begriff und Eigenart des Leistungsrechts}

1. Das Leistungsrecht umfaßt das Recht der öffentlichen Daseinsvorsorge, das Sozialrecht und das Subventionsrecht. Diese drei Gebiete kennzeichnet zum einen die Gestaltungsfreiheit, die der Gesetzgeber bei ihrer Regelung genießt, und zum andern ihre Finanzabhängigkeit, die ihren Leistungen faktische Grenzen zieht.

2. Die „erdienten“ Leistungen (Beamtenbesoldung, Abgeordnetenentschädigung etc.) und die Entschädigungsleistungen sind auszuklammern. Ihnen geht die für das Leistungsrecht typische freie Gestaltbarkeit $a b$.

3. Die zusammenfassende Betrachtung der Daseinsvorsorge, der Subventionsvergabe und der sozialen Leistungsgewähr muß bei ihren Finanzierungsproblemen ansetzen. Im übrigen divergieren ihre Handlungsformen zu stark, als daß sie eine in sich geschlossene Dogmatik des Leistungsrechts tragen könnten.

4. Das steile Wachsen des Leistungsrechts seit 1949 hat seinen entscheidenden Anstoß durch das parlamentarische Regierungssystem des GG empfangen. Es ist grundsätzlich zu begrüßen, weil das Leistungsrecht zur Integration des Bürgers in die Staats- und Verfassungsordnung beiträgt. Von einer Reduktion der Staatsleistungen, die über das Maß des aus finanzwirtschaftlichen Grïnden Unvermeidbaren hinausgreift, ist daher abzuraten.

\section{Gesetzliche Gestaltung des Leistungsrechts}

5. Den Finanzierungsproblemen des Leistungsrechts kann der Gesetzgeber durch Verschonungsleistungen und durch die Begründung privatrechtlicher Ansprüche auf Arbeitgeber-, Vermieter- und ähnliche Leistungen ausweichen. Die Verlagerung der Staatsleistungen auf private Leistungsschuldner bedarfjedoch einer besonderen Rechtfertigung. 
6. Der bewußte Verzicht auf die gesetzliche Regelung der Leistungsvergabe gehört zu den legitimen Gestaltungsformen des Leistungsrechts. Er bewirkt eine strikte Bindung der Verwaltung an den Haushaltsplan. Damit sichert er die budgetäre Beweglichkeit des Leistungsstaats.

7. Da der Vorbehalt des Gesetzes nicht jede Verwaltungsleistung erfaßt, sind gegen die Leistungssteuerung allein über das Haushaltsgesetz und den Haushaltsplan keine prinzipiellen verfassungsrechtlichen Bedenken anzumelden.

8. Es genügt, wenn der Haushaltsplan den Zweck der Verwaltungsleistungen bestimmt. Zusätzliche Zweckbestimmungen durch Gesetz sind nur geboten, wenn die betreffende Leistung dem Vorbehalt des Gesetzes unterliegt.

9. Das anspruchsbegründende Gesetz ist zugleich ein anspruchsbegrenzendes Gesetz. Es bindet die Verwaltung mit dem doppelten Imperativ: ,Nicht weniger, aber auch nicht mehr“. Dies muß der Gesetzesgestaltung zur Abstimmung des Leistungsrechts mit der Finanzlage nutzen.

10. Wie das Eingriffsrecht so kennt auch das Leistungsrecht ein Übermaßverbot. In der Ausprägung, die es durch das haushaltsrechtliche Wirtschaftlichkeits- und Sparsamkeitsgebot erfahren hat, begrenzt es jedoch nur die Ermessensleistungen der Verwaltung.

11. Leistungen, die das Parlament im Verfahren der Gesetzgebung und der Haushaltsfeststellung ausdrücklich gebilligt hat, können nicht als übermäßig und damit verfassungswidrig abqualifiziert werden. Sie wahren das rechte Maß, weil in der Demokratie das Gesetz das Maß der Dinge setzt.

12. Aus der Finanzabhängigkeit des Leistungsrechts läßt sich ein den Gesetzgeber bindendes leistungsrechtliches Übermaßverbot nicht herleiten.

a) Das steuerrechtliche Übermaßverbot limitiert nur die Summe, über die das Leistungsrecht verfigen kann, jedoch nicht auch die Entscheidungsbefugnis des Gesetzgebers dariber, für welche Leistungen das Steueraufkommen zu verwenden ist.

b) Das Verbot der Steuervenwendung für andere als dem Gemeinwohl dienliche Leistungen fiihrt nicht weiter, weil den vom Parlament in der Form des Gesetzes oder der Haushaltsbewilligung gutgeheißenen Leistungen die Vereinbarkeit mit dem Gemeinwohl nicht abgesprochen werden kann.

13. Das Leistungsrecht sprengt jedoch die Grenzen des verfassungsrechtlich Zulässigen, wenn seine Kosten nicht mehr aus den laufenden 
Einnahmen bestritten werden können. Mit der Leistungsvergabe auf Kredit greifen Parlament und Regienung über die temporären Schranken ihres Mandats hinaus; sie verbrauchen die Steuereinnahmen kïnftiger Wahlperioden Daraus resultiert ein das Leistungsrecht in seiner Gesamtheit begrenzendes Übermaßverbot. Ein Übermaßverbot, an dem die einzelnen Leistungsgesetze gemessen werden könnten, gibt auch Art. 115 Abs. 2 GG nicht her.

\section{Rechtsanwendung im Leistungsrecht}

14. Das System des verwaltungsgerichtlichen Rechtsschutzes gebietet nur der rechtswidrigen Leistungsverweigerung Einhalt, versagt aber vor der rechtswidrigen Leistungsbewilligung. Eine hohe Quote fehlerhafter Leistungsgewährungen ist die zwangsläufige Folge.

15. Thre Fixierung auf den individuellen Teilhabeanspruch hat die Rechtsprechung und die Literatur zu einer übermäßigen Beengung des Leistungsermessens verleitet. Es wird nicht genügend bedacht, daß die Selbstbindung der Verwaltung durch Richtlinien und ständige Übungen Raum für sachlich begrïndete Abweichungen offenhält.

16. Die Rechtsprechung verkennt außerdem, daß nicht jedwede Leistungsbewilligung, die von einer Richtlinie oder einer ständigen Verwaltungsübung abweicht, schon allein aus diesem Grunde rechtswidrig is. des $\$ 48 V w V f G$ ist.

17. Der Gesetzgeber mildert die typisierende Strenge der Leistungsgesetze durch Härteklauseln ab. Diese Klauseln bedürfen der Ergänzung durch Mißbrauchsklauseln, die es der Verwaltung erlauben, gesetzlich vorgeschriebene Leistungen ausnahmsweise zu verweigern, wenn sie für den Zweck, für den sie bestimmt sind, ersichtlich nicht benötigt werden.

18. Das Verfahren der Leistungsvergabe hat im SGBX eine angemessene Regelung gefunden Die bei der Subventionsvergabe gültigen Verfahrensvorschriften des VwVfG indessen genügen den Anforderungen nicht. Sie berïcksichtigen zu wenig, daß bei der Subventionsvergabe ebenso wie bei der Entscheidung über Sozialleistungen die Einkommens- und Vermögensverhältnisse des Antragstellers aufgeklärt werden müssen.

19. Eine Angleichung der Ermittlungsbefugnisse, die das VwVfG den Behörden bei der Subventionsvergabe einräumt, an die Vorschriften des SGB $X$ über die Sachverhaltsaufklärung im Sozialrecht erscheint angezeigt.

20. Begrenzungen der administrativen Kontrollbefugnisse, wie sie z.B. $\S 48$ BAFöG vorsieht, begünstigen die zweckwidrige Leistungsvergabe. Von ihnen sollte der Gesetzgeber Abstand nehmen. 


\section{Gesetzesgestaltung und Gesetzesanwendung im Leistungsrecht}

\section{Bericht von Prof. Dr. Friedhelm Hufen, Regensburg}

\section{Inhalt}

I. Einleitung - Problemstellung . . . . . . . . . . . . . 143

II. Die Geltungskraft des Gesetzes als Aufgabe von Gesetzesgestaltung und -anwendung . . . . . . . . . . . 147

III. Das anthropologische Leitbild. Selbstbestimmung, Selbstregulierung, soziale Verantwortung . . . . . . . . . 155

IV. Das Problem der Gleichheit . . . . . . . . . . . . . . . . . 159

V. Sozialstaat und Grundrechte als Maßstäbe der Gesetzesgestaltung und Gesetzesanwendung . . . . . . . . 162

VI. Das Beispiel „Daseinsvorsorge“ . . . . . . . . . . . . . . . . 164

VII. Schluß: Von den Grenzen der Gestaltung . . . . . . . . . . . 166 


\section{Einleitung - Problemstellung}

Es gehörte einmal zum demokratischen Urvertrauen, daß das parlamentarische Gesetz die alten Fragen der Gerechtigkeit ein für allemal lösen könnte ${ }^{1}$. Daß dies nur teilweise gelang, ist die Erfahrung des 19. Jahrhunderts und zugleich ein Grund für den Kernbestand heutiger Leistungsgesetze ${ }^{2}$.

Daß auch Leistungsrecht Freiheit gefährden kann, ohne in der Gerechtigkeit weiterzufuihren, daß also unser heutiges Thema das gestrige nicht etwa von selbst erledigt, ist auch keine ganz neue Erfahrung, traf das Staatsrecht aber unvorbereitet. Gesetzesvorbehalt, Gesetzesbegriff, Einzelfallgesetz: So lauteten die aus dem Eingriffsrecht stammenden Themen ${ }^{3}$. Auf sie konzentrierte sich das Fach auch noch, als die über durchaus allgemeine Gesetze verteilten Anteile des Sozialprodukts, als aber auch die Abhängigkeit der Individuen von staatlichen Leistungen immer größer wurden ${ }^{4}$. Verfassungsrechtlich allein waren die daraus entstehenden Fragen nicht lösbar: Sozialstaat und soziale Grundrechte wiesen immer wieder auf die Aufgabe gerechter Gesetzesgestaltung und -anwendung zurück.

Hier setzt unser Thema ein, und wir haben als erstes zu registrieren, daß sich Eingriffs- und Leistungsrecht im Kritikvokabular der Gegenwart vereint finden. Gleich nach dem Steuerrecht belegt die Sozialgesetzgebung einen wenig ehrenvollen zweiten Platz in der Katastrophenliga der „Gesetzesfluten“, ,-dschungel“ und ,,-infarkte "5. Aus Regens-

1 Hierzu J.Esser, Gesetzesrationalität im Kodifikationszeitalter und heute, in: H.J.Vogel/J.Esser, 100 Jahre oberste deutsche Justizbehörde. Vom Reichsjustizamt zum Bindesministerium der Justiz (1977), S. 20; ähnl. auch P.Badura, FS Huber, S. 15.

${ }^{2}$ Zur fehlenden Sicherung der Gleichheit durch die traditionelle Generellität des Gesetzes etwa Ch.Starck, Der Gesetzesbegriff des Grundgesetzes. Ein Beitrag zum juristischen Gesetzesbegriff (1969), S. 206f.; zu Mißverständnissen im Zusammenhang mit der Erfüllung der Postulate der Allgemeinheit des Gesetzes $H$. Hofmann, Das Postulat der Allgemeinheit des Gesetzes, in: Ch.Starck (Hrsg.), Die Allgemeinheit des Gesetzes, 1987, S. 9ff.; ähnl. auch H.-U.Erichsen, DVBl. 1983, S. 292.

${ }^{3}$ Zur Konzentration auf das Eingriffsrecht exemplarisch H.F.Zacher, VVDStRL 25 (1967), S. 311; O.Bachof, VVDStRL 30 (1972), S. 193ff., 212; P.Häberle, „Leistungsrecht“ im sozialen Rechtsstaat, FS G. Küchenhoff (1972), S. 453ff.; hier zit. nach ders., Verfassung als öffentlicher Prozeß (1978), S. 445ff., 461 ; ders., VVDStRL 30 (1972), S. 44ff.

${ }_{4}^{4} \mathrm{Zu}$ dieser Entwicklung st.w.N. P.Krause, VVDStRL 45 (1987), S. 217.

5 Exemplarisch K.-M.Groll. In der Flut der Gesetze (1985). Auf weitere Beispiele sei verzichtet. Vgl. etwa die wiedergegebenen Zitate bei H.Hill, Einfuihrung in die Gesetzgebungslehre (1982), S. 9; K.Eichenberger, VVDStRL 40 (1982), S. 7ff., 14; H.H.von Arnim/H.Klages, Probleme der staatlichen Steuerung und Fehlsteuerung in der Bundesrepublik Deutschland (1986), S. 48; eher skeptisch zum Flutenvokabular E.Bülow, Verhandlungen des 53. DJT 1980, Q 18; krit. 
burger Sicht hätte ich den „Gesetzesstrudel“ gerne angefügt, doch fand ich auch diese Umschreibung schon belegt ${ }^{6}$. Auf Einzelelemente solcher Kritik wird zurückzukommen sein. Mit dem Parlamentsgesetz zielt sie jedenfalls auf das zentrale Legitimations- und Steuerungsinstrument des sozialen Rechtsstaats ${ }^{7}$ - und dies zu einem Zeitpunkt, da z.B. die Probleme der Bevölkerungstruktur voll erkennbar werden, da dringende neue Aufgaben angesichts der wohl erreichten Grenzen noch zuträglicher Staats- und Transferquoten nur durch Einschnitte in alte Leistungen finanzierbar sind ${ }^{8}$. Der Legitimations- und Steuerungsbedarf des Leistungsgesetzes ${ }^{9}$ steigt also und verwehrt es uns, die Loseblattkultur unserer Gesetze als Normalität einer verfaßten Industriegesellschaft hinzunehmen ${ }^{10}$. Auch wird erklärbar, warum sich in der Folge relativ wenige Aussagen finden, die nur das Leistungsrecht betreffen. Für die Verschränkung von Eingriff und Leistung hat Herr Mußgnug schon Beispiele genannt, und er wird hierin durch das Bundesverfassungsgericht bestätigt, das neuerdings sehr hübsch vom ,Eingriff in die Leistung “ spricht ${ }^{11}$. Ich benutze den Begriff „Leistungsrecht" nur

aus empirischer Sicht auch H.Schulze-Fielitz, Theorie und Praxis parlamentarischer Gesetzgebung - besonders des 9. Deutschen Bundestages (1980-1983) (1988), S. 134.

6 D.Katzenstein, Über die Sozialgesetzgebung unserer Zeit, in: B.Rüthers/K. Stern (Hrsg.), FG zum 10jährigen Jubiläum der Gesellschaft für Rechtspolitik (1984), S. 139ff., 142.

' Dazu P.Badura, ZG 1987, S. 300, 308; Joseph H.Kaiser, Der Geltungsanspruch d. Rechts in einer freiheitlichen Industriegesellschaft, in: Badura/Kaiser, Parlamentarische Gesetzgebung und Geltungsanspruch d. Rechts (1987); Ch. Starck, Stichwort "Gesetz", in: Herder Staatslexikon, 7. Aufl., Bd. 2 (1986), Sp. $977 f f . ;$ K.Stern, Das Staatsrecht der Bundesrepublik Deutschland II (1980), S. 639ff.

B Zugrundeliegende Daten im Sozialbericht der Bundesregierung z.B. 1986, S. 98ff.; zu den Zusammenhängen von Bevölkerungsstruktur und Rentenversicherung vgl. das Gutachten der Kommission des Verbandes deutscher Rentenversicherungsträger. Zur langfristigen Entwicklung der gesetzlichen Rentenversicherung (1987), S. 13, 175ff.; zur Bedeutung der Frage etwa Ch.Zöpel, in: Hesse/Zöpel, Zukunft und staatliche Verantwortung (1987), S. 34;zu den Grenzen der Staatsquote vl. etwa K.Mackscheidt, Konsolidierung durch Erhöhung von Steuern und Abgaben?, in: H.H.von Arnim/K.Littmann (Hrsg.), Finanzpolitik im Umbruch: Zur Konsolidierung öffentlicher Haushalte (1984), S. 145ff. $M$. Kloepfer, Stichwort „Staatshaushalt", in: R.Herzog/H.Kunst/K.Schlaich/W. Schneemelcher (Hrsg.), Evang. Staatslexikon, 3. Aufl. (1987), Sp. 3409ff., 3412; R.Voigt, Gegentendenzen zur Verrechtlichung (1983), S. $23 \mathrm{ff} . ;$ J.Isensee, FS Broermann (1982), S. 365ff.; Grundlegend auch P.Saladin, FS Scheuner (1973), S. $541 \mathrm{ff}$.

9 Ähnlich T.Fleiner-Gerster, VVDStRL 45 (1986), S. 302; zum Steuerungsproblem insgesamt H.H.von Arnim/H.Klages, a.a.O. (Anm. 5).

${ }^{10} \mathrm{Zu}$ dieser Position vor allem J.Esser, a.a.O. (Anm. 1), S. 13ff., s. auch Recht und Staat, Heft 470 (1977), S. 38ff.; F.Kübler, JZ 1969, S. 645, 651.

11 BVerfGE 76, 220, 242. 
unter Vorbehalt, weil er nicht einmal als Sammelbegriff für einen bestimmten Gesetzestyp und schon gar nicht als leutselige Negativdefinition des „Nicht-Eingriffsrechts“ taugt ${ }^{12}$. Steuerung, Verteilung, Ordnungspolitik: In diesem Sinne würden wohl Ökonomen unser Thema formulieren, und darum geht es in der Sache auch ${ }^{13}$. Weder die scheinbare Harmlosigkeit des Leistungsrechts noch die angebliche Zweckfreiheit des Steuerrechts ${ }^{14}$ sollten uns daran hindern, diese Zusammenhänge angemessen einzuordnen.

Das Thema zeigt ferner Bedarf an spartenübergreifender Grundsätzlichkeit ${ }^{15}$. Daß sich die Probleme in den unterschiedlichen Leistungsfeldern auch unterschiedlich und gewiß anders als im Kodifikationszeitalter $^{16}$ stellen, muß man nicht betonen. Aber man darf die Chance unseres Themas auch nicht irgendwo zwischen Rentenreform und Hochschulzugang verrieseln lassen.

Eine letzte Vorausbemerkung zur Gesetzesgestaltung: Diese bezieht sich primär auf das parlamentarische Gesetz ${ }^{17}$, dessen Probleme aber nur unter Einbeziehung anderer Normierungs- und Reglungsebenen zu behandeln sind ${ }^{18}$. Sie beschränkt sich hier nicht auf den instrumentellen Sinn des Wortes, sondern umfaßt in der Folge Zweck und Funktion der Gestaltung ${ }^{19}$. Eine materiale Gesetzgebungslehre ${ }^{20}$ also, die

12 U.Karpen, NJW 1988, S. 2512f.; G.Haverkate, NVwZ 1988, S. 769.

13 Dazu etwa H.Lampert, Die Wirtschafts- und Sozialordnung der Bundesrepublik Deutschland, 8. Aufl. (1985), S. 64, 225ff.; B.Külp, Stichwort „Verteilungstheorie", in: Herzog/Kunst/Schlaich/Schneemelcher, a.a.O. (Anm. 8) Sp. 3799; ders., Herder Staatslexikon, Stichwort ,soziale Sicherheit“, Bd. 4 (1988), Sp. $1274 \mathrm{ff}$; zu den Konsequenzen H.F.Zacher, in: Isensee/Kirchhof (Hrsg.), Hdb. d. Staatsrechts I (1987), S. 1079 m.w.N.; grundlegend jetzt auch G.LübbeWolff, die Grundrechte als Eingriffsabwehrrechte. Struktur und Reichweite der Eingriffsdogmatik im Bereich staatlicher Leistungen (1988), S. 190ff.

${ }_{14}$ Dazu H.H.von Arnim, VVDStRL 39 (1981), S. 286, 315; P.Kirchhof, NJW 1987, 3219; H.Hill, NJW 1986, S. 2608; G.-F.Schuppert, FS Zeidler (1987), S. 702.

${ }_{15}$ G.Winkler, Gesetzgebung und Verwaltungsrecht, in: Winkler/Schilcher, Gesetzgebung (1981), S. 120; zur Aufgabe der Rechtswissenschaft in diesem Zusammenhang ähnl. wie hier W.Naucke, KritV 1986, S. 199.

${ }_{16}$ H.Hofmann, a.a.O. (Anm. 2), S. $15 \mathrm{ff}$.

17 Also auf das „formelle Gesetz“ im Sinne der (hier freilich nicht übernommenen) traditionellen Zweiteilung des Gesetzesbegriffs. Dazu st.w.N. S.Mogiera, Parlament und Staatsleitung in der Verfassungsordnung des Grundgesetzes (1979), S. 174f.; krit. K.Hesse, Grundzüge des Verfassungsrechts der Bundesrepublik Deutschland, 16. Aufl. (1988), S. 194f.

18 Ähnlich H.Schulze-Fielitz, a.a.O. (Anm. 5), S. 135f.; D.Wyduckel, DVBl. 1982 , S. 638.

${ }_{19}$ Für einen um die Gesetzesfunktion erweiterten Gesetzesbegriff auch $\mathrm{Ch}$. Starck, a.a.O. (Anm. 2), S. 175; ähnlich P.Noll, Gesetzgebungslehre (1973), S. 63; K.Larenz, Methodenlehre der Rechtswissenschaft, 5. Aufl. (1983), S. 157; zu den technischen Regeln der Gesetzgebung st.v. H.Hill, a.a.O. (Anm. 5), S. 
ihren primären normativen Bezugspunkt - wo sonst? - in der Verfassung $^{21}$ sucht, und zwar unabhängig von der verfassungsgerichtlichen Sanktion ${ }^{22}$. Ob es eine „Verfassungspflicht zur optimalen Gesetzgebung" gibt - darüber läßt sich wohl vor allem deshalb so schön streiten $^{23}$, weil die Frage viel zu abstrakt gestellt ist. Verfassung soll Demokratie und Gesetzgebung mit allen Stärken und Schwächen ermöglichen, nicht nur bändigen und bündeln ${ }^{24}$. Schon deshalb sind Leistungsgesetze nicht bloßer Verfassungsvollzug und das Grundgesetz nicht einziger Maßstab guter Gesetzgebung. Lassen wir also das Optimale und konzentrieren wir uns auf Kerngehalte der Gesetzesklugheit ${ }^{25}$, die das Grundgesetz aus der reichen Tradition staatsrechtlicher und staatsphilosophischer Gesetzgebungslehren inkorporiert hat. Die „moderne“ Gesetzgebungslehre ist kein zur Gattung der Orchideen tendierendes Eigenpflänzchen, sie ist neu ergrüntes Grün am Baum des Verfassungsrechts, dessen zentrales Thema das Gesetz schon immer war $^{26}$.

Ich beschränke mich auf vier Kernaussagen verfassungsnormativer Gesetzgebungslehre, die zugleich das Grundraster der weiteren Ausführungen bilden.

1. Das gute Gesetz muß Bedingungen seiner eigenen Geltungskraft setzen und auch im Zeichen sozialen Wandels Stetigkeit verbürgen.

126; zur sprachlichen Ebene P.Kirchhof, Die Bestimmtheit und Offenheit der Rechtssprache (1987).

${ }^{20}$ Allg. zur Notwendigkeit und zu den Anforderungen einer Gesetzgebungslehre st.w.N. P.Noll, a.a.O. (Anm. 19), S. 9; H.Schneider, Gesetzgebung (1982), S. 1 ff.; H.Hill, a.a.O. (Anm. 5), S. 1; Überblick auch bei K.Eichenberger, gS für Noll (1984), S. 37ff.; s. aber auch bereits U.Scheuner, FS H. Huber (1981), S. 141 ; zur materialen Gesetzgebungslehre s. auch W.Maihofer, in: Winkler/Schilcher, a.a.O. (Anm. 15), S. $3 \mathrm{ff}$.

${ }^{21} \mathrm{Zu}$ diesem Verfassungsverständnis (,Richtlinie und Rahmen“) U.Scheuner, vgl. etwa DÖV 1971, S. 505ff.; zum notw. Rückhalt der Gesetzgebungslehre in der Verfassung eines konkreten Staates aber auch E.V.Heyen, in: W.Schreckenberger, Gesetzgebungslehre. Grundlagen, Zugänge, Anwendung (1986), S. 19; ferner R.Rhinow, Rechtsetzung und Methodik (1979), S. 183.

${ }^{22} \mathrm{Zu}$ den verfassungstheoretischen Grundlagen P.Häberle, Verfassungslehre als Kulturwissenschaft (1982), S. 53, 74; R.Alexy. Theorie der Grundrechte (1986), S. $71 \mathrm{ff}$; H.Schulze-Fielitz, a.a.O. (Anm. 5), S. 21, 26 u. passim.

${ }^{23} \mathrm{Vgl}$. hierzu v.a. G.Schwerdtfeger, FS Ipsen (1977), S. 173; wohl auch $H$. Goerlich, JR 1977, S. 89, 91 einerseits und Ch.Gusy, ZRP 1985, S. $291 \mathrm{ff}$. andererseits.

${ }_{24}^{24}$ D.Grimm, VVDSt RL 40 (1982), S. 105.

${ }^{25}$ Ch.Starck, in: Götz/Klein/Starck (Hrsg.), Die öffentliche Verwaltung zwischen Gesetzgebung und richterlicher Kontrolle (1985), S. 355.

${ }^{26}$ Dazu E.-W.Böckenförde, Gesetz und gesetzgebende Gewalt. Von den Anfängen der deutschen Staatsrechtslehre bis zur Höhe des staatsrechtlichen Positivismus 2. Aufl. (1981); w.N. bei R.Schulze, Policey und Gesetzgebungslehre im 18. Jahrhundert (1982); w.N. bei P.Badura, ZG 1987, S. 301 ff., 306. 
2. Das gute Gesetz ist auf den Vorrang von Selbststeuerung und Selbstsicherung des Menschen vor Fremdsteuerung und Fremdsicherung ausgerichtet.

3. Das gute Gesetz muß die Spannung von Allgemeinheit und differenzierender Konkretheit aushalten oder bewältigen, auch wenn ein allgemein akzeptierter Gerechtigkeitsmaßstab nicht zur Verfügung steht.

4. Das gute Gesetz folgt dem Sozialstaatsgebot im Sinne des Schutzes der Schwachen und der Behebung von Not, ohne daß ein allgemeiner Maßstab des ,Sozialen“" zur Verfügung stünde.

\section{Die Geltungskraft des Gesetzes als Aufgabe von Gesetzesgestaltung und -anwendung}

Leistungsgesetze sollen gelten und Wirksamkeit erzeugen: Das klingt banal und es ist doch so wichtig, weil durch Demokratie, Rechtsstaat und Sozialstaat gleichermaßen gefordert ${ }^{27}$. Uberdetaillierung, Vollzugsdefizite und Unstetigkeit der Gesetze betreffen also nicht nur irgendein staatliches Steuerungsinstrument sondern Grundaussagen der Verfassung.

Uber die Diagnose wird rasch Einigung zu erzielen sein: Der Hang zum kasuistischen und damit auch störungsanfälligen Gesetz ist vielfach beschrieben und nachgewiesen ${ }^{28}$. Ähnliches gilt für die Ursachen: Das Leistungsrecht setzt sich auf die Spur der sozialen Wirklichkeit, erreicht diese aber schon deshalb nicht oder nur vorläufig, weil es die erfaßten Lebensumstände und Leistungsbedürfnisse stets aufs neue prägend verschiebt ${ }^{29}$. Anders als im Eingriffsrecht drängt der Nachbar

${ }^{27}$ Zum Geltungswillen des Gesetzes allgemein Ch.Starck, a.a.O. (Anm. 2), S. 251; H.Huber, Betrachtungen über die Gesamtsituation des Rechts (1970), in: ders., Rechtstheorie, Verfassungsrecht, Völkerrecht, ausgewählte Aufsätze (1971), S. 14; F. Wagener, VVDStRL 37 (1979), S. 215.

${ }_{28}$ Exemplarisch bereits bei H.Huber, Niedergang des Rechts und Krise des Rechtsstaates, in: Gesammelte Schriften (1971), S. 45; U.Scheuner, a.a.O. (Anm. 20), S. 135; G.Müller, Inhalt und Formen der Rechtsetzung als Problem demokratischer Kompetenzordnung (1979), S. 86; Ch.Starck, ZG 1988, S. 18f.; besonders kritisch $W$.Naucke, KritV 1986, S. 191f.; zur Störungsanfälligkeit und zu Vollzugsdefiziten infolge der Detaillierung s. die Nachw. bei W.Brohm, NVwZ 1988, S. 794; W.Zeh, Wille und Wirkung der Gesetze (1984), zusammenfassend S. $540 ; H$.Sendler, FS zum 125jährigen Bestehen der Juristischen Gesellschaft zu Berlin (1984), S. 753, 767; G.Teubner, Verrechtlichung - Begriffe, Merkmale, Grenzen, Auswege, in: Kübler u.a., Verrechtlichung von Wirtschaft, Arbeit und sozialer Solidarität (1985), S. 319.

${ }^{29}$ J.Hucke/H.Wollmann, Kriterien zur Bestimmung der Wirkung von Gesetzen (1982), S. 9; exemplarisch H.F.Zacher, FS Zeidler (1987), S. 580; T.Simons, Verfahren und verfahrensäquivalente Rechtsformen im Sozialrecht (1985), S. 433. 
des Normbetroffenen auf Ausdehnung, zumal wenn er darauf vertraut, daß die Kosten anderswo entstehen. Uberhaupt werden Handlungsund Normierungsbedarf nachhaltig verwechselt. Dabei wären strategische und langfristige Gesetzesgestaltung, aber auch die behutsame Einpassung in bestehende Gesetze, lebenswichtig für das Gesetz, aber sie sind unprofitabel für den politischen und administrativen Tatmen$\operatorname{schen}^{30}$. Bei verbleibenden erheblichen Luicken ${ }^{31}$ haben auch der Gesetzesvorbehalt und der subjektive Ansatz der Wesentlichkeitstheorie (,das für den einzelnen Grundrechtsinhaber Wesentliche “32) zur Regelungsdichte und Regelungstiefe beigetragen und gesteuerte und ungesteuerte neue Wirkungsketten in Gang gesetzt. Das Gesetz selbst wurde zum Instrument des Austeilens und Einsammelns und dient oft nur noch zum hastigen Verschnüren der in Koalitionskränzchen und Krisensitzungen gepackten Spar- oder Verschiebepakete ${ }^{33}$. Bei bekanntlich großen Reibungsverlusten ist dies nur machbar, weil eine hochspezialisierte Formulierungselite in Ministerien und Ausschüssen den Anpassungs- und Koordinationsdruck halbwegs bewältigt ${ }^{34}$ und politische Schmerzpunkte dabei so geschickt kaschiert, daß sie im Parlament entweder zu spät entdeckt oder bei Strafe des Aufschnürens des Gesamtpakets in Kauf genommen werden.

Die tatsächliche Einpassung der Änderungen in das hochkomplexe Leistungs- und Sicherungssystem obliegt nach herkömmlichen Vorstellungen der Gesetzesanwendung in Verwaltung und Rechtsprechung. Wie dies geschieht, veranlaßt mich, die Ausgangsfrage eines der Begleitaufsätze ${ }^{35}$ umzukehren und statt nach dem Transport der Gesetzesaussage in die Anwendung nach dem Formulierungs-und Änderungsimpuls der Anwender auf die Gestaltung zu fragen ${ }^{36}$. Nun ist der Einfluß der Exekutive auf die Gesetzesgestaltung im hochspeziellen Leistungsrecht alles andere als neu ${ }^{37}$. Schon Lorenz von Steins soziales

${ }^{30}$ Zum Zeitdruck im Gesetzgebungsverfahren allgemein schon H.Huber, a.a.O., (Anm. 27), S. 21; D.Katzenstein, FS Zeidler, S. 653; H.Schulze.Fielitz, a.a.O. (Anm. 5), S. 397f.; W.Naucke, KritV 1986, S. 191.

${ }^{31}$ So zu Recht kritisch vermerkt bei G.Haverkate, NVwZ 1988, S. 769ff.

${ }^{32}$ Vgl. etwa BVerfGE 40, 237, 249; Úberblick über die gesamte Rechtsprechung zur Wesentlichkeitstheorie bei K.Stern, a.a.O. (Anm. 7), S. 573ff.

33 Ähnlich P.Badura, a.a.O. (Anm. 1), S. 16; H.Hill, ZG 1987, S. 250.

${ }^{34}$ Nachw. dazu bei H.Schulze-Fielitz, a.a.O. (Anm. 5), S. 252ff., 285; W.Jann, Staatliche Programme und „Verwaltungskultur" (1983), S. 516ff.; F. Wagener, VVDStRL 37 (1979), S. 241, 243.

${ }^{35}$ G.Haverkate, NVwZ 1988, S. 769.

${ }^{36}$ Zum traditionellen Begriff der "Anwendung" noch H.-U.Evers, Das allgemeine Gesetz und seine Anwendung, in: Starck (Hrsg.), a.a.O. (Anm. 2), S. 96ff.

${ }_{37}$ Dazu oben Anm. 34; aus empirischer Sicht W.Brohm, Gesetzesvollzug als Handelsobjekt? - Zur Notwendigkeit der Rechtstatsachenforschung auf dem 
Königtum realisierte sich als ,soziales Ministerium“, das vor allem bei den Vorarbeiten zur „kaiserlichen Botschaft" und zur nachfolgenden Sozialgesetzgebung aktiver Träger der Gesetzesgestaltung ${ }^{38}$ wurde. Bis in die Gegenwart finden sich die gegenläufigen Thesen vom exekutivischen Charakter des Leistungsrechts (Ernst Forsthoff $f^{39}$ und Werner $W_{e b e r}{ }^{40}$ ) und vom Wohlfahrtsstaat als Gesetzgebungsstaat (Ulrich Scheuner ${ }^{41}$ ) auf eigentümliche Weise vereint ${ }^{42}$ : War es doch das von der Exekutive verwaltungsgerecht gestaltete Gesetz, das mit dem $\mathrm{Ge}$ setzesvorbehalt in immer neue Bereiche vordrang ${ }^{43}$. Zusätzlich zu bemerken ist aber, $\mathrm{da} B$ Anwendungsprobleme im Detail gegenwärtig im. mer weniger durch Interpretation und Anwendung ,abgearbeitet" und immer mehr in immer detailliertere Änderungsimpulse an das Gesetz umgesetzt werden ${ }^{44}$. Die moderne Leistungsverwaltung ist mit dem Seitenblick auf Rechnungshof und Regreß erst beruhigt, wenn sie ihr Detailproblem zumindest in einer generalisierenden Verwaltungsvorschrift, besser aber sogleich in einer Gesetzesänderung gelöst findet ${ }^{45}$. Die Anstoßfunktion der Rechtsprechung zu größerer Detaillierung ist ein weiteres Element der "Gestaltung durch Anwendung“, soweit es nicht ohnehin zu einem „begleitenden“ oder schon im Entstehensvorgang des Gesetzes antizipierten Richterrecht kommt ${ }^{46}$.

Gebiet des informellen Verwaltungshandelns, in: W.Heinz (Hrsg.), Rechtstatsachenforschung heute (1986), S. 103f.

${ }^{38}$ Dazu E.R.Huber, Deutsche Verfassungsgeschichte, Bd. 4 (1969), S. 1130; zum expliziten Berufen auf das soziale Königtum in der kaiserlichen Botschaft vom 17.11.1881 s. auch M.Stolleis, Quellen zur Geschichte des Sozialrechts (1976), S. 33f.

39 E.Forsthoff, Die Verwaltung als Leistungsträger (1938), S. 12, 15f.; ders., Rechtsfragen der leistenden Verwaltung (1959), S. $11 \mathrm{u}$. passim; zum Leistungsstaat als Verwaltungsstaat s. auch R.Thoma, in: G.Anschütz/R.Thoma, Handbuch des Deutschen Staatsrechts, 2. Bd. (1932), S. 108f.

${ }^{40} W$.Weber, Spannungen und Kräfte im westdeutschen Verfassungssystem, 3. Aufl. (1970), S. 128.

${ }^{41}$ U.Scheuner, Die Aufgabe der Gesetzgebung in unserer Zeit, DöV 1960, S. 601,605 .

${ }^{42}$ Zum Leistungsstaat als zugleich Gesetzgebungs-, Verwaltungs- und Richterstaat auch P.Häberle, a.a.O. (Anm. 3), S. 459.

${ }_{43}$ Ähnlich E.Bülow, a.a.O. (Anm. 5), Q 21. Die Entwicklung gilt natürlich erst recht für die Landesparlamente. $\mathrm{Zu}$ den verfassungsrechtlichen Konsequenzen F.Hufen, BayVBl. 1987, S. 513ff., 517.

S. schon U.Scheuner, VVDStRL 15 (1957), S. 74f.; ähnl. E.Franssen, FS Zeidler (1987), S. 439.

4s Kritisch zum „Umgießen" von Verwaltungsvorschriften in Gesetzestexte schon H.F.Zacher, VVDStRL 25 (1967), S. 311.

${ }^{46}$ Dazu H.Helmrich, in: Götz/Klein/Starck, a.a.O. (Anm. 25), Diskussion, S. 355; T.Ellwein, in: Benda/Maihofer/Vogel, Hdb. des Verfassungsrechts der Bundesrepublik Deutschland (1983), S. 1116; W.Zeh, a.a.O. (Anm. 28), S. 517; H. Sendler, ZRP 1979, S. 227. 
Unter anscheinend mühelosem Uberspringen vertikaler und horizontaler Gewaltenteilung ist also eine Art Gesetzgebungsspirale in Gang gekommen ${ }^{47}$, die in jeder Umdrehung das Gesetz näher an die Verwaltung, damit aber auch näher an den Einzelfall heranbringt. Unkoordinierte Folge- und Streuwirkungen in oft ganz anderen Bereichen, Kontrollprobleme für das Parlament ${ }^{48}$ und vor allem die struk turelle „Versäulung“ der Materien und eine immer engere Problemperspektive sind die Folge ${ }^{49}$.

Die traditionellen Funktionen des allgemeinen Gesetzes - Allgemeingültigkeit, Abstraktheit, Distanz vom Einzelfall ${ }^{\text {s0 }}$ - scheinen sich bei alledem zunehmend auf die Verfassungsrechtsprechung zu verlagern $^{51}$ : Verhältnismäßigkeit, Vertrauensschutz, ,Eigentum an Leistungen" sind hierfür nur Beispiele. Kaum verwunderlich, daß auch der durch detailgenaue Regeln eigentlich geschützte Bürger auf die Rechtsprechung mehr als auf das Gesetz vertraut. In den Grundentscheidungen seines Lebens vom Leistungsrecht gestützt, ist er auch in seiner Freiheit betroffen, wenn sich die gesetzliche Stütze auf immer neue Probleme herunterhaspelt und unzuverlässig wird ${ }^{52}$. Daß Wohlstand Angst erzeugt, ist nicht einmal sonderlich rätselhaft. Es hängt auch mit der Verläßlichkeit des Rechts zusammen. Unzuverlässiges Leistungsrecht im Leistungsstaat bedroht Akzeptanz und Integrationskraft des Rechts insgesamt ${ }^{53}$.

Soweit die Kurzdiagnose. Mit der Therapie greifen wir zwangsläufig aus über die offene Grenze zur Verfassungspolitik: Besserungsvorschläge zielen auf das Verfahren der Gesetzgebung, auf die Verstetigung der

${ }^{47} \mathrm{Zu}$ diesem Bild auch schon W.Hassemer, Tatbestand und Typus (1968), S. 107f.; Nachw. bei H.Schulze-Fielitz, a.a.O. (Anm. 5), S. 276; W.Leisner, DVB1. 1981 , S. 851.

48 U.Scheuner, a.a.O. (Anm. 20), S. 138; W.Thieme, in: Götz/Klein/Starck, a.a.O. (Anm. 25), S. 203; zur Abhängigkeit des Parlaments vom Fachwissen der Administration allgemein vgl. die Belege bei H.Kindermonn, ARSP, Beiheft 29 (1987), S. 41.

${ }^{49}$ Zum Einzug administrativer und arbeitsteiliger Problemlösungsmuster etwa G.-F.Schuppert, DöV 1987, S. 757; ähnl. W.Maihofer, in: Winkler/Schilcher, a.a.O. (Anm. 15), S. 4 ; ähnlich J.Hucke/H.Wollmann, a.a.O. (Anm. 29), S. 8.

${ }^{50}$ H.Hofmann, in: Starck (Hrsg.), a.a.O. (Anm. 2), S. 10; zu den historischen Quellen F.Wieacker, Privatrechtsgeschichte der Neuzeit (1967), S. 322ff.; $R$. Schulze, a.a.O. (Anm. 26), S. 28; kritisch zum Verlust der Allgemeinheit st.w.N. W.Naucke, FS Erler (1986), S. 177, 185.

s1 Ähnlich wie hier R.Scholz/R.Pitschas, in: FS zum 25jähr. Bestehen des BSG (1979), S. 630f.; zur Vermittlerrolle des BVerfG H.P.Schneider, FS Zeidler (1987), S. $293 \mathrm{ff}$.

${ }^{32}$ Dazu M.Kloepfer, VVDStRL 40 (1982), S. 65, 68, 79.

${ }^{53}$ Empirisch dazu R.Mayntz/J.Feick, Gesetzesflut und Bürokratiekritik: Das Problem der Überregelung im Spiegel der öffentlichen Meinung, DV 1982, S. $281,286$. 
Inhalte und auf angemessene Entlastung des Gesetzgebers vom sich rasch ändernden Detail ${ }^{54}$.

Verfahrensmäßig geht es um zeitliche Beruhigung, Öffnung für übergreifende Zusammenhänge und angemessene „Durcharbeitung“ des Stoffs ${ }^{55}$. Die Gesetzesvorbereitung muß ,entzirkelt" und „entsäult" werden ${ }^{56}$. Bei allen zugegebenen Schwächen steht hierfür kein besseres Instrument zur Verfügung als die Gesetzgebungskommis$\operatorname{sion}^{57}$. Diese darf nicht Gegenbürokratie und schon gar nicht Gegenparlament, auch nicht Hoffnungsträger vordemokratischer Vorstellungen des „Gesetzes aus einem Kopf" sein. Sie muß vielmehr Parlament, Exekutive, Verbände und Wissenschaft umgreifen. Dabei braucht sie Ausstattung, Ruhe und Unabhängigkeit zum „Kleinarbeiten“ von Konflikten $^{58}$. Sie muß die Scheuklappen des Faches und des Ressorts durch Zusammensetzung, Weisungsfreiheit und den personalisierten Blick auf Zusammenhänge überwinden. Die Einbeziehung externen Sachverstands, die fachliche Souveränität und Unabhängigkeit müssen ihre Abwehrwaffe gegen zu erwartende Versuche der Präjudizierung durch Zusammensetzung ${ }^{59}$ sein. Sie sind auch ihre einzige ,Macht“", denn Regierung und Parlament sind an ihre Entwürfe und Alternativen nicht gebunden ${ }^{60}$. Nicht nur die „Schlußredaktion ${ }^{\star 61}$ sondern schon

${ }^{54}$ Zum Bedürfnis nach einem abgestuften Normensystem ähnlich wie hier schon P.Krause, VVDStRL 45 (1987), S. 223.

${ }^{35}$ Zum Zeitfaktor „,klassisch" die Frage J.W.Hedemanns, FS Gierke (1911), S. 309: „Wie wird bei guter Gesetzgebung gearbeitet? - Langsam“. Zur beabsichtigten Verzögerung des Gesetzgebungsverfahrens in streng geschichteten Abschnitten z.B. in Schweden und in der Schweiz s. H.F.Zacher, Chancen und Grenzen des Sozialstaats, in: Koslowski/Kreuzer/Löw, Chancen und Grenzen des Sozialstaats (1983), S. 86; ders., Sozialer Fortschritt (1984), S. 11; M.Kloepfer, Was kann die Gesetzgebung vom Planungs- und Verwaltungsrecht lernen? (Manuskript 1988).

${ }_{56}$ Die hiermit zusammenhängenden Fragen der Parlamentsreform und der Verbesserung der Informationen des Parlaments können aus naheliegenden Gründen hier nicht einmal gestreift werden.

57 Ausführlich dazu W.Hugger, Gesetze - ihre Vorbereitung, Abfassung und Prüfung. Ein Handbuch für Praxis und Studium (1983), S. 53ff.; zur Anhörung - wiederum am Beispiel des schwedischen Gesetzgebungsverfahrens: H.Kindermann, in: W.Maihofer, Theorie und Methode der Gesetzgebung (1983), S. 87ff.

${ }^{58}$ Zur notwendigen Vertraulichkeit K.Eichenberger, VVDStRL 40 (1982), S. 131; zur Kommissionstradition im Naturrecht s. etwa F.Wieacker, a.a.O. (Anm. 50), S. 324ff.

${ }^{59}$ Skepsis z.B. bei U.Scheuner, DÖV 1960, S.608; zu den Sicherungen für pluralistische Abwägungsprozeduren in Kommissionen weiterführend H.Schulze-Fielietz, a.a.O. (Anm. 5), S.507ff.

${ }^{60}$ Es darf also zu keiner Verwischung der Verantwortlichkeit kommen, dazu B.von Maydell, Zur Reform des Sozialrechts - Notwendigkeit und Hindernisse, in: FS Zeidler, S. 674, 682 .

${ }^{61}$ Dazu vor allem E.Bülow, in: Hugger, a.a.O. (Anm. 57), S. 89; ders., a.a.O. (Anm. 5), Q 26;W.Zeh, in: Schreckenberger, a.a.O. (Anm. 21), S. 59. 
die erste Verarbeitung eines Problems muß der Gesetzgebungskommission obliegen - ebenso die permanente fachliche Begleitung, die Wirkungsanalyse $^{62}$ und die Aufarbeitung von Reformvorschlägen und Anwendungsproblemen ${ }^{63}$.

Inhaltlich ist zunächst einmal von der Vorstellung Abschied zu nehmen, daß irgendein Teilaspekt des Rechtsstaats im sogenannten Leistungsrecht grundsätzlich geringere Bedeutung haben dürfe als im Eingriffsrecht. Der Rechtsstaat ist das Thema des Sozialstaats ${ }^{64}$, doch geht auch im Leistungsrecht der Bedarf an verläßlichen Grundlagenentscheidungen weiter als das rechtsstaatliche Minimum. Diesen Bedarf zu erfüllen, kann dem Gesetzgeber niemand abnehmen. Er findet das „Wesentliche" nicht vor ${ }^{65}$. Deshalb halte ich auch wenig davon, den geistigen Höhenflügen der „Wesentlichkeitstheorie “66 nun gewiß kongeniale Bemühungen um eine „Unwesentlichkeitstheorie“ folgen zu lassen ${ }^{67}$. Der Gesetzgeber selbst - nicht das BVerfG - hat primär $\mathrm{zu}$ entscheiden, was so wesentlich sein soll, daß es normativer Grundvorrat und rechtsstaatliche wie auch sozialstaatliche Kontinuitätsreserve gegenüber tagespolitischen Korrekturen und Begehrlichkeiten werden kann $^{68}$.

Als zusätzliches Instrument schlage ich eine besondere Grundlagengesetzgebung vor, die in Rang und Verfahren verfassungsrechtlich abzusichern ist ${ }^{69}$. Zustandekommen und Änderung sollten an eine quali-

${ }^{62}$ Zur Wirkungsanalyse insgesamt W.Zeh, a.a.O. (Anm. 28), S. 469 u. passim; H.H.von Arnim/H.Klages, a.a.O. (Anm. 5), S. 58, dort auch zu den Gründen einer möglichst unabhängigen Stellung der Erfolgskontrolle; zu den theoretischen Grundlagen der Evaluation B.Rürup, in: H.H.von Arnim/H.Klages, a.a.O. (Anm. 5), S. 88; R.Steinberg, DS 15 (1976), S. 185.

${ }_{63}$ Grundl. jetzt R.Steinberg, Zur verfassungsgerichtlichen Kontrolle der „Nachbesserungspflicht" des Gesetzgebers, DS 1987, S. $161 \mathrm{ff}$.

64 Ähnlich P.Badura, Sozialstaatlichkeit und Sozialrecht, SGb 1980, S. 1, 4.

${ }^{65}$ In der Hoffnung auf „Wesentlichkeit“ mag sich auch die Sehnsucht nach der Allgemeinheit des Gesetzes i.S. vorfindlicher allgemeiner Bedeutsamkeit, vorgefaßter Weltvernunft usw. wiederfinden. $\mathrm{Zu}$ den vernunftrechtlichen Grundlagen K.Schmidt, Die Zukunft der Kodifikationsidee (1985), S. 31; R.Schulze, a.a.O. (Anm. 26), S. 23.

${ }^{66}$ Auf Einzelnachweise wird hier verzichtet. Übersicht bei J.Staupe, Parlamentsvorbehalt und Delegationsbefugnis - zur "Wesentlichkeitstheorie“" und zur Reichweite legislativer Regelungskompetenzen, insb. im Schulrecht (1986), S.110ff.; zur Kritik G.Kisker, NJW 1977, S. 1317; M.Kloepfer, JZ 1984, S. 685, 692; D.Umbach, FS Faller (1984), S. 122 ff.; v.Arnim, DVBl. 1987, S. 1241 ff.

${ }^{67}$ Ansätze dazu bei H.Maassen, Verhandlungen des 53. DJT 1980, Q 5;H.H. Rupp, in: W.Schreckenberger, a.a.O. (Anm. 21), S. 47.

${ }_{68}$ Dazu eindrucksvoll G.Dürig, VVDStRL 32 (1974), S. 248 (Disk.); G.Kisker, VVDStRL 32 (1974), S. 149ff.; zu den geistesgeschichtlichen Grundlagen R.Grawert, Historische Entwicklungslinien des neuzeitlichen Gesetzesrechts, in: Studien zum Beginn der modernen Welt, hrsg. R.Kosellek, S. 241. 
fizierte Mehrheit oder an ein besonderes Verfahren gebunden werden; das Grundlagengesetz muß im Rang über dem einfachen Gesetz stehen, auch Spezialgesetze dürften es nur konkretisieren, ihm aber nicht widersprechen. Auch unterhalb dieser ,großen Lösung “ können einzelne Ziele der Grundlagengesetzgebung wie erschwerte Änderbarkeit, konsensförderndes Verfahren, obligatorische Kommissionsvorbereitung usw. vorgesehen werden ${ }^{70}$. Der Inhalt der Grundlagengesetze wäre nicht - bewahre! - durch eine „Oberwesentlichkeitstheorie“ bestimmt. Seine Grundlagenkompetenz müßte sich der Gesetzgeber schon aus eigener Kraft erhalten.

Zwei große Gruppen von Gegenständen kommen in Betracht: Zum einen die entschlossene Fortführung der Kodifikation des Allgemeinen Verwaltungsrechts über das Verwaltungsverfahren hinaus ${ }^{71}$. Dogmatik und Zeit sind hinsichtlich allgemeiner Grundsätze, Verfahren, Rechtsverhältnisse und Instrumente überreif ${ }^{2}$ : Unsere Vereinigung hat hierzu schon in München und zuvor Grundlagen gelegt ${ }^{73}$. Diese in Gesetzesgestaltung umzusetzen, müßte als Forderung von dieser Tagung ausgehen. Insbesondere muß der Gesetzgeber das Abdriften der allgemeinen Teile des Sozialrechts vom Allgemeinen Verwaltungsrecht stoppen und die verhängnisvolle Fehlentscheidung der Doppelung von Verwaltungsverfahrensgesetzen und SGB-Verfahrensteilen ${ }^{74}$ korrigieren. Lei-

69 Dieser Gedanke ist natürlich nicht neu. Er ist z.B. verwirklicht in den „Lois organiques" der Franz. Verfassung (Art. 46). Zur Geschichte des Kodifikationsgedankens st.w.N. W.Ebel, Geschichte der Gesetzgebung in Deutschland, 2. Aufl. (1958), S. 73ff.; R.Schulze, a.a.O. (Anm. 26), S. 170ff.; zur Bedeutung in der Gegenwart K.Schmidt, a.a.O. (Anm. 65), S. 5. Die Forderung nach einer besonderen Kategorie der Gesetzgebung findet sich bei F.A.von Hajek, Recht, Gesetzgebung und Freiheit, Bd. 3, die Verfassung einer Gesellschaft freier Menschen (1981), zit. von H.H.Rupp, in: Schreckenberger, a.a.O. (Anm. 21), S. 50ff.

70 Ähnlicher Gedanke bei K.Stern, VVDStRL 40 (1982), S. 144 (Disk.); zur Moderationsfunktion des Gesetzes z.B. J.J.Hesse, in: Ellwein/Hesse/Mayntz/ Scharpf, Jahrbuch zur Staats- und Verwaltungswissenschaft, Bd. 1 (1987), S. 80; K.Schmidt, a.a.O. (Anm. 65), S. 27.

${ }_{71} \mathrm{Zu}$ Begriff und Arten der Kodifikation H.Schulze-Fielitz, a.a.O. (Anm. 5), S. 201, 268;zur Kodifikation des materiellen Verwaltungsrechts H.Spanner, Verhandlungen des 43. DJT 1960, Bd.1, A 16 sowie die Diskussion z.B. der Beitrag von H.P.Ipsen, ebenda, D 80. S. 295 .

${ }^{73}$ Als Beispiele seien genannt: Die allgemeinen Grundsätze des Verwaltungsverfahrens, das tatsächliche Verwaltungshandeln (Realakt), die Verpflichtung zur Mitwirkung im Verwaltungsverfahren, die Grenzen der Sachaufklärung, das Handeln in Privatrechtsform, das Normsetzungsverfahren und die Rückabwicklung von Leistungsverhältnissen.

${ }^{74}$ Zur Begründung dieser Trennung BT-Drucks. 8/2034, S. 60; krit. wie hier T.Simons, a.a.O. (Anm. 29), S. 37, 262; H.F.Zacher, ZfS 1977, S. 154; ders., Sozialer Fortschritt, S. $8 \mathrm{f}$. 
stungsspezifische Bestandteile des SGB-Verfahrens rechtfertigen diese Sonderung nicht. Sie verdienen es vielmehr nahezu uneingeschränkt, Modell für Ergänzung und Einstimmung des Verwaltungsverfahrens auf die Phänomene der Leistung und Verteilung zu werden ${ }^{75}$. Dabei sind die Verwaltungsverfahrensgesetze zugleich Zeichen für die Uberwindbarkeit bundesstaatlich begründeter Kodifikationshindernisse ${ }^{76}$.

Zum zweiten gehören die wichtigsten verteilungs- und ordnungspolitischen Entscheidungen der einzelnen Leistungsbereiche in die Form der Grundlagengesetzgebung ${ }^{77}$. Die Gesundheitsreform zeigt, daß einschneidende Weichenstellungen nicht mehr in der Form des typischen Ministerialentwurfs und ohne einen die Minderheit einbeziehenden Konsens möglich sind. Âhnliches gilt für die Rentenreform ${ }^{78}$ und den Familienlastenausgleich und es galt früher für die Landesschulgesetze. Jeder Leistungsbereich braucht (nur) ein "Stammgesetz" mit den Zwecken der Leistung ${ }^{79}$, den wichtigsten Anspruchs- und Eingriffsgrundlagen einschließlich der zugrundeliegenden Definitionen, Rechtsverhältnisse $^{80}$ und Verfahren sowie der langfristigen Konzeption des Gesetzes und dessen ,,vertrauensbegründenden Bestandteilen“.

Wie die Grundlagengesetzgebung das einfache Gesetz ,nach oben“ entlasten könnte ${ }^{81}$, so kann das Gesetz ,nach unten“ durch in einem vereinfachten Verfahren ${ }^{82}$ beschlossene Gesetze Entlastung und Flexibilität gewinnen. Dabei geht es nicht um parlamentarisch abgesegnete Rechtsverordnungen, sondern um Gesetze im vollen Sinne der Ver-

${ }^{75}$ Beispiele bei P.Kirchhof, FS BSG, S. 554ff.

76 U.Scheuner, DÖV 1960, S.608; H.Spanner, a.a.O. (Anm. 71), A 30; U.Ule, ebenda, D 74.

${ }^{77}$ Ordnungsentscheidungen i.S. H.F.Zachers, ZfS 1977, S. 150; ähnl. Kriterien jetzt in der Freiburger Habil.-Schrift v. A.Janssen, Uber die Grenzen des legislativen Zugriffsrechts (1987).

${ }^{78}$ Weitere Beispiele für solche Grundlagenentscheidungen im Bereich der Rentenversicherung z.B. bei H.F.Zacher, a.a.O. (Anm. 55), S. 10.

79 Entgegen allgemeiner Kritik dienen ,weiche“ Zielnormen als Leitlinie für die Interpretation unbestimmter Rechtsbegriffe und erfüllen insofern eine wichtige systematische Funktion. Ähnlich M.Oldiges, VVDStRL 42 (1984), S. 295; gegen Bedenken aus empirischer Sicht auch W.Zeh, a.a.O. (Anm. 28), S. 545.

${ }^{80}$ Dazu besonders die Münchener Tagung der Vereinigung der Deutschen Staatsrechtslehrer VVDStRL 45 (1987).

${ }^{81}$ Zur notwendigen Rechtsbereinigung vgl. etwa E.Mock, in: Winkler/Schilcher, a.a.O. (Anm. 15), S. 177; R.Hendler, in: Voigt, a.a.O. (Anm. 8), S. 62; K.Schmidt, a.a.O. (Anm.65), S. 51; w.N. (auch zur Kritik) bei H.Schulze-Fielitz, a.a.O. (Anm. 5), S. 13.

${ }_{82}$ Z.B. Art. 92 der Geschäftsordnung der Abgeordnetenkammer Italiens vom 18.2.1971, in der die Behandlung und Verabschiedung bestimmter Gesetzentwürfe in ständigen oder besonderen Ausschüssen geregelt ist. Der Minderheitenschutz ist durch ein Rückholrecht von in der Regel 1/10 der Abgeordneten bzw. der Regierung gesichert. 
fassung ${ }^{83}$. Diese müßten aber durch minderheitsschützende Rückholrechte in das normale Gesetzgebungsverfahren gesichert und inhaltlich an das ,Stammgesetz “ angebunden sein ${ }^{84}$. Ihre Hauptaufgabe wäre die Bewältigung von Detaillierungs- und Anpassungslasten; Tabellen, Anhänge und Anpassungsformeln wären ihre Instrumente ${ }^{85}$. Sie dürften aber nicht auf die tatbestandsmäßigen Grundlagen der Leistungsansprüche durchschlagen, was ja bekanntlich das Fatale am Haushaltsstruktur- und Paketgesetz der unmittelbaren Vergangenheit war ${ }^{86}$.

\section{Das anthropologische Leitbild. Selbstbestimmung, Selbstregulierung, soziale Verantwortung}

Wie alles Recht richten sich Leistungsgesetze nicht nur an ihre Anwender in der Verwaltung. Sie beziehen sich auf Menschen und deren Lebenssituation, die sie zugleich prägen ${ }^{87}$. Deshalb ist der anthropologische Grundzug ein so wichtiges Thema für das Geset $z^{88}$. Im weiten Rahmen der ,Menschenbild-Formel“" des BVerfG ${ }^{89}$ hat der Leistungsgesetzgeber über Fragen zu entscheiden, die Grundfragen der Freiheit sind: Selbstbestimmung und Fremdbestimmung, Untersteuerung und Úbersteuerung oder die Mittelwege zwischen beiden.

Griffige Thesen vor der angeblichen Entmündigung des Menschen durch staatliche Vorsorge ${ }^{90}$ helfen dabei ebensowenig wie abstrakte Verrechtlichungskritik ${ }^{91}$. Ernster für unser Thema aber scheint mir die These vom Verlust gesellschaftlicher, außerrechtlicher Normen, Solidarbeziehungen und Konfliktlösungsmechanismen ${ }^{92}$. Trifft der Vor-

\footnotetext{
${ }^{83}$ Damit ist nicht gesagt, daß nicht auch die Rechtsverordnung zur Entlastung des Gesetzes beitragen muß; zum neuesten Stand F.-J.Peine, ZG 1988, S. 121.

${ }^{84}$ Zum ,normwertrealisierenden Gesetz “ I.Ebsen, DVBl. 1988, S. 886f.

85 Ähnlich E.Bülow, a.a.O. (Anm. 5), Q 20; zum Problem von Anpassungsvorschriften im Stammgesetz einleuchtend W.Zeh, a.a.O. (Anm. 28), S. 516 am Beispiel BAFöG.

${ }_{86}$ Krit. dazu H.F.Zacher, a.a.O. (Anm. 55), S. 2 sowie die Diskussion der Kölner Staatsrechtslehrer-Tagung (1983), VVDStRL 42 (1984), S. $267 f f$.

${ }^{87} \mathrm{Zu}$ dieser Prägungswirkung des Rechts s. vor allem H.F.Zacher, der von „doppelter Schalung des Lebens durch das Recht" spricht, z.B. Akademievortrag Sozialstaat und Recht. Grundlagen-Entwicklung - Krise, VSSR (1983), S. 119ff., 125; ders., in: Kübler u.a., a.a.O. (Anm. 28), S. 31.

${ }_{88}$ P.Häberle, in: Isensee/Kirchhof, a.a.O. (Anm. 13), Bd. 1, S. 815, 843ff.; Ch. Starck, a.a.O. (Anm. 2), S. 115.

${ }^{89}$ Seit BVerfGE 4, 7, 15f.; grundl. jetzt P.Häberle, Das Menschenbild im Verfassungsstaat (1988), insbes. S. $32 \mathrm{ff}$.

${ }^{90}$ So insb. K.Schelsky, FAZ v. 5.12.1978, S. 3, zit. nach H.U.Erichsen, DVBl. 1983, S. 289, Fn. 1.

${ }_{91}$ Dazu insb. die Nachw. oben, Anm. 5.

92 Dazu H.Hofmann, FS Küchenhoff (1987), S. 242; H.Huber, a.a.O. (Anm. 28), S. 56; ders., a.a.O. (Anm. 27), S. 18.
} 
wurf von Jürgen Habermas von der „Kolonialisierung der Lebenswelt "93 auch nur für Teile der Gesetzgebung zu, dann zeigt sich, daß unser Thema nicht nur die notwendige Reichweite der Gesetzesgestaltung sondern auch deren Grenzen gegenüber Selbstbestimmung und Selbstregulierung jener „Lebenswelt" betrifft. Auf die schon bekannten normativen Schranken - Subsidiarität ${ }^{94}$, Tarifautonomie ${ }^{95}$, Verhältnismäßigkeit ${ }^{96}$ etwa - will ich hier nicht eingehen, sondern zunächst die grundrechtliche Fundierung gesellschaftlicher Selbsthilfe und Selbstregulierung ${ }^{97}$ betonen. Der normative Ausgangspunkt ist damit der gleiche wie derjenige des Subsidiaritätsprinzips: Es ist der anthropologische Kern der Grundrechte, das Menschenbild der Freiheit und Selbstverantwortung, für das individuelle Vorsorge primär Selbstvorsorge und auch die Sozialgebundenheit zunächst einmal selbst wahrzunehmen ist ${ }^{98}$. „Freiheit und soziale Verantwortung von unten" nicht delegierte Verantwortung, ,von oben"99.

Mich beeindruckt weniger die reichlich abstrakte Diskussion um Selbstreferenz und autopoietisches Recht ${ }^{100}$ oder die angebliche Entzauberung des Staates ${ }^{101}$. Beeindruckend ist aber die Vielfalt der Selbsthilfe - man kann es auch schlicht Bürgersinn und Bürgerverantwortung nennen -, mit der gerade im Bereich der Daseinsvorsorge die Gesellschaft auf die Steuerungsprobleme und Defizite der sozialen

93 J.Habermas, Theorie des kommunikativen Handelns, Bd. 2 (1981), S. $522 \mathrm{ff} ., 530,532$.

${ }_{94}$ Vgl. dazu st.w.N. J.Isensee, Subsidiarität und Verfassungsrecht (1968); $O$. Kimminich (Hrsg.), Subsidiarität und Demokratie (1981); ders., Pol. Studien 1987, S. 587ff.; R.Herzog, Subsidiarität und Staatsverfassung, DS 2 (1963), S. 399; ders., Stichwort „Subsidiaritätsprinzip“, in: Evang. Staatslex., a.a.O. (Anm. 7), Sp. 3564ff.; G.Haverkate, Rechtsfragen des Leistungsstaats: VerhältnismäBigkeitsgebot und Freiheitsschutz im leistenden Staatshandeln (1983), S. 172; H.F.Zacher, Freiheit und Gleichheit in der Wohlfahrtspflege (1964), S. 72ff.; R.Zuck, Subsidiaritätsprinzip und Grundgesetz (1968).

${ }_{95}$ Umfassende Nachw. bei F.Kirchhof, Private Rechtsetzung (1987), S. 81ff.; aus der Rspr. BVerfGE 50, 369ff. (Mitbestimmung).

96 Dazu vor allem M.Kloepfer, VVDStRL 40 (1982), S. $79 \mathrm{ff}$.

${ }^{97}$ Nachw. bei H.Schulze-Fielitz, a.a.O. (Anm. 5), S. 379; zur verfassungsrechtlichen Seite des Problems etwa H.H.von Arnim, Staatslehre der Bundesrepublik Deutschland (1984), S. 65, 465ff.; W.Leisner, DVBl. 1981, S. 849, 855.

${ }_{98}$ H. U.Erichsen, DVBl. 1983, S. 295; K.Stern, in: Evang. Staatslex., a.a.O. (Anm. 8), Sp. 3277; H.F.Zacher, in: Isensee/Kirchhof, a.a.O. (Anm. 13), S. 1062.

99 Ähnlich bereits H.P.Ipsen, VVDStRL 25 (1967), S. 293; zur Begründung aus der Menschenwürde jetzt P.Häberle, in:Isensee/Kirchhof, a.a.O. (Anm. 13), S. 815,847 .

100 Übersicht bei H.Schulze-Fielitz, a.a.O. (Anm. 5), S. 193ff. und W.Brohm, NVwZ 1988, S. 794.

${ }^{101}$ H.Wilke, Entzauberung des Staates. Uberlegungen zu einer sozietalen Steuerungstheorie (1983). 
Großorganisationen reagiert ${ }^{102}$. Ich nenne nur die Stichworte „Jugend- und Familienhilfe“, „Selbsthilfe von Arbeitslosen“, ,psychiatrische Betreuung“ und „Altenpflege“. Hier zeigen sich Entlastungsmöglichkeiten, aber auch Aufgaben für den Gesetzgeber. Zumal Selbstregulierung im grundrechtssensiblen Bereich bedarf der Absicherung und des ,richtigen Rechts“ als Rahmen, auch wenn ihre sach- und personennahe Binnensteuerung funktioniert ${ }^{103}$.

In einem führenden Lehrbuch des Sozialrechts findet sich aber unter dem Stichwort „rechtsfreie Konzepte“ neben der freien Wohlfahrtspflege nur das Stichwort ,Almosen" ${ }^{104}$. Das ist nicht untypisch. Dem öffentlichen Recht fällt zur „Selbstregulierung“ wenig ein, obwohl die heutigen Sicherungssysteme zu einem großen Teil aus gesellschaftlicher Selbsthilfe entstanden sind. Es war zu lange auf die staatliche Verantwortung und die „Ausnahme "Selbstverwaltung ${ }^{105}$ konzentriert - verstanden als Delegation staatlicher Macht und entsprechend mit Mißtrauen bedacht ${ }^{106}$. Als rechtliche Gestalt der gesellschaftlichen Erfüllung öffentlicher Aufgaben fasziniert wohl immer noch die ,reifere Schwester “ Zivilrecht; das Klagen über das Ausweichen ins Privatrecht und auf Private ${ }^{107}$ signalisiert dabei nicht untypische Haßliebe zwischen solchen Geschwistern. Was aber fehlt, ist ein öffentlich-rechtliches Konzept der ,kontrollierten Selbstregulierung“ im Bereich öffentlicher Aufgaben, das den freiheitlichen und freiheitssichernden Kern dieses Instruments ebenso beachtet wie die öffentliche Verantwortung - zumal beim Einsatz öffentlicher Mittel ${ }^{108}$. Muster - vielleicht nicht Modell - können die Privatschulgesetze sein. In ihrer

${ }^{102}$ Empirische Beispiele bei W.H.Asam/Heck, Soziale Selbsthilfegruppen in der Bundesrepublik Deutschland (1983), S. 35;C.Offe, in: Ellwein/Hesse/Mayntz/ Scharpf, a.a.O. (Anm. 70), S. 317; E.Pankoke/Nokielski/Beine, Neue Formen gesellschaftlicher Selbststeuerung in der Bundesrepublik Deutschland (1975).

${ }^{103}$ H.F.Zacher, in: Kübler u.a., a.a.O. (Anm. 28), S. 70; zu den Grenzen jetzt W.Brohm, NVwZ 1988, S. 795.

${ }^{104}$ H.Bley, Sozialrecht. Ein Lehrbuch (1984), S. 34.

${ }^{105}$ Dazu vor allem $R$.Hendler, Selbstverwaltung als Ordnungsprinzip (1984); D.Merten, in: Benda/Maihofer/Vogel, a.a.O. (Anm. 46), S. 779 sowie den Bericht von W.Henke, VVDStRL 28 (1970), S. 149ff., 163ff.; zur Geschichte $H$. Reiter, FS Zeidler (1987), S. 600.

${ }^{106}$ Exemplarisch BVerfGE 39, 302, 313; H.Reiter, a.a.O. (Anm. 105), S. 612; krit. T.Simons, a.a.O. (Anm. 29), S. 570; W.Wertenbruch, FS Horst Peters (1975), S. 203ff.

${ }^{107}$ Umfassend D.Ehlers, Verwaltung in Privatrechtsform (1984); ders., DÖV 1986, S. 897ff.; zum Problem auch die Kontroverse im Rahmen der Diskussion der Münchener Staatsrechtslehrer-Tagung von 1986, VVDStRL 45 (1987), S. $250 \mathrm{ff}$.

${ }^{108}$ Die Lücke wird bisher - soweit ersichtlich - nur von F.Kirchhofs Untersuchung zur privaten Rechtsetzung, a.a.O. (Anm. 95), teilweise geschlossen. 
Freiheit abzusichern und in sozialstaatliche Gestalt zu bringen wäre auch die ganze Vielfalt der institutionellen Verselbständigung ${ }^{109}$ von der privaten Drogenhilfe hin bis zur Ausgründung im Wissenschaftsbereich, vom singulären Leistungs-Center bis zur wohlfahrtsverbandlichen Großstruktur ${ }^{110}$. Was hier mit Selbstregulierung gemeint ist, darf nicht mit der Selbstverwaltung der Gemeinden und Sozialversicherungsträger verwechselt und damit von dem gefährlichen „Nebenschub" erfaßt werden, den der Gesetzesvorbehalt und die Wesentlichkeitstheorie in Richtung auf die Selbstverwaltung entfachten ${ }^{111}$, weil sie diese als Freiheitsbedrohung begriffen statt ihr Freiheitspotential und ihre regulative Differenzierungschance wahrzunehmen ${ }^{112}$. Zwei Probleme aber haben Selbstverwaltung und Selbstregulierung gemeinsam: Die richtige Größe der Entscheidungseinheit und den schmalen Grat zwischen grundrechtsausübender Selbsthilfe und grundrechtsgefährdender Selbstbedienung ${ }^{113}$. Probleme, die aber die grundsätzliche Aufarbeitung durch die Rechtsordnung nicht ausschließen sondern gerade zur Lösung herausfordern sollten. Zwischenformen sind die Kooperation selbstregulierender Einheiten mit der Verwaltung ${ }^{114}$ und die Delegation von Einzelaufgaben auf Kommissionen ${ }^{115}$. Aber es geht auch um problemgerechte Anerkennungs- und Aufsichtsformen $^{116}$. Der richtige Ort hierfür sind nicht die zivilrechtlichen Generalklauseln; es ist der Organisationsteil des Stammgesetzes im Leistungsbereich, in dem die freien Träger und Selbsthilfegruppen tätig werden. An das notwendige ,normative Dach“ im Allgemeinen Verwaltungsrecht, das wohl weiterreichen müßte als die altehrwürdige Beleihung ${ }^{117}$, sei hier nur erinnert.

${ }^{109}$ Dazu vor allem die Beiträge von G.F.Schuppert, Die Erfüllung öffentlicher Aufgaben durch verselbständigte Verwaltungseinheiten (1981); ders., DÖV 1987 , S. $567 f$ f.

${ }^{110}$ Weitere Beispiele bei W.Asam/Heck, a.a.O. (Anm. 102), S. 50ff.

111 Exemplarisch BVerfGE 33, 125, 136 und jetzt BVerfG, NJW 1988, S. 191 - Standesrichtlinien der Rechtsanwälte.

${ }_{112}$ Mißverständlich insoweit G.Haverkate, VVDStRL 46 (1988), S. 237f.; zur nicht nur abgeleiteten sondern ursprünglichen Legitimation der Selbstverwaltung dagegen H.H.von Arnim, VVDStRL 46 (1988), S. 276; auch der grundrechtsdogmatische Kahlschlag des BVerfG gegen die Grundrechtsstellung der öffentlichen Körperschaften (insb. BVerfGE 39, 302, 312; 61, 82, 103; 68, 193, 207) sollte im Hinblick auf das ,,Selbstregulierungspotential“ öffentlicher Selbstverwaltungskörperschaften überdacht werden.

${ }^{113}$ Ansätze zur Lösung des Problems bei R.Hendler, a.a.O. (Anm. 105), S. 402.

114 Allgem. dazu und zu den Grenzen jetzt W.Brohm, NVwZ 1988, S. 795.

115 Grundlegend E.Schreyer, Pluralistische Entscheidungsgremien im Bereich sozialer und kultureller Staatsaufgaben (1982).

${ }_{116}$ Dazu H.Hill, DöV 1987, S. 885; T.Simons, a.a.O. (Anm. 29), S. 107; zu den Grenzen F.Kirchhof, a.a.O. (Anm. 95), S. 130. 
Im Verhältnis zur Selbstregulierung wird jedenfalls die Funktion des allgemeinen Gesetzes, gleiches Recht und Elastizität zugleich zu verleihen ${ }^{118}$, erneut erkennbar.

\section{Das Problem der Gleichheit}

In enger werdenden Bögen kehren wir immer wieder zum Gleichheitsproblem zurück ${ }^{119}$, das vielleicht nicht länger ein Problem des Gesetzgebers wäre, käme dieser nur dem Rat der Klassiker nach: Die Mannigfaltigkeit der Lebensverhältnisse durch allgemeine Regeln und Prinzipien zu zügeln und den Besonderheiten des Einzelfalles durch wohlplazierte Billigkeitsentscheidungen gerecht zu werden - so wohl läßt sich dieser Ratschlag von der Nikomachischen Ethik des Aristoteles bis zu Gustav Radbruch und den künftigen Klassikern des gestrigen Tages zusammenfassen ${ }^{120}$. Der moderne Leistungsgesetzgeber aber verhält sich umgekehrt: Er ist bemüht, die Vielgestalt des Lebens durch immer detailliertere Entscheidungen einzufangen und vernachlässigt die allgemeinen Regeln und Prinzipien ${ }^{121}$.

Typisierung ${ }^{122}$ und Stichtag ${ }^{123}$ lauten die Notanker gegen diese Entwicklung. Doch ist das Problem auf abstrakt-genereller Ebene unlösbar, weil jede Typisierung und Grenzziehung normative und empirische Bezugspunkte braucht ${ }^{124}$, die sich aber mit der Normierung bzw. der Reaktion der Normadressaten sogleich verschieben und neu „,vertypen“"125. Mit ihnen ändern sich die Bezugspunkte der Gerechtigkeit, die doch den alles übergreifenden Maßstab bieten soll ${ }^{126}$.

${ }^{117}$ Dazu st.w.N. U.Steiner, Öffentliche Verwaltung durch Private (1975).

118 Ähnlich H.Hof, Rechtstheorie 17 (1986), S. 459.

119 Zum traditionellen Zusammenhang von Gleichheit und Gesetz s. statt vieler F.von Zeiler, Grundsätze der Gesetzgebung (1806/09), S. 12; G.Dürig, in: Maunz/Dürig/Herzog, Grundgesetz-Kommentar, Art. 3, Rz. 8ff. u. 323ff.

${ }^{120} \mathrm{Vgl}$. Nikomachische Ethik, 1135 a, $1137 \mathrm{~b}$; zum Problem der Billigkeit als Gerechtigkeit des Einzelfalles insb. G.Radbruch, Rechtsphilosophie, 8. Aufl. (hg. von Erik Wolf und Hans-Peter Schneider) (1973), S. 123, 333.

${ }^{121}$ Zum Streben nach Einzelfallgerechtigkeit als Grund für den gesetzgeberischen Perfektionismus bereits H.Schneider, NJW 1962, S. 1273, 1275.

${ }_{122}$ Dazu st.w.N. J.Isensee, Die typisierende Verwaltung (1976); a.d.Rspr. BVerfGE 17, 123; zuletzt etwa 63, 119, 128;70, 1, 34; 75, 348, 357.

${ }^{123}$ Exemplarisch dazu BVerfGE 58, 81, 127;75, 78, 106.

124 Zur modalen Unbestimmtheit der Gleichbehandlung jetzt auch G.LübbeWolff, a.a.O. (Anm. 13), S. 232ff.

${ }_{125}$ Dazu T.Simons, a.a.O. (Anm. 29), S. 131; H.F.Zacher, FS Ipsen (1977), S. 253.

${ }^{126}$ Dazu st.w.N. H.Hofmann, a.a.O. (Anm. 2), S. 46; grundlegend G.Robbers, Gerechtigkeit als Rechtsprinzip (1980). 
Mit der Vernetzung der Leistungssysteme und der Externalisierung der Problemlösungen bis hin zum Steuerrecht steigt zudem die Notwendigkeit, Vergleichsgruppen und Freigrenzen systemübergreifend zu formulieren ${ }^{127}$. Das potenziert die unvorhersehbaren Folgen in oft ganz woanders liegenden Politik- und Leistungsbereichen. Mitnahmeeffekte, aber auch individuelle Härten und absurde Kumulationswirkungen sind die Folge ${ }^{128}$. Diese Effekte sind im Grunde Gleichheitsverletzungen und zeigen die Unmöglichkeit, durch Trennschärfe im Gesetz Gleichheit zu schaffen ${ }^{129}$. Die in der Kontrolle der Leistungsgesetzgebung immer noch einschlägige Willkürformel ${ }^{130}$ greift nur Extremfälle heraus und erlaubt dem Gesetzgeber einen sachlichen Grund zu benennen, wo sich doch die Ungleichheit gerade aus der Verflechtung der Tatbestände und der Kumulation der Folgen ergibt ${ }^{131}$. Nötig sind also Zusatzmaßstäbe wie Verhältnismäßigkeit und Erträglichkeit, die das BVerfG mit seiner angeblich ,neuen Formel" zögernd aufgreift $^{132}$ - wohl wissend, daß die Zumutbarkeit der Differenzienung weniger über das Gesetz als solches aussagt als über seine Angemessenheit im Einzelfall ${ }^{133}$.

Damit ist das entscheidende Stichwort gefallen: In der überdetaillierten, vernetzten, von immer neuen Antizipations- und Echoeffekten hallenden Verteilungs- und Transferwelt kann die Gesetzesgestaltung nur einen Rahmen für Einzelfallgerechtigkeit bieten. Verwirklicht werden kann diese letztlich nur von den dafür im Gewaltenteilungssystem des Grundgesetzes vorgesehenen Spezialisten für Einzelfallgerechtigkeit in Verwaltung und Rechtsprechung.

Für die Gesetzesgestaltung läuft dies neben der Mißbrauchsklau$\operatorname{sel}^{134}$, über die schon Herr Mußgnug gesprochen hat, auf deren Gegen-

${ }^{127}$ T.Simons, a.a.O. (Anm. 29), S. 197; H.F.Zacher, VSSR 11 (1983), S. 126.

${ }^{128}$ Allgemein dazu B.von Maydell, a.a.O. (Anm.60), S. 678. Das derzeit prägnanteste Beispiel für die belastende Wirkung von systemüberspringenden Maßnahmen dürfte das Chaos des Familienlastenausgleichs zwischen Kindergeldund Steuerrecht sein. Hier führt die Einkommensgrenze zu Grenzbelastungen von mehr als $80 \%$. Dazu H.Laux, BB 1987, S. 905.

${ }^{129}$ So auch Ch.Starck, Stichwort "Gesetzgebung", in: Herder Staatslexikon, a.a.O. (Anm. 7), Sp. 1010.

${ }^{130}$ Dazu st.w.N. R.Wendt, NVwZ 1988, S. 779.

${ }^{131}$ Nur deshalb konnte die Kindergeld-Regelung vor 1982/83 Bestand haben. Dazu BVerfGE 43, 108, 120; krit. zu Recht $R$. Wendt, NVwZ 1988, S. 779.

${ }^{132}$ Zur sog. ,neuen Formel“ vgl. etwa BVerfGE 55, 72, 88; 63, 119, 128 ; 70, 230, 240; zusammenfassend R.Maaß, NVwZ 1988, S. 14ff.; eher skeptisch H.-W.Arndt, NVwZ 1988, S. 787.

${ }^{133}$ Zur Verhältnismäßigkeit bei der Gleichheitsprüfung auch P.Badura, a.a.O. (Anm. 1), S. 24; G.Haverkate, a.a.O. (Anm. 94), S. 12.

${ }^{134}$ S. auch Stettner, VSSR 1983, S. 155. 
stück, die an der Zumutbarkeit orientierte Härteklausel ${ }^{135}$ und auf „weiche" Ubergangsregelungen hinaus, die es der Verwaltung und Rechtsprechung ermöglichen, die persönliche Situation und die Konsequenzen der Typisierung und der Stichtage auf den Einzelfall auszuloten: Einen subjektiven Abwehranspruch gegen das „Mittelstandsloch" und ähnliche Effekte inbegriffen ${ }^{\mathbf{1 3 6}}$. Der Gesetzgeber muß der Gesetzesanwendung hierfür Eckpunkte eines gerechten Systems vorgeben, weniger einer vorfindlichen Systemgerechtigkeit folgen ${ }^{137}$. Für die Gesetzesanwendung in der Verwaltung ergibt sich damit eine Verantwortung, die weder mit Computergerechtigkeit noch mit Verwaltungsvorschriften allein zu bewältigen ist. Im Gegenteil: Jeder der guten Gründe für mehr Flexibilität bei der Gesetzesanwendung ${ }^{138}$ ist ein guter Grund gegen das binäre Denken und gegen die in ihrer Legitimität ohnehin fragwürdige faktisch außenwirksame Selbstbindung der Verwaltung ${ }^{139}$. Eine kleine Polemik sei in diesem Zusammenhang erlaubt: Ich halte den gesetzesgerechten Computer noch immer für dringlicher als das computergerechte Gesetz ${ }^{140}$.

Bedenken hinsichtlich einer zu großen Macht der Anwender muß vor allem im Verfahren ${ }^{141}$ und durch wechselseitige Kontrolle begegnet werden. Im Verwaltungsverfahren treten damit die kompensatorische Funktion: Beratung, Mitwirkung und alles, was der Stärkung des Artikulationsschwächeren dient, um so deutlicher hervor ${ }^{142}$. Auch zeigt sich, daß die Erweiterung von Entscheidungsspielräumen und die großzügige Gestaltung und Anwendung von Heilungsvorschriften nicht zusammenpassen $^{143}$. Zur weiteren Kontrolle müssen ein endlich ernst-

${ }^{135}$ Zur Technik der Härteklausel H.Schneider, Gesetzgebung, Rz. 364.

${ }^{136} \mathrm{Vgl}$. auch R.Rhinow, a.a.O. (Anm. 21), S. 65.

${ }^{137}$ Zur Systemgerechtigkeit F.-J.Peine, Systemgerechtigkeit (1985). Ch.Degenhart, Systemgerechtigkeit und Selbstbindung des Gesetzgebers als Verfassungspostulat (1976).

${ }_{138} \mathrm{Vgl}$. M.Bullinger/Ch.Starck, in: Bullinger, Verwaltungsermessen (1986), S. $9 ;$ M.Bullinger, ebenda, S. 144.

${ }^{139}$ Zum Problem K.Stern, a.a.O. (Anm. 7), S. 661f.; H.Hill, ZG 1987, S. 261; krit. z.B. D.Ehlers, DVBI. 1986, S.916; E.Franssen, a.a.O. (Anm. 44), S. 450 .

${ }^{140}$ Das sagt nichts gegen eine computergerechte Vollziehbarkeit von Tabellen usw. Skept. wie hier auch D.Katzenstein, a.a.O. (Anm.6), S. 145. Umfassend informierend G.Thieler-Mevissen, Automationsgerechtigkeit, in: Bundesakademie für öffentliche Verwaltung (Hg.), Praxis der Gesetzgebung, S. $115 \mathrm{ff}$.

${ }^{141} \mathrm{Zu}$ dieser Funktion des Verfahrens bereits P. Häberle, VVDStRL 30 (1972), S. 86ff.; F.Hufen, Fehler im Verwaltungsverfahren (1986), S. 46ff.; R. Wahl, VVDStRL 41 (1983), S. 265 (Schlußwort).

${ }_{142}$ Zur besonderen Bedeutung der Beratung im Verfahren (und zwar auch außerhalb des Sozialverfahrens) s. F.Hufen, a.a.O. (Anm. 141), S. 157.

${ }^{143}$ Ähnlich auch H.U.Evers, in: Starck, a.a.O. (Anm. 2), S. 129; ausführlicher als hier möglich auch F.Hufen, DVBl. 1988, S. 69, $75 \mathrm{ff}$. 
genommenes Widerspruchsverfahren ${ }^{144}$ und eine gleichfalls an den Maßstäben der Grundsatzgesetzgebung und der individuellen Zumutbarkeit orientierte Rechtsprechung Mißbräuchen und Härten wehren. Die Warnung vor dem Richterstaat ${ }^{145}$ halte ich dabei für um so weniger einschlägig je mehr die Richter aller Instanzen Verwaltungsprozesse statt Verwaltungsverfahren führen und Urteile statt verkappte Paragraphen fertigen. Die Verhältnismäßigkeit als wichtigster Maßstab gefährdet nicht etwa die Geltungskraft des Gesetzes ${ }^{146}$. Als Scharnier für das Besondere stärkt sie vielmehr die Geltung des Allgemeinen, wenn es ihr auch ergeht wie einem orientalischen Maulesel: Sie schleppt die ganze Last durch unwegsames Gelände und bezieht doch täglich Prügel.

\section{Sozialstaat und Grundrechte als Maßstäbe der Gesetzesgestaltung und Gesetzesanwendung}

Grundsatzgesetzgebung, Härteregeln, Verhältnismäßigkeit - verweist die Verfassung den Gesetzgeber also nur auf Verfahren und Relationsbegriffe?

Das scheint nur bisher so, denn von Sozialstaatsprinzip und Grundrechten als Gestaltungsaufträge für den Gesetzgeber war nur am Rande die Rede. Zwar weist auch der Kompromiß derivativer Teilhaberechte ebenfalls auf Gleichheit und Verhältnismäßigkeit zurück. Sozialstaatlichkeit ${ }^{147}$ ist ihrerseits von Maßstäben abhängig, die sich mit jeder sozialstaatlichen Maßnahme verschieben ${ }^{148}$.

Und doch füren Grundrechte und Sozialstaat weiter, wenn man neben ihrer Richtlinienfunktion auf Rahmen und Grenze abstellt, die sie zumal dem Leistungen einschränkenden, umverteilenden Gesetzgeber setzen, wenn also der Leistungsrückruf zum Eingriff wird ${ }^{149}$. Die Rechtsprechung zum Eigentumsschutz an kraft eigener Leistung erworbenen Anwartschaften ${ }^{150}$ ist hier nur Beispiel für grundrechtlich gesicherte Vertrauenspositionen. Sie hat aber mit Art. 14 GG den unvollständigen normativen Bezugspunkt und mit dem BVerfG den erst

${ }^{144}$ So auch Ch.Starck, in: Götz/Klein/Starck, a.a.O. (Anm. 25), S. 358, 376.

145 Etwa bei H.H.Klein, in: Götz/Klein/Starck, a.a.O. (Anm. 25), S. 82.

146 So aber P.Naucke, KritV 1986, S. 207.

${ }^{147}$ H.F.Zacher, in: Isensee/Kirchhof, a.a.O. (Anm. 13), S. 1045, 1048 - dort auch zu den Sozialstaatsklauseln der Landesverfassungen.

${ }^{148}$ H.F.Zacher, VSSR 11 (1983), S. 119ff., 126, der zu Recht vom Sozialstaat als Prozeß spricht.

149 Jetzt grundlegend G.Lübbe-Wolff, a.a.O. (Anm. 13), S. 109ff.

150 Dazu zuletzt BVerfGE 69, 272, 300; 72, 9, 18; 76, 220, 235; Ubersicht bei $D$. Katzenstein, in: FS Simon (1987), S. $847 \mathrm{ff}$. 
nachrangig kompetenten Normgestalter. Inhaltlich geht es um die Abgrenzung grundrechtlich gesicherten Vertrauens und disponibler Wohltat ${ }^{151}$, und für die hat der Gesetzgeber mit Grundlagengesetzen zunächst einmal selbst zu sorgen. Aber auch über die Sicherung des selbst Erworbenen hinaus schützen Grundrechte und Sozialstaat diejenigen, deren Leistungen sich nicht im Schutzbereich des Art. 14 GG niederschlagen. Die Familie mit Kindern etwa ${ }^{152}$ oder auch diejenigen, die als Träger von Privatschulen das immer mühevollere Geschäft der Wahrung kultureller Vielfalt mitbetreiben ${ }^{153}$. In ihrem Vertrauen in die ausgleichende Kraft des Sozialstaats besonders geschützt sind die Behinderten ${ }^{154}$ und überhaupt alle Minderheiten, für die Sozialstaatsgebot und Grundrechte Lobby und politische Vetoposition ersetzen müssen ${ }^{155}$.

Die markanteste verfassungsrechtliche Grenze jeder Gesetzesgestaltung im Leistungs- und Verteilungsrecht aber wird durch das Grundrecht der Menschenwürde markiert ${ }^{156}$. Gewiß bedarf auch das materielle und kulturelle Existenzminimum permanenter Ausgestaltung und Sicherung durch den Gesetzgeber und ist von der sich wandelnden „Normalität" menschlicher Existenz abhängig. An dem vom (Grundlagen)Gesetzgeber - z.B. im Bereich der Sozialhilfe - gesetzten Maßstab der Grundsicherung aber hört der Gestaltungsspielraum auf ${ }^{157}$. Der „Menschenwürdesockel“ des Leistungsrechts steht für Sparmaßnahmen und Umverteilung selbst dann nicht zur Verfügung, wenn er von immer mehr Schwächsten in Anspruch genommen wird. Der sozialstaatliche und familienpolitische Skandal, daß manche große Familie, daß kleine Landwirte und Beamte der untersten Besoldungsgruppen

${ }^{151}$ Dazu vor allem G.Kisker, VVDStRL 32 (1974), S. 149ff. sowie den Diskussionsbeitrag von G.Dürig, ebenda, S. 257.

${ }^{152}$ Dazu die Ergebnisse der Münchener Staatsrechtslehrer-Tagung mit den Referaten von A.von Campenhausen und H.Steiger, VVDStRL 45 (1987), S. 7, $55 \mathrm{ff}$. Die Diskussion ergab, daß das derzeitige Recht die (kinderlose) Ehe gegenüber der Familie erheblich benachteiligt; noch deutlicher W.Zeidler, in: Benda/ Maihofer/Vogel, a.a.O. (Anm.46), S. 555, 597ff.; H.H.von Arnim/H.Klages, a.a.O. (Anm. 5), S. $66 \mathrm{ff}$.

${ }_{153}$ BVerfGE 75, 40ff.; F.Müller (Hrsg.), Zukunftsperspektiven der Freien Schulen (1988); B.Pieroth/G.-F.Schuppert (Hrsg.), Die staatliche Privatschulfinanzierung vor dem BVerfG (1988).

${ }^{154}$ H.F.Zacher, Der Behinderte als Aufgabe der Rechtsordnung, in: Zweite ordentliche Verbandsversammlung des kommunalen Spitzenverbandes der Bayer. Bezirke, hrsg. vom Verband der Bayer. Bezirke (1981); ders., Die Lage der Behinderten - eine Aufgabe des Sozialrechts, ZfS 1981, S. 257ff.

1 ss Krit. auch H.F.Zacher, a.a.O. (Anm. 29), S. 594.

${ }_{156}$ Dazu schon eindeutig BVerfGE 1, 97, 104; E.Benda, in: Benda/Maihofer/ Vogel, a.a.O. (Anm.46), S. 514; grundlegend P.Häberle, in: Isensee/Kirchhof, a.a.O. (Anm. 13), S. 839f. und H.F.Zacher, ebenda, S. 1060.

${ }^{157}$ Dazu jetzt deutlich BVerfGE 78, 104, 118. 
ohnehin nur knapp über diesem Sockel leben, ist anders zu lösen. Ebenso übrigens die Not der kommunalen Träger der Sozialhilfe, die mit Recht das Versagen des Lastenausgleichs beklagen, der auch Aufgabe des Leistungsgesetzgebers ist.

Im Ergebnis ist der soziale Rechtsstaat nicht so inhaltsleer, wie oft behauptet wird. Er ist zunächst einmal Auftrag zur sozialen Gestaltung durch Leistungsgesetze ${ }^{158}$ und zur sozialen Bewältigung des Umverteilungsproblems. Diese Gestaltung ist nicht beliebig, sondern auf die Geltungskraft und Verläßlichkeit angelegt, derer individuelle Lebensplanung bedarf. Sozialstaatlichkeit fordert Grundlagengesetzgebung, die zugleich die Grenzen zwischen sozialstaatlichem und grundrechtlichem Minimum einerseits und disponibler Transfer-Wohltat andererseits selbst zieht, statt sie dem Verfassungsgericht zu überlassen.

Unerläßlich aber bleibt bei aller Flexibilität und Offenheit der verfassungsrechtliche Vorrang des Schutzes des Schwächeren und der Behebung von existentieller Not. Nur insoweit hat die Rede vom ,sozialen Rückschrittsverbot ${ }^{\text {‘159 }}$ Berechtigung.

\section{Das Beispiel „Daseinsvorsorge“}

Die Gestaltungsprobleme der Daseinsvorsorge ${ }^{160}$ sind so vielfältig wie die Daseinsfelder, denen die Vorsorge dient. Traditionelle Bereitstellungsbereiche haben mit dem besonderen Gewaltverhältnis nicht nur ihre hergebrachte Klammer verloren ${ }^{161}$, sie verlangen durch neue Ziele und Formen auch nach einem neuen Instrumentarium des Öffentlichen Rechts ${ }^{162}$. Hausaufgaben hat der Gesetzgeber auch am Dach des Öffentlichen Sachenrechts zu erledigen, und zwar nicht nur dort, wo die schneidige junge Verwandtschaft aus dem Umweltrecht längst bestimmt, was Gemeingebrauch und Sondernutzung ist. Grundbegriffe wie Widmung, Widmungsänderung, Zugang und Nutzungsverhältnis usw. harren hier sowohl der Normierung als auch der entschlossenen Ǔberwindung sachenrechtlicher Atavismen ${ }^{163}$. Auch die gequäl-

${ }^{158}$ Unbestritten seit BVerfGE 1, 97, 105; O.Bachof, VVDStRL 12 (1954), S. $37,39,80$.

${ }_{159}$ Krit. dagegen zu Recht P.Badura, SGb 1980, S. 5; H.F.Zacher, in: Isensee/Kirchhof, a.a.O. (Anm. 13), S. 1092.

${ }^{160}$ Zum - heute freilich auch nicht mehr im traditionellen Sinne abgrenzbaren - Begriff E.Forsthoff, Lehrbuch des Verwaltungsrechts I, 10. Aufl. (1973), S. $368 \mathrm{ff}$.

${ }^{161}$ In diesem Sinne schon D.Jesch, Gesetz und Verwaltung (1961), S. 212.

162 Zur heute nicht mehr möglichen ,scharfen Abgrenzung" noch E.Forsthoff, a.a.O. (Anm. 160), S. 371 .

${ }_{163}$ Grundlegend dazu M.Kromer, Sachenrecht des öffentlichen Rechts (1985), insb. S. 86ff., 102. 
te Überdehnung der Allgemeinverfügung in $\S 35 \mathrm{VwVfG}$ war kein guter Anfang - die Bereitstellung sachgerechter Normsetzungsverfahren wäre ein besserer.

Die Bedeutung des Vorsorgefaktors „Information" harrt noch der Entdeckung als Querschnittsphänomen ${ }^{164}$, und zwar auch durch die kleiner werdende Spezies der Nicht-Medienrechtler. Immer wieder wird zu Recht gefordert, den vielen nicht in Verwaltungsakte einzupassenden Leistungs- und Lenkungsformen angemessene Rechtsverhältnisse und Verfahren zu geben, die einen Rahmen bieten, die realen Lebensvorgänge aber nicht in Konditionalnormen zu pressen versuchen ${ }^{165}$. Mehr als irgendwo zeigt sich die Untrennbarkeit von Leistung und Eingriff bei grundrechtsrelevanter Daseinsvorsorge. Uber Schule und Hochschule ${ }^{166}$ hinaus wird der Gesetzgeber wohl über kurz oder lang auch andere Zulassungsverfahren und das Problem knapper Kapazitäten auszugestalten haben ${ }^{167}$. Die rechtsstaatliche Geisterbahn des Jahrmarktzugangs nach „bekannt-bewährt-Kriterien“"168 ist hierfür noch ein eingrenzungsfähiges Beispiel. In Grundrechtsrelevanz und Größenordnung unvergleichbar harrt mit dem Zugang zur technischen Medizin z.B. ein Verteilungsproblem der gesetzlichen Regelung (vielleicht auch der Erkenntnis der fehlenden Regulierbarkeit), gegen das der Zahnprothesen-Streit der Gegenwart geradezu harmlos ist ${ }^{169}$. Auch hier also Bedarf an Grundlagenentscheidung und Grundlagengesetzgebung, die die Zwecke ${ }^{170}$ und Rechtsverhältnisse einzelner Bereiche, Mitwirkung der Leistungsempfänger und Leistungsträger, aber auch die Grenzen zwischen Leistung und Bevormundung zu erfassen hätte. Schließlich ist daran zu erinnern, daß es einen „Sockel“" existentiell wichtiger Daseinsvorsorge gibt ${ }^{171}$, der - auch wenn nicht grundgesetzlich ,vorgeschrieben“ - nicht zum Opfer anderer Prioritäten werden darf.

${ }^{164}$ Bei J.J.Hesse, in: Hesse/Zöpel, a.a.O. (Anm. 8), S. 60.

${ }^{165}$ Zur rechtlichen Erfassung der Pflege- und Betreuungsverhältnisse $J$. Schmitz-Elsen/O.E.Krasney, Verh. des 52. DJT (1978), Bd. 2, N 5ff.; H.F.Zacher, GS Constantinesco (1983), S. 943.

${ }_{166}$ Dazu st.w.N. J.Staupe, a.a.O. (Anm. 66).

${ }^{167}$ Zur Bedeutung der Einrichtungen E.Schmidt-Jortzig, NVwZ 1987, S. 1025, 1031; V.Evertz, Die Bedeutung der Grundrechte im Zusammenhang mit der Benutzung gemeindlicher öffentlicher Einrichtungen (1987), S. 1, 9ff.

${ }^{168}$ BayVGH, NVwZ 1982, S. 120 ; BVerwG, NVwZ 1982, S. 194; krit. $R$. Stober, Wirtschaftsverwaltungsrecht, 5. Aufl. (1987), Rz. 893.

169 Dies auch, wenn man der Drastik von Fuchs, „who shall live?" (1974) nicht folgen will; zu den Strukturproblemen aber W.Krämer, Herder Staatslexikon II, a.a.O. (Anm. 7), Sp. 1015.

${ }_{170}$ Dazu vor allem G.Haverkate, VVDStRL 46 (1988), S. 228; ders., NVwZ 1988, S. $769 ; R$. Wahl, VVDStRL 46 (1988), S. 282.

${ }^{171}$ H.F.Zacher, in: Isensee/Kirchhof, a.a.O. (Anm. 13), S. 1082. 
Daseinsvorsorge bezieht sich vor allem in ihren kulturellen Anwendungsfeldern auf Lebensbereiche, die nicht ohne Mitwirkung der in ihnen tätigen Grundrechtsträger und unter Achtung der jeweiligen Eigengesetzlichkeit normierbar sind. So war es im Hochschulbereich eine Kommission, die half, Ungereim theiten des HRG zu korrigieren ${ }^{172}$. Im Schulbereich wird es angesichts des Selbstbewußtseins einer Bürokratie, die ihre Verwaltungsvorschriften nahezu ungebremst in Schulgesetze umgießen konnte ${ }^{173}$, wohl noch etwas dauern. Das Angebot der Schulrechtskommission des Deutschen Juristentages ${ }^{174}$ entstand jedenfalls unter Mitwirkung von Sachverständigen und Betroffenen, die wußten, wo der pädagogische Vorgang Schule etwas anderes als bloßer Gesetzesvollzug ist ${ }^{175}$. Die empörte Ablehnung durch die Verwaltung bestätigte letztlich die Richtigkeit des Konzepts ${ }^{176}$.

\section{Schluß: Von den Grenzen der Gestaltung}

Die Grenzen der Gesetzesgestaltung und -anwendung stehen also am Schluß meiner Ausführungen. Lernen, Forschen, künstlerisch Gestalten, Beraten, Heilen und Pflegen sind Vorgänge, die rechtlich nur abzusichern, nicht zu durchdringen sind, ob sie besonderen verfassungsrechtlichen Schutz genießen oder nicht ${ }^{177}$. Deshalb auch ist die Daseinsvorsorge der Bereich, in dem Gesetzesgestaltung am meisten von Dezentralisierung und Delegation gewinnen kann ${ }^{178}$. Das Bedürfnis nach bundeseinheitlicher Regelung im Sinne von Art. 72 GG ist hier die Ausnahme. Anläufe zur „Durchforstung“ der Bundeskompetenzen müssen endlich zum Ziel führen. Die wahrhaftig nicht überlasteten Landtage und Gemeinderäte aber müssen daruiber hinaus ihre

\footnotetext{
${ }^{172}$ Vgl. den Bericht der Expertenkommission zur Untersuchung der Auswirkungen des HRG (1984) und den darauf basierenden Entwurf zur 3. Änd. des HRG (BT-Drucks. 10/2883).

${ }^{173}$ Dazu B.-O.Bryde, DöV 1982, S. 661; krit. auch W.Martens, in: Götz/ Klein/Starck, a.a.O. (Anm. 25), S. 90.

${ }^{174}$ Vgl. DJT, Schule im Rechtsstaat I, Entwurf für ein Landesschulgesetz. Bericht der Kommission Schulrecht des DJT (1981).

${ }^{175}$ B.-O.Bryde, VVDStRL 46 (1988), S. 195; J.Baumert, RdJB 1981, S. 192ff.; W.Höfling, DöV 1988, S. 416ff.

${ }^{176}$ Dazu auch die schulrechtliche Wirkungsdokumentation der Kommission Schulrecht des DJT, bearb. von R.Dechsling, Bonn (1987).

${ }^{177}$ Grundlegend dazu J.Oebbecke, Weisungs- und unterrichtsfreie Räume in der Verwaltung (1986); zur Subsidiarität im Kulturbereich auch Steiner, VVDStRL 42 (1984), S. 7, 48; zu den besonderen Problemen der Beratung I.Richter, in: Gagel, AfG-Kommentar (1987), §§ 25ff., insb. vor $\S 25, \mathrm{Rz} .48$.

${ }^{178}$ Dieses Prinzip habe ich ausführlich begründet in NVwZ 1983, S. 516 sowie zu den "Gegenwartsfragen des Kulturföderalismus", BayVBI. 1985, S. 1ff., $37 \mathrm{ff}$.
} 
Gestaltungskraft gegenüber den Koordinationseliten in Bund und Ländern zurückgewinnen ${ }^{179}$. Grundsatzgesetzgebung für die wirklich grundlegenden Entscheidungen der Gemeinschaft, im übrigen aber sach- und personennahe Regulierung müssen an die Stelle von phantasieloser Linearität und das urdeutsche Mißverständnis treten, daß gerechte und kluge Gesetzesgestaltung stets etwas mit Einheitlichkeit zu tun hätte ${ }^{180}$. Das zeigt die „Gesundheitsreform“, die scheitern wird, weil sie die Probleme mit linearen Pflichtkürzungen in ebenso lineare Pflichtleistungen statt mit Flexibilität und dem simplen Individualinteresse an preiswerter Gesundheit zu lösen versucht ${ }^{181}$. Das zeigen die Hochschulzulassung und das Tollhaus der Zentralprüfungen in der Medizinerausbildung. Das zeigen aber vor allem - trotz Gängelei und Sparzwang - die Vitalität und Leistungsvielfalt in den Gemeinden ${ }^{182}$ und überhaupt in den ,kleinen Einheiten “, wo viele Probleme in Selbsthilfe und Gruppenverantwortung oft schon gelöst sind, bevor sie den Gestaltern im großen auch nur auffallen.

${ }^{179}$ F.Hufen, BayVB1. 1987, S. 513ff., 516f.

${ }^{180}$ Krit. schon U.Scheuner, DöV 1960, S.605; W.Schmitt Glaeser, DöV 1981 , S. 4.

${ }^{181}$ Krit. auch G.Haverkate, NVwZ 1988, S. 777. Alternativen auch in den Vorschlägen für die Konzertierte Aktion im Gesundheitswesen (medizinische und ökonomische Orientierung). Zusammenfassung und Empfehlungen aus dem Jahresgutachten 1988 (Bonn, Bundesminister für Arbeit und Sozialordnung) (1988); vgl. ferner den Bericht der Kommission Krankenhausfinanzierung der Robert-Bosch-Stiftung „Krankenhausfinanzierung in Selbstverwaltung“ (1987); G.Neubauer, Alternativen der Steuerung des Gesundheitswesens (1984); F.Lohse, Modellgestützte Analyse der Auswirkungen alternativer Systemgestaltungen der Gesetzlichen Krankenversicherung (1986); P.Zweifel/O.Waser, Bonusoptionen in der Krankenversicherung (1987).

${ }^{182}$ K.H.Blessing, Die Zukunft des Sozialstaats - Grundlagen und Vorschläge für eine lokale Sozialpolitik (1987). 
Leitsätze des 2. Berichterstatters über:

\section{Gesetzesgestaltung und Gesetzesanwendung im Leistungsrecht}

\section{Problemstellung. Zum Auftrag einer materialen Gesetzgebungslehre}

1. Gesetzesgestaltung und Gesetzesanwendung betreffen ein klassisches Thema des Staats- und Verwaltungsrechts, das gegenwärtig angesichts wachsender Steuerungs- und Verteilungsprobleme neues Gewicht erhält. Der Begriff „Leistungsrecht" ist wegen des untrennbaren Zusammenhangs von Leistung, Eingriff und Verteilung nur noch unter Vorbehalt verwendbar.

2. Eine rein instrumentelle Lehre der Gesetzesgestaltung greift zu kurz, weil es auch um Gestaltung durch das Gesetz geht. Gefordert ist eine materiale Gesetzgebungslehre, die ihre wichtigsten Bezugspunkte im konkreten Verfassungsrecht findet, und zwar unabhängig von der verfassungsgerichtlichen Sanktionsmöglichkeit. Grundgesetz und Landesverfassungen haben viele der traditionellen Ziele, ,guter Gesetzgebung " inkorporiert. Sie sind aber nicht einzige Maßstäbe der Gesetzesgestaltung.

\section{Die Geltungskraft des Gesetzes als Aufgabe} von Gesetzesgestaltung und anwendung

3. Rechtsstaat, Demokratie und Sozialstaat verlangen, daß Leistungsgesetze Bedingungen ihrer eigenen Geltungskraft setzen und einen verläßlichen Rahmen für die individuelle Lebensplanung bieten. Überdetaillierung, Vollzugsdefizite und Unstetigkeit gefährden diese Funktion.

4. Das Vordringen des Gesetzesvorbehalts ins Detail war kein Sieg des Parlaments über die Bürokratie, es lieferte das Gesetz in weiten Teilen kleinen Gruppen hochspezialisierter Ressort- und Fraktionsexperten aus und bestätigt mittelbar die traditionelle Exekutivabhängigkeit des Leistungsrechts. 
5. Verfassungsinterpretation und höchstrichterliche Rechtsprechung haben in weiten Bereichen die klassischen Funktionen des allgemeinen Gesetzes übernommen.

6. Unter den Reformvorschlägen für das ,innere Gesetzgebungsverfahren "sind diejenigen besonders wichtig, die zeitliche Beruhigung, frühzeitige Konfliktaustragung, Öffnung für Zusammenhänge und Durcharbeitung des Stoffes bezwecken. Hierbei gewinnt das Modell der unabhängigen Gesetzgebungskommission neue Attraktivität nicht nur für die Erarbeitung von Entwürfen und Alternativen, sondern auch für die Wirkungsanalyse und die Verarbeitung von Änderungsimpulsen.

7. Es wird vorgeschlagen, eine verfassungsrechtlich besonders hervorzuhebende und abzusichernde Grundlagengesetzgebung einzuführen. In dieser Form hat der Gesetzgeber nicht ,vorfindlich Wesentliches" zu regeln und „Unwesentliches" zu unterlassen, er hat vielmehr selbst zu entscheiden, was so wesentlich sein soll, daß es Inhalt der Grundlagengesetzgebung und damit Kontinuitätsreserve des sozialen Rechtsstaats ist. Vordringliche Aufgabe ist die Fortsetzung der Kodifikation des allgemeinen Verwaltungsrechts unter Wiedereingliederung der allgemeinen Teile des Sozialrechts. Auch die Zwecke, Rechtsverhältnisse und vertrauensbegründenden Weichenstellungen des jeweiligen Leistungsbereichs gehören in Grundlagengesetze (,Stammgeset$z e^{\prime \prime} \%$.

8. Vorgeschlagen wird ferner, zur Entlastung von Anpassungs- und Änderungsentscheidungen eine im vereinfachten Verfahren verabschiedete Form des Gesetzes einzuführen. Diese vereinfachte Gesetzgebung muß durch minderheitsschützende Rückholrechte ins normale Verfahren gesichert und einem Stammgesetz zugeordnet sein. Sie darf nur als "Anpassungsfenster" dienen und muß die Grundlagen der Leistungsverhältnisse und -tatbestände unangetastet lassen.

\section{IIL Das anthropologische Leitbild der Gesetzesgestaltung und Gesetzesanwendung: Selbstbestimmung, Selbstregulierung, soziale Verantwortung}

9. Auch die Leistungsgesetzgebung findet ein anthropologisches Leitbild des Grundgesetzes vor, das unbeschadet der Sozialgebundenheit vom Vorrang individueller Vorsorge vor staatlicher Sicherung ausgeht. Dieses Leitbild ist durch den Verlust außerrechtlicher Normen, Solidarbeziehungen und Konfliktlösungsmechanismen massiv gefährdet. 
10. Notwendig ist die Stärkung der Selbstregulierung als gemeinschaftliche Wahrnehmung von individueller Freiheit, aber auch überindividueller Verantwortung. Selbstregulierung kann das Gesetz vor allem im Bereich der Daseinsvorsorge entlasten und bedarf der öffentlich-rechtlichen Absicherung sowohl gegen Übernormierung „von oben " als auch gegen Mißbrauch ,von unten".

11. Das Öffentliche Recht hat sich zu sehr auf die Instrumente der nur als Delegation staatlicher Macht mißverstandenen Selbstverwaltung konzentriert und die Selbstregulierung auch dort in das Zivilrecht abgeschoben, wo sie zur Erfüllung öffentlicher Aufgaben in Betracht kommt. Diese Entwicklung ist durch eine ,selbstregulierungsfreundliche" Gesetzesgestaltung und anwendung im Öffentlichen Recht rïckgängig zu machen.

\section{Das Problem der Gleichheit}

12. Gesetzesgestaltung und Gesetzesanwendung müssen die Spannung von Allgemeinheit und Differenzierung gemeinsam lösen, auch wenn sich die Bezugspunkte der Gleichheit ständig verschieben und ein allgemein anerkannter Maßstab der Gerechtigkeit nicht zur Verfügung steht.

13. Einzelfallgerechtigkeit ist durch das Gesetz in der Regel nicht herstellbar. Je detaillierter Leistungsgesetze sind, desto größer ist die Gefahr gleichheitswidriger Härten, Kumulationseffekte und Mißbräuche. Einzelfallgerechtigkeit bleibt primür Aufgabe der Gesetzesanwendung und bildet eine Schranke gegen überzogene Selbstbindung der Verwaltung.

14. Mit dem Entscheidungsspielraum der Gesetzesanwendung steigt die Bedeutung der Verwaltungsverfahren besonders im Hinblick auf Beratung, Anhörung, Mitwirkung, Sachaufklärung und Begründung. Großzügig gestaltete und angewendete Heilungsvorschriften sind damit unvereinbar. Die Bedeutung des Widerspruchsverfahrens muß gestärkt werden.

\section{Sozialstaat und Grundrechte als Maßstäbe der Gesetzesgestaltung und Gesetzesanwendung}

15. Sozialstaatsgebot, Grundrechte und Minderheitenschutz enthalten objektiv-rechtliche Gestaltungsaufträge für den (Grundlagen)Gesetzgeber. Sie bilden - auch abgesehen von Art. 14 GG - Rahmen und Grenze gegenüber Eingriffen in grundrechtsgesicherte Vertrauenspositionen. 
16. Die Bekämpfung sozialer und wirtschaftlicher Not hat den verfassungsrechtlichen Vorrang vor wohlstandsförderndem Transfer. Sozialstaatsgebot und Menschenwürde verlangen den besonderen Schutz eines durch Grundlagengesetzgebung auszugestaltenden Minimums. Dieser "Leistungssockel" steht für Spar- und Umverteilungsmaßnahmen nicht zur Verfügung.

\section{VL Das Beispiel ,Daseinsvorsorge“}

17. Einheitliche Aussagen zum Recht der "Daseinsvorsorge" sind wegen der heterogenen Struktur der damit bezeichneten Leistungsbereiche kaum möglich. Es besteht aber Bedarf für eine Kodifikation der Grundzüge des Öffentlichen Sachenrechts und für die rechtliche Erfassung der Rechtsverhältnisse und Verfahren über den Verwaltungsakt hinaus. Im Recht der öffentlichen Einrichtungen sind Widmungszweck und Widmungsänderung, Zugangsregelungen bei knapper Kapazität und die Grundzüge des Nutzungsverhältnisses zu regeln, und zwar unabhängig von offentlich-rechtlicher oder privatrechtlicher Ausgestaltung.

18. Das Recht der Daseinsvorsorge verlangt in besonderem Maße nach Dezentralisierung und Delegation auf Selbstverwaltungsträger. Selbsthilfegruppen und Selbstregulierung können hier die öffentliche Aufgabenwahrnehmung besonders deutlich entlasten.

19. In der kulturellen Daseinsvorsorge ist Gesetzesgestaltung ohne angemessene Mitwirkung der im jeweiligen Bereich Tätigen nicht mehr möglich. Gesetzesgestaltung und Gesetzesanwendung haben hier besonders auf die Grenzen der Normierbarkeit und auf die Eigengesetzlichkeit der jeweiligen Lebensprozesse zu achten.

20. Im Bereich der Daseinsvorsorge spricht eine Vermutung gegen ein Bedürfnis nach bundesgesetzlicher Regelung im Sinne von Art. 72 GG. Darüber hinaus müssen die Landesparlamente ihren Gestaltungsspielraum gegen die Kooperations- und Vereinheitlichungsbürokratien in Bund und Ländern wiedergewinnen. Sie müssen aber auch Dezentralität, Delegation und Subsidiarität innerhalb der Länder beachten und absichern. 


\section{Gesetzesgestaltung und Gesetzesanwendung im Leistungsrecht}

\section{Bericht von Professor Dr. Hermann Hill, Speyer}

\section{Inhalt}

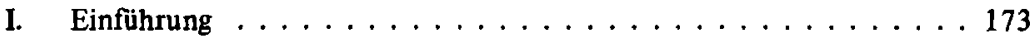

II. Gesetzesgestaltung im Leistungsrecht $\ldots \ldots \ldots \ldots \ldots \ldots \ldots 173$

1. Rechtsverhältnisse im Sozialleistungsrecht $\ldots \ldots \ldots \ldots \ldots 173$

2. Reichweite der gesetzlichen Bindung $\ldots \ldots \ldots \ldots \ldots 176$

3. Gesetzliche Gestaltung des Leistungsprogramms . . . . . . 178

4. Effektuierung durch das bewegliche System . . . . . . . 180

5. Regeln und Erfolgsvorsorge für den Gesetzgebungsprozeß $\ldots . .184$

III. Gesetzesanwendung im Leistungsrecht . . . . . . . . . . . . 187

1. Gesetzesanwendung in der Funktionenordnung des Grundgesetzes . . . . . . . . . . . . . . . . . . 187

2. Voraussetzungen der Gesetzesanwendung in der Verwaltungspraxis . . . . . . . . . . . . . . . . . . . 190

3. Gesetzesanwendung mit dem Bürger . . . . . . . . . . 192

IV. Ausblick . . . . . . . . . . . . . . . . . . . 195 


\section{Einfuihrung}

Gesetzgebungskunst ist im Leistungsstaat besonders notwendig, so Herr Häberle 1972 ${ }^{1}$. Herr Scheuner ${ }^{2}$ verwies 1981 auf den Bedarf nach einer modernen Gesetzgebungslehre im Sozialstaat und Herr Starck $^{3}$ bezeichnete es 1988 , mit Blick auf diese Tagung, als ein dringendes Desiderat der Gesetzgebungslehre, die Typen der Leistungsgesetze genauer zu erfassen und die legislatorischen Probleme ihrer Anwendung und Wirksamkeit zu erörtern. Dies zeigt die Bedeutung der Themenstellung der heutigen Sitzung.

Das Besondere daran scheint mir die Verknüpfung von Gesetzgebung und Gesetzesanwendung zu sein ${ }^{4}$. Beide Teile des Themas können nicht isoliert, sondern nur im Zusammenwirken und in Wechselbeziehung miteinander verstanden werden. Gesetzgebung bedarf des ständigen Blicks und der tätigen Mithilfe der Rechtsanwendung ${ }^{5}$; umgekehrt ist Gesetzesanwendung durch Verwaltung, Gerichte und Bürger zugleich Entwicklung und Fortbildung, Kontrolle und Rückkopplung sowie Vorstufe für neue Gesetze bzw. Gesetzesänderungen. Rechtsverwirklichung durch Gesetzesgestaltung und Gesetzesanwendung geschieht in einem vielfältig verflochtenen arbeitsteiligen Proze $B^{6}$.

\section{Gesetzesgestaltung im Leistungsrecht}

\section{Rechtsverhältnisse im Sozialleistungsrecht}

Leistungsrecht wird in objektiver Hinsicht durch die zugrundeliegenden sozialen Probleme, die Leistungszwecke sowie die Besonderheiten des jeweiligen Sachgebiets geprägt, in subjektiver Hinsicht durch

1 Peter Häberle, in: Festschrift Günther Küchenhoff, 1972, S.453 (469, Fn.73).

2 Ulrich Scheuner, in: Festschrift Hans Huber, 1981, S. 127 (141).

${ }^{3}$ Christian Starck, ZG 1988, 1 (5); vgl. auch Helmar Bley, SGb 1981, 519 (529); Rolf Stober, DVBl. 1987, 269 (279); zur Gesetzgebungstechnik der Sozialversicherungsgesetze von 1883,1884 und $1889 \mathrm{vgl}$. Hans-Peter Benöhr, in: Festschrift Ulrich von Lübtow, 1980, S. 699.

4 Vgl. schon Roman Herzog, VVDStRL 24 (1966), S. 183ff., 197ff. zu den gegenseitigen Einwirkungen von Gesetzgebung und Verwaltung.

${ }^{5}$ Kurt Eichenberger, SchwZB1StGemVerw 1984, 97 (98).

6 Scheuner, DöV 1969, 585 (589); Hans F.Zacher, in: Die verfassungsrechtliche Relevanz des Sozialrechts, 1975, S. 50; Eberhard Baden, Gesetzgebung und Gesetzesanwendung im Kommunikationsprozeß, 1977, S. 87ff.; Waldemar Schreckenberger, in: Festschrift Friedrich Schäfer, 1980, S. 76 (83); vgl. auch Ulrich Karpen, ZG 1986, 6 (16); ders., NJW 1988, 2512 (2514f.); Norbert Achterberg, ZG 1986, 221 (223) im Sinne einer allgemeinen Regelungstheorie; aus der Sozialwissenschaft vgl. Renate Mayntz, Implementation politischer Programme I, 1980, S. 1 (10). 
Leistungsansprüche und einen umfassenden Rechte- und Pflichtenkanon ${ }^{7}$. Leistungsgesetze bedürfen in objektiver und subjektiver Hinsicht zudem der Konkretisierung im Einzelfall, um Wirksamkeit zu erlangen. Dogmatisch bietet sich für eine Integration dieser verschiedenen Rechtsentstehungs- und -verwirklichungsphasen die Figur des Rechtsverhältnisses ${ }^{8}$ an. Die Rechtsverhältnisse im Sozialleistungsrecht sind durch vier Charakteristika geprägt, die ich im folgenden erläutern möchte:

a) Sozialgesetze sind von einer Vielfalt der Regelungen, Strukturen und Handlungsformen gekennzeichnet ${ }^{9}$. Diese Vielfalt ist durch den Regelungsgegenstand des Sozialrechts, nämlich die Vielgestaltigkeit sozialer Bedürfnisse und Notlagen sowie durch seine Entwicklung bedingt. Sozialrecht wurde - anders als etwa das BGB - ohne vorausgehende einheitliche Konzeption etappen- und stufenweise entwickelt ${ }^{10}$.

Das gegliederte System im Sozialrecht kennt daher manche Uberschneidungen und Widersprüche, an deren Harmonisierung es noch mangelt ${ }^{11}$. Es ist als Teil der Rechtsordnung mit anderen Rechtsgebieten, etwa Wirtschafts-, Arbeits-, Steuer- und Familienrecht, vielfältig verzahnt ${ }^{12}$. Im Hinblick auf variierende Sinnzusammenhänge, andersartige Rollen der Leistungsempfänger sowie wegen verschiedener Ansätze, Perspektiven und Phasen der Leistungsgewährung sind einheitliche Lebenssachverhalte oft mehrfach und teilweise abweichend gesetzlich erfaßt ${ }^{13}$. Gesetzliche Maßnahmen sind häufig nur Reaktionen auf festgestellte Notlagen, typisch sind hierfuir das sog. Maßnahmegesetz sowie Einzelfallregelungen.

1 Zur Anatomie des Sozialrechts vgl. Zacher, SGb 1982, 329.

- Thomas Fleiner-Gerster/Theo Öhlinger/Peter Krause, VVDStRL 45 (1987), S. 152ff./182ff./212ff.; Hermann Hill, NJW 1986, 2602; Friedrich E.Schnapp, DÖV 1986, 811; Stober, DVBI. 1987, 269 (277); ders., DVBl. 1988, 1099 (1104); Zurückhaltung bei Dirk Ehlers, DVBl. 1986, 912 und Wolfgang Löwer, NVwZ 1986, 793.

- Wolfgang Gitter, Zweckwidrige Vielfalt und Widersprïche im Recht der Sozialversicherung, 1969; Dieter Giese, in: Hans-Uwe Otto/Siegfried Schneider (Hrsg.), Gesellschaftliche Perspektiven der Sozialarbeit, 1. Halbband, 3. Auf1. 1975, S. 45 (55); Zacher, in: Festschrift Wolfgang Zeidler, 1987, S. 571ff.; allgemein für das Leistungsrecht Ingo von Münch, in: Hans-Uwe Erichsen/Wolfgang Martens (Hrsg.), Allgemeines Verwaltungsrecht, 8. Aufl. 1988, S. 24.

${ }^{10}$ Heinrich Reiter, SGb 1987, 89 (91).

11 Karl Hauck, SGb 1983, 461 (462); vgl. auch den Bericht von Eberhard Eichenhofer über die 4. Sozialrechtslehrertagung in Freiburg 1988, DAngVers $1988,197$.

12 Vgl. etwa Manfred Zuleeg, GewArch 1986, 313; grundsätzlich Zacher, in: Friedrich Kübler (Hrsg.), Verrechtlichung von Wirtschaft, Arbeit und sozialer Solidarität 1984, S. 11 (26ff.); vgl. auch Helmuth Schulze-Fielitz, Döv 1988, 758 (763).

13 Zacher, ZStW 134 (1978), 15 (18ff.). 
b) Zunehmend zeigt sich aber auch ein anderer Typus von Sozialleistungsgesetzen, der isolierte Ansprüche, Konkurrenzen und Doppelversorgungen $\mathrm{zu}$ vermeiden sucht und statt dessen vom Gesamtfallprinzip ausgeht ${ }^{14}$, auf die Regelung von Lebenszusammenhängen ( $\S 3,7 \mathrm{BSHG})^{15}$ abstellt, verschiedene Leistungen koordiniert, gegenseitige Verflechtungen und Abhängigkeiten berücksichtigt, Konkurrenzen entschärft, planerisch-vorsorgend vorgeht und die Verwaltung entsprechend verpflichtet. Als Beispiel mögen die sog. Gesamtpläne im Sozialhilfe- und Rehabilitationsrecht ${ }^{16}$ oder Präventivmaßnahmen im Gesundheitsrecht ${ }^{17}$ dienen. Die in den letzten Jahren zunehmend entstandenen Artikelgesetze, insbes. Haushaltsstruktur- und -begleitgesetze, die zusammenfassend für mehrere Sozialleistungsbereiche Einzelregelungen enthalten, könnten bei besserer Abstimmung diese Funktion erfüllen. Die Anwendung dieser ganzheitlich-vorsorgenden Gesetzesbestimmungen wird vor allem durch ausdrückliche gesetzliche Zweckbestimmungen, Leitprinzipien, wie die sozialen Rechte des SGB AT, oder Strukturprinzipien, wie etwa im Sozialhilferecht (etwa $\S \S 2,3,6$ BSHG), gesteuert.

c) Das Rechtsprogramm im Sozialleistungsrecht ist notwendigerweise unvollständig. Viele gesetzliche Vorschriften enthalten mit den Formulierungen ,darauf hinwirken“, ,soweit wie möglich zu verwirklichen“, ,anzustreben“", ,darauf ausrichten“18 lediglich Zielannäherungspflichten bzw. Optimierungsaufträge, auch Prinzipien genannt ${ }^{19}$, die nicht vollständig offen ${ }^{20}$, aber auch nicht eindeutig zielgerichtet,

${ }^{14}$ BVerwGE 22, 319 im Zusammenhang mit § 5 BSHG; vgl. auch Dietrich Schoch, ZfS 1987, 65 (66).

${ }^{15}$ Eckart Pankoke, in: Burkart Lutz (Hrsg.), Soziologie und gesellschaftliche Entwicklung, 1985, S. 103 (106); ders., in: Claus Reis/Hermann Dorenburg (Hrsg.), Selbsthilfe, 1985, S. 97 (110).

16 §§ 46 BSHG, 5 Abs. 3 RehaAnglG.

17 Vgl. $\$$ 20ff. Gesundheits-Reformgesetz vom 20.12.1988 (BGBl. I, S. 2477); BT-Drs. 11/2237, S. 143, 149; 11/2493, S. 7; Hans Schäfer, DVBl. 1972, 405 (409); Rainer Prätorius, in: Martin Pfaff, Effizienz und Effektivität staatlicher Transferpolitik in der Wirtschaftskrise, 1983, S. 145 (148); Stober, DVBl. 1987, 269 (278); Michael Wollenschläger/Eckhard Kreßel, NZA 1988, 377 (382); Görg Haverkate, NVwZ 1988, 769 (777).

18 Vgl. etwa $\S \S 17$ SGB AT, 1 Abs. 2 Satz 2, 3a, 18 Abs. 2, 25 Abs. 3, 72 Abs. 4 BSHG, 1 Abs. 1, 4 Abs. 1 und 2, 5 Abs. 1 und 6 RehaAnglG.

19 Robert Alexy, ARSP, Beiheft 25 (1985), S. 13ff.; ders., Rechtstheorie 18 (1987), 405 (407); vgl. auch Erhard Denninger, KJ 1988, 1 (7).

${ }_{20}$ Fast schrankenlose Offenheit bei medizinischen Leistungen nimmt Bertram Schulin, in: Hero Silomon, u.a. (Hrsg.), Sozialmedizin, Sozialrecht, Gesundheitsökonomie, 1986, S. 13 (15) an; für noch mehr Offenheit Bernd von Maydell, in: Festgabe 25 Jahre Bundesverwaltungsgericht, 1980, S. 405 (415f.); Rainer Pitschas, ArchsozArb 1981, 240 (251). 
sondern eher richtungweisend sind ${ }^{21}$. Sie können schon bei annähernder Zielerreichung erfüllt sein, obwohl immer noch ein weitergehender Gebotsinhalt verbleibt. Sie verlangen eine ständige Erfolgskontrolle, Zielentwicklung und Anpassung der Mittel und Leistungen, also eine ständige, gestaltende Optimierung.

d) Das Geschehen im Sozialstaat erfordert ein Denken in Prozessen. Die Sozialgesetze fixieren den Vorgang, nicht den Zustand. Sozialrecht ist prozeßorientiertes, d.h. prozeßgestaltendes und prozeßbegleitendes $R e c h t^{22}$. Die Wechselhaftigkeit und Anfälligkeit des Lebensprozesses, der sozialen Wirklichkeit, aber auch der sozialpolitischen Zielvorstellungen, erklären, daß Gesetze im Sozialstaat i.d.R. Änderungsgesetze darstellen. Viele Gesetze, insbesondere im Bereich sozialer Dienstleistungen (etwa im Rehabilitationsangleichungsgesetz, Arbeitsförderungsgesetz), enthalten keine direkten verbindlichen Verfahrensanweisungen, sondern eher Verhaltensstandards, denen so gut wie möglich nachzukommen ist ${ }^{23}$. Sie stellen Handlungsziele und -pflichten dar, weniger Kontrollziele und sind wegen ihrer Situationsabhängigkeit nur eingeschränkt überprüfbar.

\section{Reichweite der gesetzlichen Bindung}

Gemäß § 31 SGB AT dürfen Rechte und Pflichten in den Sozialleistungsbereichen dieses Gesetzbuches nur begründet, festgestellt, geändert oder aufgehoben werden, soweit ein Gesetz es vorschreibt oder zuläßt. Es fragt sich, ob dieser Gesetzesvorbehalt der Sozialverwaltung genügend Raum läßt, auch abweichenden und neuartigen Fallgestaltungen Rechnung zu tragen ${ }^{24}$. Nach inzwischen anerkannter Auffassung $^{25}$ sind Zielweisungsgehalt und Bindungsdichte der Gesetze in

${ }^{21}$ Pitschas, VSSR 1977, 141 (171); Zacher, ZStW 134 (1978), 15 (31f.); vgl. auch BVerwGE 71, 163 und Rudolf Steinberg, NVwZ 1986, 812 (815) zum Straßenplanungsrecht.

${ }^{22}$ Horst Peters, SGB AT, $\S 1$ Anm. 5f.; Häberle, in: Festschrift Küchenhoff, S. 453 (467); Zacher, ZStW 134 (1978), S. 15ff.; ders., in: Josef Isensee/Paul Kirchhof (Hrsg.), Handbuch des Staatsrechts, Band 1, 1987, § 25 Rdn. 66; Wilhelm Wertenbruch, in: Festschrift Bundessozialgericht, 1979, S. 325 (333); Rupert Scholz/Pitschas, in: Festschrift Bundessozialgericht 1979, S. 627 (655); Jörg Müller-Vollbehr, ZRP 1984, 262 (263); Karpen, NJW 1988, 2512 (2516).

${ }^{23}$ E.Blankenburg/U.Krautkrämer, in: Mayntz (Hrsg.), Implementation politischer Programme I, 1980, S. 138 (140).

${ }^{24}$ Gerhard Igl, NDV 1987, 130 (136).

${ }^{25}$ Herzog, VVDStRL 24 (1966), 183 (190ff.); Scheuner, DöV 1969, 585; Fritz Ossenbühl, in: Erichsen/Martens (Hrsg.), Allgemeines Verwaltungsrecht, 8. Auf1. 1988, S. 64; Winfried Brohm, DÖV 1987, 265 (270); ders., NVwZ 1988, 794 (798) sowie in: Hill (Hrsg.), Zustand und Perspektiven der Gesetzgebung, 1989, S. 217 (229f.); Hill, DÖV 1987, 885 (893). 
vielfacher Weise abgestuft. Dies gilt umso mehr für § 31 SGB AT, der mit den Begriffen ,vorschreibt oder zuläßt" eine abgestufte Gesetzesbindung normiert, die nach dem Wortlaut sowohl die Regelungsgenauigkeit (Bestimmtheit) als auch die Verbindlichkeit betreffen kann und Anforderungen an den Gesetzesinhalt je nach der Grundrechtsrelevanz bzw. Intensität der staatlichen Handlungsform festsetz $\mathrm{t}^{26}$. Dies läßt innerhalb der gesetzlichen Rahmenvorgaben vielfältige Gestaltungs-, Konkretisierungs- und Dispositionsmöglichkeiten für die Verwaltung offen.

Das Sozialleistungsrecht kennt insbesondere die Gesetzestypen Befehl, Plan, Auftrag und Information ${ }^{27}$. Neben klassischen Vorschriften mit unmittelbarem Rechtsanwendungsbefehl, die vor allem Leistungsansprüche sichern, haben andere mehr programmatisch-planhaften Charakter. Dabei reicht die Palette von idealistischen Zukunftsentwürfen über programmatische, teilweise nur symbolische Zielerklärungen bis hin zu konkreten gesetzgeberischen Planvorstellungen (sog. Leitvorschriften, vgl. § 1 SGB, BSHG, WoGG, BaföG, AFG und soziale Rechte, $\S \S 2$ ff. SGB AT) ${ }^{28}$. Diese Gesetzgebung ist auf Verwirklichung der vorgegebenen Ziele in Zusammenarbeit mit der Verwaltung angelegt ${ }^{29}$. Die Zielverwirklichung hat sich an Problem, Zeitpunkt und Situation und den sich daraus jeweils ergebenden Anforderungen zu orientieren (vgl. etwa die Begriffe zeitgemäß, ausreichend, notwendig, zweckmäßig in $\S \S 17$ SGB AT, $182 \mathrm{RVO}, 36 \mathrm{Nr} .3 \mathrm{AFG})^{30}$.

Ähnlich, jedoch teils konkreter, sind die Aufträge, die das Gesetz erteilt $^{31}$. Es handelt sich teils um allgemeine Ermittlungs- ( $\S \S 71,95$ BSHG), Prüfungs- und Bewertungs- ( $\S 78$ Abs. 1 BSHG, 18 WoGG) sowie Prognoseaufträge ( $\S 39$ Abs. 4, 44, 72 Abs. 3, 92a Abs. 1 Satz 2 BSHG), teils um spezielle Aufwands- ( $\S 91$ Abs. 3 Satz 2, 111 Abs. 2 BSHG) und Kostenbewertungsaufträge ( $\S 3$ Abs. 2 Satz 3, 27 Abs. 2 BSHG). Sie stellen weitgehende Anforderungen an eine selbständige Verwaltungstätigkeit, werden allerdings, da es sich überwiegend um tat-

\footnotetext{
${ }^{26}$ Hans-Jürgen Kretschmer, Der Vorbehalt des Gesetzes im Sozialversicherungsrecht, Diss. Berlin 1983, S. 151.

27 Vgl. etwa Häberle, in: Festschrift Küchenhoff, S. 453 (468); von Maydell, NJW 1976, 161 (162, 165); Blankenburg/Krautkrämer (Fn. 23), S. 138ff.

${ }^{28}$ Wolfgang Rüfner, in: Georg Wannagat, SGB AT, § 2 Rdn. 6; allgemein zum Programmcharakter der Sozialleistungsgesetze Zacher (Fn. 12), S. 38.

29 Walter Bogs, in: Festschrift Kurt Jantz, 1968, S. 71 (85); Pitschas, in: Rüdiger Voigt (Hrsg.), Verrechtlichung, 1980, S. 150 (161).

30 Vgl. auch Krause, in: Festschrift Wannagat, 1981, S. 239 (248, 250).

${ }^{31}$ Vgl. schon Scheuner, DöV 1969, 585: Das Gesetz als Auftrag der Verwaltung; Wolfgang Zeh, in: Schreckenberger (Hrsg.) Gesetzgebungslehre, 1986, S. $57(65)$.
} 
bestandliche Voraussetzungen von Leistungsansprüchen handelt, i.d.R. von der Rechtsprechung vollständig nachvollzogen und ersetzt ${ }^{32}$.

Typisch für den Leistungsstaat sind schließlich die sog. Informationsvorschriften, die durchaus als neuer Normentyp im Bereich der neben den imperativen Normen sekundären Normarten (Auslegungsvorschriften, Legaldefinitionen) angesehen werden können ${ }^{33}$. Sie wenden sich vor allem an die potentiellen Leistungsempfänger und umfassen etwa die sozialen Rechte der $\S \S 2$ ff. SGB AT sowie die sog. Einweisungsvorschriften in $\S \S 18 \mathrm{ff}$. SGB AT. Sie stellen eine erste grundlegende Information und damit Vorkehrung dafür da, daß potentielle Leistungsempfänger von den ihnen zustehenden oder angebotenen Leistungen erfahren. Unterstützend wirkt die generelle Aufklärung durch die Verwaltung gem. § 13 SGB AT sowie die Information durch die Verwaltung im Einzelfall gem. $\S 14,15$ SGB AT.

\section{Gesetzliche Gestaltung des Leistungsprogramms}

Bei der Gestaltung des Leistungsprogramms bietet das Grundgesetz dem Gesetzgeber nur wenige und zudem konkretisierungs- und ausgleichsbedürftige Richtpunkte ${ }^{34}$. Die Umsetzung der verfassungsrechtlichen Grundlagen und Aufträge durch Gesetz ist aus Gründen der Funktionsgerechtigkeit der Gesetze an der Leistungsfähigkeit der Gesetzesanwender und dem Verständnishorizont der Adressaten zu orientieren $^{33}$. Neuere Sozialgesetze enthalten Hilfen für den systematischen Zugang zum Gesetz. So wird etwa im SGB AT das Sozialstaatsprinzip auf verschiedenen Stufen der Abstraktionsleiter entfaltet (Aufgaben, soziale Rechte, Einweisungsvorschriften, einzelne Ansprüche $)^{36}$, der

${ }^{32}$ Hinzu kommen die schon erwähnten Optimierungs-, Dynamisierungs- und Interaktionsaufträge bis hin zu einer Pflicht zur sozialen Aktivität oder bloßen Initiative im weiten Feld der Dienst- und Sachleistungen, vgl. Zacher (Fn. 6), S. 52; Pitschas, VSSR 1977, 141 (158); ders. (Fn. 29), S. 159; Michael Stolleis, ZSR 1988, 442 (445).

${ }^{33}$ Josef Siegert, in: Das neue Sozialgesetzbuch, 1972, S. 30 (44); Wolfgang Gitter, in: Festschrift Erich Fechner, 1973, S. 223 (237f.); von Maydell, NJW 1976, 161 (162, 165); kritisch Manfred W. Wienand, Bedeutungsgehalt und Funktionen der sozialen Rechte im AT des SGB, Diss. Freiburg 1980, S. 200f.

${ }_{34} \mathrm{Vgl}$. insgesamt zur neueren Rechtsprechung des Bundesverfassungsgerichts Dietrich Katzenstein, SGb 1988, 177 (180ff.).

${ }^{35}$ Hill, Einführung in die Gesetzgebungslehre, 1982, S. 96; Eichenberger, SchwZBIStGemVerw 1984, 97 (100).

${ }^{36}$ Harry Rohwer-Kahlmann/Heinz Ströer, SGB AT, Einführung, Anm. 23 und Anm. 64ff. vor § 1; Wienand (Fn. 33), S. 279f.; Helmut Vent, Grundlagen und Grundformen des Sozialrechts, Teil 1, 1984, S. 33ff.; aA Karlheinz Rode, in: Bochumer Kommentar zum SGB AT, 1979, § 18 Rdn. 4: Funktionales Nebeneinander. 
Aufbau des AFG entspricht seiner Zielsetzung (Aufgabenstellung, general-, spezialpräventive Maßnahmen und schließlich Leistungen an Arbeitslose als ultima ratio) ${ }^{37}$, die dem BSHG vorangestellten Strukturprinzipien enthalten die wesentlichen Leitgedanken und sind so bei der Auslegung und Lückenfüllung behilflich ${ }^{38}$. Rangfolgeregelungen bei potentieller Leistungskumulation (etwa Nachrang oder Vorrang, Günstigkeitsprinzip, Sachnähe, Zweckgleichheit) dienen der Harmonisierung und versuchen, ungerechtfertigte Doppelversorgungen zu vermeiden ${ }^{39}$.

Die Vielzahl der Mittel bei der technischen Programmgestaltung, die in Ergänzung zur systematischen eher die Feinsteuerung darstellt, kann nur angedeutet werden. Teilweise bestimmt der Gesetzgeber Tatbestand und Rechtsfolge der Leistung mehr oder weniger selbst, teilweise delegiert er die Konkretisierung generell, etwa an den Verordnungs-, Satzungs- oder Anordnungsgeber ${ }^{40}$, oder für den Einzelfall an die Verwaltung bzw. das Gericht, wie bei Ermessen, unbestimmten Rechtsbegriffen und Prognosen ${ }^{41}$. Vielfach findet man gerade bei unbestimmten Rechtsbegriffen interpretationslenkende Kriterien in den Sozialgesetzen, die die (vorrangige) Berücksichtigung bestimmter Belange vorschreiben und damit die Richtung der Interpretation vorgeben (etwa die Umschreibung des notwendigen Lebensunterhalts in $\S 12$ BSHG oder die gesetzlichen Leitlinien für die Beurteilung einer zumutbaren Arbeit in $\S 18$ Abs. 3 BSHG $)^{42}$. Dies stellt gewissermaßen einen verlängerten Gesetzesvorbehalt dar.

${ }^{37}$ Werner Hennig/Horst Kühl/Ernst Heuer, AFG, Einleitung.

38 Bernhard Atzler, DVBl. 1987, 1142.

${ }^{39}$ Ausfiuhrlich Rupert Stettner, in: Sozialversicherung - organisatorische Gliederung und funktionale Einheit der Sozialverwaltung, erscheint demnächst.

${ }^{40}$ Zeh (Fn. 31), S. 65; Ferdinand Kirchhof, VSSR 1983, 175 (184ff.); Blankenburg/Krautkrämer (Fn. 23), S.141; Alexander Gagel, AFG, § 39 Rdn. 4; ausführlich Ingwer Ebsen, DVBl. 1988, 883 (890); speziell für Regelsatzverordnungen gem. § 22 Abs. 3 BSHG vgl. Karl-Jürgen Bieback/Günther Stahlmann, SF 1987, 1;Joachim von Bargen, in: Festschrift Helmut Simon, 1987, S. 745 (765ff.); neben dieser ergänzenden bzw. konkretisierenden untergesetzlichen Rechtsetzung stellen Verwaltungsvorschriften und Richtlinien Hilfen zur Gesetzesanwendung dar, vgl. dazu Jürgen Brand, NDV 1983, 289; Erwin Quambusch, ZfSH/ SGB 1986, 382; Kommunale Spitzenverbände Rheinland-Pfalz (Hrsg.), Sozialhilferichtlinien.

${ }^{41}$ Die Abgrenzung bereitet häufig Schwierigkeiten, vgl. etwa für $\S 84$ Abs. 1 BSHG Walter Schellhorn, BSHG, § 84 Rdn. 8f.; Anton Knopp/Otto Fichtner, BSHG, $\S 84$ Rdn. 3 (Ermessen); Lothar Schmitt, BSHG, $\$ 84$ Rdn. 3 (unbestimmter Rechtsbegriff ohne Beurteilungsspielraum); Otto Mergler/Günter Zink, BSHG, $\S 84$ Rdn. 18ff. (unbestimmter Rechtsbegriff mit Beurteilungsspielraum).

${ }_{42}$ Vgl. auch $\S \S 3$ Abs. 1, 22 Abs. 3, 84 Abs. 1 Satz 2 BSHG sowie $\S 2$ Abs. 2 SGB (Auslegungsregel); $\$ 4$ Abs. 3 Satz 3 WoGG (gesetzliche Vermutung); $\S 12$ 


\section{Effektuierung durch das bewegliche System}

Eine der eklatantesten Schwächen der herrschenden Dogmatik und Gesetzgebung liegt in dem in der traditionellen Gesetzestechnik vorherrschenden Gegensatz zwischen konkreter und abstrakter Tatbestandsgestaltung ${ }^{43}$. Auf der einen Seite findet man bis ins Detail ausformulierte Tatbestände, enumerative Kasuistik, die doch nie alle Fälle erfassen kann, aber mit einer Menge von administrativem Aufwand und Ingerenz in private Verhältnisse verbunden ist. Das Gegenteil bilden abstrakte Generalklauseln, die Variablen reduzieren und vereinheitlichen. Aufgrund ihres Abstraktionsgrades beruhen sie zwangsläufig auf Durchschnittswerten und bieten daher auch nur eine durchschnittliche Lösung. Wegen ihrer Inhaltsleere stehen diese Generalklauseln mit dem rechtsstaatlichen Bestimmtheitsgrundsatz in Konflikt. Wegen ihres Abstands zur Realität und zum Einzelfall bieten sie Veranlassung, den jeweiligen Sachverhalt planvoll hin zum Durchschnitt zu gestalten - manche sagen dann zu manipulieren und sprechen von Mißbrauch - und einen Wettbewerb um den größtmöglichen Vorteil aus der Abstraktion zu veranstalten ${ }^{44}$.

Kombinationen zwischen beiden Tatbestandsgestaltungen (etwa Generalklausel und Regelbeispiele) erfassen nur den Durchschnittsfall und viele klar umrissene Einzelfälle. Gleiches gilt für Regel-AusnahmeSchemata. Auch sonstige gesetzliche Hilfstechniken, wie Billigkeitsoder Härteklauseln, sind unter diesen Gesichtspunkten bedenklich. Sie überlassen die Entscheidung im wesentlichen der Verwaltung oder dem Gericht ${ }^{45}$. Die gesetzliche Vorgabe einer mittleren Zahl von Tatbestandsmerkmalen, um den intendierten Sachverhalt genauer, aber nicht zu genau zu umschreiben, verengt zwar die Interpretationsspielräume der Gesetzesanwender, hat aber weiterhin ,,den (typisierten) Fall" im Blick und bleibt daher statisch und unflexibel.

Sowohl die abstrakte als auch die konkrete Tatbestandsgestaltung enthalten beide Definitionen, sie grenzen ab und damit auch aus. Dies entspricht einem Grenz-bzw. Trennungsdenken, einer harten Trennung zwischen Fall und Nicht-Fall, einem Entweder-Oder. Ein solches binäres Schema kann aber all die vielen Grenzfälle, Randbereiche und Grau-

Abs. 2, 36 Abs. 2, 37b Satz 2 BSHG (,,vor allem"); §§ 3a BSHG, 5, 91 Abs. 3 AFG, 26 2. WoBauG (Prioritäten und Schwerpunkte).

${ }^{43}$ Zecher (Fn. 12), S. 65; ders., in: Festschrift Zeidler, 1987, S. 571 (583); ders., in: Festschrift Werner Maihofer, 1988, S. 669 (675); Bernd Schilcher, in: Franz Bydlinski u. a. (Gesamtredaktion), Das Bewegliche System im geltenden und künftigen Recht, 1986, S. 287 (289); vgl. auch Schulze-Fielitz, DÖV 1988, 758 (767).

${ }^{44}$ Zacher, SGb 1982, 329 (333f.); ders., SF 1984, $1(6,9)$.

${ }^{45}$ Schilcher (Fn. 43), S. 307; Bydlinski, in: Starck (Hrsg.), Die Allgemeinheit des Gesetzes, 1987, S. 49 (69). 
zonen im Vor- und Umfeld der definierten Fälle nicht erfassen ${ }^{46}$. Die einzelnen Entscheidungsvariablen (Tatbestands- und Rechtsfolgemerkmale) stehen sowohl untereinander als auch zu den Umweltbedingungen in einem komplexen Verhältnis von Wechselwirkungen. Durch fest umrissene und feststehende Tatbestände werden Veränderungen zwischen den einzelnen Merkmalen oder in ihrem Verhältnis zur Umwelt, d.h. den jeweiligen Situationen, auf die das Gesetz Anwendung finden soll, nicht erfaßt. Als Fazit bleibt festzuhalten, daß eine optimale (also gerechte) gesetzliche Entscheidung (hier die Gewährung einer Leistung unter bestimmten Voraussetzungen) und eine entsprechende Steuerung der Verwaltung nicht allgemein, d.h. generell und gleichbleibend definierbar sind, weder konkret noch abstrakt ${ }^{47}$. Vielmehr muß die gesetzliche Entscheidung in der Lage sein, variabel, adäquat und aktuell auf die jeweilige konkrete Situation zu reagieren. Es müßte daher ein Mechanismus für die Gesetzesgestaltung gefunden werden, der die gesetzliche Steuerung im Hinblick auf den jeweiligen Fall einerseits flexibler gestaltet, andererseits aber auch die rechtsstaatlichen Postulate der Verbindlichkeit und Berechenbarkeit der aufgrund des Gesetzes getroffenen Entscheidung wahrt.

Auf die neuerdings in Rechtsprechung und Schrifttum vertretene Prinzipienlehre ${ }^{48}$, die statt von zwingenden Geboten von durch Abwägung überwindbaren Leitsätzen und von Optimierungsaufträgen ausgeht, habe ich schon hingewiesen. Sie ist geeignet, zumindest teilweise ein starres Grenz- oder Trennungsdenken zu vermeiden und zu flexibleren Lösungen zu gelangen. Sie kann jedoch die geschilderten Probleme allein nicht beseitigen.

In dieser Situation bietet sich die von dem Österreicher Walter Wilburg entwickelte Lehre vom beweglichen System als mögliche Hilfe zur Beseitigung der Schwächen der dualen Legistik (Kasuistik und Generalklauseln) an ${ }^{49}$. Diese Lehre sieht das Gesetz nicht als starres Muster der Realitätserkenntnis und der schematischen Beurteilung von Einzelfällen an, auch nicht als bloßes Prinzip, Leitsatz oder Optimierungsgebot, sondern geht von einer gesetzlichen Basiswertung

46 Berthold Becher/Pankoke, in: Pfaff (Fn. 17), S. 113 (126ff.); Pankoke, in: Reis/Dorenburg (Fn. 15), S. 97 (99ff.); G.Hennies, in: Silomon (Fn. 20), S. 51.

${ }^{47}$ Vgl. auch Schulze-Fielitz, DöV 1988, 758 (764f.); Doris Lucke/Stefan Hradil, in: Jahresschrift für Rechtspolitologie, 1988, S. 76 (93); von ähnlichen Ansätzen geht im Bereich der Organisationslehre der sog. situative bzw. kontingenztheoretische Ansatz aus, vgl. Pitschas, Archsoz Arb 1981, 240 (243f.); Wolfgang Staehle, in: Alfred Kieser (Hrsg.), Organisationstheoretische Ansätze, 1981, S. $215 \mathrm{ff}$.

48 Vgl. oben Fn. 19 und 21.

49 Walter Wilburg, Entwicklung eines beweglichen Systems im bürgerlichen Recht, 1950; vgl. in Bydlinski (Fn. 43) die Beiträge von Bydlinski, S. $21 \mathrm{ff}$., Karl Korinek, S. $243 \mathrm{ff}$., Gerhard Otte, S. $271 \mathrm{ff}$., Schilcher, S. $287 \mathrm{ff}$. 
aus, die durch vom Gesetzgeber vorgegebene komparative Wertreihen, also Wertrelationen zwischen verschiedenen Merkmalen, ergänzt wird. Dabei regelt die Basiswertung den typischen Normalfall, und die komparativen Wertreihen dienen als Anleitung zum Lösen der Grenzfäl$\mathrm{le}^{50}$. Die einzelnen Merkmale und ihre Bedeutung werden nicht abstrakt durch sich selbst, sondern vor allem durch ihre Beziehung definiert. Ein solches bewegliches System könnte im Sozialleistungsrecht, vor allem im Bereich der Dienstleistungen, zu angemesseneren gesetzlichen Lösungen führen. Es könnte etwa für Tatbestandsmerkmale wie Bedürnis, Notlage oder Härte oder für komplexe Tatbestände, die aus Bedürftigkeitsmerkmalen und Leistungsbemessungsgründen zusammengesetzt sind, Anwendung finden, aber auch für Verknüpfungen zwischen Tatbestand und Rechtsfolgen bei sog. Koppelungsvorschriften, für die Bestimmung von Leistungen oder die $A b$ stufung von Leistungen entsprechend der Gegenleistung, etc.

Komparative Wertreihen bzw. verhältnismäßige Relationen sind der geltenden Rechtsordnung keineswegs fremd. In verschiedenen Bereichen des Verfassungs- und Verwaltungsrechts wird damit von der Rechtsprechung operiert, ohne daß sie sich allerdings dieser Tatsache immer bewußt ist. Einige Beispiele:

- aus der Rechtsprechung des Bundesverfassungsgerichts zum Gesetzesvorbehalt bei grundrechtsrelevanten Maßnahmen: Je intensiver der Grundrechtseingriff, desto bestimmter muß die gesetzliche Grundlage sein.

- aus der Rechtsprechung der Verwaltungsgerichte:

- zur Gefahr im Polizeirecht: Je gewichtiger das Rechtsgut und je größer der zu befürchtende Schaden, desto geringere Anforderungen werden an das Vorliegen einer Gefahr gestellt. Je nach Gefahr sind auch die Anforderungen an die Verhältnismäßigkeit polizeilichen Einschreitens zu beurteilen.

- Zum Gebot der Rücksichtnahme im Baurecht, das nach der Rechtsprechung in unbestimmten Rechtsbegriffen wie ,einfügt", „öffentliche Belange", „unzumutbar", etc. enthalten ist: Je empfindlicher und schutzwürdiger die Stellung derer ist, denen die Rücksichtnahme im gegebenen Zusammenhang zugute kommt, um so mehr kann an Rücksicht verlangt werden. Je verständlicher und unabweisbarer die mit dem Vorhaben verfolgten Interessen sind, um so weniger braucht derjenige, der das Vorhaben verwirklichen will, Rücksicht zu nehmen.

- zum wichtigen Grund, der beim Wechsel der Fachrichtung gemäß § 7 Abs. 3 BAföG zur Weiterzahlung der Ausbildungsförderung

so Vgl. insbesondere Schilcher (Fn. 43), S. 289, 299. 
erforderlich ist: Eine feste Regel, die besagt, daß die Absolvierung einer bestimmten Anzahl von Semestern der Anerkennung eines wichtigen Grundes entgegensteht, läßt sich nach der Rechtsprechung nicht bilden. Je länger jedoch das Erststudium betrieben wurde, um so größer wird das Gewicht der einem Fachrichtungswechsel entgegenstehenden öffentlichen Interessen eingeschätzt. ${ }^{50 a}$

Zuletzt noch ein Beispiel aus dem Sozialhilferecht. §88 Abs. 2 Nr. 7 BSHG kennt den unbestimmten Rechtsbegriff des kleinen Hausgrundstücks. Das Bundesverwaltungsgericht ${ }^{51}$ hat für die Subsumtion unter diesen Begriff die sog. Kombinationstheorie entwickelt, nach der das Merkmal „klein“" von vier Faktoren (Personen, Bedarf, Qualität, Wert) abhängt, die kombiniert berücksichtigt, d.h. zueinander ins Verhältnis gesetzt werden müssen, und so das Gesamtergebnis erbringen.

Ähnlich könnte man auf der Grundlage des beweglichen Systems auch bei anderen Tatbestandsmerkmalen ein Gesamtbild, etwa durch Skalierung einzelner Merkmale, erstellen, die vom Gesetzgeber vorgegeben sind und teils mehr, teils weniger vorliegen, aber insgesamt einen Mindestwert oder -summe ergeben. Dabei wäre es denkbar, daß neben den vom Gesetzgeber zur Berücksichtigung aufgegebenen PflichtDaten weitere Kann-Daten von der Verwaltung oder dem Bürger eingebracht werden, die ergänzend, kompensierend oder substituierend zum Gesamtbild und zur verhältnismäßigen Abwägung im Sinne der vom Gesetzgeber vorgegebenen Wertrelationen beitragen.

Das bewegliche System wird also auch bisher schon in der Rechtsordnung praktiziert. Was fehlt, ist eine methodische Reflexion sowie eine systematische und funktionsgerechte Anwendung dieser Technik. Die Aufstellung von Basiswerten und verhältnismäßigen Relationen nimmt bisher vor allem die Rechtsprechung vor. Innerhalb der Funktionenordnung des Grundgesetzes würde es jedoch der Gesetzgebung zukommen, solche grundlegenden Wertungen zu setzen. Allerdings müßte der Gesetzgeber sich zunächst die maßgeblichen Wertungen und Relationen bewußt machen und dann auch offenlegen.

Der Grundsatz der Gewaltenteilung steht der Einführung eines beweglichen Systems nicht entgegen. Der Gesetzgeber begibt sich nicht seiner Verantwortung, er nimmt sie sogar noch effektiver wahr. Die Steuerungsfunktion der Gesetze wird nicht mehr nur durch Vorgabe von Organisation und Verfahren, von gesetzlichem System und Zwekken sowie einzelnen interpretationslenkenden Kriterien gesichert, sondern vor allem durch gesetzliche Wertungen, insbesondere Relationen zwischen einzelnen Merkmalen.

${ }^{\text {soa }} \mathrm{Zu}$ den beiden letzten Beispielen vgl. OVG Münster, NVwZ 1988, 377 und VGH Kassel, NVwZ 1988, 856.

${ }^{51}$ BVerwG, NDV 1980. 321; Bernd Schulte, NVwZ 1986, 354 (361). 
Die offengelegte gesetzliche Wertung des Basisfalles und die komparativen Anleitungen zur Lösung der Grenzfälle vermitteln auch dem Bürger eine größere Orientierungssicherheit als Generalklauseln oder kasuistische Einzelregelungen. Die komparative Konkretisierung erlaubt auch eher die adäquate Durchführung des Gleichheitssatzes. Während bisher die Beurteilung von Einzelfällen anhand der abstrakten gesetzlichen Entscheidung gleichmäßig, d.h. systematisch-formal erfolgte, kann nunmehr eine verhältnismäßige Gleichbehandlung entsprechend dem Maß der sachlichen Divergenzen stattfinden ${ }^{52}$.

\section{Regeln und Erfolgsvorsorge fur den Gesetzgebungsproze $\beta$}

Auch in Anbetracht notwendiger Rationalitätsverluste durch den politischen Proze ${ }^{53}$ bleibt zu prüfen, inwieweit über die ausdrücklichen verfassungsrechtlichen Vorgaben hinaus weitere Regeln oder Bindungen für den Gesetzgebungsprozeß erforderlich sind.

Eine inhaltliche Bindung des Sozialgesetzgebers durch Gesetze höherer Ordnung zwischen Verfassung und einfachem Recht, die soziale Leistungen für längere Zeit außer Streit stellen würden, gibt es im Sozialrecht nicht ${ }^{54}$. Die sozialen Rechte des SGB AT stellen lediglich ein politisches Programm des Gesetzgebers dar, eine rechtsverbindliche Festlegung enthalten sie nicht, ein Vorrang gegenüber anderen gesetzlichen Regelungen kommt ihnen nicht $\mathrm{zu}^{55}$. Die einzige Bindung, die der $\mathrm{Ge}$ setzgeber sich im Sozialrecht selbst auferlegt, ist, generell die Regelung von Rechten und Pflichten nur durch Gesetz zu treffen ( 31 SGB AT) sowie in einigen Gesetzen die Verpflichtung zur Anpassung der Leistungen durch Gesetz.

Als institutionelle Vorkehrungen zur Disziplinierung und Rationalisierung des Gesetzgebungsprozesses werden unabhängige Gesetzgebungskommissionen, -ämter oder Beiräte vorgeschlagen. Diese könnten die Aufgabe der Informationssammlung, sachverständigen Bewertung von Daten und Entwicklungen, der Erarbeitung und Prüfung von Vorschlägen und Gesetzentwürfen sowie der nachträglichen Kontrolle von Gesetzen oder auch der probeweisen Konsensbildung übernehmen ${ }^{56}$.

s2 Schilcher (Fn. 43), S. 302.

53 Vgl. ausführlich Schulze-Fielitz, Theorie und Praxis parlamentarischer Gesetzgebung, 1988, S. 393ff.; 454ff.; 553ff.

${ }^{54}$ Zacher, in: Handbuch des Staatsrechts (Fn. 22), § 25 Rdn. 102, Fn. 421; Michael Kloepfer, VVDStRL 40 (1982), 63 (83); vgl. auch Karpen, NJW 1988, 2512 (2518).

ss Rüfner, in: Wannagat, SGB AT, § 2 Rdn. 6.

56 Zacher, SF 1984, 1 (11); ders., in: Handbuch des Staatsrechts (Fn. 22), § 25 Rdn. 92ff. sowie Verhandlungen des 55. Deutschen Juristentages, 1984, Bd. II, Beschluß Nr. 17 a, jeweils unter Hinweis auf die schwedischen Kommissionen, 
In methodischer Hinsicht wird teilweise aus verfassungsrechtlichen Gründen eine rationale Willensbildung, Abwägung und Entscheidungsfindung gefordert oder zumindest dem Gesetzgeber nahegelegt, aus den gesetzlichen Regeln für den Erlaß untergesetzlicher Rechtsnormen zu lernen und grobe Fehler in der Willensbildung zu vermeiden, teilweise wird all dies nur als bloße Verfahrensmaxime angesehen ${ }^{57}$.

In redaktioneller Hinsicht wäre zu überlegen, für das reichhaltige Instrumentarium der Gesetzesgestaltung, das bisher eher unsystematisch und zufällig eingesetzt wird, einen Katalog von Stilmitteln und Programmelementen, wie etwa Definitionen und Verweisungstechniken, abgestufte gesetzliche Anweisungen an die Verwaltung und Verpflichtungen der Leistungsempfänger, zu entwickeln und als Redaktions- und Interpretationsstatut dem Gesetzgeber, den Anwendern und Leistungsadressaten an die Hand zu geben. Seine einheitliche Verwendung könnte die Kommunikation zwischen Gesetzgeber und Gesetzesanwender bzw. Adressaten und das Verständnis der Gesetze erheblich erleichtern ${ }^{58}$.

Unabhängig von Rechtsgehalt, Bindungsgrad und verfassungsgerichtlicher Überprüfbarkeit dieser Meta-Regeln, insbesondere der methodischen Anforderungen an den Entstehungsprozeß der Gesetze, ist davon auszugehen, daß der verfassungsrechtlichen Einrichtung der Funktion der Gesetzgebung auch das Gebot innewohnt, diese Funktion effektiv wahrzunehmen. Dem Gesetzgeber obliegt daher zur Sicherung der Effektivität, d.h. der Wirksamkeit und Akzeptanz seiner Gesetze eine verfassungsrechtliche Verpflichtung zur Erfolgsvorsorge, Erfolgskontrolle und Erfolgssicherung. Soweit den Gesetzen Grundrechtsrelevanz zukommt, ergibt sich dies aus grundrechtlichen Schutzund Sorgepflichten ${ }^{59}$.

dazu Werner Jann, ZParl 1981, 377 (382); Gustaf Lindencrona, in: Werner Maihofer (Hrsg.), Theorie und Methoden der Gesetzgebung, 1983, S. $17 \mathrm{ff} . ; \mathrm{vgl}$. auch von Maydell, in: Festschrift Zeidler, 1987, S. 673 (686); Schulze-Fielitz, DöV 1988, 756 (768); im Hinblick auf eine probeweise Konsensbildung verdienen auch die Überlegungen von Peter Dienel, Die Planungszelle, 1978, Beachtung, vgl. dazu Peter Fricke/Werner Hugger, Test von Gesetzentwürfen, Teil 2, Speyerer Forschungsbericht Nr. 12, 1979, S. $245 \mathrm{ff}$.

${ }_{57}$ Zur ersten Auffassung vgl. Gunther Schwerdtfeger, in: Festschrift Hans-Peter Ipsen, 1977, S. 173ff.; ders., in: Festschrift Wannagat, 1981, S. 543 (562ff.); zur zweiten Kloepfer, ZG 1988, 289ff., dazu Hill, ZRP 1988, 437; zur dritten Detlef Merten, in: Hill (Fn. 25), S. 81 ff.; insgesamt Hill, Jura 1986, 286 (291f.) m.w. N.

s8 Ähnlich Baden (Fn. 6), S. 245, 248; vgl. auch Schulze-Fielitz, DÖV 1988, 758 (768).

59 BVerfGE 49, 89 (142ff. iVm 130ff.); 56, 54 (78f.); 65, 1 (55f., 58ff.); Peter Badura, in: Festschrift Eichenberger, 1982, S. 481 (484); Lerche, in: Peter Lerche/Walter Schmitt Glaeser/Eberhard Schmidt-Aßmann, Verfahren als staatsund verwaltungsrechtliche Kategorie, 1984, S. 97 (109ff., 114). 
Zur Erfolgsvorsorge gehört die Entstehung, Vorabkontrolle und Vermittlung des Gesetzes. Bei der Entstehung kann im Bereich der Problemerkundung die neuerdings sich auch im Sozialrecht entwickelnde Rechtstatsachenforschung wertvolle Hilfe leisten ${ }^{60}$. Bei der Zieldefinition und Programmformulierung sollte soweit wie möglich schon die Anwenderebene, d.h. Vollzugsverwaltung und Betroffene, beteiligt oder zumindest gehört werden, um die spätere Anwendungssicherheit zu erhöhen (vgl. auch § 114 BSHG) ${ }^{61}$. Modellvorhaben und Experimente, die Übernahme bewährter Regelungen aus Richtlinien oder Vereinbarungen sowie Test- und Prüfmethoden zur Vorabkontrolle von Gesetzentwürfen können zur Verbesserung der Gesetze, zumindest zur Vermeidung grober Fehler, beitragen ${ }^{62}$.

Wesentlicher Bestandteil der Erfolgsvorsorge ist sodann die Vermittlung des Gesetzesinhaltes an seine Adressaten (sog. Gesetzesmarketing) ${ }^{63}$. Insoweit könnte gerade angesichts der Bedeutung der Zwecke im Leistungsrecht ein Gesetzesvorspruch ${ }^{64}$, in dem die Ziele, Gründe und der wesentliche Inhalt zusammenfassend und verständlich dargestellt werden, wertvolle Hilfen leisten, da bisher die gesetzlichen Zwecke erst mühsam aus den Materialien und Einzelbestimmungen zusammengesucht werden müssen ${ }^{65}$. Diese Information aller Adressaten sollte durch ein Begleitprogramm ${ }^{66}$ zur Schulung und Motivation der Anwender ergänzt werden.

${ }^{60}$ Schulin/Wolfgang Dreher (Hrsg.), Sozialrechtliche Rechtstatsachenforschung - Probleme und Perspektiven, 1987; Igl, ZfSH/SGB 1986, 473;Dreher, SGb 1987, 547.

${ }_{61}$ Zur Beteiligung der Vollzugsverwaltung vgl. Baden (Fn. 6), S. 246; SchulzeFielitz, DöV 1988, 758 (763); zur Beteiligung der Betroffenen vgl. die Theorie der responsiven Demokratie, dazu Herbert Uppendahl, ZParl 1981, 123 und 440; ders., in: Dietrich Thränhardt/Uppendahl (Hrsg.), Kommunikationstechnologien und kommunale Entscheidungsprozesse, 1982, S. $257 \mathrm{ff}$; Adrienne WindhoffHéritier, in: Joachim Jens Hesse/Helmut Wollmann (Hrsg.), Probleme der Stadtpolitik in den achtziger Jahren, 1983, S. 358 (368); Karlheinz Blessing, Die Zukunft des Sozialstaates, 1987, S. 241f.

${ }_{62}$ Wollmann, in: Schreckenberger (Fn. 31), S. 72; Carl Böhret/Werner Hugger, in: Schreckenberger, aaO, S. 135; Böhret, in: Hill (Fn. 25), S. 55 (76).

${ }^{63} \mathrm{Vgl}$. BVerfGE 65, 1 (58ff.) sowie Gerhard Stadler, in: Heinz Schäffer/Otto Triffterer (Hrsg.), Rationalisierung der Gesetzgebung, 1984, S. 276 (277); Harald Kindermann, ZRP 1983, 204, 205; Starck, ZG 1988, 1 (21); Hill, JZ 1988, 377 (380); vgl. auch schon Siegers (Fn. 33), S. 44f.

${ }^{64}$ Hill (Hrsg.), Gesetzesvorspruch - Verbesserter Zugang des Bürgers zum Recht, 1988; vgl. auch Jörg Lücke, Begründungszwang und Verfassung, 1987, S. 214ff.

${ }^{65}$ Baden (Fn. 6), S. 250; Ursula Köbl, in: Festschrift 25 Jahre Bundessozialgericht, 1979, Band 2, S. 1005 (1029); Zeh (Fn. 31), S. 70; vgl, auch Haverkate, NVwZ 1988, 769 (772ff.).

${ }^{66}$ Christian von Hammerstein, in: Hill (Fn. 25), S. 141 (142). 
Der Erfolg eines Gesetzes entscheidet sich jedoch erst bei seiner konkreten und mehrfachen Anwendung. Die bisherigen Methoden der Erfolgskontrolle sind noch unzureichend. Obwohl in vielen Leistungsgesetzen eine Uberprüfung durch Berichtspflichten und Statistiken vorgesehen ist, wirken diese weitgehend unkritisch und teilweise geschönt ${ }^{67}$. Konkrete Regelungs- oder Denkanstöße vermitteln sie nur selten. Eine systematische Rechtstatsachenforschung könnte auch hier weiterhelfen.

Die Erfolgssicherung schließlich verlangt, ungeeignete sowie überholte, weil den finanziellen und sonstigen Rahmenbedingungen nicht mehr entsprechende, Leistungsgesetze zu ändern oder nachzubessern. Die Anpassungspflicht ist in einigen Leistungsgesetzen teilweise automatisch oder periodisch vorgesehen ${ }^{68}$. Sie geschieht durch Gesetz, Verordnung, Verwaltungsvorschrift oder auch im Rahmen der Pflicht zur zeitgemäßen Leistungserbringung gemäß $\S 17$ Abs. 1 Nr. 1 SGB AT durch die Verwaltung im Einzelfall ${ }^{69}$.

Bei der Art und Weise, wie der Gesetzgeber seiner Verpflichtung zur Erfolgsvorsorge, -kontrolle und -sicherung nachkommt, verfügt er über einen erheblichen Spielraum. Erst bei evidentem Verstoß wird eine Verfassungswidrig- oder gar Nichtigkeitserklärung durch das BVerfG in Betracht kommen ${ }^{70}$.

\section{Gesetzesanwendung im Leistungsrecht}

\section{Gesetzesanwendung in der Funktionenordnung des Grundgesetzes}

Rechtsverwirklichung durch Gesetzesanwendung erfolgt durch Beachtung von Zweck, Wert, System und Zeit ${ }^{71}$. Dabei gewinnt das ge-

$67 \mathrm{Vgl}$. etwa $\S \S 35,55$ BAföG, 8 Abs. 7, 35 WoGG; weggefallen ist die Berichtspflicht nach §126 c BSHG, dazu auch Zacher, SF 1984, 1 (11); vgl. noch Christian von Pestalozza, NJW 1981, 2081 (2085); Kloepfer, VVDStRL 40 (1982), 63 (90); Klaus König, in: Schreckenberger (Fn. 31), S. 96 (101).

${ }_{68} \S \S 35$ BAföG, 8 Abs. 7 WoGG, $\S 22$ Abs. 3, 69 Abs. 6 BSHG, 112 a AFG, 1272 RVO; vgl. auch Schreckenberger, VerwArch 1977, 28 (37); Schulin, NJW 1984, 1936 (1938); Schulze-Fielitz, DöV 1988, 758 (766).

${ }^{69}$ Nicht nur verfassungsrechtliche, sondern vor allem politische Probleme bereitet die Anpassung von Sozialleistungen durch Streichung oder Kürzung; vgl. Stober (Hrsg.), Eigentumsschutz sozialrechtlicher Positionen, 1986; Gitter, NZA 1984, 137; Schulin, NJW 1984, 1936; Rüfner, JZ 1984, 801, Krause, DöV 1984, 740.

70 BVerfGE 56, 54 (80f.); Badura (Fn. 59), S. 487f.; Hill, Das fehlerhafte Verfahren und seine Folgen im Verwaltungsrecht, 1986, S. 65 zur Nachbesserungspflicht des Gesetzgebers: Hill, DöV 1988,666 (669) zur Vermittlungspflicht; sowie Kloepfer, VVDStRL 40 (1982), 63 (91).

${ }^{71}$ Wolfgang Fikentscher, Methoden des Rechts, Bd. IV, 1977, S. 279ff.; Köbl (Fn. 66), S. 1036, Fn. 115 (,Rechtsbildungselemente"). 
setzliche Programm konkrete Form durch die Wirkkraft des Einzelfalls und die Kompetenzausübung der handelnden Organe. Gesetzesanwendung im Leistungsrecht hat vor allem zweckorientiert zu erfolgen. Unbestimmte Rechtsbegriffe, wie notwendig, zweckmäßig, Krankheit, etc. $^{72}$, Regel-Ausnahme-Verhältnisse ${ }^{73}$ und sonstige Programm-Elemente sind unter Berücksichtigung des Regelungs- und Leistungszwecks auszulegen.

Gesetzliche Wertentscheidungen sind bisher aus den Zwecken und den Einzelregelungen häufig nur schwer erkennbar. Das oben ${ }^{74}$ dargestellte bewegliche System mit Basiswertung und komparativen Wertreihen würde die gesetzliche Wertung deutlicher zum Ausdruck bringen. Die grundlegenden gesetzlichen Wertungen werden vor allem bei Dienstleistungen und persönlichen Hilfen durch subjektive Wertentscheidungen der einzelnen Leistungserbringer beeinflußt ${ }^{75}$.

Neben Zweck und Wert liefert das gesetzliche System weitere Rechtsbildungs- oder Rechtsverwirklichungshilfen. Die Einzelentscheidung muß sich in das gesetzliche System einfugen und es zugleich konkretisieren. Gesetzesanwendung stellt sich so durch das Harmonisieren verschiedener gesetzlicher Regelungen, das Lösen von Widersprüchen und Konflikten und schließlich die Auswahl der einschlägigen Regelung ${ }^{76}$ als ein „Fallmanagement mit Hilfe von Gesetzen“ dar. Deshalb sind nicht nur unbestimmte Rechtsbegriffe, sondern auch einzelne Leistungen unter Berücksichtigung des System- und Funktionszusammenhangs auszulegen ${ }^{77}$.

$\mathrm{Zu}$ diesen Rechtsbildungselementen kommt als viertes die Zeit. Sie ist, bedingt durch den schnellen Wandel der Verhältnisse, eine Dimension des Sozialrechts von besonderer Bedeutung. Sozialleistungen sind, wie nicht nur die Generalklausel des $\S 17$ Abs. 1 Nr. 1 SGB AT, sondern auch viele unbestimmte Rechtsbegriffe ${ }^{78}$ erkennen lassen, in zeit-

72 Johannes Baltzer, JuS 1982, 568; Walther Ecker, in: Festgabe aus Anlaß des 100jährigen Bestehens der sozialgerichtlichen Rechtsprechung, 1984, S. 299ff; Erwin Brocke, JuS 1987, 874 (876).

${ }^{73}$ OVG Hamburg, FamRZ 1988, 988 mit Anm. Helmut Goerlich; ausführlich Haverkate, NVwZ 1988, 769 (772ff.).

$74 \mathrm{Vgl}$. oben II 5.

75 Giese (Fn. 9), S. 54, 60ff.; Pitschas, ArchsozArb 1981, 240 (255ff.); Erichsen, DVBl. 1983, 289 (290); Hill, NJW 1986, 2602 (2609); vgl. auch Gerhard Frank/Manfred Wolf, Führen und Leiten in sozialen Diensten. Eine Untersuchung zur Subjektivität von Leitungskräften, 1988.

${ }^{76}$ Brohm, DöV 1987, 265 (266f.); vgl. auch Stettner, DöV 1984, 611 (621); Meinhard Schröder, DVB1. 1984, 814 (821).

${ }^{77}$ BVerwG, NDV 1980, 321; NJW 1988, 2966; Ossenbühl, DVBl. 1974, 309 (311).

${ }^{78}$ Vgl. etwa $\S \S 12$ BSHG, 182 Abs. 2, 368 Abs. 3, 368 e Satz 1, 368g Abs. 1, 405 a Abs. 1 Satz 1 RVO, dazu Zacher, Krankenkassen oder nationaler Gesund- 
gemäßer Weise zu erbringen. Dies bewirkt, insofern ähnlich wie andere Generalklauseln im Bereich der Abwehr von Gefahren der Technik, einen dynamischen Grundrechtsschutz bzw. eine dynamische Anpassung der Voraussetzungen und Hilfen zur Grundrechtsverwirklichung.

Wie verschiedene Untersuchungen ${ }^{79}$ gezeigt haben, erfahren Rechtsprogramme durch die Wirkkraft des Einzelfalls, durch die Anpassung an die jeweilige Person und Situation Programmverschiebungen und Modifikationen. Während bei der Programmformulierung die wahrscheinliche Interessenrealisierung wegen Abstraktionen und möglicher Verflechtungen nur schwer überschaubar und erkennbar war, sind bej der Programmdurchführung die Adressateninteressen leichter zu identifizieren, und die unmittelbaren Auswirkungen des Programms werden sichtbar und bewertbar ${ }^{80}$.

Bei der Umsetzung des Rechtsprogramms ist schließlich der Handlungs- und Entscheidungs- bzw. Kontrollauftrag der rechtsanwendenden Organe zu beachten. Da die Verteilung dieses Auftrags auf die zweite und dritte Gewalt auch aus den Sozialgesetzen i.d.R. nicht eindeutig erkennbar ist, sind die Kompetenzen und Verantwortungsbereiche zwischen beiden, insbesondere bei unbestimmten Rechtsbegriffen, Koppelungsvorschriften und Prognoseentscheidungen, umstritten $^{81}$. Gemäß Art. 19 Abs. 4 GG liegt die Kompetenz zur Letztverantwortung, solange eine ausdrückliche gesetzliche Zuweisung an die Verwaltung fehlt, bei den Gerichten ${ }^{82}$.

Neben der Rechtsbildung nehmen die Gerichte im Sozialrecht in noch erheblicherem Umfang die Aufgabe der Rechtsfortbildung wahr. $\mathrm{Da}$ sich hier besonders viele ausfüllungsbedürftige unbestimmte Rechtsbegriffe finden (,Stücke offengelassener Gesetzgebung ${ }^{\text {“83 }}$ ), legen die Gerichte den Inhalt sog. genereller Tatsachen (legislative facts) im Zwischenfeld zwischen abstrakter Rechtsnorm und zu subsumierender Einzeltatsache (etwa „Verschlossenheit des Arbeitsmarktes“) fest $^{84}$ oder übersetzen unbestimmte Rechtsbegriffe in feste Zahlen

heitsdienst?, 1980, S. 19 (30); vgl. auch die Bezugnahme auf die Menschenwürde in $\S 1$ Abs. 2 BSHG und die sich daraus ergebende dynamische Funktion.

79 Mayntz, Implementation politischer Programme I, 1980, S. 1 (10); dies. (Hrsg.), Implementation politischer Programme II, 1983, S. 50 (58); vgl. auch Karpen, NJW 1988, 2512 (2519).

${ }^{80}$ Blessing (Fn. 62), S. 302.

81 Vgl, auch Joachim Martens, JuS 1987, 103; Erwin Brocke, JuS 1987, 874.

${ }^{82}$ Ebsen, DVB1. 1988, 883 (892) sieht Gesetzesgestaltung als Steuerungsentscheidung über die Verteilung rechtlicher Steuerungskompetenz.

${ }^{83}$ Wannagat, in: Rechtsfortbildung durch die sozialgerichtliche Rechtsprechung, 1973, S. 17 (26); ders., in: Festschrift Marie-Luise Hilger/Hermann Stumpf, 1983, 687 (695).

${ }^{84}$ Bruno Rauscher, SGb 1986, 45 (47). 
und Prozentwerte. Diese Quantifizierung beruht weder auf empirischen Erfahrungen noch auf einer gesetzlichen Analogie, sondern stellt nur eine Faustregel, eine sog. gegriffene Größe dar, die lediglich an dem Grundgedanken der Regelung orientiert ist ${ }^{85}$. Die Notwendigkeit zum Greifen solcher Größen leiten die Gerichte aus dem Bedürfnis der Verwaltung nach einer praktikablen und einheitlichen Handhabung der unbestimmten Rechtsbegriffe angesichts massenhaft auftretender Sachverhalte $a^{86}{ }^{86}$. Mit dem Vorbehalt des Gesetzes ist diese Art der Normverdichtung vereinbar, da sie sich als Ausfüllung unbestimmter Rechtsbegriffe innerhalb des gesetzlichen Rahmens bewegt und daher nach dem Wortlaut des $\S 31$ SGB AT vom Gesetz zugelassen ist ${ }^{87}$. Die gesetzlich fixierten sozialen Rechte, Strukturprinzipien, Zwecke und Wertentscheidungen bilden Wegweiser und Programm für diese Rechtsfortbildung.

\section{Voraussetzungen der Gesetzesanwendung in der Verwaltungspraxis}

Da nur wenige Fälle der gerichtlichen Kontrolle unterbreitet werden, sind die organisatorischen Bedingungen der Verwaltungspraxis von entscheidender Bedeutung für die Rechtsverwirklichung ${ }^{88}$. Der Gesetzgeber hat daher, etwa im SGB I und X oder im BSHG $^{89}$, ausführliche Aufträge und Hinweise zur Optimierung dieser Medien der Rechtsverwirklichung normiert. Dennoch bleibt die Realität der Gewährung von Sozialleistungen, insbesondere nach dem BSHG, erheblich hinter den gesetzlichen Vorstellungen zurück ${ }^{90}$.

${ }_{85}$ Wannagat, 1973 (Fn. 83), S. 23f.; Ecker (Fn. 72), S. 299 (312f.); Heinrich Reiter, SGb 1987, 89 (92); Bedenken wegen Willkür bei Rudolf Kolb, in: Festschrift 25 Jahre Bundessozialgericht, S. 1097 (1112).

${ }_{86}$ Wannagat, 1973 (Fn. 83), S. 23; Reiter, SGb 1987, 89 (92f.).

B7 Köbl (Fn. 66), S. 1059, 1079.

${ }^{88}$ Pitschas, VSSR 1977, 141 (149ff.); ders., ArchsozArb 1981, 240 (250); Heinrich A.Henkel/Franz Pavelka, SF 1981, 225 (228); Zacher, Der Behinderte als Aufgabe der Rechtsordnung, 1982, S. 21ff.; Hans-Ulrich Weth. BldW 1984, 88; Zeh (Fn. 31), S. 68; Blankenburg, in: Schreckenberger (Fn. 31), S. 109 (114f.); Frank Hennecke, DÖV 1988, 768 (774).

${ }^{89}$ Vgl. nur $\S \S 1$ Abs. 2, 13ff., 17 SGB AT, 8 Abs. 2, 10 Abs. 3, 102, 114 BSHG.

90 Richard Albrecht/Eckart Reidegeld, SozSich 1977, 138; Reidegeld, in: Voigt (Fn. 29), S. 275ff.; Karl Bronke/Gerd Wenzel, in: Siegfried Müller/Hans-Uwe Otto (Hrsg.), Sozialarbeit als Sozialbürokratie? Zur Neuorganisation sozialer Dienste, 1980, S. $121 \mathrm{ff}$; Renate John, ZSR 1981, 129; Helmut Hartmann, TuP 1981, 431; ders., in: Stephan Leibfried/Florian Tennstedt (Hrsg.), Die Politik der Armut und die Spaltung des Sozialstaates, 1985, S. 169ff.; Weth, BldW 1984, 88; Bernd Schulte/Peter Trenk-Hinterberger, Sozialhilfe, 2. Aufl. 1986, S. 136ff.; Wolfgang Scherer, BldW 1987, 57; ders., Wie Sozialämter Hilfebedürftige abschrecken, 3, Aufl. 1988; Schoch, TuP 1986, 99; ders., TuP 1987, 213; Dieter Grunow, Bürgernahe Verwaltung, 1988. 
Die Leistungsverwaltung im Sozialbereich ist noch zu sehr an den Strukturen der Eingriffsverwaltung und an inneradministrativen Anforderungen orientiert, sie muß sich mehr auf ihren Dienstleistungscharakter, auf die zu lösenden Aufgaben sowie ihre Klienten einstellen. Sie ist bisher im wesentlichen auf verwaltungsübliches Abwarten und bloßes Reagieren beschränkt ${ }^{91}$. Ansprüche werden oft isoliert $a b$ gehandelt und bürokratisch entschieden. Die Koordination etwaiger Einzelleistungen obliegt meist dem Betroffenen.

Doch Gesetzesanwendung in der Leistungsverwaltung im Sozialbereich ist mehr als Vollzug, auch mehr als bloße Anspruchserfüllung ${ }^{92}$. Sie erfordert eine ganzheitliche Behandlung und Betreuung. Wenn die Verwaltung die gesetzlichen Ziele verwirklichen will, muß sie danach trachten, die Zielgruppen auch zu erreichen. Sie muß eigene Aktivitäten entfalten, Leistungen anbieten, über zur Verfügung stehende Angebote informieren und sie partnerschaftlich realisieren ${ }^{93}$. Dazu gehören ein fairer Umgang mit dem Bürger, Gesamtverantwortung und Problemdenken ${ }^{94}$ statt isoliertem ressourcen-, anspruchs- oder ergebnisbezogenem Denken.

Das alles sind zwar hohe Anforderungen an die Verwaltung. Als Repräsentant des Staates im Alltag muß sie sich jedoch dieser Herausforderung stellen, denn ihr Erscheinungsbild prägt das Bild vom Staat und die Akzeptanz seines Handelns.

Zur Zeit wird das Erreichen dieser Ziele noch durch Mängel der einzelnen Verwaltungsstrukturen erschwert. Die Vielzahl der Leistungsträger in vertikaler und horizontaler Hinsicht beeinträchtigt die Koordination und Einheitlichkeit des Verwaltungshandelns. Hinsichtlich der organisatorischen Binnenstruktur machen sich Bürokratisierungstendenzen negativ bemerkbar. Mangelnde Ausstattung in personeller, finanzieller, räumlicher und zeitlicher Hinsicht erschwert den Kontakt. Unzureichende Ausbildung, fehlendes Rollenverständnis und negative Erfahrungen im Umgang mit der Klientel prägen vielfach den Stil der Gesetzesanwendung, vor allem im Sozialhilferecht ${ }^{95}$.

91 Udo Kruse, Die Sozialversicherung 1976, 113 (115); Rolf-Richard Grauhan/ Leibfried, ZSR 1977, 65 (70ff.); Theo Siebeck, in: Festschrift Horst Peters, 1975, S. 143 (151ff.).

92 Paul Kirchhof, in: Festschrift 25 Jahre Bundessozialgericht, 1979, S. 537 (543); Gagel, AFG, vor § 142, Rdn. 8, 10, 13; Siebeck (Fn. 91), S. 151.

${ }_{93}$ Hans Schäfer, DVBl. 1972, 405 (409); Pitschas, VSSR 1977, 141 (167); Siebeck (Fn. 91), S. 150ff.; vgl. auch BVerfGE 56, 1 (18); BSGE 51, 89 (93) zur Verpflichtung der Verwaltung, das gesetzgeberische Programm möglichst weitgehend zu verwirklichen.

${ }_{94}$ Eberhard Walter Lang, in: Gedächtnisschrift René Marcic, 1974, S, 811 (813ff.).

${ }_{95} \mathrm{Vgl}$. die Nachweise in Fn. 90. 
Grundlegende Änderungen der Verwaltungspraxis sind sicher nicht von heute auf morgen möglich. Dennoch sind Ansätze erkennbar. Das SGB enthält die Aufgabe und weist die Richtung. Die Realisierung hängt vor allem von der internen Steuerung, von Organisation, Ausbildung und Führung $a b^{\%}$. Erhebliche Verbesserungen der Ausstattung werden angesichts der Situation der öffentlichen Haushalte nicht möglich sein. Doch zwingt etwa die Beachtung der Wirtschaftlichkeit in der Leistungsverwaltung nicht zu einseitigen Lösungen. In die MittelZweck-Relation, in das Verhältnis zwischen Aufwand und Erfolg, müssen auch außerhalb des Haushaltsrechts getroffene normative Zielund Wertentscheidungen einfließen ${ }^{97}$, etwa das Sozialstaatsprinzip und die sozialen Rechte des SGB AT. Auch in der Massenverwaltung des Sozialrechts, die angesichts der Vielzahl der Fälle den Aufwand für jeden einzelnen Fall aus Gründen der Gleichheit und der Funktionsfähigkeit gering halten muß, ist eine sorgfältige Bearbeitung sowie Beratung und Betreuung langfristig effektiver als eine schematischnachlässige, die dem Bürger zu unwirtschaftlichen, unzweckmäßigen und unvollkommenen Leistungen verhilft, damit nicht nur das Leistungsdefizit erhöht, sondern u.U. auch weiteres Fehlverhalten und Ausnutzung bzw. Mißbrauch hervorruft ${ }^{98}$.

\section{Gesetzesanwendung mit dem Bürger}

Wenn das Sozialrecht in objektiver Hinsicht von dem Gegensatz zwischen Kasuistik und Generalklausel gekennzeichnet ist, so entspricht dem im subjektiven Bereich ein Nebeneinander von Ansprïchen (vor allem bei Geldleistungen) und Ermessen (vor allem bei Sach- und Dienstleistungen) ${ }^{99}$. Beide Gestaltungsformen haben sowohl Vor- als auch Nachteile. Direkte Rechtseinräumung und differenzierte Verrechtlichung sichern materielle Rechtsklarheit und Berechenbarkeit sowie Einklagbarkeit vor Gericht. Sie dienen damit der Freiheitssicherung der Betroffenen ${ }^{100}$, aber sie engen diese Freiheitsentfaltung auch ein, indem sie ein Abweichen vom Schema verhindern.

Dagegen lassen offene, konkretisierungsbedürftige Berechtigungen auch flexible Gestaltungen und Individualisierungen bei Einzel- und atypischen Sonderfällen $\mathrm{zu}^{101}$. Dadurch, daß sie jedoch der institutio-

${ }^{96}$ Kruse, Die Sozialversicherung 1976, 113 (116).

97 Albert von Mutius, VVDStRL 42 (1983), S. 147 (177).

98 Kruse, Die Sozialversicherung 1976, 113 (115).

99 Zacher, SGb 1982, 329 (334, 335f.); Georg Vobruba, in: Michael Opielka/ Mona Ostner (Hrsg.), Umbau des Sozialstaats, 1987, S. 103 (104).

${ }^{100}$ Bogs, SGb 1970, 1; Pitschas (Fn. 29), S. 160.

${ }^{101}$ Hill, DÖV 1987, 885. 
nellen, personellen und prozeduralen Vermittlung bedürfen, schaffen sie Ansatzpunkte und Gefahren für Gutsherrlichkeit, Ideologie und Willkür ${ }^{102}$. Annäherungen zwischen beiden Arten der Rechtsgewährung sind vorhanden - etwa bürokratische Verrechtlichungen durch Verwaltungsvorschriften oder ein Anspruch auf pflichtgemäße Ermessensausübung gem. § 39 Abs. 1 Satz 2 SBG AT - doch bleibt das grundsätzliche Dilemma bestehen. Es scheint jedoch, ebenso wie dasjenige zwischen Kasuistik und Generalklausel, nicht unausweichbar.

Ein dritter Weg könnte in der Kooperation zwischen Verwaltung und Leistungsempfänger, insbesondere in der einverständlichen $\mathrm{Ge}$ staltung der Leistung mit dem Adressaten liegen ${ }^{103}$. Die materielle Offenheit vieler gesetzlicher Regelungen könnte insofern nicht nur durch Verfahren ${ }^{104}$, sondern auch durch Vereinbarungen kompensiert werden; in dieser materiellen Offenheit könnte sogar eine Legitimation oder ein Auftrag ${ }^{105} \mathrm{zu}$ einer solchen Einigung der Partner bei der Rechtsgestaltung im Einzelfall, insbesondere der Art und Weise der Leistungserbringung, liegen.

Die gesetzlichen Vorschriften, die das Rechtsverhältnis zwischen Verwaltung und Leistungsadressaten konstituieren, enthalten vielfältige Aufforderungen und Hinweise für eine kooperative Rechtskonkretisierung. Ich denke etwa an Ermessensvorschriften, Optimierungsaufträge, Anhörungs- und Beratungspflichten der Verwaltung, Wunschund Wahlrechte sowie Mitwirkungspflichten des Bürgers ${ }^{106}$. Diese Ansätze könnten durch weitergehende Aufklärungs- und Beratungspflichten über konkrete Leistungsangebote und -alternativen noch ausgebaut werden. Dies würde dazu beitragen, die Wahl und Inanspruchnahme der Leistungen durch den Adressaten sowie seine Mitwirkungsmöglichkeiten zu verbessern und den Informationsvorsprung und die faktische Úberlegenheit der Verwaltung abzubauen ${ }^{107}$. Notwendig ist aber vor

${ }^{102}$ Katzenstein, in: Festgabe Gesellschaft für Rechtspolitik, 1984, S. 139 (155).

${ }^{103}$ Ausführlich Thomas Simons, Verfahren und verfahrensäquivalente Rechtsformen im Sozialrecht, 1985, S. 100ff.; Gagel, AFG, vor $\S 142 \mathrm{Rdn} .84 \mathrm{ff}$.; Hill, NJW 1986, 2602 (2609).

104 Jirgen Held, Der Grundrechtsbezug des Verwaltungsverfahrens, 1984, S. 226f.; 247; Hill, Das fehlerhafte Verfahren und seine Folgen im Verwaltungsrecht, 1986, S. $170,237 \mathrm{ff} ., 360$.

${ }^{105}$ Eberhard Schmidt-Aßmann, Art. 19 Abs. 4 GG, Rdn. 184ff., 193, 196, 198; Paul Kirchhof, Die Bestimmtheit und Offenheit der Rechtssprache, 1987, S. 25; Hill, DöV 1987, 885 (886); ders., JZ 1988, 377 (379); Rainer Wahl, VB1BW 1988, 387 (388).

${ }_{106}$ Vgl. $\S \S 2$ Abs. 2, 13 ff., 17 Abs. 3, 33, 39, 60ff. SGB AT, 24 SGB X, 3 Abs. 2, Abs. 3, 10 Abs. 3 BSHG.

${ }^{107}$ Krause, in: Festschrift Wannagat, S. 239 (247f.); vgl. auch $\$ 9$ Abs. 4 des Entwurfs eines JHG, BR-Drs. 287/80; zu überlegen wäre auch, inwieweit die Vor- 
allem eine Änderung des Selbstverständnisses und des Stils der Verwaltungsmitarbeiter, damit dieses Zukunftsbild des Verwaltungshandelns nicht nur eine Vision bleibt, sondern Wirklichkeit werden kann.

Eine einverständliche Rechtskonkretisierung durch Gesetzesanwendungen mit dem Bürger erscheint gerade in der Leistungsverwaltung auch aus verfassungsrechtlicher Sicht angezeigt. Der leistende Sozialstaat macht aus normativ gewährleisteter Freiheit reale Freiheit. Er schafft Voraussetzungen und Hilfen für die Grundrechtsverwirklichung. Die Teilhabe an staatlicher Leistung kann aber auch Abhängigkeit bewirken, das Verhalten des Leistungsempfängers indirekt steuern und so seine Freiheit beeinträchtigen. Diese verschiedenartige Grundrechtserheblichkeit staatlicher Leistung ${ }^{108}$ legt anstelle einseitiger Leistungsbestimmung durch den Staat eine verantwortliche Mitwirkung des Leistungsempfängers bei der Konkretisierung und Erbringung der Leistung nahe. Dies würde sein Recht auf individuelle und eigenverantwortliche Lebens- und Freiheitsgestaltung besser verwirklichen. Daneben entspricht es dem aus dem Gleichheitsgrundsatz abgeleiteten Gebot zu verhältnismäßiger Differenzierung. Aus dieser Grundrechtserheblichkeit staatlicher Leistung erwächst somit eine Kooperationsfunktion der Grundrechte im Leistungsrecht ${ }^{109}$.

Neben diesen grundrechtlichen Aspekten sprechen für eine Gesetzesanwendung mit dem Bürger weiterhin Funktion und Effektivität der Leistungsvenwaltung. Der praktische Nutzen der Kooperation liegt nicht nur in einer Steigerung der Richtigkeitsgewähr bei der Sachverhaltsermittlung, sondern auch in einer Effektivitätssicherung bei der Leistungserbringung. Teilweise, etwa bei Rehabilitationsleistungen (vgl. § 4 Abs. 1 RehaAnglG), ist der Leistungserbringer sogar auf die Mitwirkung des Leistungsempfängers angewiesen, wenn die Leistung Erfolg haben soll. Die Mitwirkung stellt sich daher als versteckte Ressource erfolgreicher Gesetzesanwendung in der Leistungsverwaltung dar ${ }^{110}$. Sie fördert die Effektivität und erhöht die Befriedung und Akzeptanz.

Bei aller Betonung der Vorteile des Kooperationsprinzips in der Leistungsverwaltung dürfen indes seine Grenzen nicht übersehen werden ${ }^{111}$. Nicht zweckmäßig scheint eine Kooperation zwischen Verwal-

bereitung und Vermittlung der Leistung noch weitergehend durch neutrale Dritte, wie Arzt, Sozialarbeiter etc. erfolgen könnte; zum Konzept der Mediation in USA vgl. Oliver Passavant, DÖV 1987, 516.

${ }^{108}$ Erichsen, DVBl. 1983, 289 (290, 293).

${ }^{109}$ Hill, DöV 1987, 885 (894).

${ }^{110}$ Peter Gross/Bernhard Badura, in: Ferber/Kaufmann (Hrsg.), Soziologie und Sozialpolitik, 1977, S. 361 (377); Blessing (Fn. 62), S. 295.

${ }^{111}$ Hill, NJW 1986, 2602 (2609). 
tung und Bürger bei Geldtransferleistungen. Hier ist aus Gründen der Klarheit und Berechenbarkeit weiterhin am System der normativ fixierten Ansprüche festzuhalten ${ }^{112}$. Im übrigen liefert das Gesetz den Rahmen für die beiderseitigen Dispositions- und Gestaltungsbefugnisse. So behält § 31 SGB AT ausdrücklich die Festlegung von Rechten und Pflichten dem Gesetzgeber vor, § 33 SGB AT erlaubt die Berücksichtigung der persönlichen Verhältnisse und der Wünsche des Berechtig. ten lediglich bei der Ausgestaltung dieser Rechte und Pflichten. Ähnlich räumt $\S 4$ Abs. $1 \mathrm{BSHG}$ bei entsprechender gesetzlicher Normierung einen grundsätzlichen Anspruch auf Sozialhilfe ein, während Abs. 2 nur die Entscheidung über Form und Maß der Leistung ins Ermessen der Behörde stellt. Weitere Schranken zu Gunsten des Leistungsempfängers bestehen in der Begrenzung seiner Mitwirkungs- und Anrechnungspflichten auf das zumutbare Maß (etwa $\S \S 65$ Abs. 1 Nr. 2 SGB AT, 79ff., 84 BSHG), in einer Beachtung des Grundsatzes der Verhältnismäßigkeit ( 865 Abs. 1 Nr. 1 SGB AT) und des Koppelungsverbotes (vgl. \& 55 Abs. 1 Satz 2 SGB X). In verfahrensrechtlicher Hinsicht wären sie durch zusätzliche Mißbrauchs- und Willkürkontrollen zu ergänzen ${ }^{113}$. Der Schutz der Interessen Dritter und der Allgemeinheit kommt in den gesetzlichen Bestimmungen zum Ausdruck, die die Beriicksichtigung der Wünsche und Interessen des Leistungsempfängers auf das Angemessene beschränken (etwa $§ 3$ Abs. 2 BSHG) ${ }^{114}$ und der Verwaltung die Beachtung des Grundsatzes der Wirtschaftlichkeit (etwa § 93 Abs. 2 Satz 2 BSHG) auferlegen.

\section{Ausblick}

Der soziale Leistungsstaat steht in Zukunft vor nicht geringen Aufgaben. Einerseits scheint die Problematik sozialer Hilfsbedürftigkeit und Ratlosigkeit sich auszuweiten, nicht zuletzt deshalb, weil die Tragfähigkeit natürlicher Netzwerke zerstört oder geschwächt ist, andererseits stoßen die offiziellen und professionellen Leistungssysteme auf Grenzen ihrer Leistungsfähigkeit und ihres Wachstums ${ }^{115}$.

In dieser Situation werden neue und alternative Steuerungsmodelle offeriert, die eine Ergänzung der traditionellen rechtlichen und ökonomischen staatlichen Interventionsformen durch ökologische, die Umwelt und die Verbesserung der sozialen Infrastruktur einbeziehen-

112 Vgl. auch Zacher, SGb 1982, 329 (336); Vobruba (Fn. 99).

113 Hill, DöV 1987, 885 (895).

${ }^{114} \mathrm{Igl} /$ Giese, ZfS 1982, 65 .

115 Pankoke, in: Hubert Oppl/Arnold Tomaschek (Hrsg.), Soziale Arbeit 2000, Band 2, 1986, S. 31 (33). 
de, sowie pädagogische Maßnahmen zur Verbesserung der Handlungsfähigkeit von Personen vorgeschlagen ${ }^{116}$.

Es bleibt aber zu beachten, daß trotz der bisher zu sehr auf Geldund Sachleistungen abgestellten Leistungssysteme nun nicht eine pauschale Kehrtwende des Leistungsstaates und seiner Steuerungsmuster richtig sein kann.

Vielmehr müssen stringente Bindung und offene Programmierung bzw. Auftrag, Anspruchs- und Ermessensleistung je nach Sachbereich weiterhin vorhanden und nebeneinander bestehen bleiben. Organisationsmodelle und Entscheidungsstrukturen sind ebenenspezifisch und funktions- bzw. sachadäquat sowie entsprechend der Handlungs- und Leistungsfähigkeit des Trägers und der Leistungsadressaten zu differenzieren ${ }^{117}$. Abgestufte Modelle, wie etwa bewegliches System und Kooperation, sind ergänzend zu integrieren. Zweckbestimmungen, Prinzipien und Generalklauseln der Sozialgesetze lassen jedenfalls genügend Raum für eine differenzierte und entwicklungsfähige Gesetzesgestaltung und Gesetzesanwendung.

${ }^{116}$ Kaufmann, in: Joachim Matthes (Hrsg.), Krise der Arbeitsgesellschaft, 1983, S. 474ff.; ders., in: Jahrbuch für Rechtssoziologie und Rechtstheorie, Bd. XIII, 1988, S. 65 (90ff.); vgl. noch Blessing (Fn. 62), S. $51 \mathrm{ff}$., 76ff.; Claus Offe/Rolf G.Heinze, Leviathan 1986, 471 (492); dies., in: J.J.Hesse/Christoph Zöpel (Hrsg.), Neuorganisation der Zeit, 1987, S. 150 (156ff.).

${ }^{117}$ Zacher (Fn. 6), S. 52; Pitschas, ArchsozArb 1981, 240 (345f.); Vobruba (Fn. 99). 
Leitsätze des 3. Berichterstatters über:

\section{Gesetzesgestaltung und Gesetzesanwendung im Leistungsrecht}

\section{Einfuihrung}

1. Gesetzesgestaltung und Gesetzesanwendung können nicht isoliert, sondern nur im Zusammenwirken und in Wechselbeziehung miteinander verstanden werden.

\section{Gesetzesgestaltung im Leistungsrecht}

2. Für eine dogmatische Integration der verschiedenen Rechtsentstehungs- und -verwirklichungsphasen bietet sich die Figur des Rechtsverhältnisses an. Rechtsverhältnisse im Sozialleistungsrecht sind

- vielfältig strukturiert

- ganzheitlich-zweckbestimmt

- richtungweisend und optimierungsbedürftig

- prozeßorientiert.

3. Der Gesetzesvorbehalt des $\S 31$ SGB AT enthält eine abgestufte Gesetzesbindung, die der Verwaltung genügend Raum läßt, auch abweichenden und neuartigen Fallgestaltungen Rechnung zu tragen.

4. Bei Leistungsgesetzen im Sozialrecht findet man vor allem die Gesetzestypen Befehl, Plan, Auftrag und Information.

5. Die Umsetzung der verfassungsrechtlichen Grundlagen und Aufträge durch Gesetz ist an der Leistungsfähigkeit der Gesetzesanwender und dem Verständnishorizont der Adressaten zu orientieren. Hilfen für den systematischen Zugang und interpretationslenkende Kriterien in den Sozialgesetzen bieten hierfür Ansätze.

6. Die traditionelle Gesetzestechnik ist dem Gegensatz zwischen konkreter und abstrakter Tatbestandsgestaltung verhaftet. Beide Formen sind nicht geeignet, Grenzfälle, Randbereiche und Grauzonen im Vor- und Umfeld der definierten Fälle zu erfassen. Eine optimale gesetzliche Entscheidung ist nicht allgemein, d.h. generell und gleichbleibend definierbar, sondern muß in der Lage sein, variabel, adäquat und aktuell auf die jeweilige Situation zu reagieren. 
7. Als Lösung bietet sich das sog. bewegliche System an, das von einer gesetzlichen Basiswertung ausgeht, die durch vom Gesetzgeber vorgegebene komparative Wertreihen, d.h. Wertrelationen zwischen verschiedenen Merkmalen, ergänzt wird. Ansätze dazu sind in der Rechtsordnung schon vorhanden. Das bewegliche System ist in der Lage, die Rechtsverwirklichung im Rahmen der grundgesetzlichen Funktionenordnung zu effektuieren.

8. Es ist zu prïfen, inwieweit zur Verstetigung und Rationalisierung des Gesetzgebungsprozesses inhaltliche, institutionelle, methodische und redaktionelle Bindungen bestehen oder Meta-Regeln gebildet werden können.

9. Der Gesetzgeber hat durch Vorabkontrolle und geeignete Vermittlung Erfolgsvorsorge für die Wirksamkeit und Akzeptanz seiner Gesetze zu treffen. Sie wird durch Erfolgskontrolle und Erfolgssicherung mittels Anpassung der Gesetze fortgesetzt.

\section{Gesetzesanwendung im Leistungsrecht}

10. Rechtsverwirklichung durch Gesetzesanwendung erfolgt durch Beachtung von Zweck, Wert, System und Zeit. Dabei gewinnt das gesetzliche Programm konkrete Form durch die Wirkkraft des Einzelfalls und die Kompetenzausübung der handelnden Organe.

11. Kompetenzen und Verantwortungsbereiche von Verwaltung und Gerichten sind auch im Sozialrecht umstritten. Neben der Rechtsbildung nehmen die Gerichte in erheblichem Umfang die Aufgabe der Rechtsfortbildung wahr.

12. Die Leistungsverwaltung im Sozialbereich ist noch zu sehr an den Strukturen der Eingriffsverwaltung und an inneradministrativen Anforderungen orientiert. Sie muß sich mehr auf ihren Dienstleistungscharakter, auf die zu lösenden Aufgaben sowie ihre Klienten einstellen. Verbesserungen mängelbehafteter Verwaltungsstrukturen (Finanzen, Organisation, Personal) können vor allem durch interne Steuerung. Organisation, Ausbildung und Führung erfolgen.

13. Dem kritisierten Gegensatz zwischen Kasuistik und Generalklausel im objektiven Bereich entspricht im subjektiven Bereich der Gesetzesgestaltung ein ebenso unbefriedigendes Nebeneinander von Ansprüchen und Ermessen. Als Lösung bietet sich insoweit eine kooperative Entwicklung bzw. einvernehmliche Gestaltung des Rechtsverhältnisses durch Verwaltung und Bürger an. Dies würde nicht nur der Kooperationsfunktion der Grundrechte im Leistungsrecht entsprechen, sondern auch die Effektivität der Leistungsverwaltung erhöhen. 
Die Kooperation der Partner hat im Rahmen der durch die gesetzlichen Vorgaben gezogenen Grenzen zu erfolgen.

IV. Ausblick

14. Der soziale Leistungsstaat steht in Zukunft vor nicht geringen Aufgaben. Dafür werden neue Steuerungsmodelle vorgeschlagen. Sie können jedoch die bisher zu sehr auf Geld- und Sachleistungen abgestellten Leistungssysteme nicht vollständig ersetzen. Zu empfehlen sind daher je nach Sachbereich und Leistungsfähigkeit der Träger und der Adressaten ebenen- und bereichsspezifisch differenzierte Programm-, Organisations- und Entscheidungsstrukturen. 


\section{Aussprache und Schlußworte}

\section{Gesetzesgestaltung und Gesetzesanwendung im Leistungsrecht}

Vorsitzender (Starck): Ich eröffne die Aussprache zum Thema Gesetzesgestaltung und Gesetzesanwendung im Leistungsrecht, indem ich in Ihrem Namen den Referenten vielmals für die Vorträge danke. Sie haben durch den Applaus heute vormittag zu erkennen gegeben, daß Ihnen diese Vorträge gut gefallen haben. Nach einer Tradition in der Vereinigung sind die Vorträge entweder kontrovers angelegt oder ergänzen einander thematisch wie heute vormittag, wobei immer noch genügend Kontroverses bleibt. Der Schwerpunkt des Vortrages von Herrn Mußgnug war der Finanzierung gewidmet. Herr Hufen hat sich mit inhaltlichen Problemen der Gesetzgebungslehre beschäftigt, einschließlich der verfassungsrechtlichen Grenzen der Leistungsgesetzgebung, während der Schwerpunkt des Referates von Herrn Hill mehr den Techniken der Gesetzgebung im Leistungsrecht gewidmet war. Ich möchte zur Begründung des Themas keine weiteren Ausführungen machen; denn nach dem Anhören der Referate ist die Fruchtbarkeit des Themas zur Genüge erwiesen.

Die Gliederung dort unten auf der Tafel können Sie lesen: (1) Aufgaben und Grenzen des Leistungsstaates, (2) Instrumente und Techniken des Leistungsrechts und (3) Reformvorschläge. Die Gliederung ist uns sehr abstrakt geraten, weil das beschränkte Ausmaß der Tafel die Aufnahme von Untergesichtspunkten nicht erlaubt hat. So kann man sich eigentlich zu jedem dieser Punkte melden und auch zu allen Punkten etwas sagen. Ich möchte zwei allgemeine Bemerkungen zu der Gliederung machen. Ihnen fällt sicher auf, daß die beiden Fragen „,Gesetzesgestaltung “ und „Gesetzesanwendung" hier nicht vorkommen. Das hängt damit zusammen, daß sie im Thema vorkommen und daß unserer Meinung nach „Gesetzesgestaltung“ und „Gesetzesanwendung" in der Diskussion nicht getrennt behandelt werden sollten. Das ist ja auch eine wesentliche These von Herrn Hill. Dies entspricht genau der Konzeption des Vorstandes, weswegen er das Thema gegeben hat. Ferner wird Ihnen auffallen, daß die in allen Referaten - insbesondere in dem Referat von Herrn Mußgnug - angesprochene Frage der Haushaltsverantwortlichkeit und der Finanzierung ebenfalls nicht in der Gliederung vorkommt, weil wir der Meinung sind, daß das Fi- 
nanzierungsproblem ein durchgängiges Problem ist und deswegen un. ter allen Punkten eine gewisse Bedeutung hat. Ich möchte zu dem ersten Punkt der angeschriebenen Gliederung noch einige Erläuterungen geben, in dem ich Ihnen Stichworte nenne: 1. Sozialstaatlichkeit unter dem Gesichtspunkt der Aufgaben des Staates, 2. die Selbstverantwortung des Bürgers, dann 3. die Eigengesetzlichkeit von Lebensbereichen, 4. das mehrfach angesprochene Übermaßverbot im Leistungsrecht, 5. Kontrollen und Eingriffe um der Gerechtigkeit der Leistung willen, 6. Einzelfallgerechtigkeit und Ermessen, 7. Typisierungen und System. gerechtigkeit und schließlich 8. Mißbrauchsverhinderung. $\mathrm{Zu}$ dem 2. Gliederungspunkt möchte ich jetzt keine genaue Untergliederung geben, sondern nur darauf hinweisen, daß hier etwa das Problem abzuhandeln ist, ob der Gesetzgeber regeln soll oder ob der Haushaltsplan genügt, schließlich die Frage der richterlichen Rechtsfortbildung. Was die Reformvorschläge anbelangt, beziehen sie sich selbstverständlich auf die Gesetzgebung und auf die Verwaltung.

Eine letzte Bemerkung zum Verfahren der Aussprache. Ich habe noch nicht ganz so viele Wortmeldungen wie gestern; wir haben eine halbe Stunde länger Zeit als gestern, so daß ich guter Hoffnung bin, daß alle, die sich gemeldet haben, zu Wort kommen, und daß durch weitere Spontanmeldungen eine lebendige Aussprache stattfinden kann. Es ist vorgesehen, daß wir in etwa $11 / 2$ Stunden den Referenten Gelegenheit zu einem Zwischenwort geben wollen, damit sie nicht mit allen Antworten auf das Schlußwort warten müssen. Ich möchte die einzelnen Diskutanten bitten, sich darum zu bemühen, nicht mehr als 5 Minuten zu sprechen. Wer freilich mehr zu sagen hat und viele Themen anspricht, hat etwas mehr Zeit, ich werde dann aber 8 Minuten als Obergrenze ansehen.

Als ersten Diskussionsredner bitte ich Herrn Paul Kirchhof.

P. Kirchhof: Wir verdanken dem Vorstand ein Thema, das in der dogmatischen Struktur und in der praktischen Bedeutung nach neuen Ufern drängt. Und wir verdanken den Referenten Ausführungen, die teilweise im Grundsätzlichen, teilweise aber auch in konkreten Anwendungsfällen diese Fragen aufnehmen und uns veranlassen, eher über das Wie, denn über das Ob logischer und gesetzlicher Strukturierung des Leistungsstaates nachzudenken. Wenn man sich bewußt macht, was Leistungsrecht ist, so wird man dieses Recht finanzwirtschaftlich als die Rechtsmaßstäbe zur Verteilung von Abgabenaufkommen definieren. Es macht allerdings einen guten Sinn, wenn das Staatsrecht Steuerrecht und Leistungsrecht strikt trennt, das Haushaltsrecht Einnahme- und Ausgabeseite kategorisch voneinander unterscheidet. Diese Sonderung gewährleistet, daß der Finanzstaat unabhängig von seinem Financier bleibt, nicht in irgendeine Abhängigkeit zu demjeni- 
gen gerät, der durch seine Steuerzahlung staatliche Finanzkraft begrïndet hat oder die Zahlung von Steuern unter einen Vorbehalt stellen will. Deshalb ist es richtig, daß - obwohl das logisch zusammenhängende Thema „Staatliches Geben und Nehmen“ aufgenommen worden ist - keiner der Referenten der Versuchung unterlegen ist, hier ein normativ zwingendes, dauerndes Junktim herzustellen.

Allerdings führt dieses Trennungsprinzip zu praktischen Problemen. Eine Schwierigkeit liegt darin, daß der Vorbehalt des finanziell Möglichen, der langfristig finanzstaatliches Handeln zwingend begrenzt, ein wenig in Vergessenheit gerät, damit staatliche Leistungsversprechen nicht hinreichend auf die verfügbare finanzstaatliche Leistungskraft abgestimmt werden. Eine zweite Gefahr sehe ich darin, daß wir den Leistungsstaat nur als den Wohltäter erleben, die vorausgehende Steuerbelastung bei der Nachfrage nach staatlichen Leistungen deshalb vergessen wird und dadurch die Mäßigung staatlicher Abgabenpolitik durch Ausgabenverzicht geschwächt ist. Zudem macht die Geste staatlichen Gebens nicht immer sichtbar, daß leistungsstaatliche Tätigkeit Ausübung von finanzieller Macht ist, daß sich damit das Erfordernis parlamentarischer Mitwirkung in besonderer Deutlichkeit stellt.

$\mathrm{Zu}$ den beiden Themenkreisen „Vorbehalt des Möglichen“ und „Grenzen staatlicher Finanzmacht" möchte ich einige grundsätzliche Bemerkungen machen.

Der Vorbehalt des Möglichen fordert zunächst die Koordination staatlicher Einnahme- und Ausgabepolitik. Diese Abstimmung hat das Parlament zu leisten. Dies geschieht nicht, indem ein Gesetz beide $\mathrm{Ge}$ setzgebungsbereiche verzahnt, sondern dadurch, daß das Parlament in seinen politischen Entscheidungen stets diese Brücke schlägt. Dabei ist es eine wesentliche Hilfe, daß der Bundesrechnungshof seit wenigen Jahren sich des Zusammenhangs von Steuerpolitik und Leistungsgebaren ausdrücklich annimmt und nicht nur die Ausgabenseite prüft, sondern sich auch kritisch zur Einnahmeseite und zum Gesamtvolumen von Einnahmen und Ausgaben äußert, z.B. gegenwärtig zu den ,Einkünften aus Kapitalvermögen“. Ein zweites Beispiel für den Koordinationsbedarf zwischen statlichem Geben und Nehmen bietet die Tatsache, daß staatlich gewährte Subventionen bei dem subventionsberechtigten Privatunternehmer der Einkommen- und Körperschaftsteuer unterworfen werden, der Staat also im Subventionsangebot den besonderen, mit öffentlichen Haushaltsmitteln ganz oder teilweise zu deckenden Bedarf des Unternehmers anerkennt, diesen Tatbestand aber zugleich als rechtfertigenden Grund für Steuerbelastungen in Anspruch nimmt. Staatliches Geben und Nehmen ist hier schlechthin unkoordiniert. Der Staat kann nicht einerseits geben und andererseits zugleich - teilweise mit progressivem Steuersatz - das Gegebene wieder zurücknehmen. 
Die Steuer- oder Verschonungssubvention wird formal innerhalb des Steuerschuldverhältnisses angeboten, scheint deshalb noch am ehesten eine auf den staatlichen Steuerzugriff abgestimmte Subvention. Bei den Steuersubventionen müssen wir uns jedoch andere Probleme bewußt machen: Die parlamentarische Kontrolle, die im Leistungsrecht als jährliche Kontrolle gedacht ist, wird unterlaufen, weil die Steuerentlastungstatbestände irgendwann einmal in das Steuerrecht eingebracht werden, sie dann jedoch im Parlament in Vergessenheit geraten und deshalb über Jahre und Jahrzehnte weder in ihrem rechtfertigenden Anlaß noch in ihrer tatsächlich wirksamen Höhe überprïft werden müssen. Bundesstaatlich fragwürdig ist, ob der Gesetzgeber einen Verschonungstatbestand ganz oder teilweise zu Lasten fremder Kassen begründen darf, insbesondere der Bundesgesetzgeber bei der Regelung der Gemeinschaftsteuern oder der Landesertragsteuern lenkende und intervenierende, also verwaltungsrechtlich wirksame Entlastungstatbestände vorsehen darf. Außerdem ist fragwürdig, ob im Rahmen einer progressiven Steuer Subventionen ausgereicht werden dürfen, die dann den Steuerpflichtigen mit hoher Leistungskraft mehr begünstigen als den Steuerpflichtigen mit geringer Leistungskraft.

Im Problembereich der Staatsverschuldung - der zeitlichen Dimension des Leistungsstaates - möchte ich Herrn Mußgnug nachdrücklich zustimmen. Es ist eine Fundamentalfrage unserer Verfassungsordnung, ob der Leistungsstaat sich durch Leistungen an die Gegenwart zu Lasten der Zukunft finanzkräftiger darstellen darf als der gegenwärtige Financier ihn ausstatten kann.

Eine weitere UUberlegung, der wir uns näher widmen sollten, gilt der Frage, ob ein Vorbehalt des finanziell Möglichen nicht auch in den Bereich der Leistungsschuldverhältnisse eingebracht werden muß. Auch in dem Individualschuldverhältnis zwischen Leistungsstaat und Leistungsempfänger ist die Finanzierbarkeit der Leistungsverbindlichkeit entweder auf der Tatbestandsseite oder aber zumindest - wie es die Referenten fordern - im Ermessensbereich zu beachten. Dennoch lesen wir noch immer Äußerungen, die besagen, daß die Berücksichtigung des finanziell Möglichen zumindest einem Ermessensfehler nahekomme. Gerade hier ist es geboten, das Leistungsrecht in seiner Funktion und in seinen Grenzen sorgfältig zu definieren: Wenn eine bestimmte staatliche Zuwendung dem Regime des Leistungsrechts unterstellt ist, muß im Rahmen dieser individuellen Teilhabe an staatlicher Finanzkraft auch der Vorbehalt des Finanzierbaren berücksichtigt werden.

Meine zweite grundsätzliche Bemerkung hat die Finanzmächtigkeit des Staates zum Thema: Die Verfügungsgewalt über Finanzmittel befàhigt zum Handeln, zum Steuern, zum Ordnen und zum Umverteilen. Unser Staatswesen leitet einen wesentlichen Teil seiner Stabilität aus 
seiner Finanzmächtigkeit her. Deswegen haben die Lenkungs- und Reaktionskompetenzen des Parlaments hier eine wichtige Funktion. Es ist begrüßenswert, daß alle drei Referenten nachdrücklich eine Zementierung staatlicher Leistungsgepflogenheiten durch entsprechende individualrechtliche Leistungsansprüche abwehren wollen. Diesen Weg werden wir sicherlich gemeinsam gehen müssen. Dann aber stellt sich die weitere Frage, ob über die parlamentarischen Globalermächtigungen und die auch im Haushaltswesen enthaltenen sachbereichs- und gegenstandsbezogenen Individualermächtigungen noch ein gesetzlicher Regelungsbedarf besteht. Wir haben im Grundgesetz z.B. einige Gesetzesvorbehalte aus bundesstaatlichem Anlaß: die Geldleistungsgesetze, die Ausgaben für die Auftragsverwaltung, die Finanzhilfen und die finanzwirtschaftlichen Gemeinschaftsaufgaben. Diese bundesstaatlichen Gesetzesvorbehalte fordern allerdings nicht eine Regelungsdichte und Regelungsweite von einer Intensität, wie wir sie herkömmlich bei den rechtsstaatlichen Gesetzesvorbehalten postulieren. Darüber hinaus wäre erwägenswert, ob der Gesetzgeber nicht jedenfalls in einem allgemeinen Teil eines Leistungsgesetzes die Grundkategorien staatlichen Leisten-Dürfens und Leisten-Müssens definieren sollte. Ich möchte nicht unbedingt den Hinweis auf eine Grundlagengesetzgebung im Sinne einer Normenstufung, wie sie Herr Hufen vorschlägt, oder die gesetzliche Basiswertung, die Herr Hill im Auge hat, aufnehmen. Diese Anregungen müßte man diskutieren und insbesondere von der bei den Gemeinschaftsaufgaben im Hochschulrecht, im Haushaltsgrundsätzegesetz und im Staatskirchenrecht geläufigen Grundsatzgese tzgebung abheben. Jedenfalls wäre es in der Tendenz aber eine richtige Lösung, wenn die Art staatlichen Leistens gesetzlich geregelt würde. Es macht einen erheblichen Unterschied, ob der Staat dem Bürger ohne Auflagen Geldmittel gibt, er also schlicht den finanziellen Handlungsspielraum des Empfängers erweitert, er ihn zu einer beliebigen Nachfrage befähigt, oder ob er ihm Sachleistungen gewährt, damit den Bedarf definiert, den der Bürger zu befriedigen in der Lage sein soll. Für die rechtlichen Maßstäbe wesentlich ist auch die Unterscheidung zwischen einem Dauerschuldverhältnis oder einem Einmalschuldverhältnis; zwischen der vom Staat geschaffenen Einrichtung, die nur die vom Staat definierten Nutzungsmöglichkeiten anbietet, und der staatlichen Unterstützung privater Einrichtungen, die lediglich das Entstehen und die Zielrichtung der Institution in staatliche Mitverantwortung gibt, die Nutzungsart aber privater Hand überläßt. Wichtig wäre auch eine Definition der Ziele staatlichen Leistens. Die Erhaltungssubvention z.B. wahrt den Besitzstand auch in der Phase, in der freiheitliches Handeln zu Risiken führt, diese typische Folge der Freiheitsausübung aber offenbar nicht in der alleinigen Verantwortlichkeit des Freien, des privatrechtlichen Tätigen belassen sein soll. Anpassungssubventionen hin- 
gegen binden die privaten Initiativen durch die goldenen Zügel des Geldes in staatliche Verwaltungsprogramme, „erkaufen“" also ein Zusammenwirken zwischen öffentlicher und privater Hand.

Sodann wäre auch der Konkretisierungsgrad von Leistungszielen klärungsbedürftig. Wenn wir etwa Subventionen mit dem Ziel, Arbeitsplätze zu schaffen oder das Wirtschaftswachstum zu fördern, begründen, so stellt sich die Frage, ob wir uns mit einer Zielvorgabe von dieser Allgemeinheit begnügen können. Selbstverständlich erfüllt jede Aktivität, die irgendwie marktwirksam ist, die Kriterien der Marktbelebung und zumindest der mittelbaren Arbeitsplatzsicherung oder erweiterung. Hier wird die Staatsleistung sich nicht mit diesen abstrakten ökonomischen Zielen zufrieden geben dürfen, sondern zu unterscheiden haben, ob der neugeschaffene Arbeitsplatz z.B. ein Kulturgut oder wohl eher Vulgärliteratur hervorbringt. Wenn der Staat vor der Alternative steht, mit dem Stabilisierungsauftrag zugleich einen kulturstaatlichen Auftrag zu erfüllen (oder ihm zumindest nicht zuwider zu handeln), so wird er beiden Zielen dienen müssen. Der Einwand der leistungsstaatlichen Bevormundung privater Initiativen würde sich gegen die Subvention schlechthin, nicht gegen die Auswahl zwischen einem anspruchsvollen und einem belanglosen Vorhaben wenden.

Schließlich möchte ich noch eine Bemerkung zu der von den Referenten angeschnittenen Frage von Freiheit und Autonomiebereich anfügen. Zunächst müssen wir im Bewußtsein halten, daß privatautonome Selbstregelung den Staat entlastet. Die staatlichen Instrumente zur Entscheidungsfindung sind nicht darauf angelegt, vielleicht auch nicht geeignet, eine prinzipielle Vermögensumverteilung ohne das Korrektiv privater Freiheit zu bewirken. Würde man sich einmal vorstellen, der Staat solle mit seinen Entscheidungsfindungsverfahren den Markt ersetzen, so würde man deutlich sehen, daß diese öffentlich-rechtliche Verteilungstechnik nicht funktionieren kann. Andererseits neigt eine autonome Gruppe, die durch staatliches Recht in ihren Handlungsmitteln und in ihrem Einflußbereich gestützt wird, zu einer Selbstbestimmung zu Lasten Dritter. Gegen eine derartige Verfremdung der Autonomie, wie wir sie z.B. im Sozialversicherungswesen kennen, müssen Verantwortlichkeiten der Betroffenen neu begründet werden. Wenn z.B. das Recht der Pflichtversicherungen die finanzielle Nachfragekraft am Markt des Gesundheitswesens abgeschöpft hat und jetzt der Nachfrager bei Empfang der medizinischen Leistung nicht selbst den Preis erbringen muß, also die Kontrolle der Leistung durch die Preiszahlungspflicht nicht mehr funktioniert, so ist die Kostenexplosion in dem System angelegt. Sind sich Arzt und Patient einig, daß das Teuerste ,gerade gut genug“ ist, so hilft nur eine sozialstaatlich vertretbare Mitbeteiligung des Patienten. 
Unsere Grundsatzfrage nach der Gesetzesgestaltung im Leistungsstaat müssen wir mit einem arbeitsteiligen Gestaltungsauftrag beantworten: Der Gesetzgeber hat die Global- und Sachbereichsermächtigung, sodann auch die Struktur eines allgemeinen Leistungsrechts zu regeln, zugleich aber den Gestaltungsspielraum der Verwaltung zu wahren, die den Gläubiger und die Höhe der Leistung weitgehend bestimmen soll.

Vorsitzender: Vielen Dank, Herr Kirchhof, für Ihre umfassenden Bemerkungen zu den drei Referaten. Das Wort hat jetzt Herr Hans Peter Ipsen.

H.P. Ipsen: Das Thema, das heute behandelt worden ist, bezieht sich auf drei Bereiche des Leistungsrechts. Die Referenten haben sich ihre Aufgabe geteilt: Subventionen, Daseinsvorsorge, Sozialleistungen. Allen diesen Leistungsarten dürfte gemeinsam sein, daß es sich um finanzielle oder geldwerte Leistungen der öffentlichen Hand an einzelne handelt. Gleichwohl besteht ein elementarer Unterschied zwischen dem Subventionswesen einerseits, auf der anderen Seite der Daseinsvorsorge und den Sozialleistungen. Diese beiden werden - selbstverständlich in Wahrnehmung öffentlicher Aufgaben und Staatszwecke gewährt zur Grundrechtsbefriedigung und -verwirklichung im Interesse eines Individuums oder der Allgemeinheit. Es sind Leistungen, die für die Existenz des einzelnen oder die Lebensbedürfnisse der Allgemeinheit erheblich sind.

In diesen Leistungen steckt aber nicht eine davon abgespaltene spezifische öffentliche Zweckverfolgung, wie sie bei der Subventionierung stattfindet. Sie erfolgt zugunsten eines einzelnen (eines sehr großen einzelnen wie Krupp-Stahl oder eines kleineren), für jemand, der vorwiegend im Wirtschaftsbereich tätig ist und dem die Subventionsleistung zugewendet wird, um mit seiner wirtschaftlichen Aktivität einen öffentlichen Zweck zu verfolgen, wie er weder von Sozialleistungsempfängern noch von den Nutznießern der Daseinsvorsorge erwartet wird. Subventionierung verfolgt einen besonderen öffentlichen Zweck durch Verhaltensbeeinflussung des Subventionsempfängers. Subventionierung ist also Zuwendung prinzipiell nicht im grundrechtlichen Individualinteresse eines einzelnen, auch nicht im Allgemeinwohlsinne, sondern Finanzleistung an einen einzelnen zur Verfolgung eines bestimmten öffentlichen Zwecks.

Wenn ich dabei überwiegend die Wirtschaftssubventionierung vor Augen habe, dann deshalb, weil sie im Etatvolumen zweifellos den größten Umfang einnimmt und aus diesem Bereich auch die kritischen Fragen der Rechtsgestaltung entstehen. Ich denke bei Elementen solcher Zweckverfolgung in der Wirtschaftssubventionierung etwa an die 
Sorge um die Arbeitsplätze, an Wachstumsvorsorge, Strukturpolitik, Regionalpolitik usw., so daß der einzelne Subventionsempfänger mit seiner Tätigkeit dazu beiträgt, einen spezifischen öffentlichen Zweck zu erfüllen.

Einen Grenzfall mag die Landwirtschaftssubventionierung darstellen. Aber wenn man die Geschichte der Agrarsubventionierung verfolgt, auch in frühere Zeiten zurück, dann ist doch immer entscheidend gewesen ein öffentlicher Zweck: die Vorratshaltung für den Heeresbedarf, für den nächsten Krieg, Unabhängigkeit von Importen, „Blut- und Boden"-Parolen bevölkerungspolitischer Art im Dritten Reich oder heute Leistungen, die von der Landwirtschaft für den Umweltschutz erwartet werden. Dabei verkenne ich nicht, daß die individuelle Leistungszuwendung (z.B. durch Preis- und Abnahmegarantien) an die Landwirtschaft auf der Grenze liegen mag. Das hängt heute mit Art. 39 EWGV zusammen, der der Landwirtschaft eine angemessene Lebenshaltung gewährleistet.

Die Folgerungen, die ich zwischen jenen drei Bereichen für die Rechtsgestaltung ziehe, scheinen mir erheblich zu sein. In den Referaten von Herrn Hufen und Herrn Hill sind zur Gesetzesgestaltung und -anwendung gewisse Elemente einer Gesetzgebungslehre vorgetragen worden. Darauf kann ich nicht näher eingehen. Ich meine bei Herrn Hufen (Thesen 7 und 8) die Grundlagengesetzgebung mit einem anschließenden vereinfachten Gesetzgebungsgang oder bei Herrn Hill (These 7) das System gesetzlicher Basiswertung.

Der Ausgangspunkt von Herrn Mußgnug mußte ein ganz anderer sein, und ich begrüße es, daß er das Problem der Finanzierung der Subventionierung an den Anfang gesetzt hat. Das ist deshalb entscheidend, weil mit der Etatausweisung der Subventionsmittel zunächst einmal eine Bemessung des etwa erforderlichen Subventionsaufwandes notwendig ist und sich dann anschließend ein Problem ergibt, das in den beiden anderen Bereichen der Leistungsverwaltung selten oder überhaupt nicht auftritt, nämlich das der Verteilung der bereitgestellten Mittel, die in aller Regel zu knapp sind. Dieses Problem löst spezifische Anforderungen für die Rechtsgestaltung des Verfahrens aus. Im Etatposten selbst können solche Regeln über die Art der Verteilung nicht gegeben werden. Der Etat kann nur eine Zweckbestimmung setzen, an die man sich zu halten hat, und deren Nichtbeachtung stellt dann nicht, wie gesagt worden ist, einen Mißbrauch dar, sondern eine schlichte Verletzung der gesetzten Norm, denn der Etattitel ist mit dem Haushaltsgesetz Normelement geworden.

Da irgendwelche Regeln bestehen müssen, um die Verteilung zu ermöglichen, ist im Subventionswesen die Figur der Richtlinien relevant geworden, die auch das Verfahren im übrigen regeln. Herr Mußgnug ist dabei nicht auf die früher im Subventionsrecht erörterte Frage einge- 
gangen, wieweit diese Richtlinien normative Außenwirkung haben, was bei Rechtsschutzfragen, bei der Konkurrentenklage relevant werden kann. Die Selbstbindung der Verwaltung an die Richtlinien führt dazu, daß den Richtlinien mit Hilfe der Gleichheitsprüfung rechtliche Außenwirkung zukommt.

Zum Verteilungsproblem stellt sich die Hauptfrage, nach welchen Maßstäben verteilt werden soll, wenn der Etattitel nicht für alle Interessenten ausreicht. Hier stellt sich die Prioritätsproblematik, die einer Quotierung usw. Hierüber handeln die Richtlinien. Im Bereich der Stahlsubventionierung, die ein Dauerthema ist, hat ein ausführlicher europarechtlicher Kodex hierzu subtile Regelungen bereitgestellt. Herr Hufen (These 17) und Herr Hill (These 9) haben Anregungen zu diesen Fragen gegeben.

Ich schließe mit einer Bemerkung zur These 4 von Herrn Mußgnug, Subventionen tunlichst zu reduzieren und individueller Vorsorge den Vorrang zu geben. Das ist eine Thematik, die nach meiner Vorstellung vom Subventionswesen - jedenfalls im Wirtschaftsbereich - kaum praktikabel ist und eine Preisgabe der öffentlichen Zweckverfolgung bedeuten würde.

Letztlich ein Folgerungssatz zu allen drei Referaten: die Berichte haben unterschiedliche Antworten gegeben auf die gestellte Frage der Gesetzesgestaltung ihrer Materien. Aus den Berichten zu den Themata „Daseinsvorsorge“ und „Sozialgestaltung“ können für das Subventionswesen nur wenige Anregungen entnommen werden.

Vorsitzender: Vielen Dank, Herr Ipsen. Wir sind besonders dankbar für Ihr Votum, weil gerade in Ihrer Person die leistungsstaatliche Thematik der Vereinigung gegenwärtig geworden ist. Es ist ja häufig über die Leistungsstaatlichkeit gesprochen worden. Als nächster hat das Wort Herr Kollege von Arnim.

von Arnim: Wenn der klassische Vorwurf von Ernst Forsthoff, die Staatsrechtswissenschaft sei zu einer Rechtsstaatswissenschaft verkommen, die im engen normativen Gehäuse ihr Wesen treibe, wenn dieser Vorwurf überhaupt jemals eine Berechtigung hatte, auf die 5 Referate von gestern und heute trifft er jedenfalls nicht zu. Kompliment und Anerkennung. Es hat gestern und wird heute sicher auch Versuche geben, insbesondere Sie, Herr Hufen und Herr Hill und gestern Herr Zippelius, in das Prokrustesbett überkommener rechtsstaatlicher Enge zurückzuholen. Das darf Sie nicht berühren! Ich möchte gern einen Aspekt, der gestern und heute eine Rolle spielte, ansprechen und die drei heutigen Referenten bitten, darauf im Zusammenhang noch einmal einzugehen. Die Frage, die gestern und heute - wie ich meine hinter den Referaten und auch den Diskussionen stand, war, ob das 
optimierende Richtigkeitsdenken, das wir für die Rechtsprechung und Verwaltung mehr oder weniger zu akzeptieren gelernt haben, ob dieses optimierende Richtigkeitsdenken legitimerweise auch von der Gesetzgebung verlangt werden kann. Die Herren Referenten Zippelius, Hufen und Hill haben - wenn ich recht sehe - diese Frage ohne weiteres bejaht. Die Herren Ipsen und Stern haben sie - wenn ich sie recht verstanden habe - gestern implizit verneint. Diese Frage kommt zum Schwur, wenn es um die Kontrolle des Gesetzgebers durch die Rechtsprechung geht. Die Antworten drücken sich im Umfang der Intensität der gerichtlichen Kontrolle aus, die man jeweils empfiehlt, und hängen sehr von der faktischen Richtigkeitserwartung ab, die wir hinsichtlich des politischen Prozesses, aus dem die Gesetze ja hervorgehen, haben oder glauben haben zu können. Gestern in einem Diskussionsbeitrag hat Herr Riedel dies mit dem Hinweis auf Elys „Democracy and Distrust" zum Ausdruck gebracht, und Herr Schuppert hat mit seinem Hinweis auf die strict-scrutiny-Prüfung des amerikanischen Supreme Court bei verdächtigen Akten gleichfalls darauf abgehoben. Wenn es nun aber zutrifft, daß bestimmte, besonders wichtige Belange in der realexistierenden pluralistischen Demokratie unserer Tage leicht zu kurz kommen, wie es besonders bei Herrn Hufen anklang, wenn er darauf hinwies, daß langfristiges allgemeinorientiertes Denken unprofitabel für den politischen Tatmenschen sei, und wenn er weiter eine Stärkung der Artikulationskraft Schwächerer unterstützen wollte, wenn dies also zutrifft, müßte dann nach dem - ich möchte es mal so nennen - democracy-distrust-Kontrollgrundsatz nicht eigentlich eine besonders intensive Kontrolle durch die Rechtsprechung erfolgen, sofern sie nicht ähnliche oder andere Defizite als der politische Prozeß aufweist? Hier kommt man allerdings, meine ich, in ein offenbares Dilemma. Die Rechtsprechung wäre wohl überfordert, wollte man ihr die Korrektur aller Pluralismusdefizite, die Korrektur aller Fälle von Staatsversagen aufbürden. Als Ausweg, und das ist nun meine Frage an die drei Referenten, als Ausweg aus diesem Dilemma wird zunächst von den Herren Zippelius, Müller, Hufen und Hill - wenn ich sehe, einheitlich - die Differenzierung zwischen strenger verfassungsrechtlicher Handlungsbindung und loserer Gerichtskontrolle angeboten. Dadurch soll einerseits die Utberforderung der Rechtsprechung vermieden werden, andererseits es aber trotzdem ermöglicht werden, die strenge Bindung des Gesetzgebers beizuhalten. Ich stimme dem zu, möchte aber die Referenten fragen, ob die Diskrepanz zwischen Soll und Ist, die durch eine direkte Gerichtskontrolle nur sehr beschränkt in Richtung auf das Soll verringert werden kann, nicht durch das Einziehen einer zusätzlichen Ebene, durch das Einziehen zusätzlicher Elemente, nämlich der Organisation und des Verfahrens, erfolgversprechend verringert werden kann. Anders ausgedrückt: Reichen Appelle an den Ge- 
setzgeber, was er alles tun soll, wirklich aus oder müssen wir uns nicht auch Gedanken darüber machen, wie die Ordnung der Willensbildung durch organisatorische und verfahrensmäßige Innovationen so verbessert werden kann, daß die Akteure in der politischen Praxis es leichter haben, „Richtiges“ auch durchzusetzen? Dazu, um es konkret zu machen, zwei kleine Beispiele. Eines betrifft den gestrigen Tag, das andere den heutigen. Ein Beispiel aus der Verwaltung, das andere aus der Gesetzgebung. Zunächst aus der Verwaltung: Herr Zippelius hat u.a. darauf abgehoben, daß die Einhaltung des Art. 33 Abs. 2 GG gefordert werden muß, und hat parteipolitische Ämterpatronage kritisiert. Können wir uns auf diesen Appell, Art. 33 Abs. 2 einzuhalten, beschränken oder müssen wir uns nicht auch und vielleicht in erster Linie Gedanken darüber machen, mit welchen institutionellen Innovationen wir den Adressaten dieses Postulats die Einhaltung des Art. 33 Abs. 2 in der Praxis so erleichtern, daß aus dem frommen Wunsch und abstrakten Postulat etwas wirklich Realisierbares wird. Das zweite Beispiel aus dem Gesetzgebungsprozeß: Hier scheint mir Herrn Hufens Gedanke der unabhängigen Gesetzgebungskommission, den ja auch Herr Hill aufgegriffen hat, genau in die gleiche Richtung zu gehen. Dabei geht es nicht nur um bessere Information des Gesetzgebers, in Wahrheit wohnt diesem Kommissionsgedanken ja wohl auch eine Gegengewichtsvorstellung inne: Wissen ist Macht, Information ist Macht, und das durch solche Kommissionen aufgedrängte Wissen um die $\mathrm{Zu}$ sammenhänge soll auch denen ihr Werk erschweren, die unter Ausblendung und Abdunklung der durch Informationen hergestellten $\mathrm{Zu}$ sammenhänge ihr partikuläres Süppchen kochen möchten. Meine These also, zu der ich die Referenten bitten würde, Stellung zu nehmen, wäre, daß das Nachdenken über derartige institutionelle Verbesserungen auf absehbare Zeit besonders ertragversprechend wäre. Vielleicht handelt es sich sogar um die Verfassungsfrage unserer Zeit. Jedenfalls sollten wir uns damit intensiver beschäftigen als wir es vielleicht in der Vergangenheit getan haben, um einem Abwandern dieser Fragestellung in andere Disziplinen - etwa in die politische Ökonomie - vorzubeugen.

Vorsitzender: Vielen Dank, Herr von Arnim. Herr Hoffmann-Riem, bitte.

Hoffmann-Riem: Eine Prämisse der drei Referate war der Befund, $\mathrm{daß}$ die mit der Industrialisierung verbundene gewaltige Verantwortungsübernahme durch den Staat an ihre Grenzen gestoßen ist. Wir wissen, daß der Staat heute mit der Fülle seiner Aufgaben und Verantwortlichkeiten uiberfordert ist, und wir merken, daß es eine Reihe von Krisensymptomen gibt, von der Finanzkrise, die Herr Kirchhof eben 
erneut angesprochen hat, bis hin zur Umweltkrise und zu tiefgreifenden Legitimationskrisen.

Ich bin dankbar, daß die Referenten auf die Krisensymptome nicht mit einfachen Antworten reagiert haben, wie sie früher in Diskussionen üblich waren. Wir haben z.B. weder die Aufforderung zur Entrechtlichung noch einen schlichten Appell „Zurück zum Markt" gehört. Es ist allgemein bekannt, daß die staatliche Verantwortungsübernahme auch eine Reaktion auf Marktversagen war. Politikversagen allein schafft keine Legitimation, wieder zum Marktversagen zurückzukehren.

Wir haben noch eine weitere Antwort nicht gehört, die vor zehn oder zwanzig Jahren in diesem Kreis en vogue gewesen wäre, nämlich den Ruf nach staatlicher Planung. Das Wort Planung ist in den Referaten wenig oder gar nicht vorgekommen, und dies, obwohl sie vom Lejstungsstaat gehandelt haben. Statt dessen erklang ein neues Zauberwort, das vor allem Herr Hufen und Herr Hill betont haben, das der Selbstregulierung. Selbstregulierung im Zusammenhang des Leistungsstaats zu fordern, ihn also nicht aufzugeben, heißt, daß der Staat mit dazu beitragen muß, daß Selbstregulierung im Leistungsstaat funktionsfähig wird. Es sollen nicht die sozial- und rechtsstaatlichen Ziele und demokratischen Vorgaben aufgegeben werden; es soll nur ein modifizierter Weg der Zielerreichung eingeschlagen werden. Gefordert ist insofern eine staatliche Politik der Selbstregulierung. Notwendig ist weiterhin eine staatliche Verantwortungsübernahme, die vor allem auf ein Problem reagieren muß, das mit gesellschaftlicher Selbstregulierung verbunden ist, nämlich das Problem von Macht und Machtasymmetrien. Die Aufgabe des modernen Leistungsstaats dürfte insofern darauf zielen, im Rahmen selbstregulativer Systeme das Machtproblem zu bewältigen. Der Markt versagt in vielem als Steuerungsmechanismus vor dem Machtproblem. Gefordert ist ein Wächter über Machtgebrauch und -mißbrauch. Dies kann letztlich nur der Staat sein. Daher wird eine staatliche Rahmensetzung für selbstregulative Prozesse benötigt. Erforderlich ist eine Steuerung von Selbstregulierung. Soll Selbstregulierung zur Staatsentlastung führen, so setzt deren Erfolg - wie Offe formuliert hat - eine staatliche Politik dieser Staatsentlastung voraus.

Das Vertrauen auf regulierte Selbstregulierung wird dazu führen müssen, daß eine Reihe von Tendenzen der Entwicklung umgekehrt werden, die für die letzten Jahrzehnte prägend waren. So bedeutet Selbstregulierung eine Abkehr von Tendenzen der Zentralisierung. Wichtige Stichworte der Zukunft lauten: Dezentralisierung, Lokalisierung, die Hineingabe von Verantwortung in kleinere Einheiten. Dies erfordert auch ein großes Maß an Toleranz, etwa Toleranz für Wertvorstellungen und für Wertewelten, die sich in diesen kleinen Einheiten bilden und die nicht unbedingt den Konsens der Mehrheiten finden. 
In diesem Sinne ist also eine machtarme und von Toleranz begleitete Selbstregulierung gefordert. Dies zu ermöglichen, bedeutet eine schwierige Aufgabe nicht nur für die staatliche Politik. Sie wird von der Gesetzgebung und Gesetzesanwendung und damit auch von der Rechtswissenschaft schwieriger zu bewältigen sein als der Umgang mit der bisherigen imperativen Steuerung und die bloße Verteilung von Überschußleistungen. Gerade weil Knappheitsprobleme zu bewältigen sind, muß die zukünftige Politik erheblich voraussetzungsvoller konzipiert werden als die bisher praktizierte. Was not tut, ist die Entwicklung einer politischen Programmatik und einer rechtswissenschaftlichen Dogmatik des selbstregulativen Sozialstaats, der zugleich ausgleichender Sozialstaat ist.

Vorsitzender: Vielen Dank, Herr Hoffmann-Riem, auch besonders dafür, daß Sie sich so präzise ausgedrückt haben, daß Sie die 5 Minuten unterschritten haben.

Herr Wenger ist der nächste, und zwar Herr Wenger als normaler Diskussionsteilnehmer, nicht als österreichischer Korreferent, also auch auf 5 Minuten beschränkt. So ist es verabredet.

Wenger: Wenn ich Herrn Mußgnug richtig verstanden habe, so sind die vom aktuellen Leistungsrecht erfaßten Leistungen an den Bürger vor allem durch zwei Merkmale gekennzeichnet, die in einem gewissen antagonistischen Verhältnis zueinander stehen. Einerseits räumt die Verfassung dem Gesetzgeber eine weitgehende Gestaltungsfreiheit ein und stellt ihm grundsätzlich mehrere Gestaltungs- und Handlungsformen zur Verfügung, andererseits zieht die Finanzabhängigkeit der Leistungen ihrer Gewährung in der sozialen Wirklichkeit faktisch Grenzen. Das gilt nach den Darlegungen von Herrn Mußgnug sowohl für Leistungen der öffentlichen Daseinsvorsorge als auch für Sozialleistungen und Subventionen, nicht dagegen für sogenannte ,erdiente " Leistungen wie Beamtenbesoldung, Abgeordnetenentschädigung u.ä. und für Entschädigungsleistungen, weil diesen die freie Gestaltbarkeit abgeht. Dieser Ausklammerung kann man durchaus zustimmen, wenngleich, wie die Beamtenbesoldungsrunden immer wieder zeigen, auch hier die faktischen Finanzierungsmöglichkeiten in den konkreten Anwendungsfällen das eigentlich Ausschlaggebende zu sein pflegen. Ich frage mich aber, ob die Situation bei den Sozialleistungen, insbesondere bei den Pensionsleistungen nicht mit dem Beamtenbesoldungsrecht aus der Sicht der Leistungsempfänger mehr Gemeinsamkeiten aufweist als mit dem Subventionsrecht. Bei der gesetzlichen Regelung der Pensionsleistungen werden Rechtsansprüche geschaffen, die im Einzelfall mittels der Sozialgerichtsbarkeit durchsetzbar sind. Wenn nun die Po- 
litiker der sechziger Jahre, offenbar in der optimistischen Erwartung, reale Wachstumsraten von 3 bis 6 Prozent des Sozialprodukts pro Jahr wären für die kommenden Jahrzehnte ein Dauerzustand, eine jährliche Anpassung der Pensionsleistungen durch die Verwaltung als sogenannte "Rentendynamisierung " vorgesehen haben, so ist die damit ausgelöste Tendenz zur stetigen Erhöhung der Pensionsleistungen realpolitisch auch in Jahren konjunktureller Rezession nicht mehr in einem dem Finanzierungsspielraum entsprechenden Ausmaß umkehrbar. Anders ausgedrückt, die Gestaltungsfreiheit des Gesetzgebers ist ähnlich eingeschränkt wie für die Regelung der Beamtenbesoldung. Als zusätzliche Finanzierungsquelle muß dann eben der Staatshaushalt herhalten, der die zwar als Institution der sozialen Selbstverwaltung eingerichtete, aber mit staatlicher Ausfallshaftung ausgestattete Pensionsversicherungsanstalt heute in die Lage versetzt, die staatlich festgesetzten Pensionsleistungen tatsächlich auszuzahlen. Dazu kommt als weitere Ähnlichkeit der Pensionsleistungen mit den Beamtenbezügen, daß in beiden Fällen der Leistungsempfänger rechtlich frei darüber entscheiden kann, wofür er die ihm zugekommenen Geldbeträge verwendet, ob er damit seine laufenden Lebenshaltungskosten bestreitet, ob er Teile davon spart, verschenkt oder im Extremfall sogar im Casino verspielt. Diesbezügliche Verwendungsbeschränkungen seitens des Gesetzgebers wären, auch wenn sie noch so gut gemeint wären, wohl als Einschränkung der Konsumfreiheit als essentiellem Element der Wirtschaftsfreiheit wirtschaftsverfassungsrechtlich unzulässig.

Ganz anders ist dagegen der rechtliche Gestaltungsspielraum bei der Regelung der Subventionsleistungen. Schon rein budgetrechtlich wird der Unterschied dadurch deutlich, daß Staatszuschüsse an die Pensionsversicherung als gesetzliche Verpflichtung, Förderungsausgaben aber als Ermessensausgaben zu veranschlagen sind. Nach dem neuen österreichischen Bundeshaushaltsgesetz ( $\$ 20$ Abs. 5) dürfen Förderungsausgaben im Bundeshaushalt nur vorgesehen werden, wenn der Förderungsempfänger mit Hilfe der Förderung eine Leistung zu erbringen beabsichtigt, an der ein erhebliches vom Bund wahrzunehmendes öffentliches Interesse besteht. Die in Österreich grundsätzlich privatrechtlich gestalteten Subventionsverträge sind nach den Verfassungsgrundsätzen der Wirtschaftlichkeit und Zweckmäßigkeit staatlicher Gebarung grundsätzlich als entgeltliche Verträge zu gestalten, die für den Fall der Nichterbringung der Gegenleistung des Subventionsempfängers die Rückzahlung der Subventionsleistung vorzusehen haben. Hier verstößt die Verwendungsbeschränkung in keiner Weise gegen die grundrechtlich geschützte Privatautonomie des Subventionsempfängers. Im Gegenteil, sie ist systemimmanente Konsequenz aus den verfassungsgesetzlich festgelegten Gebarungsgrundsätzen mit öffentlichen Vermögen einerseits und aus einem richtigen Verständnis 
des Gleichheitssatzes für das Handeln der Staatsorgane in der Leistungsverwaltung andererseits.

Vorsitzender: Vielen Dank, Herr Wenger. Der nächste ist Herr von Mutius.

von Mutius: Erlauben sie mir zunächst eine scherzhafte Vorbemerkung: Die Diktion einiger Ausführungen von Herrn Mußgnug zur BAFöG-Praxis veranlaßt mich dazu, ihm die Zusendung der letzten im Auftrage des BMBW erstellten Sozialerhebung des Deutschen Studentenwerkes anzubieten. Ich möchte gerne mit ihm zusammen diese Sozialerhebung daraufhin durchsehen, ob wir wirklich hier den BAFöGDarlehens-Empfänger finden, der mit seinem Porsche aus dem sog. Mittelstandsloch herausfährt. Wenn es ihn oder andere seiner Art erkennbar gibt, bin ich gern bereit, mein Vorverständnis zur Praxis der derzeitigen Ausbildungsförderung zu korrigieren. Aber nun ernsthaft zu drei Aspekten der Referate:

1. Wie bereits soeben Herr Wenger vorgetragen hat, habe auch ich mich gefragt, ob es wirklich notwendig bzw. sachgerecht war, die ,erdienten " Leistungen aus der kritischen Würdigung des geltenden Leistungsrechts auszuklammern (These $2 \mathrm{im}$ Referat Mußgnug). Geht man davon aus, daß Leistungen Geld- bzw. vermögenswerte Zuwendungen darstellen, so kann es im Grunde genommen nicht darauf ankommen, ob etwaige Leistungsansprüche durch Freiheitsbetätigung (Arbeit usw.) oder Kapitaleinsatz erworben worden sind. Gerade die von Herrn Mußgnug beschriebenen Begrenzungen des Leistungsrechts durch die Finanzverfassung und ein etwaiges Ubermaßverbot sowie die Parallelen zu Leistungen der Sozialversicherung, insbesondere der Rentenversicherung, sprechen dafür, „erdiente" Leistungen nicht von vornherein auszuklammern. Denn es ist gerade die Frage, ob die ,freie Gestaltbarkeit " für das Leistungsrecht wirklich durchgängig typisch ist.

2. Im Gegensatz zu den Referaten von Hufen und Hill beruhen die von Herrn Mußgnug vorgetragenen Gedanken auf einer nahezu strikten Trennung von Leistungs- und Eingriffsrecht. Ich habe erhebliche Bedenken, ob sich diese Trennung wirklich rechtsdogmatisch durchhalten läßt. Wie bereits Herr Ipsen zutreffend betont hat, haben Leistungsgewährung und Leistungsverweigerung in der heutigen Verwaltung des Mangels und der Verteilung knapper Ressourcen unter konkurrierenden Interessenten vielfältige Grundrechtsrelevanz (ich erinnere nur an die Teilhabe- und Verfahrensdimensionen des Grundrechtsschutzes und an das Verständnis der Grundrechte als Ausübungsvoraussetzungen), Gleichheitsbezug sowie föderative Relevanz. Hieraus ergeben sich eine Reihe von Konsequenzen, die ich anders als im Referat von Mußgnug dargestellt sehe: 
a) Zunächst hat dies Konsequenzen für den Vorbehalt des parlamentarischen Gesetzes, welches selbst Intensität und Voraussetzungen der Grundrechtsrelevanz hinreichend bestimmt normieren muß. Eine Steuerung des staatlichen Leistungsrechts mittels Haushaltsgesetz und Haushaltsplan (These 7 von Herrn Mußgnug) reicht meines Erachtens nicht aus. Wie bereits in der Kölner Tagung erörtert, kann durch Haushaltsrecht nur eine quantitative und möglicherweise funktionale Begrenzung finanzieller Leistungen erreicht werden, nicht jedoch eine qualitative, strukturelle und modale Steuerung sowie eine sachgerechte Verteilung der Finanzmittel.

b) Das Leistungsrecht nur via Haushaltsgesetz und Haushaltsplan steuern zu wollen, blendet die Außenrechtsbeziehungen zum Bürger, die sonstigen Drittwirkungen, die Vernetzungen der Leistungssysteme weitgehend aus. Eine Folge dieses Ansatzes findet sich in der These 14 von Herrn Mußgnug (mangelnde gerichtliche Kontrolle im Leistungsrecht); aber auch die negativen Wirkungen der Haushaltsstrukturgesetzgebung sprechen eher für als gegen die Notwendigkeit eines materiellen Gesetzes.

c) Die Steuerung des Leistungsrechts überwiegend durch Haushaltsgesetz und Haushaltsplan verschiebt im übrigen die politische und administrative Entscheidungsverantwortung in der Gesetzesgestaltung und -anwendung. Ich verweise nur auf die im Gegensatz zur materiellen Leistungsgesetzgebung abweichenden Zuständigkeiten der Ministerialbürokratie, der Parlamentsausschüsse und der Kontrollinstitutionen.

3. Der möglicherweise unauflösbare Konflikt zwischen notwendiger parlamentarisch-gesetzlicher Bestimmtheit auf der Rechtsgeltungsebene und erwünschter Flexibilität bzw. Einzelfallgerechtigkeit für die Rechtsanwendungsebene haben die Referenten, insbesondere die Herren Hufen und Hill, mit gleicher Tendenz, aber etwas unterschiedlichen Instrumenten aufzulösen versucht. Ich stimme vielen der gemachten Vorschläge nachdrücklich $\mathrm{zu}$, etwa der Notwendigkeit von allgemeinen oder Stammgesetzen mit „Anpassungsfenstern" (These 8 bei Hufen), der stärkeren Betonung von Organisation und Verfahren in der Gesetzesgestaltung sowie der stärkeren dogmatischen Differenzierung zwischen Tatbestand und Rechtsfolge etwa durch Aufnahme von Wertrelationen (These 7 bei Hill). Ob man hierfür allerdings den Ausdruck ,bewegliches System“ verwenden sollte, erscheint mir fraglich; hier bedarf es, um überhaupt von Dogmatik und System sprechen zu können, noch einer intensiven methodologischen Verfeinerung. Aber die Referate von Hufen und Hill werfen auch zahlreiche offene Fragen auf, von denen ich nur einige andeuten kann:

a) Ist es etwa wirklich richtig, für Stammgesetze qualifizierte Mehrheiten zu verlangen mit der Folge eines generellen Vorrangs vor besonderen oder fachspezifischen Gesetzen (These 7 bei Hufen)? Meines Er- 
achtens ist dies im Hinblick auf die Rechtsquellenlehre bedenklich und im Hinblick auf den Grundsatz der Systemgerechtigkeit aus Art. 3 Abs. 1 GG überflüssig.

b) Ist die Schaffung von Gesetzgebungskommissionen (These 6 bei Hufen) wirklich erforderlich, bedenkt man die Schwierigkeit einer gewiß notwendigen Legitimation, einer politisch-parlamentarischen Einbindung sowie einer Verzahnung mit den verfassungsrechtlich vorgesehenen Institutionen des inneren und äußeren Gese tzgebungsverfahrens?

c) Müssen nicht die begrüßenswerten Verfahren der Selbstregulierung (These 10 bei Hufen) weiter ausdifferenziert werden in Selbstverwaltungs- und Selbstregulierungsinstitutionen? Und warum bedürfen diese der notwendigerweise öffentlich-rechtlichen Absicherung? Kann dies nicht auch durch verfassungsrechtlich durchdrungenes Zivilrecht geschehen bzw. sind hier nicht die überkommenen Grenzen zwischen öffentlichem Recht und Zivilrecht längst verwischt?

d) Und schließlich: Was heißt es eigentlich, wenn man den Gesetzgeber für verfassungsrechtlich verpflichtet hält, im Leistungsrecht eine Vorabkontrolle und Erfolgsvorsorge vorzunehmen (These 9 bei Hill)? Geht es hier wirklich um Verfassungsgebote mit der Folge, daß bei ih rer Verletzung das Gesetz nichtig ist oder nicht nur um Optimierungsvorstellungen der Gesetzgebungslehre? Meines Erachtens ist letzteres der Fall, weil das politisch-parlamentarische Mandat, um es einfach zu sagen, die Befugnis einschließt, auch miserable Gesetze zu verabschieden, für die in dem geltenden parlamentarischen Regierungssystem unterhalb der Schwelle der Verfassungswidrigkeit nur politische Kontrollen etwa durch Wahlen eröffnet sind. Insoweit habe ich viele Sympathien für die These 11 von Herrn Mußgnug, daß ,in der Demokratie das Gesetz das Maß der Dinge setzt" - natürlich dies nur innerhalb der verfassungsmäßigen Ordnung.

Vorsitzender: Vielen Dank, Herr von Mutius. Sie haben bezüglich des ersten Punktes, den Sie angesprochen haben, gewissermaßen als ein Repräsentant der Exekutive gesprochen, nämlich als Präsident des Deutschen Studentenwerks. Herr Oppermann, bitte!

Oppermann: Den verschiedenen Dankesworten an die Referenten des heutigen Tages vermag ich mich ohne weiteres anzuschließen. Ich könnte sehr viel Zustimmung zu den Referaten zum Ausdruck bringen, tue das aus Gründen der Diskussionsökonomie und der Kurzweil nicht, sondern beschränke mich auf zwei oder drei Bemerkungen, wo ich etwas divergiere.

Herr Mußgnug, ich möchte den demokratischen Bürger doch etwas vor Ihren Thesen 14 in Schutz nehmen, nämlich daß von einer Reduktion der Staatsleistungen über das Maß des aus finanzwirtschaftlichen 
Gründen Unvermeidbaren abzuraten ist, und zwar im Grunde - so habe ich Sie jedenfalls verstanden -, weil sonst Gefahren für das parlamentarische System bestehen würden. Dem vermag ich nicht zu folgen. Ich meine, der demokratische Bürger ist - das hat sich immer wieder gezeigt - durchaus zu Opfern bereit. Er ist klüger, als die Politiker glauben. Wenn man etwa an Situationen denkt wie im letzten Jahrzehnt in England oder auch an den Regierungswechsel bei uns 1982/83, der ja im wesentlichen aus wirtschaftlich-finanziellen Gründen erfolgte: die - relativ schüchternen - Leistungskürzungen bei BAFöG oder die Liberalisierung des Mietrechts damals haben keineswegs den Bürger veranlaßt, denjenigen, die diese Opfer von ihnen forderten, aus Gründen des parlamentarischen Systems ihre Zustimmung zu versagen. Hier wäre ich also etwas optimistischer dazu, was der demokratische Bürger in bestimmten Situationen bereit ist, als notwendige Opfer anzuerkennen. Natürlich muß ihm in solchen Situationen ein schlüssiges Konzept geboten werden. Das gehört dazu.

Insofern unterstütze ich sehr Ihre Worte zugunsten der Selbstregulierung, Herr Hufen. Herr Hoffmann-Riem hat das ja auch schon angesprochen. Ich bitte aber insoweit von Ihnen, Herr Hufen, noch etwas um weitere Aufklärung. Sie sagen Ja zur Selbstregulierung im Sinne eines Vorranges der individuellen Vorsorge vor der staatlichen Sicherung. Ich sehe den Gedanken der Selbstregulierung noch stärker in der Nähe der Deregulierung, des Abbaues überflüssiger staatlicher Regelungen. Und, Herr Hoffmann-Riem, der Ruf nach mehr Markt hier und dort, er mag sicherlich auch schon vor zehn oder zwanzig Jahren erklungen sein. Aber was damals gesagt worden ist, muß nicht unbedingt, nur weil es bereits vor zehn Jahren war, falsch sein. In einem Augenblick, in dem selbst in der Sowjetunion Gorbatschows der Markt allmählich entdeckt wird, sollten wir das Marktdenken, zu dem die Selbstregulierung und Deregulierung gehören, in einem Lande erneut groß schreiben, das seit Jahrzehnten sehr starke ordnungspolitische Vorstellungen zugunsten einer sozialen Marktwirtschaft entwikkelt hat.

Herr Mußgnug, Ihre These 11 ist mir nicht ganz geheuer. Wenn Sie hier sagen, „Leistungen, die das Parlament im Verfahren der Gesetzgebung und der Haushaltsfeststellung ausdrücklich gebilligt hat, können nicht als übermäßig und damit verfassungswidrig abqualifiziert werden. Sie waren das rechte Maß, weil in der Demokratie das Gesetz das $\mathrm{MaB}$ der Dinge ist". Klingt wunderbar. Herr von Mutius hat es eben auch positiv gewürdigt. Aber ich weiß doch nicht, ob man das immer so sagen kann. In praxi ist es natürlich in vielen Fällen so. Aber der letzte Satz, diese Glorifizierung von allem und jedem, was der Gesetz. geber tut - wenn ich das vor dem Hintergrund des hessischen Diätengesetzes und der Steuerbefreiung fur Privatfliegerbenzin sehe - dann 
weiß ich nicht, ob der Satz in dieser Allgemeinheit verfassungspolitisch stehenbleiben kann.

Herr Hufen, meine letzte Bemerkung zur Wesentlichkeitstheorie. Da möchte ich doch eine kleine Verteidigung gegenüber Ihrem kritischen Ansatz unternehmen. Ist es nicht etwas gefährlich zu sagen ich übersetze einmal Ihre Bemerkung in etwas andere Worte, aber ich glaube, das ist der Sinn -, wesentlich ist, was der Gesetzgeber als wesentlich einstuft? Der Sinn der Wesentlichkeitstheorie ist eine langsame, nie zu Ende gehende Ewigkeitsaufgabe ähnlich wie beim Gleichheitssatz, bei der neben dem Gesetzgeber die Rechtsprechung ein gewichtiges Wort mitzureden hat. Die Bedeutung der Wesentlichkeitstheorie liegt darin, daß man glaubt, es gibt bestimmte Dinge, die vor das Parlament gehören, und es gibt andere, weniger wichtige Dinge, die in die Rechtsverordnung gehören. Sie haben übrigens interessanterweise in Ihrem Stufenbau - ich hätte beinahe gesagt: „Hufenbau“ das unternommen, mit dem "Stammgesetz" und dem „einfacheren“ Gesetz usw., was ungefähr in diese Richtung geht und auf Grundgedanken beruht, die eigentlich das Fundament der Wesentlichkeitstheorie darstellen.

Vorsitzender: Vielen Dank, Herr Oppermann. Ich darf die folgenden Diskussionredner bitten, im Sinne der Selbstregulierung, für die Herr Oppermann sich eingesetzt hat, möglichst die 5-Minuten-Grenze nicht zu überschreiten. Nach Hern Schmidt-Aßmann, der jetzt dran ist, sprechen Herr Suhr und dann Herr Püttner.

Schmidt-ABmann: Wir müssen uns immer wieder vergegenwärtigen, welchen Beitrag wir mit den Vorträgen und Diskussionen unserer Vereinigung zur Standortbestimmung und Entwicklung der Grundlinien des Staats- und Verwaltungsrechts, zu den allgemeinen Teilen dieser Disziplinen leisten. Hier scheint mir die Leistungsverwaltung, als heuristischer, nicht als ein dogmatischer Begriff verstanden, ein glücklicher Beschäftigungsgegenstand; denn er führt, wie insbesondere die intensiven Analysen von Herrn Hill deutlich gemacht haben, hin auf zahlreiche Probleme moderner Verwaltung allgemein. In den Anforderungen, die dieser große Bereich des Verwaltens an das verwaltungsrechtliche Denken stellt, werden Grundanforderungen an die verwaltungsrechtliche Systematik deutlich. Ich nenne drei Punkte: Da ist zum einen ein Bedürfnis nach einer besonderen Nüchternheit im Umgang mit überkommenen Dogmen und manchen Uberzogenheiten, die sich in sie eingeschlichen haben. In diesem Sinne hat Herr Mußgnug klar und wohl auch überzeugend am Beispiel der Leistungsverwaltung dargetan, daß das administrative Ermessen in seine legitime Position wieder eingesetzt werden muß, was dann auch Konsequenzen für eine zuweilen 
übertrieben intensive gerichtliche Ermessenskontrolle haben muß. Nützlich erscheint mir auch die vom Erstberichterstatter betonte stärker budgetäre Ausrichtung der Verteilungsprobleme in der Leistungsverwaltung. Eine solche Sicht entlastet die seit Jahrzehnten geführte Diskussion um den Gesetzesvorbehalt in der Leistungsverwaltung, zumal im Subventionswesen, die oft zu stark im Bann der traditionellen Eingriffsdogmatik gestanden hat. - Ein zweiter Punkt betrifft die Rückorientierung am Allgemeinen. Hier hat Herr Hufen Wichtiges gesagt. Nicht zufällig ist dabei die Bedeutung einer Grundlagengesetzgebung herausgehoben worden. Das ist ein Institut, das in der Tat die Denkkategorie des Allgemeinen herau sstellt. Sie ist für die verwaltungsrechtliche Systembildung unverzichtbar. Die Kodifikationskritik, die die Zivilistik am Bürgerlichen Gesetzbuch übt, ist nicht unser Thema. Im derzeitigen Entwicklungsstand des Verwaltungsrechts brauchen wir das Allgemeine in einem ganz elementaren Sinne als Garanten von Uberschaubarkeit. Zu Recht sind die Begriffe Transparenz, Akzeptanz und Legitimation von den Referenten in einen Zusammenhang gestellt worden. Mit diesem Ziel unterstütze ich nachhaltig auch die Forderung von Herrn Hufen, Verfahren zu vereinheitlichen und Desiderate des Verfahrensrechts, z.B. das Normsetzungsverfahren, einer systematischen gesetzgeberischen Bewältigung zuzuführen. - Ein dritter Punkt, den ich hervorheben will, betrifft die in der Diskussion auch von Herrn Hoffmann-Riem schon genannte Selbstregulierung. Wir müssen im Verwaltungsrecht neben den Instrumenten hoheitlicher Regelung einen zweiten Systemteil ausbilden, in dem administrative Handlungsformen sichtbar werden, die mehr Rat, Organisationshilfe, Rahmengewährleistung für private Aktivitäten als regelnde Ordnung, Verteilung und Planung sind. Neben die verteilende muß im verwaltungsrechtlichen Denken die vermittelnde Verwaltung - wiederum zunächst als heuristischer Begriff - treten!

Vorsitzender: Vielen Dank, Herr Schmidt-Aßmann. Sie haben die Zeit genau eingehalten. Herr Suhr bitte.

Suhr: Ich teile die Sympathie von Herrn Hufen und von Herrn Hoffmann-Riem hinsichtlich der neuen Selbstregulierungen und die von Herrn Oppermann hinsichtlich der alten Selbstregulierungen, zu denen man vielleicht durch Deregulierungen eines Tages wieder zurückkommen kann. In diesem Zusammenhang möchte ich bewußt machen: Die Prinzipien der Gleichheit und Gerechtigkeit in der Welt der Selbstregulierung sind die Prinzipien der justitia commutativa, auf die ich gestern hinzuweisen versuchte. Und wenn diese Prinzipien in der primären Welt der Selbstorganisation, mit der wir es in der Wirtschaft zu tun ha- 
ben, nicht stimmen, darf man sich nicht wundern, daß man sich selber Asymmetrien einhandelt, auf die dann mit sekundären Mechanismen des sozialen Leistungsstaates ,reaktiv“ im Sinne Forsthoffs geantwortet werden muß. Wir produzieren vielleicht also mit einer vom Gesetz. geber und von den Staatsrechtslehrern nicht durchschauten Asymmetrie in den primären Selbstregulierungen jene Ungleichheit, die wir dann mit den Mitteln des sozialen Leistungsstaates am Symptom korrigieren. Wenn wir jetzt also wieder mehr Sinn entfalten für Selbstregulierungen, dann sollten wir uns die kritische Frage nach den etwaigen Defekten der primären Selbstregulierungsordnung nicht abschneiden. Das ist der eine Gesichtspunkt. Man kann das so formulieren: Was wir durch Gesetzgebung mit primärer justitia commutativa erledigen, das brauchen wir nicht hinterher mit großem Aufwand an Normen, Leistungen und Freiheitsbeschränkungen mit den Mitteln der leistungsstaatlichen justitia distributiva nachbessern.

Ein zweiter Gesichtspunkt, der in diesen Zusammenhang gehört und ebenfalls zurückverweist auf gestern, wird angezeigt durch das Stichwort der ,Transferwelt", das Herr Hufen hier eingebracht hat:

Man kann hinter den finanzverfassungsrechtlichen Gesichtspunkten, hinter den Sonderabgaben und hinter den Einwirkungen des einen Bürgers auf den anderen ein allgemeines ungeschriebenes oder Hintergrundraster zeichnen, das man als „Transferverfassungsrecht" bezeichnen kann. Wir haben eine ganze Menge von Transfers, und wenn man jetzt einmal die Sonderabgaben als pekuniäre Transfers von einer Gruppe zu einer anderen betrachtet und wenn man hinzunimmt die nichtpekuniären Transfers (wie Naturalleistungen, die irgendwo erbracht werden, oder Naturalnachteile, die auferlegt werden), dann stellt sich die gestrige Frage der Gleichheit, die heute auch ständig präsent ist, ganz anders. Denn wenn man die Lasten als Transfers ansieht, dann ist etwa die Belastung der einen Gruppe, um einer anderen Gruppe eine Vergünstigung zukommen zu lassen, ein kombinierter staatlicher Akt: ein Eingriff bei der belasteten Gruppe und eine Subvention oder Begünstigung bei der begünstigten Gruppe. Wir haben also Eingriffsproblematik plus eine Subventionierungsproblematik, und beides zusammen ergibt eine Asymmetrie, nämlich der eine wird belastet und der andere begünstigt, und das ergibt die Gleichheitsproblematik. Und das ist das Phänomen, das wir eigentlich packen müssen, wenn wir Gleichheit in diesem Bereich behandeln wollen, und dafür brauchen wir eine Art Verbundmaßstab. Man kommt da nicht heran mit dem Willkürverbot, auch nicht mit bloßen Gerechtigkeitsvorstellungen, sondern wir müssen fragen: Was rechtfertigt den Eingriff bei den einen? Was rechtfertigt die Subvention bei den anderen? Und was legitimiert die Ungleichbehandlung beider? Danke sehr! 
Püttner: Die Referate haben im Grunde nur zum Teil Leistungsrecht betroffen. Im wesentlichen habe ich Gesetzgebungslehre gehört. Vielleicht ist das kein Zufall, vielleicht ist das, was wir als Leistungsrecht bezeichnen, dadurch gekennzeichnet, daß es erst geformt werden muß durch den Gesetzgeber und daß wir deshalb in erster Linie nachdenken, welche Regeln denn der Gesetzgeber zu beachten hat, wenn er Leistungsrecht formt. Die zweite Frage, wie dieses Recht richtig angewendet werden soll, bleibt zunächst noch relativ offen. Auf der anderen Seite habe ich mich gefragt, ob die Regeln, die insbesondere Herr Hufen und Herr Hill vorgetragen haben, nicht ebensogut auf das Eingriffsrecht und die Eingriffsverwaltung passen würden. Es wäre einmal interessant, durchzuchecken, ob wir irgendeine dieser Regeln wegstreichen müssen, wir wir ein Eingriffsgesetz verfassen. Es ist sehr naheliegend, daß ich das hier bemerke, denn ich vermag überhaupt zwischen Eingriff und Leistung nicht zu unterscheiden. Die Subvention belegt es am deutlichsten; sie ist ja keine Wohltat für den Unternehmer, sie ist zweckgebunden. Hier in Württemberg hat es im vorigen Jahrhundert schon Subventionen gegeben, über die heftig Klage geführt wurde, weil den Leuten etwas aufgedrängt wurde, was sich ihnen nachher als konkursträchtiges Kuckucksei erwies (unrentable Maschinen); es ist verständlich, daß man diese Subventionen keineswegs als Wohltat empfunden hat. Bitte also noch einmal um klare Auskunft darüber; wenn Leistungsverwaltung als Verstreuen von Wohltaten verstanden wird, dann müßte man die Subventionen wohl weitgehend herauslassen.

Dann, Herr Hufen, zum Grundlagengesetz. Ich kann mich mit Ihrer Vorstellung nicht ganz anfreunden. Sie meinten doch wohl, daß eine neue Kategorie von Gesetzen geschaffen werden müsse (übrigens nicht eine ,neue“, dazu gleich), eine Kategorie von Gesetzen, die sich herausheben würde durch besondere Mehrheitsbildung, durch besonderen Rang und eine entsprechende Verstetigung. Wir haben so etwas ja in Form des organischen Gesetzes früher einmal gehabt, und ich bemerke, daß in Spanien noch heute diese Kategorie von Gesetzen existiert (ich weiß nicht, ob unsere spanischen Gäste noch im Raum sind und dazu etwas sagen können). Es wäre also zu testen, welche Erfahrungen damit gemacht worden sind.

Ich persönlich kann mich nicht ganz anfreunden mit dieser Zwischenstufe zwischen einfachen Gesetzen und Verfassung. Wenn Sie einmal den Komplex Rahmengesetz und Gesetze der Länder überdenken, wie sie ineinandergreifen, welche Schwierigkeiten es gibt, dann ist das eben nicht gerade ermutigend. Und ich glaube, die Österreicher könnten aus ihrer Grundlagengesetzgebung plus Ausführungsgesetzgebung in den Ländern einiges an Schwierigkeiten anführen. Immerhin, ich will nicht verhehlen, daß wir möglicherweise durch Einführung sol- 
cher Kategorien die Zahl der Medienrechtler wieder herabsetzen und die Zahl der Gutachter auf diesem Gebiet erhöhen könnten. Ich sehe in der Tendenz, die sich damit andeutet, Grundlagengesetzgebung im Zusammenhang mit dem Stichwort, das sowohl Herr Hufen als auch Herr Hill gebraucht haben, nämlich Verstetigung, die Tendenz, zu einer anderen Staatsform überzugehen, in der die Stetigkeit grundlegender Gesetze höher angesetzt wird als es wechselnde parlamentarische Mehrheiten eigentlich ermöglichen. Der alte Traum des wahren Staatsrechtlers von der Monarchie schien mir hier wieder durchzubrechen. Und so glaube ich, daß Ihnen Paul Laband voll zustimmen würde zu Ihren Referaten.

$\mathrm{Zu}$ Herrn Mußgnug noch eine kurze Bemerkung: Ein Ubermaßverbot für Leistungsgesetze kann es sicherlich nicht geben, schon gar nicht aus Art. $115 \mathrm{GG}$, der allerdings - und da bewundere ich Ihren Optimismus hinsichtlich dieses Artikels - nicht so sicher greift, wie Sie angedeutet und geschildert haben. Der Begriff "Investitionen“, der in diesem Artikel auftaucht (übrigens ein Fremdwort, das wir früher in der Gesetzessprache nicht zu benutzen pflegten) ist außerordentlich unklar. Studenten mache ich es immer verständlich, indem ich sage: Der Kauf eines Buches von mir ist eine Investition, der Kauf eines Buchs von Kollegen eine Konsumausgabe! So kann man beides gut unterscheiden. Ich will damit nur andeuten, daß Art. 115 GG keine Bremse darstellt, so daß Ihre Überlegungen durch den Art. 115 GG jedenfalls nur wenig abgestützt werden.

Vorsitzender: Vielen Dank, Herr Püttner. Herr Quaritsch hat gebeten, zu einer kurzen Intervention Gelegenheit zu bekommen, die nur drei Sätze umfaßt. Bitte schön.

Quaritsch: Einige Kollegen haben gegen die These II 7 von Herrn Hufen die "traditionelle" Gesetzgebungslehre ins Feld geführt. Die Frage, ob der parlamentarische Gesetzgeber sich durch ein „Grundlagen-“ oder „Stammgesetz“ selbst binden könne, ist m.W. zuerst 1961 in Hamburg mit dem von Herrn Hufen vorgetragenen Ergebnis erörtert worden. Im Anschluß daran vertrat Herr Hans Julius Wolff diese These seit der 5. Auflage 1963 seines Lehrbuchs (Verwaltungsrecht I, § 26 III), Herr Bachof hat in der 9. Auflage 1974 die Autoren genannt, die sich ihr angeschlossen haben. Die Vorstellung, ein "Grundlagengesetz" könne durch seinen Inhalt einen höheren Rang gegenüber „Ausführungsgesetzen" haben, ist in der deutschen Rechtsquellenlehre also nicht so ganz neu oder ungewöhnlich.

Vorsitzender: Vielen Dank. Herr Bachof, Sie müßten bitte zum Mikrofon gehen, sonst wird das nicht aufgenommen, was Sie sagen. Aber nur einen Satz jetzt. 
Bachof: Eine Ergänzung dazu: Der Baden-Württembergische Staatsgerichtshof hat unter dem Gesichtspunkt der ,Systemgerechtigkeit“ festgestellt, ein Einzelfallgesetz, das dem systembestimmenden ,Allgemeinen Gemeindereformgesetz" widerspreche, sei wegen dieser Systemwidrigkeit gleichheitswidrig, also verfassungswidrig und deshalb nichtig (Urteil vom 1.4.1976, GR 68/74).

Vorsitzender: Vielen Dank. Herr Soell, ich sehe ein gewisses Pro. blem, Sie haben in Ihrem Meldungszettel vier Unterthemen angegeben und wollen zu allen drei Themenkreisen sprechen.

Soell: Will ich nicht mehr. Das hat sich erledigt. Ich will nicht wiederholen, was Vorredner schon gesagt haben.

Vorsitzender: Sehr schön. Ich darf Sie bitten, sich auf fünf Minuten zu beschränken.

Soell: Ich will auch jetzt im Grunde nur zu Thema 1 etwas sagen, und zu Thema 3, den Reformvorschlägen, nur eine Frage an Herrn Hufen dann am Schluß anknüpfen.

Es ist wiederholt gesagt worden, daß beide Themenkreise innerlich zusammenhängen, und dies hat sich auch heute gezeigt, denn die $\mathrm{Zu}$ kunftsfragen, die man gestern vielleicht vermißt hat bei der Behandlung des Gleichheitssatzes, sind nun heute in voller Stärke aufgetreten. Es sind zwei, meines Erachtens, die man unter leistungsstaatlichen Gesichtspunkten einmal näher prüfen sollte. Die 1. Frage ist das Schicksal der Rentenreform. Herr Hufen, Sie haben das unter anderem angesprochen. Herr Mußgnug hat mit Recht in den Mittelpunkt seiner Uberlegungen die Frage der Finanzierbarkeit gestellt, hat aber in These 1 zugleich auch dem Gesetzgeber eine sehr weitgehende Gestaltungsfreiheit zugebilligt. Herr Mußgnug, sicherlich stimmen Sie damit überein, daß man natürlich auch fragen muß, wie weit diese Gestaltungsfreiheit nicht doch durch verfassungsrechtliche Vorgaben eingeschränkt ist. Ich meine beispielsweise - auch das ist eine leistungsstaatliche Frage -, man muß überlegen, ob der Staat seine Förderpflicht in bezug auf die Familienförderung schon richtig und in dem notwendigen Sinne erfüllt hat. Das hängt mit der weiteren Frage zusammen, darf der Gesetzgeber denn nun Leitbilder seiner Reform der Rentenversicherung zugrundelegen, die schlechterdings ihre reale Basis verloren haben. Ich denke an das Leitbild des Generationenvertrages. Der Generationenvertrag basiert auf demographischen Voraussetzungen, die heute schlechterdings nicht mehr vorhanden, ja geradezu umgekehrt sind. Nun mag man darüber streiten, ob der Generationenvertrag, und das 
ist ja auch in der sozialrechtlichen Literatur ein gewisser Streit, ob der Generationenvertrag ein juristischer Begriff ist. Er ist jedenfalls aber ein programmatischer Begriff und hat als solcher für die politische $\mathrm{Ge}$ staltung einer Rentenreform zweifelsfrei auch eine inhaltliche Bedeu. tung. Und wenn das nicht mehr stimmt, dann hört hier eben auch die Gestaltungsfreiheit des Gesetzgebers auf, selbst wenn der zuständige Bundesminister die Figur des Generationenvertrages in der gegenwärtigen Diskussion immer wieder beschwört.

Zweiter Punkt: Die Nachweltsorge, die Sorge für die zukünftigen Generationen, was die Erhaltung der biologischen Existenzgrundlagen anbelangt. Hier sind ebenfalls leistungsstaatliche Aspekte von zentraler Bedeutung. Hier geht es einmal schon - und da spreche ich Herrn Mußgnug noch einmal an - um die Frage der Finanzierbarkeit, nämlich die Frage der Prioritäten, und zwar beispielsweise bei der Forschungsförderung. Wir wissen, daß Umweltschutz ohne eine sehr gezielte Forschungspolitik im Grunde gar nicht sinnvoll betrieben werden kann. Muß der Staat nun nicht angesichts der wachsenden Bedrohung der natürlichen, der biologischen Existenzgrundlage ganz andere Prioritäten setzen als er das bisher getan hat, indem er beispielsweise die Umweltforschung in besonderer Weise fördert, und wenn Sie den Forschungskatalog des BMFT ansehen, gibt es zwar eine stattliche Anzahl von Projekten, also Umweltforschungsprojekten, aber - wenn man die Finanzvolumen miteinander vergleicht - ist doch der Anteil der Umweltforschung bisher relativ bescheiden.

Ein weiterer Punkt: Die Frage, ob nicht der Staat umweltschonende Produkte dadurch überhaupt einmal in den Markt einführt, daß er bei seiner Beschaffungspolitik diese umweltschonenden Produkte zunächst einmal besorgt, ankauft, um damit zu zeigen, wie vernünftig und wie funktionsfähig diese Produkte sind, selbst wenn das gegen einen zu eng verstandenen Grundsatz der Sparsamkeit und Wirtschaftlichkeit verstoßen sollte.

Ein letzter Punkt: Die Frage an Herrn Hufen. Herr Hufen, Stammgesetz und Ausführungsgesetz - ein interessanter Gedanke. Herr Quaritsch hat jetzt ein Hamburger Schmankerl gebracht, aber das ist ja eine Besonderheit, nicht wahr, daß Sie die Bebauungspläne durch Gesetz aufstellen lassen. Das Bundesverfassungsgericht hat gerade wegen der Besonderheit dieser gesetzlichen Regelung gesagt, hier muß der $\$ 47$ VwGO zunächst einmal beachtet werden, nämlich die Normenkontrolle, die sonst bei Bebauungsplänen möglich ist. Nur, ich frage mich, warum klammern Sie eigentlich die Verordnung aus? Warum lösen Sie das Problem nicht durch ein Gesetz, das ein klares Zweckprogramm hat, das die Anspruchsvoraussetzungen hinreichend bestimmt, und lassen dann die Einzelheiten durch den Verordnungsgeber regeln? Das entspricht doch unserer rechtsstaatlichen Formentypik so wie wir sie 
sonst auch kennen. Müssen wir da ein neues Instrument haben? Vielen Dank.

Vorsitzender: Vielen Dank, Herr Soell. Der nächste ist Herr Schuppert. Ich darf auch sie bitten, Herr Schuppert, Dinge, die schon angesprochen worden sind, zu verkürzen oder ganz wegzulassen.

Schuppert: Ich hatte mich gemeldet unter dem Stichwort „Grenzen des Leistungsstaates" und möchte zwei kleine Bemerkungen machen, und zwar zu den Begriffen Regelungsumfang und Regelungsdichte. Dazu haben Herr Hoffmann-Riem und Herr Schmidt-Aßmann schon etwas gesagt, so daß ich mich kurz fassen möchte. Ich unterstütze ebenfalls die Idee der Selbstregulierung, möchte aber im Anschluß an eine Bemerkung von Herrn von Mutius, ob man da nicht die Trennlinien zwischen öffentlichem Recht und Privatrecht aufgibt, dazu anregen, etwas schärfer zu differenzieren und unterhalb des Obertitels "Staatsentlastung“ - oder wie Offe das formuliert hat - der staatlichen Politik der Staatsentlastung -, drei Bereiche sauber auseinanderzuhalten: einmal den Bereich der klassischen Selbstverwaltung, die - Herr Schmidt-Aßmann hat das immer wieder betont - Verwaltung ist und bleibt, also öffentlich-rechtlich organisierte Ausübung staatlicher Verwaltung ist; dann der Bereich der Selbststeuerung als das, was nicht öffentlich-rechtlich verfaßt ist, wie z.B. die Selbststeuerung in der Wissenschaft durch die DFG, einen privatrechtlichen Verein, oder die Tätigkeit der Wohlfahrtsverbände; das dritte ist die eigentliche Selbsthilfe oder Selbstorganisation, die ja auch, weil sie gerade in dem Bereich der Sozialpolitik vorkommt, soziale Selbsthilfe und soziale Selbstorganisation genannt wird. Das scheint mir eigentlich das qualitativ Neue zu sein, weil es sich hierbei um Erscheinungsformen handelt, die von ihrem Selbstverständnis antietatistisch, antibürokratisch, antiprofessionell angelegt sind und damit sozusagen als Antipoden des Verwaltungssystems erscheinen könnten. Worauf es gerade ankommt, ist aber, sie in dieser Trias von Staatsentlastungsmodalitäten zu sehen, indem man - und da möchte ich anknüpfen an das, was Herr Schmidt-Aßmann gesagt hat - die Funktionsweise rechtlicher Regelungen hier etwas anders begreift als bisher, also nicht als regulative Politik, sondern - ich möchte mich diesem Stichwort anschließen als ,,vermittelnder Verwaltung".

Zweiter Gesichtspunkt: Grenzen der Rationalität der Gesetzgebung im Leistungsstaat. Ich möchte mich zu diesem Punkt hinbewegen, indem ich kurz anknüpfe an das, was Herr Mußgnug über das leistungsrechtliche Ubermaßverbot gesagt hat. Damit habe ich Schwierigkeiten, und ich meine, man kommt dem Problem der Krise des Sozialstaates, die auch eine Finanzkrise ist, eher dadurch näher, daß man von einem 
leistungsrechtlichen „Untermaßverbot" spricht. Es handelt sich hier um einen meiner Lieblingsbegriffe, den ich jetzt nur als Brücke benutzen möchte, um zu dem Problem einer gerechten Verteilung knapper Ressourcen zu kommen. Und da habe ich Zweifel, ob - wenn wir den politischen Prozeß betrachten - da insoweit ein rationales Gesetzgebungsverfahren überhaupt verlangbar ist. Zwei Beispiele: Erstens Finanzausgleichsgesetzgebung - das will ich jetzt nicht vertiefen, zweitens: Strukturhilfefonds als Antwort auf den Albrecht-Plan. Es scheint in der politischen Praxis ein verfassungsrechtliches Mißverständnis vorzuherrschen, weil eine offenbar neue ,Gesetzgebungskommission “ tätig geworden ist, nämlich das CDU-Präsidium. Ich sage das jetzt ganz ohne parteipolitische „Spitze“, es könnte genausogut ein SPD-Präsidium sein, in dem ausgehandelt wird, wieviel jedes Bundesland haben muß, um dann anschließend die Indikatoren so zu errechnen, daß das gewünschte Ergebnis herauskommt. Und jetzt zwei Stichworte dazu: Einmal das Stichwort von Herrn Hufen - bei Strafe des Aufschnürens des Gesamtpakets -, also die Herstellung eines Verbundes zwischen verschiedenen Leistungen an verschiedene Gruppen, die miteinander verknüpft werden. Und das zweite Stichwort ist kürzlich von Herrn Badura geliefert worden: das Gesetz als pluralistisches Abkommen. Wenn wir diese beiden Stichworte ernst nehmen, wie kann man dann eigentlich verlangen, daß ein Gesetzgebungsverfahren an Kriterien der Gerechtigkeit orientiert bleibt, eine rationale Verteilung von knappen Ressourcen stattfindet? Vielen Dank.

Vorsitzender: Vielen Dank, Herr Schuppert. Herr Isensee, bitte.

Isensee: Ein paar Bemerkungen zu den rechtlichen Grenzen der staatlichen Leistungen.

Die rechtlichen Systeme der staatlichen Leistungen und der staatlichen Einnahmen, Leistungsstaat und Steuerstaat, sind voneinander rechtlich unabhängig. Die Unabhängigkeit wird vor allem hergestellt durch die Gegenleistungsfreiheit der Steuer und durch das haushaltsrechtliche Prinzip der Non-Affektation. Dennoch sind beide Systeme von Rechts wegen wechselseitig aufeinander bezogen. Es besteht politische wie ökonomische Abhängigkeit. Der Zweck der gegenleistungsfreien Abgabe geht letztlich dahin, die finanzielle Grundlage für staatliche Leistungen zu schaffen. Die finanzielle Kapazität des Staates bildet die faktische Grenze möglicher Staatsausgaben (und darin auch der finanzwirksamen Wahrnehmung von Staatsaufgaben). Herr Mußgnug meint, daß darüber hinaus rechtliche, jedenfalls materiellrechtliche Grenzen der Staatsausgaben nicht existierten. Doch er geht um einiges zu weit, wenn er die bloße parlamentarische Entscheidung, die 
der Staatsleistung nur formale demokratische Legitimation vermittelt, als verfassungsrechtliche Grundlage und Grenze genügen läßt.

Das übliche materiellrechtliche Regulativ zur Begrenzung der Staatstätigkeit, das grundrechtliche Übermaßverbot, fällt weitgehend aus, und zwar sowohl im Steuerrecht (soweit die Steuer nicht im Dienst nichtfiskalischer Zwecke steht) als auch im Leistungsrecht. Es fehlt jeweils die typische Mittel-Zweck-Relation, auf die das Prinzip angewendet werden könnte. Einnahmen und Ausgaben lassen sich - eben wegen der rechtlichen Unabhängigkeit der beiden Bereiche - nicht ohne weiteres in ein Raster einbringen. Anwendbar sind dagegen Gebote der Ökonomie und Effizienz. Doch bei diesen handelt es sich um öffentliche, nicht grundrechtliche Belange. Ein Übermaß an Staatszuwendung verletzt nicht Grundrechte des Empfängers, unter Umständen freilich, auf indirekte Weise, solche konkurrierender Dritter.

Was die materiellrechtlichen Vorschriften nicht erreichen, müssen verfahrensrechtliche Vorkehrungen zu kompensieren versuchen. Als Barriere kommen der Vorbehalt des Haushaltsgesetzes sowie der Vorbehalt des materiellen Gesetzes in Betracht, wie ihn das Sozialgesetzbuch für die Leistungsverwaltung exemplarisch vorgibt, sowie verfahrensrechtliche Kontrollinstrumente der Verwaltung. Haushalts- und Leistungsgesetze greifen ins Leere, wenn die Verwaltung nicht die Befugnisse hat, das Vorliegen der tatbestandlichen Leistungsvoraussetzungen im Einzelfall zu prüfen. Hier erweist sich die Ausstattung der Verwaltung nicht selten als defizitär. Das prominenteste Defizit dieser Art zeigt sich derzeit ausgerechnet im Steuerrecht, und zwar bei der Besteuerung von Kapitalvermögen. Die Vollzugsdefekte ergeben sich nicht zuletzt daraus, daß der Verwaltung durch das (demnächst auch noch gesetzlich abgesicherte) Bankgeheimnis die Informationen vorenthalten werden, die sie braucht, um den materiellen Steueranspruch zu realisieren. Ehe das materielle und das formelle Steuerrecht nicht aufeinander abgestimmt werden, ist die Behebung des Mißstandes nicht zu erwarten.

Es gibt auch materiellrechtliche Vorkehrungen, die das weitgehende Versagen des Ubermaßverbotes ausgleichen können. Eine von diesen ist die Staatsentlastung durch Ausweitung privater Initiative und durch gesellschaftliche Selbstregulierung.

Wichtig ist die systemgerechte Harmonisierung von Sozialrecht und Einkommensteuerrecht. Beide Rechtsgebiete sind nicht angemessen aufeinander abgestimmt. Das zeigt die Behandlung der familiären Unterhaltspflichten. Den Vorgaben der freiheitlichen Verfassung, zu denen das Subsidiaritätsprinzip gehört, entspricht es, die Unterhaltspflichten für Kinder im Einkommensteuerrecht zu berücksichtigen und die sozialrechtliche Leistung des Kindergeldes auf die Fälle echter Bedürftigkeit zu beschränken, in denen Steuerverschonung nicht zum 
Zuge käme. Soweit die Einkommenssteuer den familiären Belastungen in realitätsgerechter Weise Rechnung trägt, liegt kein Steuerprivileg und keine Steuersubvention vor, sondern die strukturgebotene $\mathrm{Zu}$ rückhaltung der Steuer, die auf die Zahlungsfähigkeit des Schuldners abstellt, also das bürgerlichrechtlich gebundene Einkommen aussparen muß. Das geltende Recht leidet an Wertungswidersprüchen, wenn es auch dort noch besteuert, wo nach sozialrechtlichen Vorschriften schon Leistungsbedürftigkeit gegeben ist, wenn es steuerlich entzieht, was es leistungsrechtlich zurückgeben muß, und - eng im Nehmen, aber weit im Geben - letztlich den privaten Leistungswillen desavouiert, von dem der Steuerstaat und mittelbar auch der Leistungsstaat zehren.

Ein Versuch, den Leistungsstaat zu entlasten, geht dahin, die kleinen Gruppen der Gesellschaft zu fördern, freilich wiederum mit (finanziellen) Staatsleistungen. Hier liegt sicherlich ein brauchbarer Ansatz. Dennoch sollten gerade in diesem Bereich die Subventionsmaß. stäbe vom Gesetzgeber fixiert sowie von der Verwaltung durchgesetzt und kontrolliert werden. Längst hat sich eine Subkultur der Subventionskonsumenten gebildet. Ich bin nicht der Meinung, daß das Modell, dem die Zukunft gehört, in den subventionierten, autonomen, selbstregulierenden Gruppen der Hamburger Hafenstraße liegen sollte.

Gleichwohl fuhrt die Förderung privater Leistungshersteller und privater Leistungsmittler - der freien Träger - auf die Gleichheitsund Freiheitsgrundrechte hin und über diese in bestimmten Konstellationen zur Anwendbarkeit des Ubermaßverbotes. Die freien Träger können sich auch dort auf Grundrechte berufen, wo sie staatliche Mittel weiterleiten und Dezentralisierung und Pluralisierung der Leistungsangebote ermöglichen. Ansätze zum Schutz der freien Träger finden sich - freilich formelkompromißhaft und vage formuliert - bereits im Sozialgesetzbuch. Hier tut sich ein Weg auf, Grenzen des Leistungsstaats zu markieren.

Vorsitzender: Vielen Dank, Herr Isensee. Herr Gramlich hat das Wort.

Gramlich: Wenn ich richtig gehört und recht verstanden habe, dann hat von den Referenten nur Herr Mußgnug zur Rückseite - oder vielleicht besser gesagt zu den Voraussetzungen - der Gesetzesgestaltung im Leistungsrecht eingehender Stellung bezogen. Nun, Leistungen sind ja Geldleistungen oder zumindest geldwerte Leistungen. Der Finanzierungsaspekt ist auch schon in einigen Diskussionsbeiträgen angesprochen worden, aber ich möchte auf einen Punkt hinweisen, der zur Ergänzung beitragen könnte, denn eine Finanzierung kann ja nicht nur durch Staatsverschuldung stattfinden - das dramatische Beispiel dafür 
sehen wir in den Entwicklungsländern, in manchen jedenfalls -, sondern eine Finanzierung kann auch durch Inflationierung erfolgen, und hier haben wir einen Aspekt, der wiederum die Gesetzesgestaltung betrifft. Natürlich ist in der Bundesrepublik eine Finanzierung über die Notenpresse oder durch Münzausprügung einfach-gesetzlich und möglicherweise auch verfassungsrechtlich untersagt. Es besteht auch kein Zwang dazu, Bund und Ländern Kassenkredite einzuräumen, aber es gibt ja nicht nur das Bar-, sondern auch das Buchgeld, und hier praktiziert - wie Sie wissen - die Bundesbank eine Geldmengensteuerung, insbesondere bezüglich dieses Buchgeldes. Und dessen Begrenzung ist doch eine reale staatliche Aufgabe, die von der Bundesbank selbst abhängig gemacht wird vom realen Wirtschaftswachstum: Es wird also hier abgestellt mit dem Geldmengenziel, mit dem Geldmengenrahmen auf das Wachstum der realen Wirtschaft. Andererseits habe ich da die Frage an die Referenten: Es wurde ja in allen drei Referaten betont der Gesichtspunkt der parlamentarischen Mitwirkung, daß der Gesetzgeber doch eine große Rolle zu spielen habe. Hat er dies auch auf der Rückseite - wenn ich es nochmals so formulieren darf - des Leistungsrechts in gleicher Weise zu tun? Bei der Geldmengensteuerung, was immer das auch rechtlich sei, sehe ich eine solche Mitwirkung momentan jedenfalls nicht.

Und ein zweiter kurzer Punkt: Auch zuvor ist bereits angesprochen worden, daß zwischen den Referaten von gestern und heute thematische Bezugspunkte bestehen. Nun, insbesondere Herr Hufen hat in These 16, wenn ich das recht sehe, von einem „minimum standard“, einer Untergrenze, einem Leistungssockel gesprochen. Frage: Hat dieser Leistungssockel auch - und wenn ja, welche - gleichheitsrechtlichen Aspekte? Sie erlauben, daß ich das zugespitzt an zwei Beispielen demonstriere. Beispiel 1: Wenn man sagt, Sozialhilfe muß einen bestimmten Mindestsatz haben, gilt das dann in gleicher Weise für Deutsche und für Ausländer? Und zweitens: Wenn man es nun sogar grenzüberschreitend angeht, hat dies zur Folge, daß - da ja die Staatsgewalt nicht nur im Inland an Grundrechte gebunden ist, sondern auch, wenn auch modifiziert, im grenzüberschreitenden Bereich - sich auch Auswirkungen, und da wäre ich wieder bei der Staatsverschuldung, auf die Entwicklungspolitik ergeben? Danke schön.

Vorsitzender: Vielen Dank, Herr Gramlich. Das Wort hat Herr Haverkate.

Haverkate: Punkt 1: Die wichtigste Verbindung zwischen dem gestrigen und dem heutigen Thema liegt für mich in dem Gleichheitsbezug des Leistungsstaates in die Zukunft hinein. Gibt es eine Gleichheit in der Zeit? Da haben viele Autoren abgewunken: Nein, da gebe es ei- 
ne immanente Begrenzung; Gleichheit sei geboten, aber Gleichheit zwischen den Generationen, das überschreite die rechtlichen Regelungsmöglichkeiten. Ich denke, wir stehen heute beim Leistungsstaat vor allem vor Zeitproblemen, vor Gleichheitsproblemen zwischen den Generationen; bei der Staatsverschuldung nicht weniger als etwa beim Generationenvertrag in der Rentenversicherung. Hier gibt es jetzt, glaube ich, kein Entkommen mehr. Wir müssen die Gleichheit in der Zeit als Rechtsproblem sehen, als zentrales Problem wahrscheinlich des Leistungsstaates. Dort, wo vom Recht getragene und gestaltete Leistungsbeziehungen zwischen den Generationen bestehen, muß auch dem Gleichheitssatz Rechnung getragen werden. Das Generationenverhältnis im Recht der gesetzlichen Rentenversicherung aufgrund der Umlagefinanzierung: der heutige Arbeitnehmer zahlt an den früher tätigen Arbeitnehmer Renten, in der durch Art. 14 GG geschützten Hoffnung, selbst später einmal Rente zu bekommen, die dann von denen gezahlt wird, die zu dieser Zeit erwerbstätig sein werden. Hier ist augenfällig: Wir würden diesen Leistungsbeziehungen zwischen den Generationen ihre Legitimitätsgrundlage entziehen, wenn wir sagen würden, es gebe grundsätzlich keine Gleichheit in der Zeit. Ähnliches gilt für die Staatsverschuldung, wie für anderes zeitrelevantes Staatshandeln: Ohne die Annahme einer prinzipiellen „Lastengleichheit“ zwischen den Generationen kommen wir zu einer rechtlichen Gestattung grober Ungerechtigkeiten zu Lasten künftiger Generationen.

Herr Mußgnug, eine Anmerkung zu Ihrer These XIII: Sie berühren hier gerade den Punkt der Lastengleichheit bei der Staatsverschuldung und sagen: „Keine Kreditaufnahme zur Finanzierung des Leistungsstaates“. Diese Ihre Lösung ist mir etwas zu ,hemdsärmelig“, etwas zu unvermittelt. Ich wüßte übrigens auch ganz praktisch nicht, wie ich denn innerhalb eines großen Staatshaushaltes die Kreditaufnahmen den einzelnen Leistungstiteln zurechnen sollte; welche Leistungen des Staates werden denn nun durch die Kreditaufnahme finanziert? Wird die Anschaffung der Phantom-Düsenjäger solide vorgenommen und wird der Sozialhaushalt unsolide, durch Kredit, finanziert? Da fehlt mir der Maßstab für die Zurechnung. Aber das Problem ist klar, ich bezweifle nur, daß dies hier schon die Lösung ist.

Punkt 2: Zum Autonomieproblem. Herr Hufen, ich stimme Ihrer These XI grundsätzlich gerne zu. Das ist ein faszinierender Gedanke. Ich denke nur, Sie haben sich im entscheidenden allzusehr bedeckt gehalten, nämlich: Wessen Autonomie steht in Frage? Wenn man sich in die Problematik etwas hineinbegibt, dann weiß man ja, daß hier ein großer Kampf stattfindet, wessen Autonomie eigentlich gemeint ist. Z.B.: Wir hatten vor etwa drei Jahren den Anlauf zu einer ,selbstregulierungsfreundlichen " Rechtsgestaltung genommen; es sollte der Versuch gemacht werden, die Arzneimittelkosten zu deckeln durch ver- 
tragliche Regelung der jährlichen Preiserhöhungsrate bei den Arzneimitteln; die Regelung sollte durch Vertrag zwischen dem Bundesverband der pharmazeutischen Industrie und den Verbänden der Krankenkassen erfolgen. Das lief unter dem Stichwort ,autonome Regelung der Beteiligten", war aber in der Sache doch nur ein schlechtes Preiserhöhungskartell. (Dieses Preiserhöhungskartell fand übrigens Beifall von nahezu allen Seiten, vom Minister, von den Parteien, von den Verbänden; skeptische Stimmen galten fast nichts). Dieses Preiserhöhungskartell ist an Nebensächlichkeiten gescheitert. Es wurde unter dem Stichwort „Autonomie“ gefeiert, es war aber nichts als der großangelegte Versuch, einen Preiswettbewerb im Pharmabereich endgültig abzuschaffen. Das wichtigste: Uberhaupt nicht in Betracht gezogen wurde bei dieser Lösung die Autonomie dessen, auf den es nach meiner Meinung eigentlich ankommen muß, nämlich die Autonomie des Bürgers, des Patienten, dessen, der die Arzneimittel konsumieren soll. Also nochmals in aller Schärfe die Frage: Wessen Autonomie soll hergestellt werden? Die des Bürgers? Soll er in eine aktiv gestaltende Rolle gebracht werden? Oder ist nur die Autonomie der Verbände, der großen intermediären Gewalten gemeint?

Punkt 3: Zu Herrn Mußgnug, der eine Gegenthese zu mir formuliert hatte. Ich hatte gemeint, Leistungszwecke müßten präzise und auBenrechtlich verbindlich durch den Gesetzgeber gesetzt werden, und das heißt für mich: durch Gesetz. Herr Mußgnug, Sie haben da widersprochen. Ich denke, es lohnt sich, einen Augenblick festzuhalten, worin die eigentliche Abweichung liegt, denn Sie haben dann gesagt, ” wir bräuchten präzise nach außen hin verbindliche Zweckangaben durch das Parlament". Da stimmen wir also ganz überein. Erst im folgenden unterscheiden wir uns - das ist dann Ihre These VIII: ,,Es genüge, wenn der Haushaltsplan den Zweck angebe." Nun, die Formulierung „, es genüge " könnte (und soll wohl auch?) den Eindruck erwekken, wir hätten bereits präzise Zweckangaben im Haushaltsplan. - Ich kann nicht sehen, daß die jetzigen Zweckangaben im Haushaltsplan auch nur annähernd präzise genug sind; noch kann ich sehen, daß wir eine Anwendungspraxis etwa der Gerichte hätten, die diese Zweckangaben als nach außen hin verbindliches, durch den Richter anwendbares Recht nach Art. 20 Abs. 3 GG ansähen. Da müßten wir also doch noch einmal diskutieren, ob unsere gemeinsame Voraussetzung - auBenrechtliche, präzise Zweckangaben durch das Parlament - schon durch die jetzigen Zweckangaben im Haushaltsplan abgedeckt sind.

Ein letztes Wort: Zum Verhältnismäßigkeitsgebot, zum Ǔbermaßverbot. Herr Mußgnug, bei Ihrer These X besteht die Gefahr eines terminologisch begründeten Mißverständnisses. Das Verhältnismäßigkeitsgebot zielt auf Freiheitsschutz. Auch dann, wenn wir dieses Gebot auf das Leistungsrecht übertragen, müssen wir darauf bestehen, daß es nur 
und ausschließlich um Freiheitsschutz geht. Es geht also nicht darum, ,übermäßige“ staatliche Leistungen zu bekämpfen. Es geht darum, übermäßige Freiheitsverluste aufgrund staatlicher Leistungen zu erfassen. Mit dieser Klarstellung, so denke ich, könnte man Ihrer These X im Ergebnis durchaus zustimmen. „Ubermäßige“ Leistungen sind nicht ohne weiteres vom Übermaßverbot erfaßt, wohl aber solche Leistungen, die ,übermäßige“ Freiheitsverluste für den Bürger mit sich bringen; hier besteht eine Unverhältnismäßigkeit zwischen Regelungszweck und Leistungsausgestaltung. Hier liegt ein Verstoß gegen das Verhältnismäßigkeitsgebot vor. - Danke schön.

Vorsitzender: Vielen Dank, Herr Haverkate. Jetzt Herr Bachof bitte, Sie wollten zu Ermessen und Einzelfallgerechtigkeit, insbesondere zur These 16 von Herrn Mußgnug sprechen.

Bachof: Jawohl, dazu. Herr Mußgnug hat in These XVI geschrieben, die Rechtsprechung verkenne, daß nicht jede Leistungsbewilligung, die von einer Richtlinie oder einer ständigen Verwaltungsübung - die Verwaltungsubung lasse ich jetzt draußen - abweiche, schon allein aus diesem Grunde rechtswidrig sei. Ich stimme dem zu mit der Bemerkung, daß das natürlich - anders wird Herr Mußgnug es auch nicht gemeint haben - nicht nur für die Leistungsbewilligung gilt, sondern für jeden Verwaltungsakt. Aber ich möchte noch darüber hinausgehen: Ich meine, daß eine Ermessensrichtlinie ihrerseits rechtswidrig ist, wenn sie sich anmaßt, eine solche Abweichung nicht zu gestatten. Wenn ein Gesetz einer Behörde einen Verwaltungsakt zur Ausübung nach Ermessen zuweist, dann kann dieses Ermessen nicht durch Richtlinien einer höheren Behörde vollständig ausgeschlossen werden. Die höhere Behörde kann zwar im Interesse gleichmäßiger Handhabung eine allgemeine Richtlinie erlassen. Aber diese steht notwendig unter dem ungeschriebenen Vorbehalt: ,es sei denn, daß aus besonders gewichtigen Gründen anders zu entscheiden ist." Wollte man das ausschließen, so würde man das Einzelfallermessen beseitigen und außerdem das Ermessen der gesetzlich zuständigen Behörde generalisierend auf eine höhere Behörde übertragen. Das geht nicht. Bei Richtlinien, die Begriffe auslegen oder gar so weite Begriffe wie z.B. „Stand der Technik" durch ein dickes Buch von Detailregelungen ausfülen und konkretisieren, sieht die Sache wohl anders aus. Hier, meine ich, kann die nachgeordnete Behörde in der Tat strikt angewiesen werden; was freilich nicht bedeutet, daß ein Verwaltungsakt, der davon abweicht, deswegen notwendig rechtswidrig wäre. Denn für die Rechtswidrigkeit kommt es darauf an, ob vom Gesetz abgewichen wurde und nicht nur von einer Richtlinie. Erst recht kann ein Gericht in einem solchen Fall nicht gebunden sein. Das halte ich, anders als das Bundesverwaltungs- 
gericht, nicht für zulässig. Es widerspräche der Gewaltenteilung. Denn auch ,Konkretisierung“ muß sich im Rahmen möglicher Auslegung halten, und diese ist letztlich Sache der Gerichte. Ich möchte hier nicht mißverstanden werden. Ich befürworte keineswegs, daß die $\mathrm{Ge}$ richte ihren oft sehr viel geringeren Sachverstand an die Stelle des Sachverstandes besser damit ausgerüsteter Gremien setzen sollen; in der Vergangenheit ist gerade damit genug Unfug getrieben worden. In der Praxis wird es darauf hinauslaufen, daß solche Richtlinien für die Gerichte mehr oder minder ,verbindlich" sind, weil diese sich in der Regel über den größeren Sachverstand der Richtlinien nicht hinwegzusetzen vermögen. Aber eben nur in der Regel! Dogmatisch kann man hier von Letztverbindlichkeit nicht sprechen.

Vorsitzender: Vielen Dank, Herr Bachof. Die Diskussionsredner haben eine Fülle von Anregungen an die Referenten herangetragen. Diese haben jetzt Gelegenheit zu antworten. Ich möchte aber vorschlagen, daß Sie dieses „Zwischenwort" nicht dazu benutzen, zu jeder Frage ausführlich Stellung zu nehmen. Gewisse Kernaussagen können Sie sich noch für das Schlußwort vorbehalten. Zunächst hat das Wort Herr Hill.

Hill: Ich möchte als Zwischenbilanz vier Bemerkungen machen.

Zunächst ist mir in der Diskussion als ein wesentliches Problem die Uberlastung des Gesetzgebers im Leistungsstaat und die Suche nach Möglichkeiten, seine Steuerungskapazitäten, bezogen auf die Regelung des „Wesentlichen“ bzw. den Rahmen staatlicher Leistungen zu erhalten, aufgefallen. Unter diesem Aspekt sehe ich verschiedene Vorschläge, die von Herm Hufen und von mir im Hinblick auf eine Abschichtung und Entlastung der Gesetze sowie eine Flexibilität der gesetzlichen Vorgaben gemacht worden sind. Zunächst zum Vorschlag eines Stamm- oder Grundlagengesetzes. Ein solches Gesetz ist in der Gesetzgebung nicht unbekannt. Herr Bachof und gestern Herr Stern haben als Beispiel die Neugliederungsgesetze genannt. Unter diesem Aspekt sehe ich auch den zweiten Vorschlag eines vereinfachten Verfahrens von Herrn Hufen. Differenzierte Verfahrensabläufe gibt es auch im Bereich des Verwaltungsverfahrens, etwa im Verhältnis der $\S \S 10$ und $63 \mathrm{ff}$. VwVfG oder bei der Sanierung gem. $\S 142$ Abs. 4 BauGB. Auch im Bereich der Gesetzgebung sind teilweise, etwa bei der Haushaltsgesetzgebung, gewisse Restriktionen im Verfahren anerkannt. Jedoch müßte man bei diesem Vorschlag die Abgrenzung zur Rechtsverordnung und die Frage einer Zustimmung des Bundesrates noch genauer prüfen. Unter dem genannten Aspekt sehe ich drittens auch meinen Vorschlag der Einführung eines sog. beweglichen Systems. Dabei soll in der gesetzlichen Regelung zunächst eine Basiswertung vorangestellt werden. Herr Ipsen, diese Basiswertung soll die Regel beinhalten für den Grund- 
bzw. den Normalfall. Diese Regel soll dann ergänzt werden in einem Absatz 2 durch eine Anleitung für Grenzfälle. Wir müssen sehen, daß letztlich hinter allen gesetzlichen Regelungen implizit Zwecke und Wertungen stehen und diese sollen in der Basiswertung vom Gesetzgeber deutlich zum Ausdruck gebracht werden. Dies zur Anmerkung 1: Uberlastung des Gesetzgebers und Erhaltung seiner Steuerungskapazität.

Die Anmerkung 2 geht aus von der Anregung von Herrn Püttner, zu überlegen, inwieweit wir heute über Gesetzgebungslehre statt über Leistungsrecht gesprochen haben bzw. worüber wir mehr gesprochen haben. Sicherlich hat das Leistungsrecht keine grundsätzlich andere Dogmatik als das Eingriffsrecht. Es gibt gewisse Modifikationen, etwa in der Weise, daß im Leistungsrecht die Zwecke eine stärkere Rolle spielen, daß sie zwischen Staat und Leistungsempfänger eher kongruent sind als im Eingriffsrecht. Daneben ist im Leistungsrecht wohl auch eine stärkere Zukunftsbezogenheit als im Eingriffsrecht vorhanden. Unter Beachtung dieser Besonderheiten müßte man prüfen, inwieweit die hier gemachten Vorschläge auch auf das Eingriffsrecht zu übertragen sind. Bei der Frage der Rechtsverhältnisse stimme ich Herrn Schmidt$A ß m a n n \mathrm{zu}$, sie greift sicherlich über das Leistungsrecht hinaus. Auch beim beweglichen System, das ich vorgestellt habe, gibt es Ansätze im Eingriffsrecht. Ich habe das Beispiel der Gefahr im Polizei- und Ordnungsrecht genannt. Beim Kooperationsprinzip würde ich nicht ganz so weit gehen, insoweit gibt es sicherlich im Eingriffsrecht etwas andere Konstellationen, obwohl etwa im Polizeirecht die Figur des Austauschmittels bekannt ist.

Dritte Anmerkung zum Gesetzgebungsverfahren, ausgehend von der Frage von Herrn von Arnim. Herr von Arnim, ein ,optimierendes Richtigkeitsdenken " für die Gesetzgebung ginge mir etwas zu weit. Ich störe mich an dem Teilbegriff "Richtigkeit", denn Richtigkeit im eigentlichen Sinne kann es so bei der Gesetzgebung nicht geben, weil dem Gesetzgeber bei seiner Konkretisierungsaufgabe ein erheblicher Spielraum innerhalb der Verfassung zukommt. Trotzdem würde ich nicht dem von Herrn Mußgnug eingeführten und von Herrn von $\mathbf{M u}$ tius, wenn ich ihn richtig verstanden habe, bestätigten Satz zustimmen, daß das Gesetz das Maß aller Dinge sei. Ich möchte den Gesetzgeber nicht ganz aus den verfassungsrechtlichen Anforderungen entlassen, sowohl inhaltlich als auch verfahrensrechtlich. Allerdings ist es eine andere Frage, inwieweit diese Verpflichtungen des Gesetzgebers oder auch die Einführung organisatorischer oder verfahrensrechtlicher Neuregelungen vom Bundesverfassungsgericht kontrolliert werden können bzw. dürfen. Insofern ist es sicherlich richtig, Herr von Mutius, daß andere Kontrollmechanismen zu dieser verfassungsgerichtlichen Kontrolle hinzutreten und sie ergänzen. 
Vierte Anmerkung zu der Frage der Selbstregulierung. Hier möchte ich vor allem der Bemerkung von Herrn Hoffmann-Riem zustimmen, daß Selbstregulierung schwieriger zu bewältigen ist als imperative Steuerung. Dennoch erscheint es auch mir notwendig, sich mehr mit diesen Fragen der Selbstregulierung zu beschäftigen. Allerdings muß man auch die Bedenken sehen, etwa daß der Staat sehr leicht in die Gefahr kommen kann, sich in solche Selbsthilfeorganisationen einzumischen, und daß auch die Selbsthilfeorganisationen selbst irgendwann bürokratische Formen annehmen können und damit ähnliche Binnenstrukturen aufweisen wie der Staat. Dann aber gingen ihre eigentlichen Vorteile der Flexibilität und selbstverantwortlichen Bearbeitung eigener Probleme verloren. Insgesamt stellt jedoch das Verhältnis staatliche Steuerung - Selbstregulierung ein wichtiges $\mathrm{Zu}$ kunftsproblem dar. Wenn ich meinen Speyerer Kollegen aus der Politikwissenschaft aufmerksam zugehört habe, dann habe ich erfahren, daß das sog. regulative Recht zur Bewältigung neuartiger Steuerungsprobleme nicht mehr ganz ausreicht und daß man sich in Zukunft ein etwas modifiziertes Staatsbild machen muß, weil die Aufgaben und auch die Handlungsformen des Staates sich sehr stark wandeln, weg von einem reinen Eingriffsdenken hin zu einer Motivation und Organisation von Selbstorganisationsprozessen, zu einer Vermittlung also, und daß insoweit diese Selbsthilfemechanismen eine sehr große Rolle spielen werden.

Soweit als Zwischenbilanz.

Vorsitzender: Vielen Dank, Herr Hill, auch für die konzentrierte Kürze. Herr Hufen, bitte.

Hufen: Auch ich möchte mich an den Vorschlag des Herrn Vorsitzenden halten und manches in das Schlußwort verlagern und dort konzentriert behandeln. So möchte ich die Kollegen, die zum Problem der Selbstregulierung gesprochen haben, um Verständnis bitten, wenn ich auf ihre Beiträge erst im Schlußwort eingehe. Das gleiche gilt für das Gleichheitsthema, das ja ohnehin wie eine Spange die beiden Teile unserer Tagung umgreift.

Beginnen möchte ich mit den grundsätzlichen Fragen. Wenn ich es richtig sehe, hat Herr von Arnim die grundsätzlichste Frage überhaupt gestellt: Geht es bei der Gesetzgebung um optimierendes Richtigkeitsdenken oder haben wir den Zustand der Gesetze als notwendige Konsequenz des demokratischen Prozesses hinzunehmen? Wer sich mit Gesetzgebung, mit Gesetzesgeschichte und insbesondere mit dem Postulat der Allgemeinheit des Gesetzes befaßt, stößt dabei natürlich auf jene Tradition des allgemeinen Gesetzes, die Ausdruck der Hoffnung war, im Gesetz einen Zipfel der Weltvernunft zu erhaschen. Herr Pütt- 
ner hat meinen Vorschlag der Grundlagengesetzgebung sogar in die Nähe der Monarchie gerückt, was ich übrigens auch nach einigen wunderschönen Lebensjahren im Schatten von Neuschwanstein immer noch für ein zweischneidiges Kompliment an mich halten würde. Alle drei Referate des heutigen Tages wären aber wohl mißverstanden, wollte man unterstellen, wir hätten uns hier auf die Suche nach dieser Weltvernunft oder einer anderen Form vorgefaßter Gesetzesrichtigkeit begeben. Was allerdings gefragt ist, sind strukturelle und verfahrensmäBige Bedingungen für mehr Verläßlichkeit, innere Konsequenz und damit Geltungskraft der Gesetze; substantielle Rationalität könnte man es wohl nennen. Auch geht es um nicht weniger als die Erhaltung der Steuerungsfähigkeit der Demokratie und ihrer zentralen Legitimationsmuster. So sei hier noch einmal mit aller Deutlichkeit betont: Das parlamentarische System und das Parlamentsgesetz sind das bis jetzt eindeutig bewährteste und erhaltenswürdigste System zur Lösung der Steuerungsprobleme auch des modernen Sozialstaats. Darum geht es, und alle Vorschläge, die ich gemacht habe, gelten der Sicherung und der Erhaltung, gleichzeitig aber auch der problemadäquaten Fortentwicklung dieses Systems. Das gilt sowohl für die Gesetzgebungskommissionen, die ich - Herr von Arnim hat es angesprochen - nicht als Gegengewicht zur Demokratie, sondern als Moment der Demokratie und der Konfliktaustragung begreife. Sie hätten aber die Aufgabe, gleichsam Angebote rationaler Konfliktbewältigung und deren gesetzlicher Ausformulierung an den Gesetzgeber zu liefern. Dabei glaube ich deutlich genug gesagt zu haben, daß die eigentliche Verantwortung beim Parlament bleiben muß. Das gilt auch für die Grundlagengesetzgebung, mit der ich dem Parlament nicht eine Art Obergesetzgeber aufoktroyieren will, die ich vielmehr als Chance begreife, daß das Instrument Gesetz den gewachsenen Ansprüchen, aber auch der wachsenden Kritik an eben diesem Instrument weiter gerecht werden kann. Insoweit geht es - und hier muß ich Ihnen widersprechen, Herr Ipsen nicht um eine irgendwo im Bereich der Politologie angesiedelte Gesetzgebungslehre sondern um ein eminent wichtiges staatsrechtliches Problem. Auch der Blick auf neuere Verfassungen in Europa zeigt, daß sowohl die Idee der Grundlagengesetzgebung als auch diejenige der Entlastung des Gesetzgebers durch vereinfachende Verfahren durchaus aktuell ist. Herrn Quaritsch bin ich hier für den Hinweis dankbar, daß die Grundidee auch im innerstaatlichen Bereich vorhanden ist. Ebenso Herrn Bachof für den Hinweis auf die Systemgerechtigkeit bei der Gemeindereform, die ja auch im Grunde nichts anderes war als eine strukturelle Grundlagengesetzgebung auf Landesebene. Die Idee der Grundlagengesetzgebung stammt also nicht von mir, sie ist vielfach vorhanden und ich meine, es liegt hier ein lohnenswerter Ansatzpunkt um weiterzudenken - auch im verfahrensrechtlichen Sinne. Wenn 
der Gesetzgeber es schaffen würde, inhaltliche und zeitliche Stetigkeit auch ohne ein solches spezifisches Instrument zu verbürgen und damit z.B. die sich abzeichnenden Probleme des Generationenkonfliktes übergreifend zu lösen, dann wäre ich natürlich auch damit einverstanden. Ich hege nur Zweifel, ob die gegenwärtigen Instrumente und Verfahren ausreichen werden. Wenn wir nämlich erkennen, daß wir es mit strukturellen und politischen Bedingungen zu tun haben, die eine solche Konfliktbewältigung nicht mehr gewährleisten, müssen wir einfach auch neue Instrumente in unsere Überlegungen einbeziehen.

Herr Oppermann und Herr Soell haben gefragt, warum ich zur Entlastung des Gesetzgebers das bewährte Instrument der Rechtsverordnung außer acht gelassen habe. Ich habe es aber für selbstverständlich gehalten, daß es gerade im Leistungsbereich Details gibt, die unterhalb auch vereinfachter Gesetzesformen in den Rechtsverordnungen bleiben und damit den Gesetzgeber entlasten können. Es ging mir aber gerade auch um vereinfachte und damit entlastende Verfahren in solchen Bereichen, die nach unserem parlamentarisch-demokratischen Verständnis und nach der jüngeren Rechtsprechung zum Gesetzesvorbehalt der gesetzlichen Regelung bedürfen.

Zurück zu einer etwas grundsätzlicheren Frage, der Abgrenzung von Leistungsrecht und Eingriffsrecht. Herr Püttner hat hier völlig zu Recht darauf hingewiesen, daß es wenige Aspekte gibt, die jeweils ausschließlich für den Leistungs- bzw. für den Eingriffsbereich gelten würden. Die Dinge überschneiden sich hier und weisen durchaus ähnliche Probleme auf. Den Gedanken der Selbstregulierung würde ich mir allerdings in bestimmten Bereichen des Eingriffsrechts nur sehr schwer vorstellen können. Ich mag keinen privaten Strafvollzug; ich mag auch keine "schwarzen Sheriffs“. Vielleicht erbringt auch die Diskussion noch weitere Beispiele für die Eignung oder den Ausschluß bestimmter Instrumente und Verfahren in dem einen oder anderen Bereich.

Auf die Zusammenhänge von Eingriff und Leistung haben auch Herr Kirchhof, Herr Isensee, Herr Gramlich und Herr Suhr hingewiesen. Diese Zusammenhänge waren auch mir sehr wichtig. Das führt zur eingriffsrechtlichen Kehrseite des Leistungsstaates, der ich in steuerrechtlicher und haushaltsrechtlicher Hinsicht nicht nachgehen konnte. Es sollte aber deutlich werden, daß wir die Probleme der Verteilung und des Transfers staatsrechtlich in den Griff bekommen müssen. Meine Grundsatzthese in diesem Zusammenhang wäre die, daß dem Bürger - wie übrigens auch dem Gesetzgeber - der Zusammenhang von Leistung und Eingriff in kleineren Einheiten besser begreiflich zu machen ist als in anonymen Großsystemen, in denen nur sehr indirekt spürbar wird, daß keine Leistung ohne Eingriff denkbar ist. Wer weiß, daß er das städtische Hallenbad im Grunde genommen selbst bezahlt, der wird in der Regel diesen Zusammenhang besser begreifen als derje- 
nige, der Leistungen einfach ,,mitnimmt", weil er die Quelle der Leistung - die eigene Brieftasche - nicht spürt. Der Zusammenhang von Eingriff und Leistung gilt wohl auch in anderen Bereichen. So hat schon Herr Soell darauf hingewiesen, daß das Umweltrecht, das wir immer noch dem Eingriffsrecht zuordnen, das wahrscheinlich zukunftsträchtigste Gebiet der Daseinsvorsorge ist. Deshalb kann ich auch im Hinblick auf die Zweckfreiheit der Daseinsvorsorge Herrn Ipsen nicht zustimmen. Gerade in den traditionsreichen Bereichen der Daseinsvorsorge fallen heute ganz eminent wichtige Grundsatzentscheidungen der staatlichen Leistungs- und Eingriffspolitik. Ob Sie im Bereich der Infrastruktur z.B. eine Entscheidung für den Individualverkehr oder für die Bundesbahn treffen, ist eine hochpolitische Weichenstellung der Daseinsvorsorge, aus der sich ganze Ketten von Eingriffen und Leistungen - auch solchen in Gesetzesform - ergeben. Soweit für jetzt.

Vorsitzender: Vielen Dank, Herr Hufen. Das Wort hat Herr Mußgnug.

Mußgnug: Auf meine Stellungnahme warten derart viele Diskussionsbeiträge, daß mir ganz gegen meine Absicht der eine oder andere aus dem Blick geraten könnte. Sollte mir das im Eifer der freien Rede passieren, so bitte ich um Nachsicht.

Herr Kirchhof hat mit dem Vorbehalt des finanziell Möglichen einen Begriff gefunden, nach dem ich vergeblich gesucht habe. Dieser Vorbehalt bringt exakt zum Ausdruck, was beim Nachdenken über das Leistungsrecht schärfer in den Mittelpunkt gerückt werden muß. Es ist verdienstlich, daß Herr Kirchhof dafür eine treffende Formulierung geprägt hat.

Herr Ipsen hat angeregt, zwischen der Daseinsvorsorge und dem Sozialrecht als den beiden grundrechtsverwirklichenden Sparten des Leistungsrechts und den grundrechtsferneren Subventionen zu unterscheiden. Das hat vieles für sich. $\mathrm{Zu}$ bedenken bleibt freilich, daß es auch grundrechtsverwirklichende Subventionen gibt; die Kunstförderung belegt das. Wie die Subventionierung der Landwirtschaft zeigt, können bei der Subventionsvergabe auch soziale Komponenten mitspielen. Die Daseinsvorsorge leistet sich umgekehrt manchen Luxus, der so gut wie nichts zur Grundrechtspflege und zur Verwirklichung des Sozialstaatsprinzips beiträgt. Ich erwähne nur die Schlittschuhbahnen, die sich mittlerweilse selbst kleine Gemeinden zulegen. Das warnt davor, die Grundrechtsrelevanz der Daseinsvorsorge und des Sozialrechts überzubewerten und die Grundrechtsrelevanz der Subventionen zu unterschätzen. Beides hat in der Trennung des sozialrechtlichen Verwaltungsverfahrens von dem für die Subventionsvergabe gültigen VwVfG 
einen nach meinem Dafürhalten wenig überzeugenden Niederschlag gefunden. Dienten die Subventionen allein dem schnöden Kommerz, die Sozialleistungen dagegen per se der hehren Grundrechtsverwirklichung, so würde ohne weiteres einleuchten, warum das SGB-X die Rücknahme fehlerhafter Renten- und Sozialhilfebescheide schärfer einengt als $\S 48 \mathrm{VwVfG}$ die der rechtswidrigen Subventionsbewilligung. Aber ich habe meine Zweifel, ob diese Rechnung aufgeht. Ein für das gesamte Leistungsrecht einheitliches Verwaltungsverfahrensrecht käme m.E. der Natur der Sache näher. Denn ich sehe keinen rechten Grund, den um seine Existenz ringenden Landwirt, der zu Unrecht eine Subvention erhalten hat, härter anzupacken als den Sozialhilfeempfänger, bei dem vergessen worden ist, ihn zunächst zur Verwertung seines anrechnungspflichtigen Vermögens anzuhalten. Der zu Unrecht subventionierte Landwirt und der gesetzwidrig unterstützte Sozialhilfeempfänger verdienen beide den gleichen Vertrauensschutz. Kein Grund also, die Rücknahme von Subventions- und Sozialhilfebescheiden nur im Prinzip übereinstimmend, in den für den konkreten Einzelfall ausschlaggebenden Details aber doch recht unterschiedlich zu regeln.

In Herrn von Arnims Plädoyer für die Rechtspflicht zur optimalen Gesetzgebung klang das Unbehagen an, das ich mit meinen Demokratiethesen - wohl nicht nur bei ihm - geweckt habe. Mit diesen Thesen will auch ich nicht bestreiten, daß der Gesetzgeber die Probleme des Leistungsrechts optimal lösen muß. Aber ich sehe darin nur eine politische, keine Verfassungspflicht. Denn das Verfassungsrecht kann nur das verfassungskonforme vom verfassungswidrigen, nicht jedoch auch das gute vom schlechten Gesetz abschichten. Paul Laband hat das mit zeitloser Gültigkeit begründet. Die von ihm beschworenen $\mathrm{Ge}$ setze über den Farbanstrich der Eisenbahnwaggons 1. Klasse und den Hufbeschlag der Kavalleriepferde wären auch in seinen Augen schlechte, aber dank ihrer Absegnung durch den Gesetzgeber dennoch verbindliche, rechtlich nicht zu beanstandende Gesetze gewesen. Diese Sicht der Dinge birgt, konsequent zu Ende gedacht, Gefahren in sich. Dessen bin ich mir bewußt. Aber diese Gefahren liegen im Wesen der Demokratie, die das Rechtsstaatsprinzip nur auf dem Felde des Eingriffsrechts vor dem Abgleiten in die politische Unvernunft schützen kann. Die Unvernunft des Leistungsrechts indessen vermag das Rechtsstaatsprinzip nicht aufzuhalten. Vor ihr bewahrt uns allein unsere eigene und die politische Vernunft unserer Parlamente. Es kommt darauf an, diese Vernunft zu stärken. Diese Aufgabe fällt in den Bereich der politischen Bildung. Sie geht somit vor allem die Schulen und die Medien an, die sie freilich, wenn ich es richtig sehe, arg vernachlässigen. Im Staatsbürgerkundeunterricht der Schulen kommt die Kardinaltugend des Maßhaltens zu kurz, in den Medien wird das genaue Gegenteil gepredigt. Statt einzuschärfen, daß maximale Staatsleistun- 
gen mit maximalen Steuern bezahlt werden müssen, wird so ein ungezügeltes Anspruchsdenken genährt, dem die Politik nicht standhalten und dem die Staatsrechtslehre nichts entgegensetzen kann. M.E. folgt daraus, daß die Optimierung des Leistungsrechts nur durch politische Aufklärungsarbeit zu erreichen ist, die vor Augen führt, was finanziell möglich ist, und verdeutlicht, daß das Leistungsrecht kollabiert, wenn es sich auf den Versuch einläßt, das Unmögliche möglich zu machen.

Herr Wenger und Herr Soell haben mir vorgehalten, daß die Gestaltungsfreiheit der Leistungsgesetzgebung schon deshalb Grenzen kenne, weil einmal durch Gesetz eingeführte Leistungen nicht, zumindest nicht kurzfristig, wieder eingestellt werden können. Das ist ein Hinweis von zentraler Wichtigkeit, mit dem ich mich in meinem Referat gerne näher auseinandergesetzt hätte. Aber darauf habe ich aus Zeitgründen verzichten müssen. Hätte ich mehr Zeit gehabt, so hätte ich die These vertreten, daß die Irreversibilität, die ebenso wie die dynamische Rente auch zahlreiche weitere soziale Errungenschaften kennzeichnet, die Gestaltungsfreiheit der Leistungsgesetzgebung in ihrem Ansatz unberührt läßt. Uber die Einführung der dynamischen Rente hat der Gesetzgeber jedenfalls frei entscheiden können. Daß er von dieser Entscheidung nicht mehr wegkommt, findet seine Erklärung darin, daß es Gestaltungsfreiheiten gibt, die man nur einmal nutzen kann, und preisgibt, wenn man von ihnen einen irreversiblen Gebrauch macht. Das gilt eben nicht nur für die Freiheit der Gattenwahl. Die Leistungsgesetzgebung steht in gleicher Weise unter dem Gebot des ,respice finem". Aber das ändert nichts daran, daß sie immerhin so lange frei schalten kann, als sie sich nicht in den Bannkreis rechtlicher Änderungsverbote oder faktischer Änderungshindernisse begibt und sich damit bewußt oder unbewußt selbst die Hände bindet.

Herr Hoffmann-Riem vermißte in Herrn Hills, Herrn Hufens und meinem Referat das Stichwort Planung. In meinem Referat war die Planung freilich indirekt in dem miteingeschlossen, was ich zur Finanzabhängigkeit des Leistungsrechts angemerkt habe. Denn die Finanzabhängigkeit des Leistungsrechts zwingt dazu, bei seiner Weiterentwicklung auf einer zukunftsorientierten Finanz- und Ausgabenplanugn aufzubauen. Die Finanz- und Leistungsplanung in die Leistungsgesetze einzubauen, halte ich dagegen für verfehlt. Diesen Fehler hat sich das Strafvollzugsgesetz geleistet. In ihm finden sich einige Paragraphen, die den Strafgefangenen u.a. die Aufnahme in die Sozialversicherung und die Gewährung eines arbeitsunabhängigen Taschengelds versprechen, dieses Versprechen aber nicht einlösen. Denn § 198 Abs. 3 StVollzG hat das Inkrafttreten dieser Paragraphen ad calendas graecas vertagt, indem er es vom Erlaß eines „,besonderen Bundesgesetzes“ abhängig macht, auf das die Strafgefangenen seit 1976 vergeblich warten und wohl noch lange vergeblich werden warten müssen. Diese Pa- 
ragraphen sind also m.a.W. vorerst nur, geplant ". Ob und wann sie in Geltung treten werden, liegt in nebelhaftem Dunkel. In diesem Verfahren des "rule now, pay later" sehe ich einen Mißbrauch der Gesetzesform. Paragraphen, die Leistungen nicht vorschreiben, sondern lediglich sine obligo in Aussicht stellen, gehören in die Schubladen der Regierung. In den Gesetzblättern wirken sie deplaziert. Sie sind ein Ärgernis, weil sie legislative Augenwischerei betreiben.

Herr Starck zeigt auf die Uhr. Darum nur noch ein letztes Wort zu Herrn von Mutius: Der Student, dem ein Verwandter einen Luxuswagen als Dauerleihgabe zur Verfuigung gestellt hat, ist mir tatsächlich begegnet. Er fuhr allerdings beim Studentenwerk vor, als dieses noch nach den Verwaltungsverordnungen des Honnefer Modells zu entscheiden hatte. Deshalb fiel es nicht weiter schwer, ihn an seinen Onkel zu verweisen und die Honnef-Gelder bedürtigeren Studenten ohne Herrenfahrer-Allüren zu reservieren. Unter der Geltung des BAFöG sehen die Dinge anders aus. Was sich mit einigem Geschick aus dem BAFöG herausholen läßt, hat sich auch rasch herumgesprochen. Es gibt eben nicht nur „1000 ganz legale Steuertricks", über die ein im Knaur-Verlag erschienenes Taschenbuch informiert. Auch die ganz- und halblegalen BAFöG-, Sozialhilfe-, AFG- und Rententricks sind in aller Munde. Es fehlt nicht an Sachkennern, die sie teils öffentlich, teils von Mund zu Mund propagieren.

Vorsitzender: Vielen Dank, Herr Mußgnug. Damit kann ich die zweite Runde eröffnen, und es wird als erster sprechen Herr Meyer und dann Herr Breuer.

Meyer: Erlauben Sie mir zunächst vier aphoristische Bemerkungen.

Erstens: Ich habe gestern zur Tradition der Vereinigung gesprochen und habe gesagt, wir sollten sie wahren. Ich will heute gegen die Tradition der Vereinigung sprechen. Die beiden Themen zeigen, daß es ungerecht war, das heutige Thema am zweiten Tag und das andere Thema am ersten Tag zu behandeln. Ich würde für die Zukunft vorschlagen, daß man alterniert. Es gibt keinen vernünftigen Grund, das Staatsrecht oder Verfassungsrecht immer an den Anfang zu stellen, zumal das Staatsrecht ohne Verwaltungsrecht nicht zu betreiben ist und das Verwaltungsrecht nicht ohne das Staatsrecht.

Zweitens: Wenn ich den Begriff Rechtsverhältnis höre, muß ich mein ceterum censeo einbringen, daß er zu keinerlei Erkenntniszuwachs führt, weshalb man es lassen sollte, davon zu reden.

Drittens: Ich habe noch nie einen überforderten Richter gesehen, wenn man damit die subjektive Befindlichkeit meint.

Viertens: Der Generationenvertrag ist eine große Heuchelei, denn es ist ein einseitiges Rechtsgeschäft zu Lasten Dritter. 
Und nun zu dem Vorbehalt des finanziell Möglichen von Herrn Mußgnug. Ich habe meine großen Bedenken, ob man sich tatsächlich im Ermessensbereich ganz schlicht auf die Erklärung zurückziehen kann: Jetzt haben wir kein Geld mehr - Schluß aus. Der Haushalt ist so aufzustellen, daß die voraussichtlichen Ausgaben eingesetzt werden. Die Verwaltung hat am Anfang des Jahres zu überlegen, was auf sie zukommt, und eine vernünftige Verwaltung agiert so, daß sie das Geld durch das Jahr gleichmäßig verteilen kann.

Was den Haushaltsplan als Erfüllung des Gesetzesvorbehaltes angeht, so ist Herrn Mußgnug zuzugeben, daß der Haushaltsplan in Deutschland, was die Titel angeht, relativ spezifiziert ist; aber dies ist keine verfassungsrechtliche Notwendigkeit. Außerdem sind die Titel höchst unterschiedlich spezifiziert. Es gibt Titel, die so spezifiert sind, daß sie den Empfänger, den Zweck und die Summe haben. Bei ihnen gibt es natürlich keine Schwierigkeiten zu sagen, dem Gesetzesvorbehalt sei Genüge getan. Aber es gibt Milliarden-Titel, in denen der Empfänger unbekannt und die Zweckbestimmung ziemlich unbestimmt ist, und ich kann nicht einsehen, daß das für den Gesetzesvorbehalt ausreicht.

Schließlich zu den allgemeinen Gesetzen im Sinne von Herrn $\mathbf{H u}$ fen. Ich glaube, die Idee ist fruchtbar, zentrale Rechtsgedanken in einer Weise zu formulieren, daß sie nicht mehr so leicht abänderbar sind, daß sie also - auch vom Gesetzgeber - ernster genommen werden. Das Problem dabei liegt aber darin, daß unsere Gesetze nicht vom Parlament gemacht werden, - das ist ja ein alter Irrtum -, sondern von der Verwaltung, und selbst das ist eine falsche Aussage. Nicht ,die Verwaltung “ macht die Gesetze, sondern die Ressorts machen die Gesetze. Unsere Ressort-Einteilung hat nun zur Folge, daß die Gesetze sozusagen ressortgeeignet gemacht werden, und die Ressorts haben als höchstes Interesse die Bestätigung ihres Eigenwertes mit der Konsequenz, daß allgemeine Ideen und Gedanken nicht berücksichtigt werden, wenn sie dem Ressort-Interesse widersprechen. Wenn wir allgemeine Gesetze einer etwas übergeordneten Art haben wollen, müssen wir notwendigerweise gegen die Ressort-Einteilung ankämpfen, was freilich im Sinne der Rechtsstaatlichkeit ein Vorteil wäre.

Breuer: Hinter dem heutigen Thema steht die Sorge um die Normierbarkeit und die Vollziehbarkeit unseres Leistungsrechts, und deswegen scheint es mir notwendig zu sein, noch einmal auf die Frage zurückzukommen, welche Instrumente wir eigentlich empfehlen, um den Defiziten und den Problemen des Leistungsrechts gerecht zu werden. Es ist ja weidlich darüber geklagt worden, daß wir eine Gesetzesflut hätten und gleichzeitig Regelungsdefizite - ein paradoxes Phänomen. 
Unter diesem Gesichtspunkt will ich versuchen, vier Punkte in die Debatte einzuführen.

Der erste Punkt betrifft den Gedanken der Gesetzestypen. Sie, Herr Hill, haben in Ihren Thesen 2 und 4 von Gesetzestypen gesprochen. Auch zwischen den Zeilen des Referates von Herrn Hufen klang dieser Gedanke an. Herr Püttner hat zu Recht schon bemerkt, daß wir dabei zu Fragen der Gesetzgebungslehre kommen; das scheint mir auch richtig zu sein. Aber mir drängt sich doch der Eindruck auf, daß wir die Ansätze der Gesetzgebungslehre bislang nicht hinreichend ausgeschöpft haben. Es gibt etwa den fundamentalen Unterschied zwischen konditionalen Gesetzen, die namentlich Anspruchstatbestände regeln, und finalen Gesetzen, die nur ein Programm aufstellen, was insbesondere im Subventionsrecht eine große Rolle spielt. Es gibt weiter den Ansatz, daß man langfristig angelegte Kodifikationsgesetze, kurzfristig angelegte Anpassungsgesetze und situative Maßnahmegesetze unterscheidet. Man kennt weitere Unterscheidungen. Ich will das hier im einzelnen nicht ausführen. Staatsrechtlich muß aber die entscheidende Frage sein, was diese Unterscheidungen bewirken, was sie für die Maßstäbe des Verfassungsrechts bedeuten und was sie dem Verfassungsgericht und überhaupt der Gerichtsbarkeit an Möglichkeiten eröffnen, ein Gesetz für verfassungswidrig und nichtig zu erklären. Ist es vielleicht möglich, daß unterschiedliche Kontrollmaßstäbe für die verschiedenen Gesetzestypen gelten? Ich könnte mir solche Unterschiede in der Tat vorstellen. Wo der Gesetzgeber im Einklang mit dem Gesetzesvorbehalt nur Programme aufstellt, kann er sich natürlich nur in relativ unbestimmter Weise äußern. Wo der Gesetzgeber langfristig Ansprüche einräumt, auf die der Bürger sich einrichtet, ist eine Aufhebung des Gesetzes vermutlich aus rechtsstaatlichen und grundrechtlichen Gründen sehr viel schwieriger als dort, wo der Gesetzgeber nur situative Einzelfallgesetze erläßt. Auf der anderen Seite kann bei situativen Einzelfallgesetzen vielleicht eine Anleihe bei verwaltungsrechtlichen Grundsätzen über die Rücknahme oder den Widernuf von Verwaltungsakten möglich sein. Ich erwäge dies alles vor dem Hintergrund der Frage, ob die unterschiedlichen Gesetzestypen, die wir in der Gesetzgebungslehre unterscheiden, verfassungsrechtliche Erkenntnisse vermitteln können.

Zweiter Punkt: Mich bewegt nach wie vor Ihre bestechende These, Herr Hufen, über das Grundlagengese tz, und eine gewisse geistige Wahlverwandtschaft $\mathrm{zwischen}$ uns beiden wird Ihnen ebenso vor Augen stehen wie mir. Nur haben Sie sozusagen das Maximum dieses Gedankens eingeführt, indem Sie in Ihrer These 7 von verfassungsrechtlich besonders hervorzuhebenden und abzusichernden Grundlagengesetzen gesprochen haben. Ich verstehe das so, daß Sie einen strikten Vorrang eines solchen Grundlagengesetzes kraft einer einzuführenden Verfas- 
sungsbestimmung befürworten wollen. Das Bestechende an dem Gedanken liegt darin, daß man auf diese Art und Weise den Gesetzgeber zwingen kann, sich grundsätzlich über seine Ziele zu äußern und daß man den Gesetzgeber später auch daran messen kann. Hierin steckt also ein Stück an Rationalität und an Disziplinierung des Gesetzgebers. Die Bedenken gegen diese These scheinen mir jedoch einer weiteren Diskussion bedürftig zu sein. International gesehen, gab es zu Anfang der 60er Jahre in Italien eine Diskussion über die super legge, also das „Supergesetz", das einen solchen Vorrang haben soll. In Italien ist aber meines Wissens die Debatte nicht zu einer Einführung eines solchen "Supergesetzes“ gediehen. Sachlich stellt sich aus meiner Sicht ein Problem des demokratischen Prinzips. Ein solches "Supergesetz“ würde nämlich, wenn es mit einem Vorrang ausgestattet ist, nicht nur während der laufenden Legislaturperiode wirken, sondern auch in spätere Legislaturperioden hinein den künftigen Gesetzgeber binden. Es würden dem künftigen Gesetzgeber zusätzliche Hürden aufgebaut werden. Daher stellt sich doch die Frage, ob der aktuelle Gesetzgeber einer Legislaturperiode den künftigen Gesetzgeber späterer Legislaturperioden insoweit binden kann. Ich habe auch eine gewisse Sorge vor einer Hypertrophie unseres Stufenbaus der Rechtsordnung. Schon am gestrigen Tage ist zu Recht darauf hingewiesen worden, daß die europarechtlichen Vorgaben zunehmende Bedeutung gewinnen. Auf der staatlichen Ebene des Verfassungsrechts haben wir es zudem nicht nur mit den dürren Normen des Grundgesetzes zu tun, sondern auch mit Unterprinzipien, die in der verfassungsgerichtlichen Judikatur herausgearbeitet werden, dann aber bei der weiteren Judikatur ebenso wirken wie Sätze des geschriebenen Verfassungsrechts. Wir haben sodann die einfache Gesetzgebung, die Rechtsverordnung, ferner außer der Bundesgesetzgebung die Landesgesetzgebung und im Sozialrecht ein Satzungsrecht von erheblicher Bedeutung; auch im Kommunalrecht hat das Satzungsrecht die bekannte Bedeutung. Ich frage mich nun, ob es wirklich verfassungspolitisch überzeugend ist, eine zusätzliche Schicht einzuführen, indem der Gesetzgeber nicht nur einfache Gesetze normalen Ranges erläßt, sondern auch „Supergesetze“.

Um auf die Wahlverwandtschaft zurückzukommen, Herr Hufen: Eine vorsichtigere Alternative für das gemeinsame Anliegen, den Gesetzgeber zur Rationalität zu zwingen und ihn zu disziplinieren, könnte es vielleicht sein, aus grundsätzlichen und programmatischen Gesetzen eine Selbstbindung nach Maßgabe rechtsstaatlicher Prinzipien abzuleiten. Wenn der Gesetzgeber programmatische Ziele aufstellt und sich dann in einem Einzelfallgesetz anders verhält, wenn man ihm also einen Widerspruch zu seinen eigenen Programmgesetzen vorhalten kann, dann spricht doch vielleicht einiges dafür, nach den Grundsätzen des Rechtsstaates, des Vertrauensschutzes und auch der Systemgerechtig- 
keit das nachfolgende Einzelfallgesetz wegen eines Widerspruchs zum Programmgesetz für verfassungswidrig und nichtig zu erklären. So könnte schon auf der Grundlage des geltenden Rechts - ohne einen förmlichen Vorrang eines „Supergesetzes“ - manches von dem realisiert werden, was Ihnen offenbar unter dem Gedanken des Grundlagengesetzes vorschwebt.

Drittens, Herr Hill: Mit Ihrer These 7 - Stichwort: „,bewegliches System der Gesetzesgestaltung “ - vermag ich mich nicht recht anzufreunden. Ich frage mich, ob dies eigentlich im Ergebnis etwas anderes ist als die Technik der Gesetzesauslegung und -konkretisierung, wie wir sie bislang gewohnt sind. Mir ist jedenfalls nicht verständlich geworden, inwieweit Sie damit über die bisherige Methodik und Technik der Gesetzesauslegung hinaus etwas Neues und anderes sagen wollen.

Viertens: Zur These 13 von Herrn Hill scheint mir ein Hinweis darauf notwendig zu sein, daß die Kritik an dem Nebeneinander von anspruchsbegründenden Gesetzen und Ermessensvorschriften meines Erachtens ihrerseits fragwürdig ist. Ich habe immer den rechtsstaatlichen und sozialstaatlichen Fortschritt des Leistungsrechts darin gesehen, daß es eben nicht nur ein Verwaltungsermessen gibt, sondern auch einige gesetzlich zementierte Anspruchspositionen. Ich meine auch, daß man dem Gesetzgeber ein Stück Weisheit unterstellen kann, wenn er auf der einen Seite vor dem Hintergrund der Grundrechte, des Rechtsstaatsprinzips und des Sozialstaatsprinzips rechtsbegrifflich begründete Ansprüche gewährt und auf der anderen Seite zusätzliche Ermessensvorschriften vorhält. Es erscheint mir höchst gefährlich zu sein, diese Abstufung zwischen Gesetzesbindung und Ermessen dadurch zu beseitigen und einzuebnen, daß man ein kooperatives System des Verhandelns zwischen Bürger und Verwaltung befürwortet. Hier droht etwas von dem verloren $\mathrm{zu}$ gehen, was im grundrechtlich abgesicherten, rechts- und sozialstaatlichen Leistungsrecht in den letzten Jahrzehnten errungen worden ist.

Vorsitzender: Vielen Dank, Herr Breuer. Sie haben einen grundlegenden Diskussionsbeitrag gegeben, wie er am Anfang hier auch zugelassen worden ist. Ich möchte aber jetzt alle folgenden Diskussionsteilnehmer bitten, vier Minuten nicht mehr zu überschreiten, und zwar deshalb, weil ich noch 11 Wortmeldungen habe, und wir um 17.45 Uhr mit den Schlußworten beginnen müssen, damit wir pünktlich enden können. Auch alle die, die sich von vornherein für den Punkt 3 gemeldet haben, müssen eine Chance bekommen, sich auch noch zu äußern und dafür die notwendige Zeit zur Verfügung zu haben. Herr Dittmann, dann kommt Herr Zeh, dann Herr Schachtschneider. Also, Herr Dittmann, Sie gehen jetzt mit gutem Beispiel voran und unterschreiten die 4-Minuten-Grenze, zumindest überschreiten Sie sie nicht. 
Dittmann: Nach den ausführlichen verfassungsrechtlichen Bemerkungen von Herrn Breuer kann ich mich darauf beschränken, zu der These VII von Herrn Hufen nur einen Gesichtspunkt nachzuschieben und gleichzeitig eine Beziehung zwischen dieser These und der These VI von Herrn Mußgnug herzustellen. Zwischen beiden Thesen besteht m.E. nämlich eine gewisse Unverträglichkeit. Während Herr Mußgnug eingangs seines Referates zu Recht auf die Finanzabhängigkeit des Leistungsstaates hingewiesen und dann sehr konsequent in seiner These VI auf die Notwendigkeit verwiesen hat, den Leistungsstaat hinreichend flexibel zu halten, um auf veränderte finanzielle Rahmenbedingungen reagieren zu können, scheint mir die Forderung von Herrn $\mathrm{Hu}$ fen nach einer besonderen Grundsatz-oder Stammgesetzgebung genau das Gegenteil zu bewirken. Ich sehe die Gefahr, daß die Handlungsfähigkeit und damit letztlich die Funktionsfähigkeit des Leistungsstaates beeinträchtigt werden, wenn neben die bereits bestehenden europarechtlichen und verfassungsrechtlichen Bindungen des einfachen Gesetzgebers nun auch noch eine weitere besondere Bindung durch eine Grundsatz-oder Stammgesetzgebung treten soll. Aber vielleicht - und das ist meine Frage an Herrn Hufen - lassen sich aus seiner Sicht diese verschiedenen Ebenen der Gesetzgebung funktional so voneinander abschichten, daß diese Gefahr gebannt werden könnte.

Zeh: Bei so mutigen und so gehaltvollen Vorträgen, wie wir sie gehört haben, möchte man am liebsten zu allem etwas sagen. Das geht nicht. Deshalb greife ich einen einzelnen Punkt heraus und bitte, das nicht mißzuverstehen.

Herr Hufen, Ihre Vorschläge zu den institutionellen und instrumentellen Möglichkeiten werfen mancherlei Fragen auf. Zunächst die gesetzesvorbereitende Kommission: Wenn ich sie richtig verstehe, wird von ihr erwartet, daß sie etwas produziert, was besser ist als die bisherige Vorbereitung von Gesetzen; die Kommission müßte ihr Ergebnis dann dem Gesetzgeber anbieten oder zur Verfügung stellen. Das setzt voraus, daß es einen Gesetzgeber als Adresse in diesem Stadium gibt. Das trifft aber so nicht zu. Man muß vielmehr davon ausgehen, daß es den Gesetzgeber, der die Gesetze gibt, nicht gibt. Vielmehr haben wir einen hochkomplexen Prozeß von vielen Beteiligten, unter denen das Parlament ein wichtiger oder der wichtigste Beteiligte ist; es wirkt als Moderator, als Scharnier und Integrator, ,gibt" aber nicht selbst die Gesetze. Der Ausdruck stammt aus dem Absolutismus. In das heutige komplizierte und langwierige Verfahren der Gesetzgebung sind Parteien, Verbände und Organisationen, Medien und alle anderen, die Interessen vertreten, eingeschaltet - und für alle diese Beteiligten ist es legitim, Interessen zu vertreten. Diesen Prozeß können wir mit einer 
wie auch immer zusammenzusetzenden und zu legitimierenden Kommission weder ersetzen noch verbessern. Fragwürdig scheint zudem die Forderung, daß es sich um eine unabhängige Kommission handeln soll. Unabhängig wovon? Wir akzeptieren alle, daß die Verfassung Parteien vorsieht und daß sie eine bedeutende Rolle spielen, daß es im Pluralismus legitime Interessen und ihre Vertretungen gibt, daß wir Teilinteressen und unterschiedliche Belange durch Föderalismus und kommunale Selbstverwaltung zur Geltung bringen. Von all dem könnte eine Kommission nicht unabhängig sein, wenn sie zugleich repräsentativ sein sollte. Wir sollten statt dessen zugestehen, daß die Kommission, die gesucht wird, schon existiert: Es ist das Parlament mit seinen Ausschüssen, und dabei sollte es auch bleiben. Etwas anderes wäre ein Verfahren der Gesetzesvorbereitung wie in Schweden, wo zahlreiche kleine spezialisierte Kommissionen mit den einzelnen Gesetzentwürfen befaßt werden; dabei handelt es sich aber lediglich um eine andere Form der Gewinnung von spezialisierter Sachkunde und der Kanalisierung des Verbandseinflusses. Ich glaube nicht, daß der Versuch lohnen würde, unser Verfahren in dieser Richtung umzuorganisieren.

Einem anderen Vorschlag kann ich mehr abgewinnen: Der Neudefinition und Neuaufteilung von Gesetzeskategorien. Das Modell eines Grundsätzegesetzes oder Grundlagen- oder Stammgesetzes würde Gestalt annehmen, wenn es von alledem freigehalten würde, was sich heute in einem durchschnittlichen Gesetz an Vorschriften verschiedenster Ebenen mischt. Man müßte dann die vielen Verwaltungsvorschriften, Durchführungshinweise, Informationen, Definitionen usw. in eine neue Form bringen, in eine Art „Konkretisierungsfenster“. Allerdings denke ich, daß die dafür geeignete Form nach wie vor die Rechtsverordnung sein könnte. Ich glaube nicht, daß wir eine neue, dritte Ebene der vereinfachten Gesetzgebung zwischen Rechtsverordnung und $\mathrm{Ge}$ setz brauchen. Statt dessen sollten wir an Art. 80 Grundgesetz ansetzen und das Verordnungsrecht der Regierung erleichtern, etwa die Ermächtigung an die Einhaltung der Gesetzesziele binden. Dann könnte dem eigentlichen Gesetz das verbleiben, was Sie nur noch im Stammgesetz sehen möchten, nämlich Grundlegendes, Richtungweisendes und damit vielleicht auch etwas zeitlich Stabilisierendes. Schon die Enquete-Kommission Verfassungsreform des Bundestages hat sich in den frühen siebziger Jahren mit entsprechenden Uberlegungen befaßt. Ich halte das aus den Erfahrungen mit der Weimarer Verfassung stammende Mißtrauen gegen ein selbständigeres Verordnungsrecht der Regierung inzwischen nach 40 Jahren parlamentarischer Regierungsweise - welche die Regierung ja doch stark an das Parlament bindet - für nicht mehr gerechtfertigt. Der Vorschlag einer neuen und rationaleren Aufteilung der Rechtsetzungsmaterien auf zwei Normebenen könnte deshalb mit vorhandenen Instituten - Gesetz und Verordnung - ange- 
gangen werden. Das wäre unter Umständen aussichtsreicher als neue Kategorien zu ersinnen.

Vorsitzender: Vielen Dank. Ich habe hier zwei Spontanmeldungen; ich möchte den Versuch machen, sie zuzulassen, indem ich davon ausgehe, daß sie nur eine kurze Aussage oder eine Frage enthalten. Erstens, Herr Schneider, zweitens, Herr von Arnim.

Schneider: Kurze Zwischenbemerkung. Ich widerspreche Ihnen, Herr Zeh, zwar nur ungern, muß aber Herrn Hufen in Schutz nehmen. Ein kleines Beispiel: Ohne die Alterssicherungskommission der Bundesregierung wäre es wahrscheinlich nicht möglich gewesen, auch nur zu hoffen, daß die Rentenreform einigermaßen einvernehmlich zustandegebracht wird. Wir haben das Gegenbeispiel bei der Krankenversicherungsreform erlebt. Dort hat der Sozialbeirat allein den Versuch machen wollen, ein konsensfähiges Konzept zu entwickeln, und ist gescheitert. Es sind nämlich dieselben Leute, die in der Alterssicherungskommission saßen, damals noch nicht unter Zeitdruck arbeiteten, die dann hinterher wieder als Interessenvertreter auftraten. Diese Kommunikations- und Konsensmöglichkeiten, die wir da hatten, sind notwendige Voraussetzungen dafür, daß das Reformwerk gelingen kann. Ich plädiere also nachdrücklich für solche Gesetzgebungskommissionen, und zwar unabhängig davon, ob sie bei der Regierung oder beim Parlament angesiedelt sind.

Vorsitzender: Vielen Dank, Herr Schneider. Herr von Arnim, noch kürzer.

von Arnim: Auch ein Beispiel dafür, daß das Parlament nicht unbedingt gleichbedeutend mit einer Kommission ist: Der hessische Diätenfall hat dazu geführt, daß viele Parlamente von sich aus die Einsetzung unabhängiger Diätenkommissionen gefordert haben.

Vorsitzender: Ebenso kurz, Herr Steinberg.

Steinberg: Ich würde doch sehr bitten, daß man die Schweizer Kollegen zu der Praxis der schweizerischen Expertenkommissionen hört, die - wie ich glaube - ja doch ganz in dem von Herrn Hufen geforderten Sinne tätig werden. An dieser Stelle beschränke ich mich auf diese Bemerkung.

Vorsitzender: Herr Schachtschneider. Danach Herr Wallerath, Herr Schmidt-Jortzig und Herr Ress. Dann hätten wir den Punkt 2 damit abgearbeitet. Herr Schachtschneider, bitte. 
Schachtschneider: Zwei kurze Bemerkungen zur Rechtstechnik der Verwirklichung des Leistungsrechts, zunächst zum Bereich der Krankenversorgung: Ich möchte auch Skepsis gegenüber dem Modell der Kooperation anmelden. Wir kennen Kooperation, nämlich die zwischen Arzt und Patient zu Lasten der Allgemeinheit der Versicherten. Kooperation wird allzu leicht zum kollusiven Zusammenwirken. Zweitens zur Rechtstechnik der notwendigen Differenzierung zwischen der Grundlagengesetzgebung und flexibler Ausführungsrechtsetzung. Zum einen stehen, wie Herr Zeh schon sagte, die Rechtsverordnungen zur Verfügung; zum anderen sollten der rechtsetzende Verwaltungsakt, das rechtsetzende Verwaltungshandeln, welches Verbindlichkeit schafft, anerkannt werden. Das würde den Umweg ersparen, den Verwaltungsvorschriften über den Gleichheitssatz Verbindlichkeit für zukünftige Fälle zu verschaffen. Rechtsetzung ist nicht allein der Legislative vorbehalten. Anderes ist konstitutionalistisch. Rechtsetzung muß den Vorbehalt und den Vorrang des Gesetzes respektieren. Der Vorbehalt kann auf Grundlagenfragen, auf die Zweckfestsetzung beschränkt sein. Der Verwaltungsrechtssatz wäre eine weitere instrumentelle Hilfe für die angesprochene Differenzierung. Danke schön.

Wallerath: In These 5 formuliert Herr Mußgnug, daß der Gesetzgeber den Finanzierungsproblemen des Leistungsrechts u.a. auch durch „Verschonungsleistungen“" ausweichen kann. Ich sehe damit vor allem die Frage der Austauschbarkeit von Formen des Leistungsrechts mit denen der Verschonung im Eingriffsrecht aufgeworfen. Das Bundesverfassungsgericht hat hierzu - gleichsam aus umgekehrter Perspektive - formuliert, der Gesetzgeber sei berechtigt, Umstände, die die wirtschaftliche Leistungsfähigkeit des Betroffenen mindern, ausnahmsweise nicht im Steuerrecht, sondern im Sozialrecht zu berücksichtigen. Das entspricht einer Neigung des modernen Gesetzgebers, die fehlende Verschonung bei Eingriffen, insbesondere im Steuerrecht, durch eigenständige Leistungssysteme $\mathrm{zu}$ kompensieren und sich so einen größeren ,strategischen “ Spielraum zu eröffnen.

Ich habe Zweifel, ob eine Aktivierung des Leistungsrechts ohne weiteres die fehlende Verschonung im Eingriffsrecht zu ersetzen vermag. Um dies an einem Beispiel, nämlich dem des Famlienlastenausgleichs, zu verdeutlichen - Herr Isensee hat das Stichwort ja eben bereits eingebracht: Der Gesetzgeber kann den Familienlastenausgleich herstellen, indem er Kindergeld zahlt, eine steuerrechtliche Entlastung vorsieht oder indem er beide Möglichkeiten miteinander kombiniert. Angenommen, der Gesetzgeber entschiede sich, wie in der Vergangenheit zeitweise praktiziert und vom Bundesverfassungsgericht auch sanktioniert, für eine reine Kindergeldlösung: Dann entspräche die Zahlung eines Kindergeldes in Höhe von DM 50,- im Effekt einem 
Kinderfreibetrag in Höhe von DM 210,- im Eingangssteuerbereich. Unterstellt, diese DM 210,- entsprächen genau der zu berücksichtigenden zusätzlichen Belastung. Sollte es nun wirklich zutreffen, daß die DM 50,- Kindergeld die steuerliche Berücksichtigungsfähigkeit des gesamten Aufwandes für die Kindererziehung ausschließen, nur weil die steuerliche Entlastung im Eingangssteuerbereich im Ergebnis ebenfalls nicht höher liegen würde? Oder ist es nicht vielmehr so, daß das geringere Kindergeld lediglich den steuerlich zu berücksichtigenden Gesamtaufwand mindert, also zumindest solange nach einer ergänzenden steuerrechtlichen Regelung verlangt, als es eine progressive Einkommenssteuer gibt?

Mir scheint es wichtig, darauf hinzuweisen, daß die leistungsrechtliche Lösung die steuerrechtliche Lösung gerade nicht zu substituieren vermag, sofern sie nicht, was finanziell kaum zu leisten wäre, den gesamten zusätzlichen Aufwand abdeckt. Sie kann damit lediglich den notwendigen Flankenschutz für eine ebenfalls nur begrenzt geeignete steuerrechtliche Lösung abgeben. Diese ergënzende Funktion wird in These 5 von Herrn Mußgnug sehr viel deutlicher als in der Rechtsprechung des Bundesverfassungsgerichts, die das Problem m.E. entscheidend verkürzt.

Vorsitzender: Vielen Dank, Herr Wallerath, für diese wichtigen Hinweise. Jetzt wird Herr SchmidtJortzig über das Sozialgeheimnis und über das Problem des Rechtsverhältnisses sprechen.

Schmidt-Jortzig: Ich habe mir mehrere Stichworte zum derzeitigen Diskussionsbereich notiert, verspreche aber, daß ich mich an die Zeit halte.

Als erstes möchte ich in aller Dringlichkeit eine Eingangsbemerkung von Herrn Meyer dem Reich des Aphoristischen entreißen. Genau wie ihm liegt mir daran nachzufragen, lieber Herr Hill, was denn die Figur des „Rechtsverhältnisses “ dogmatisch und methodisch wirklich an Nutzen bringt. Ich vermag hier jedenfalls bisher nicht sehr viel zu erkennen. Zwar läßt sich sehen, daß jener Ansatz rechtstheoretisch, vielleicht auch rechtsphilosophisch, den einen oder anderen Aspekt verdeutlichen mag. Neuartiges aber, was ohne ihn noch nicht geläufig war, eigenständig Handgreifliches, bringt er kaum. Deshalb wäre ich Ihnen (und der Punkt ist ja ein schon längerwährendes Thema bei uns in der Vereinigung) dankbar, wenn Sie mir noch ein wenig Nachhilfe gäben, was konkret mit der dogmatischen Figur des Rechtsverhältnisses gewonnen werden könnte.

Zweites Stichwort, nur ganz kurz. Lieber Herr Hufen, zu Ihrem Vorschlag einer Operationalisierbarkeit gesetzlichen Regelungszugriffs durch Festlegung des Längergültigen, Grundlegenden in einem 
„Stammgesetz“ und einer Ubernahme der Tagesanpassung und Durchführung in rascher änderbare, irgendwie nachrangige Gesetzesnormen bewegt mich schon während der ganzen letzten Wortmeldungen das Beispiel des Haushaltsgrundsätzegesetzes. Wäre damit nicht ein Vorbild gegeben? Dort haben wir doch, selbst wenn sie inhaltlich Rückgriffe auf Art. 109 GG nehmen kann, eine einfachgesetzliche Norm, welche indes die nominell gleichrangigen, jährlichen Haushaltsgesetze in Griff hält und dirigiert.

Drittes Stichwort, und wenn es erlaubt ist, möchte ich hier noch einmal auf einen Punkt zurückkommen, der schon mehrfach in der Diskussion angesprochen wurde, aber eben auch eine ganz gezielt instrumentelle Bedeutung hat. Ich habe die These 11 von Herrn Hufen jedenfalls so verstanden (und möchte mir darüber Rechenschaft geben), daß wir das Thema „Selbstregulierung“ weniger als eine Frage grundsätzlicher Problematisierung des Leistungsstaates denn als seines veränderten Instrumentariums behandeln sollten. Jedenfalls gilt es, davor zu warnen, sich hierbei zu rasch etwas in Richtung Staatsentlastung zu versprechen. Verschiedentlich klang es schon in Zwischentönen an, und ich möchte mich nun ausdrücklich dazu bekennen: „Selbstregulierung" in bisher staatlich bestrittenen Handlungsbereichen kann eigentlich nur heißen, daß es in gezielter, hoheitlicher Anstrengung der Staat selber ist, welcher individuelle Verantwortungsübernahme und Gestaltungsinitiative anregt, unterstützt und gewährleistet. Es geht also um eine spezifische, neue Förderung der personalen Freiheit, und das muß gar nicht unbedingt zu einer Entlastung des Staates führen. Ich erinnere nur an gewisse Aspekte der Privatisierungsdiskussion, wo man den aufgabenausgliedernden Hoheitsträger noch über sog. Garantenpflichten in der Verantwortung zu halten sucht.

Viertens und letztens, lieber Herr Mußgnug, zu Ihrer These 18. Sie haben dort den Datenschutz angesprochen, und zwar die Wahrung des Sozialgeheimnisses zwischen zwei Behörden desselben Verwaltungsträges. Offenbar ist dies ein Querschnittsproblem für die gesamte Leistungsverwaltung, und ich möchte uns deshalb anregen noch nachzudenken, wie wir dort griffiger werden können. Materiell-rechtlich ist es seit der bekannten Bundesverfassungsgerichtsentscheidung keine Frage mehr, daß es zur Sicherung der persönlichen Daten für jede ihrer verwaltungsmäßigen Verarbeitung einer bereichsspezifischen Ermächtigung mit bereichsspezifischer Zweckfestlegung und bereichsspezifischen Abschottungsvorkehrung bedarf. Aber verfahrensmäßig, meine Damen und Herren Kollegen, verfahrensrechtlich sehe ich eigentlich die Zugkraft dieser Vorgaben, ihre Konsequenz noch nicht gesichert. Zum einen sind datenschutzwidrig erlangte Kenntnisse ja sicherlich unrechtmäßige Momente, die deshalb nicht verwandt werden dürfen. Aber ich erinnere an $\S 44 \mathrm{a}$ VwGO, wonach jener Verfahrensmangel 
kaum angegriffen werden kann, wenn die Sachentscheidung gleichwohl zugunsten des Antragstellers ausging. Zum anderen sei nur (ich habe da selber Bedenken) der vorsichtige Hinweis auf $\S 46 \mathrm{VwVfG}$ erlaubt: Wäre ein Datenschutzverstoß nicht salviert, wenn mit dem rechtmäßig gewonnenen Faktenmaterial die gleiche Sachentscheidung hätte herauskommen können? Und schließlich, Herr Mußgnug: Was passiert, wenn die Sozialverwaltung gewissermaßen auf Verdacht handelt, sich also gar nicht auf das schwierige Geschäft einer präzisen und eben datenschutzkonformen Tatsachenermittlung einläßt, sondern die heiklen personalen Voraussetzungen einfach annimmt? Dann würde im Rechtsschutzverfahren doch das Verwaltungs- oder Sozialgericht das wirkliche Vorliegen der Tatbestandsvoraussetzungen per Untersuchungsgrundsatz zu ermitteln haben, und dem Gericht kann das Sozialgeheimnis nach SGB X nur in begrenztem Maße entgegengehalten werden. Also ich glaube, man muß sich für die Praxis der Leistungsverwaltung nachdrücklicher fragen, wie denn das Sozialgeheimnis effektiv durchgehalten werden kann oder ob es in diesem Bereich nicht von vornherein nur einen begrenzten Geltungsraum hat. Danke sehr.

Vorsitzender: Danke. Ich habe jetzt noch eine Wortmeldung zu Punkt 2. Das ist Herr Ress. Er will zu Punkt 2 und zu Punkt 3 sprechen. Nun ist aber eine weitere Wortmeldung von Herrn Isensee gekommen, die ich leider nur als Kurzintervention zulassen kann. Sie haben nach Herrn Ress das Wort. Dann würde ich die Diskussionsrunde zu Punkt 3 eröffnen, die mit Herrn Häberle beginnen würde. Bitte schön.

Ress: Ich möchte zu den Reformvorstellungen sprechen, die schon angeklungen sind. Das Problem, das alle drei Referenten bewegt hat, ist u.a. die Leistungsfähigkeit des parlamentarischen Gesetzgebers im Leistungsstaat. Ich war überrascht durch die Ausführungen einiger Intervenienten, die man dahin interpretieren könnte, daß die Abdankung und ein weitgehender Funktionsverlust des parlamentarischen Gesetzgebers gegenüber der Exekutive erreicht sei. Der Vorschlag von Herrn Hufen läuft darauf hinaus, dem parlamentarischen Gesetzgeber noch jenen Raum der Festlegung und Dauerhaftigkeit zu sichern, der mit dem Begriff "Stammgesetz", „Wesentlichkeitsgesetz" u.ä. verknüpft ist. Ich möchte ein solches Modell nachdrücklich unterstützen. In Anknüpfung an Herrn Isensee und vielleicht im Gegensatz zu Herrn Mußgnug bin ich der Ansicht, daß wir auch im Subventionsrecht gesetzliche Regelungen über Voraussetzungen und Arten der Subventionen benötigen; denn der Zweck der Subventionen wird im Haushaltsplan in der Regel nicht ausreichend geregelt. 
Herr Hufen hat zwei Reformen angeregt, die die Rolle des parlamentarischen Gesetzgebers verbessern könnten. Was er als Kommission angeregt hat, ist im Grunde im angelsächsischen Rechtsraum längst akzeptiert und verwirklicht. Die law commissions sind im angelsächsischen Rechtsraum ein etabliertes Instrument unabhängiger, begleitender Beratung, auch kontroverser Beratung. Sie haben sich bewährt. Ich frage mich, warum wir diesen Erfahrungsschatz nicht aufgreifen. Es wird natürlich immer ein Problem der Unabhängigkeit derartiger Kommissionen geben. Dafür lassen sich aber Vorkehrungen treffen. Diese Kommissionen entsprechen zwar nicht dem von Herrn Schneider eingebrachten Modell einer parteienübergreifenden Schlichtungskommission. Sie sind hochspezialisierte, permanent arbeitende Kommissionen, die dem Parlament Anregungen für Gesetzgebungsvorhaben geben. Wer jemals in der angelsächsischen Welt diese Kommissionen besucht und mit ihren Mitgliedern diskutiert hat, weiß, daß sie weitgehend unabhängig sind und außerordentlich anregend zu arbeiten verstehen. Ich halte derartige Kommissionen in der Tat für eine Möglichkeit, dem parlamentarischen Gesetzgeber eine Hilfe bei seiner schwierigen Aufgabe, u.a. auch seiner Auseinandersetzung mit der in der Regel besser informierten Ministerialbürokratie zu geben.

Der zweite bedenkenswerte Aspekt ist eine gestufte Gesetzgebung. Wir kennen derartige Rang- und Verfahrensunterschiede zwischen verschiedenen Arten der Gesetzgebung nach ihrer inhaltlichen Gewich. tung aus vielen anderen Staaten. Sowohl Spanien als auch Frankreich mit der loi organique haben in ihren Verfassungen derartige Regelungen. Warum soll man nicht auch bei uns eine derartige Möglichkeit aufgreifen? Natürlich bedarf es einer Verfassungsänderung. Für die Einführung eines derartigen, speziellen Gesetzestypus kommen wir ohne eine Verfassungsänderung nicht aus. Ob man sich unter der gegenwärtigen Verfassungslage mit irgendwelchen internen Behelfen wie z.B. § 2 der Abgabenordnung 1977 über den Vorrang der Doppelbesteuerungsabkommen vor innerstaatlichen Steuergesetzen - begnügen kann, will ich nicht diskutieren. Solche Regelungen, die auch für die EMRK erwogen wurden, sind im Grunde keine Lösungen. Es wäre demgegenüber der Uberlegung wert, ob man nicht mit einer echten gestuften Gesetzgebung, die andere Staaten auch praktizieren, der Qualität und Dauerhaftigkeit der parlamentarischen Gesetzgebung bei uns einen Dienst erweisen würde.

Und schließlich, wenn es darum geht, aus der Sorge um den parlamentarischen Gesetzgeber im Leistungsrecht Úberlegungen anzustellen, dann müssen wir auch die europäische Dimension einbeziehen. In Europa entwickelt sich über das Jahr 1992 hinaus eine Exekutivgesetzgebung durch den Ministerrat, die ausgehend von der Ministerialbürokratie der einzelnen Mitgliedsstaaten - natürlich unter Beteiligung des 
Europäischen Parlaments, aber nicht mit einer Letztentscheidung des Parlaments ausgestattet - zustandekommt. In der EWG haben wir wenn Sie sich die Visionen Delors, die durch die Zeitungen gingen, vorstellen, wonach die wesentlichen Finanz- und Wirtschaftsgesetze ab 1992 nur noch vom Ministerrat der EG mehrheitlich nach dem neuen Verfahren des Art. 100a EWG-V. verabschiedet werden - den Zustand einer ausufernden Exekutivgesetzgebung, gerade auch in leistungsrelevanten Bereichen. Wirtschafts- und Sozialrecht in enormer Breite wird der nationalen Gesetzgebung entzogen und einem nur mittelbar demokratisch legitimierten Rechtsetzungsverfahren in der EG überantwortet. Wenn Sie sich das vorstellen, dann ist die Sorge um den parlamentarischen Gesetzgeber in diesem Zusammenhang um so mehr begründet. Die Frage nach der verfassungsrechtlichen Zulässigkeit einer derartigen dynamischen „Entparlamentarisierung" wird sich nach 1992 in aller Schärfe stellen.

Isensee: Die Frage, die zu Teil 2 noch aussteht: Gibt es rechtliche Kriterien des richtigen Weges, den Leistungsbedarf der Gesellschaft zu erfüllen? Die Typologie der möglichen Mittel und Wege läßt sich jetzt nicht darstellen. Aber es seien wenigstens einige Grundformen der Leistungserbringung genannt: privatautonome Leistungen im Rahmen der Marktwirtschaft, sei es ohne, sei es mit staatlichen Vorgaben; staatliche Leistungsanreize und belohnungen, etwa Steuerverschonung und Subvention;staatliche Regulierung; staatlich organisierte und garantierte Selbsthilfe: die Sozialversicherung; schließlich unmittelbare Leistungen der öffentlichen Hand, vor allem die Sozialhilfe. Ein Prinzip, das hier die Wahl der richtigen, dem jeweiligen Leistungsbedarf gemäßen Leistungsform leiten müßte, könnte man Formgerechtigkeit oder Formadäquanz nennen. Ein Anwendungsfall wurde soeben deutlich im Familienlastenausgleich.

Ein weiteres Beispiel - der vielleicht wichtigste Problembereich der heutigen Gesellschaft - ist der Pflegefall. Derzeitige Lösung: Selbsthilfe durch Geldleistungen der Betroffenen und durch Dienstleistungen der nächsten Angehörigen. Das soziale Netz der Familie funktioniert noch, wenigstens partiell. Subsidiär tritt Sozialhilfe ein. Die Lösung, die der Gesetzgeber mit der "Gesundheitsreform" anstrebt, ist die Ubernahme des Pflegefalles in die Sozialversicherung. Der Einstieg wird nunmehr gemacht, jedoch in so schmalem Umfang, daß eher unerwünschte als erwünschte Wirkungen eintreten dürften. Für die wirklich Belasteten wird nicht mehr herauskommen als ein Tropfen auf den heißen Stein. Im übrigen könnte sich der Mitnahmeeffekt ergeben. Schlimmeres könnte folgen. Die Sozialversicherung dürfte niemals fähig sein, den gesamten Leistungsbedarf im Pflegefall abzudecken. Aber die Schaffung eines sozialversicherungsrechtlichen Anspruchs, der 
(wenn auch nur scheinbar) beitragsfundiert ist, wird das Anspruchsdenken provozieren, den Willen zur Eigenleistung und den Opfersinn im Dienste der nächsten Angehörigen schwächen und das noch leidlich intakte Netz privater Hilfe diskreditieren. Deswegen ist es unerläßlich, bei neuen Formen staatlicher Hilfe auf Formadäquanz gegenüber den realen Gegebenheiten zu achten.

Vorsitzender: Vielen Dank, Herr Isensee. Herr Häberle, bitte, als erster Redner jetzt zu Punkt 3.

Häberle: Ich konzentriere mich auf Punkt 3 „Reformvorschläge“ und möchte drei Problemfelder anschneiden: Erstens die interessante Forderung von Herrn Hill, den Leistungsgesetzen in Zukunft Vorsprüche voranzustellen; zweitens den Vorschlag von Herrn Hufen (LS 6), auch Herrn Hill, in Sachen unabhängige Gesetzgebungskommissionen, auch ich fühle mich dazu dank rechtsvergleichender Erfahrungen in Schweden und in der Schweiz ermutigt; drittens ein Wort zu einem Thema, das mir dank seiner besonderen europarechtlichen Kompetenz ein Vorredner aus Saarbrücken fast vorweg genommen hat, zum Verhältnis unseres Themas zu „1992“ (Europäischer Binnenmarkt). Zum ersten Punkt: Herr Hill, ich war zunächst bestochen von Ihrer Idee, Leistungsgesetzen Vorsprüche bzw. Zwecke voranzustellen. Indes lehne ich sie doch ab. Bei verfassungsstaatlichen Verfassungen des westlichen Kodifikationsstils ist dies anders. Hier gibt es eine hohe Präambel-Kultur mit bestimmten Elementen und Funktionen wie: feierliche Einstimmung der Bürger auf bzw. ihre Integration in die Verfassung via Sprache, Verarbeitung der Zeitdimension, Präambelinhalte als ,Konzentrat" der Verfassung. Wir dürfen diese Präambelkunst der Verfassunggeber gerade nicht auf einfache Leistungsgesetze übertragen. Warnen sollten die Negativ-Beispiele in autoritären und totalitären Staaten z.B. der NS-Zeit und des Ostblocks, die gerne ihren Gesetzen überfrachtete Präambeln vorausschicken. Stets droht die Gefahr der Ideologisierung des Rechts, der Uberwucherung der Parlamentsgesetze. Es sollte Sache des auslegenden Juristen der Verwaltung bzw. der Gerichte bleiben, das Gesetz und seine „Zwecke“ dank der teleologischen bzw. in ihrem Dienst stehenden klassischen Methoden zu erschließen. Ich warne davor, dieses bewährte Handwerkszeug von präambelartigen Zweckkatalogen in Leistungsgesetzen her zu verfälschen.

Ein Ja-Wort zu Punkt 2: unabhängige Gesetzgebungskommissionen. Diesen Vorschlag finde ich bestechend, auch wenn die von einigen Vorrednern erwähnten Demokratieprobleme zu bedenken sind. Indessen gibt es ja in England die royal commissions. Meines Wissens sind in Schweden gute Erfahrungen mit sogar obligatorischen Gesetzgebungskommissionen gemacht worden. Ich verweise vor allem auf die Schweiz 
als Vorbild. Dort arbeitete auf der Ebene der Bundesverfassung die berühmte Expertenkommission zur Totalrevision(1977), über die die Schweizer Kollegen Näheres sagen können. Auf kantonaler Ebene wurden gerade jüngst viele Totalrevisionen durch sehr erfolgreiche Kommissionen bzw. „Verfassungsräte“ vorbereitet. Auch auf anderen Feldern, etwa vor der Datenschutz- und Umweltschutzgebung, sind kantonal und auf Bundesebene unabhängige Gesetzgebungskommissionen mit Erfolg tätig geworden. Bei uns gibt es ja gewisse Vorformen neben den Hearings in Gestalt des Deutschen Juristentags. Auch erwähne ich gerne den bayerischen Senat als eigene Kammer, um so lieber als ein Bayreuther Kollege seit kurzem Senator in München ist. Er und Herr Ekk. Schumann rühmen den Senat in seiner Eigenschaft als beratende, begutachtende Kammer, also als eine Art Gesetzgebungskommission, vielleicht sogar als Vorbild für den Bund. Wie stellen Sie sich, Herr Hufen und Herr Hill die Zusammensetzung Ihrer Kommission vor? Ich plädiere dafür, möglichst wenige, am besten gar keine deutschen Staatsrechtslehrer vorzusehen: denken wir nur daran, wie wenig erfolgreich wir in eigener Sache bei Satzungsfragen in Mitgliederversammlungen sind!

Der 3. Punkt, Herr Vorsitzender, nur noch in einer Sekunde: Auch ich erinnere wie schon Herr Ress an das Delors-Wort, in 10 Jahren seien 80 Prozent der Wirtschafts- und Sozialgesetzgebung nicht mehr nationalen Ursprungs, sondern Gemeinschaftsrecht. Könnten die Referenten in ihren gewiß glanzvollen Schlußworten zeigen, wie sie ihre Reformvorschläge im Blick auf „1992“ auf der höheren Ebene des Europarechts und seines Leistungsrechts konkretisieren? Im übrigen folge ich dem mächtigen Votum des allgemeinen Verwaltungsrechtslehrers Schmidt-Aßmann: Allen drei Referenten ist ein großer Sprung nach vorn geglückt in der Strukturierung des seit 1971 behandelten „Leistungsrechts“.

Vorsitzender: Vielen Dank. Das Wort hat jetzt Herr Riedel. Vielleicht können Sie auf die Punkte, die schon angesprochen worden sind, verzichten und dadurch etwas kürzen.

Riedel: Ich werde in der Tat alles das, was zu den Vorschlägen de lege ferenda und de constitutione ferenda von den drei Vortragenden gesagt worden ist, jetzt nicht affirmativ bestätigen, sondern mich auf Kritikpunkte beschränken. Hervorheben möchte ich aber, daß ich insbesondere die Vorschläge zu Thesen VI und VII von Herrn Hufen in Übereinstimmung mit vielen Vorrednern für ausgezeichnet und für vertiefungswürdig halte. Auch Herrn Ress möchte ich zustimmen in seinen rechtsvergleichenden Bemerkungen, insbesondere zum anglo-amerikanischen Recht, zugleich aber etwas Wasser in den Wein gießen. Die 
Erfahrungen in Großbritannien mit den „law commissions“, mit den „law reform commissions“ und vor allen Dingen mit der „Law Commission" selber geben ein doch differenzierteres Bild. In vielen Bereichen des Privatrechts, wenn es um die Konsolidienung bzw. sogar um Versuche der Kodifizierung des mäandernden „case law" ging, hat es hervorragende Ergebnisse gegeben. Gerade aber im Bereich des öffentlichen Rechts fällt die Bilanz nicht so positiv aus. Herr Ress wird mir da wohl zustimmen. Es hat vor 14 Jahren den Versuch gegeben, das Klageformensystem im öffentlichen Recht in Großbritannien zu konsolidieren, zu verändern und ein modernes, dem Verfassungsrecht entsprechendes Verwaltungsrecht zu schaffen. Diese Versuche sind weitgehend gescheitert; es ist bekanntlich lediglich aufgrund der restriktiven Vorschläge der ,law commission" zu einer Konsolidierung des „case law" und infolgedessen nur zur Amalgamierung der alten „prerogative writs" zu einer einheitlichen ,application for judicial review“ gekommen. Wir haben hier ein Beispiel, daß eine flächendeckende, wirklich grundsätzliche Regelung durch eine solche Kommission letztlich verhindert wurde; fast könnte man sagen: „If you don't want a decision, put it to a commission."

Nun mag das für die Bundesrepublik eine ganz andere Problematik sein, hier liegen die verfassungsrechtlichen und gesetzesrechtlichen Bedingungen ganz anders. $\mathrm{Zu}$ bedenken geben möchte ich aber insbesondere die Frage, wenn die Kommission die Themen selber stellen könnte oder gestellte Themen selber im Umfang definieren könnte, statt daß dies exekutivisch vorgegeben wird, wie es in Großbritannien der Fall ist, dann wäre es vielleicht ein ganz hervorragender Vorschlag und würde sich decken mit dem, was auch Herr Schneider eben sagte. Soviel zur These VI.

Zur These VII noch viel kürzer. Die Bemerkung von Herrn Oppermann zur Wesentlichkeitstheorie möchte ich voll unterstreichen und sagen, daß sicherlich der Streit um diese „Theorie“ durch eine Grundlagengesetzgebung nicht beseitigt würde, da es bei der Wesentlichkeitstheorie und dem Streit darum ja im wesentlichen um die Auslegung einer Gesetzesvorschrift am Maßstab der Verfassung geht und nicht um Auslegung von Gesetzesmaterien im Verhältnis untereinander.

Und schließlich kritisch, obwohl ich im Grunde genommen für eine solche Grundlagengesetzgebung eintrete, vermittelt ein solches Grundlagengesetz, wenn es vorhanden wäre, nicht eine zu große Statik? Ist die dadurch gewonnene Rechtssicherheit nicht vielleicht ein zu hoher Preis? Vielen Dank.

Vorsitzender: Vielen Dank, Herr Riedel. Herr Steiger, bitte. 
Steiger: Ich möchte noch einmal auf die Gesetzeskommission eingehen. Ich bin eher der Meinung von Herrn Zeh. Ich meine, daß diese unabhängige Gesetzeskommission, so wie Sie, Herr Hufen, sie als eine frühzeitige ,Konfliktbereinigungsinstitution " beschrieben und in der Zwischenbemerkung auch noch einmal ausdrücklich bestätigt haben, zu einer Entpolitisierung des Politischen führt. Denn worum gehen die Konflikte? Sie gehen doch um Ziele und Zwecke. Herr Mußgnug hat uns in seinem Referat nach meinem Eindruck sehr deutlich gemacht, $\mathrm{daß}$ das $\mathrm{Ob}$, das Wie und der Umfang von Leistungen heute der Inhalt des Politischen im parlamentarisch-demokratischen Staat sind. Wenn wir die Konfliktbereinigung darüber in eine unabhängige Gesetzgebungskommission verlegen, und ich frage mich mit Herrn Zeh, was hier „unabhängig“ heißt, dann läuft das m.E. auf den Versuch heraus, dieses Politische zu entpolitisieren. Das kann nicht funktionieren. Man mag eine Gesetzgebungskommission über Methoden zur Regelung bestimmter Sachmaterien befragen; sie mag Informationen hinzusteuern; sie mag irgendwelche systematischen Zusammenhänge den Abgeordneten erläutern; aber die eigentliche Konfliktfrage, nämlich über Ziel und Zweck zu entscheiden, und das gilt meines Erachtens auch für die Rentenreform, kann einer solchen Kommission nicht übertragen werden, wenn denn das parlamentarische Regierungssystem noch ein politisches sein und die Entscheidung über den Konflikt nicht aus dem Parlament hinausverlagert werden soll. Das scheint mir jedoch die groBe Gefahr einer ,frühzeitigen Konfliktbereinigung" durch eine derartige Gesetzgebungskommission zu sein. Da wäre ich auch für eine Präzisierung dankbar, wie denn diese Kommission zusammengesetzt werden sollte.

Ein Wort, lieber Herr Mußgnug, zu Ihrer These 6. Ich sehe zwar ein, daß es eine budgetäre Beweglichkeit geben muß. Aber im Hinblick auf die mir am Herzen liegende Familie meine ich, doch auch die Verläßlichkeit von Subventionen betonen zu müssen. Man muß sich auf solche Leistungen verlassen können, wenn man einen Lebensbereich auf Zukunft und Selbstregulierung hin gestalten will.

Vorsitzender: Danke schön, Herr Steiger. Herr Steinberg, bitte, auch zur Gesetzgebungskommission.

Steinberg: Ich begrüße es außerordentlich, daß die Referenten sich bemüht haben, Kriterien für Grenzen und Maß des - wie Herr Mußgnug gesagt hat - überbordenden Leistungsstaates zu entwickeln. Ich stimme den Referenten auch $\mathrm{zu}$, daß sie das Heil derartiger Lösungen nicht in inhaltlichen Kriterien im Sinne einer optimalen Gesetzgebung gesucht haben. Ich glaube, das ist in der Tat verfehlt. Es bleibt damit nur die Lösung in der Suche nach prozeduralen oder organisatorischen 
Vorkehrungen, und hier möchte ich mit Nachdruck das unterstützen, was Herr von Arnim in seinem Beitrag im ersten Teil heute morgen vorgetragen hat.

Ich glaube, wir müssen uns über eins klar werden. Gesetzgebung ist heute vereinbarte Gesetzgebung. Wenn das Gesetz als Akt der Vernunft bezeichnet wird, muß jemand, der die aktuelle Gesetzgebung verfolgt, meiner Ansicht nach heute rot werden. Es kann auch gar nicht anders sein. Das Gesetz ist heute ein pluraler Schöpfungsakt, wie es Herr Eichenberger treffend formuliert hat, und dafür - für die heutigen Bedingungen der Gesetzgebung im demokratischen, pluralistischen Staat - müssen Vorkehrungen geschaffen werden mit dem Ziel richtiger Gesetzgebung. Das ist jetzt wieder keine inhaltlich-richtige Gesetzgebung. Aber ich glaube, daß wir als Juristen, als Verfassungsjuristen, hier Beiträge leisten können; denn seit der amerikanischen Verfassung mit den federalist papers ist bekannt, daß die Verfassung ja eine Vorkehrung ist für die Erreichung einer bestimmten Richtigkeit der staatlichen Willensbildung. Um es schlagwortartig zu sagen, die Verfassung als Schutz des Volkes vor sich selbst in bestimmten Fragen, vor allem durch das repräsentative System. In diesem Sinne sind Regelungen der Landesverfassungen zu verstehen, in denen Volksgesetzgebung zugelassen ist, aber bestimmte Materien, z.B. finanzwirksame Gesetzentwürfe, ausgenommen sind.

Ich will zu den Verfahrensvorschlägen im einzelnen nicht Stellung nehmen, mir scheint der Vorschlag von Herrn Hufen zu den Gesetzgebungskommissionen bedenkenswert. Es kann sich hierbei selbstverständlich nur um vorbereitende Kommissionen handeln. Wenn Sie, Herr Zeh, sagen, das Parlament sei die Kommission, geht das nicht ein wenig an der Realität der Gesetzgebung vorbei? Es geht doch hier um die Frage, wer die Gesetze vorbereitet. Der ist doch in den meisten Fällen der effektive Gesetzgeber. Auf die Bedeutung des Schöpfungsaktes des Gesetzgebungsentwurfs hat Walter Burkhardt außerordentlich präzise vor mehr als 50 Jahren hingewiesen. Es geht darum, wer den Entwurf vorbereitet. Und wenn Herr Hufen in seiner Ziffer IV, wenn ich recht erinnere, auf die Spezialisten der Ressorts und der Fraktionen hingewiesen hat, dann muß man natürlich ergänzen: und auf die Spezialisten der Interessenverbände. Angesichts dieses Befundes könnte möglicherweise eine andere Organisation der Vorbereitung bei der Gesetzgebung den Kreis der hierbei Beteiligten verändern. Wie das im einzelnen funktioniert, müßte man überlegen. Hier sind ja in der Diskussion eine Reihe von wichtigen rechtsvergleichenden Hinweisen gebracht worden.

Noch ein abschließender Hinweis. Auch die Projektgruppe Regierungs- und Verwaltungsreform hat sich Anfang der 70er Jahre hieruiber Gedanken gemacht. Auch wenn ich vielen Überlegungen zustimme, 
möchte ich doch einen ganz wesentlichen Vorbehalt anmelden. Ich bin nämlich der Meinung, daß letztendlich auch alle organisatorischen oder verfahrensmäßigen Vorkehrungen nur begrenzt das Ergebnis des Gesetzgebungsprozesses verändern werden, weil die diesem Verfahren zugrundeliegenden Interessen eben unterschiedliches Gewicht haben. Und ich glaube, allen Bemühungen und Überlegungen etwa von Herrn von Arnim zum Trotz, daß letztendlich das unterschiedliche Gewicht allgemeiner Interessen und bestimmter Sonderinteressen nicht aufzuheben ist, jedenfalls nicht durch derartige Vorkehrungen. Es bleibt hier meiner Ansicht nach nur der Appell an die demokratische Öffentlichkeit, auch an die Wissenschaft. Und ich glaube, das jüngste hessische Beispiel hat ja sehr deutlich gezeigt, welche positiven Wirkungen die Interventionen eines einzelnen Wissenschaftlers haben können.

Vorsitzender: Vielen Dank, Herr Steinberg. Das Wort hat Herr Sachs. Bitte ähnlich kurz wie gestern. Sie haben sich da selbst schon ein Vorbild gegeben.

Sachs: Ich werde mich bemühen. Ein paar Worte gegen eine problematische Rechtsfigur, die bei Herrn Hufen und Herrn Hill, These IX bzw. II auftaucht. Herr Mußgnug vermeidet sie bewußt. Ich vermag den juristischen Sinn von Gesetzen nicht recht einzusehen, die einerseits binden sollen, andererseits aber keiner Sanktion unterliegen und praktisch nicht kontrolliert werden. Das sind im Grunde Pseudorechtsnormen, Täuschungs- oder Selbsttäuschungsmanöver. Zum zweiten zur These VII von Herrn Hufen, nur ergänzend: Eine neue Stufe in der Normenhierarchie ist auch wieder ein neuer Anlaß für neue Normenkontrollverfahren, von denen wir schon genug haben. Als Verfassungsänderung ist sie zur Zeit wohl ohnehin nicht zu realisieren. Für das geltende Recht sollte man betonen, daß der einfache Gesetzgeber keine Kompetenz besitzt, seinen Nachfolger zu binden. Das verstieße gegen die Periodizität des jeweiligen Parlaments.

Zur Kooperationsthese 13 von Herrn Hill möchte ich einmal den Vergleich zum Steuerrecht wagen. Dort begnügt sich der Bürger auch nicht gerne damit, nur mit der Verwaltung zu kooperieren, von ihr optimal beraten zu werden. Er vertraut seinem Steuerberater, dem seine Interessen am Herzen liegen. Ähnliches wäre dann wohl auch bei den Sozialleistungen nötig, nur wieder schwieriger zu finanzieren.

Und ein letztes Wort zur These 14 bei Hern Mußgnug. Das Versagen des verwaltungsgerichtlichen Rechtsschutzes im Leistungsbereich könnte zu einem Teil über den Gleichheitssatz im Sinne meines gestrigen Vorschlages korrigiert werden, und auf derselben Grundlage könnte man auch wieder einmal eine verfassungsgerichtliche Kontrolle gleichheitswidriger Leistungsgesetzgebung durchführen. Vielen Dank. 
Vorsitzender: Danke schön, Herr Sachs. Ich rufe jetzt den letzten Diskussionsteilnehmer, Herrn Schweizer, auf.

Schweizer: Herr Steinberg und Herr Häberle waren so freundlich, die schweizerischen Erfahrungen mit den unabhängigen Gesetzgebungskommissionen anzusprechen. Darf ich ganz kurz dazu ein paar Hinweise geben. Tatsächlich werden in der Schweiz in der Regel alle wichtigen Gesetze durch außerparlamentarische, verwaltungsunabhängige Expertenkommissionen vorbereitet. Meistens werden diese von der Regierung eingesetzt. Bedeutsam ist, daß im Sozialversicherungsbereich das Gesetz selbst eine ständige Rentenrevisionskommission vorsieht, die seit vielen Jahren die jeweiligen Anpassungen sämtlicher Rentenbereiche vorberät. Die Zusammensetzung dieser Expertenkommissionen ist meistens viergeteilt. Es sind Wissenschaftsvertreter, es sind Verbandsvertreter, es sind Kantons- (= Länder)Vertreter und Verwaltungsbeamte, diese natürlich in der Minderheit. Die Vorteile, die wir in diesen Expertenkommissionen sehen, sind sicherlich, daß auch Sachinformationen, die außerhalb der Verwaltung entstanden sind, frühzeitig in das Gesetzgebungsverfahren eingebracht werden und diskutiert werden können. Zweitens glauben wir, in diesen Expertenkommissionen auch grundsätzlichere Lösungen zu finden, eben in dem, was Herr Meyer angesprochen hat, die Distanz haben zu bloßen vertikalen Verwaltungskenntnissen und ressortunabhängige Querschnittslösungen ermöglichen. Drittens ist diese Expertenkommissionstätigkeit sehr wichtig für die Prüfung der Akzeptanz und der Vollzugsdeutlichkeit der Entwürfe. Damit haben wir eigentlich auch zum Teil recht ordentliche Erfahrungen gemacht. Es gibt auch Nachteile. Ich nenne darum einen: $\mathrm{Da}$ m.E. der Druck der Verbände auf die Regierung größer geworden ist, beruht auf einer steten Erwartungshaltung, obligatorisch beteiligt $\mathrm{zu}$ werden, und zwar in angemessenem Maße. Und zweitens ist tatsächlich das Problem, das Herr Steiger angesprochen hat, existent, ob nicht vor dem parlamentarischen Verfahren gewisse Kompromisse geschlossen werden, die dann nachher gleichsam tabu sind. Das gilt z.B. für die Rentenreform. Es mag möglich sein, daß es nicht anders geht. Und es ist die Frage - gestatten Sie diese kritische Frage -, ob nicht auch hierzulande in den von Ministerien geführten Verfahren mit den Anhörungen solche Vor-Kompromisse immer wieder vorkommen.

Gestatten Sie noch zwei Hinweise zu etwas anderem.

Erstens, der Vorschlag von Herrn Mußgnug, den Haushaltsplan als genügende Grundlage anzusehen, wäre bei uns undenkbar. Wir gehen grundsätzlich von einem Zweischritt aus: rechtliche Grundlage, also gesetzliche Grundlage plus gültiger Beschluß. Nur in Ausnahmefällen, z.B. bei der Entwicklungshilfe, bei Auslandstätigkeiten oder im Kul- 
turbereich, nur in solchen Randbereichen der rechtlichen Normierung kommen wir mit bloßen Budgetbeschlüssen aus. Das hängt damit zusammen, daß bei uns der Haushaltsplan natürlich nicht Gesetzesstufe hat, sondern ein untergesetzlicher Parlamentsbeschluß ist. Und zweitens, wichtiger: Es wäre bei uns verfassungswidrig, in ein so großes Superpaket divergierende Beschlüsse zu verknüpfen und zu entscheiden, ohne daß einzelne Vorentscheidungen auf Gesetzesstufe mit Referendumsrechten möglich wären. Also, die sogenannte Einheit der Materie der Entscheidungen würde das verbieten.

Einen letzten, ganz kurzen Hinweis bitte. Es liegt in der Schweiz jetzt ein allgemeiner Teil eines Rechts der Subventionen vor, ein Regierungsentwurf für ein allgemeines Subventionsgesetz. Meine Damen und Herren, Sie können sich diesen Entwurf beim Eidgenössischen Finanzministerium oder beim Eidgenössischen Justizministerium besorgen. Vielen Dank.

Vorsitzender: Vielen Dank, Herr Schweizer. Wir kommen jetzt mit einer geringfügigen Verzögerung zu den Schlußworten der Referenten. Ich darf Herrn Hill bitten zu beginnen.

Hill: Ich darf mich zunächst einmal sehr herzlich bedanken beim Vorstand, daß er mir Gelegenheit gegeben hat, heute hier zu referieren und Ihnen einige Aspekte einer öffentlich-rechtlich orientierten Gesetzgebungslehre nahezubringen. Ich habe sehr viele Anregungen aus der Diskussion erfahren und werde noch gern und häufig darüber nachdenken.

Nun zum Schlußwort. Zunächst, Herr Isensee, zu Ihrer Frage nach Kriterien zur Auswahl der Instrumente im Leistungsstaat. Ich finde, solche Kriterien sind schon in der Verfassung angelegt. Die Staatszielbestimmungen des Grundgesetzes und die Grundrechte sowie die sich daraus ergebenden Leistungszwecke und die Anforderungen des jeweiligen Sachbereichs gilt es zu harmonisieren, und zwar im Hinblick auf die Ordnung des Zusammenlebens im Spannungsfeld von Individualität und Solidarität. Unter diesen Gesichtspunkten und den dabei gewonnenen Erkenntnissen sind dann die Instrumente sach- und systemgerecht auszuwählen.

Der nächste Punkt enthält eine Anmerkung zum Thema „Gesetzestypen ". Ich glaube, die heutige Diskussion hat gezeigt, daß wir in $\mathrm{Zu}$ kunft noch sehr viel mehr darüber nachdenken werden müssen, ob man an dem einheitlichen Gesetzesbegriff festhalten, ob also Gesetz gleich Gesetz bleiben kann. Herr Breuer hat das ausführlich problematisiert. Ich habe hier als Gesetzestypen im Leistungsrecht den Befehl, den Plan, den Auftrag und die Information aufgeführt. Ich habe damit an eine Differenzierung angeknüpft, die Herr Brohm in einem Einfüh- 
rungsaufsatz gemacht hat. Er hat Gesetzestypen im Eingriffsrecht, insofern etwas abweichend von meiner Differenzierung, als Befehl, Auftrag, Ermächtigung und Schranke dargestellt. Herr Breuer, Sie haben gefragt: „Was bringt das an verfassungsrechtlichen Erkenntnissen?“ Ich meine, es muß darüber nachgedacht werden, welche Auswirkungen diese Differenzierung der Gesetzestypen auf die Funktionenordnung und die Kompetenzen der einzelnen Organe hat. Zunächst gilt das im Hinblick auf die Selbstbindung des Gesetzgebers, etwa was die Grundsatzgesetzgebung angeht, dann aber auch im Hinblick auf eine abgestufte Bindung der Verwaltung. Man muß sich fragen, haben die unterschiedlichen Gesetzestypen auch verschiedene Bindungen der Verwaltung zur Folge? Und drittens, das haben Sie angesprochen, im Hinblick auf unterschiedliche Kontrollmaßstäbe des Bundesverfassungsgerichtes. Ich darf nur erinnern an die Entscheidung des Bundesverfassungsgerichtes zum Mitbestimmungsgesetz, in der das Gericht von verschiedenen Kontrollmaßstäben im Hinblick auf Prognoseentscheidungen des Gesetzgebers ausgegangen ist. Es hat eine Abstufung in eine bloße Evidenzkontrolle, eine Vertretbarkeitskontrolle und eine intensivierte inhaltliche Kontrolle vorgenommen. Insofern wäre auch eine abgestufte Kontrolldichte im Hinblick auf die unterschiedlichen Gesetzestypen denkbar. Ich glaube, darüber müssen wir noch verstärkt nachdenken.

Herr Häberle, zum Gesetzesvorspruch will ich heute nicht sehr viel sagen, das habe ich an anderer Stelle getan. Ich verweise dazu vor allem auch auf den demnächst erscheinenden Tagungsband der diesjährigen Speyerer Frühjahrstagung „Zustand und Perspektiven der Gesetzgebung". Vielleicht nur so viel: Das Vorbild zum Gesetzesvorspruch ist Art. 190 des EWG-Vertrages. Der Gesetzesvorspruch ist ei$n e$ Möglichkeit zur Vermittlung der Gesetze an die Adressaten. Eine andere Variante wäre der Vorschlag von Herrn Lücke, bei Gesetzen zwingend eine Begründung vorzusehen; eine andere Möglichkeit wäre ein Begleitprogramm zum Gesetz. Es gibt mehrere Alternativen, ihr gemeinsames Ziel ist eine Verbesserung der Vermittlung der Gesetze an die Adressaten.

Nächste Anmerkung zum beweglichen System. Herr Breuer, Sie haben gefragt, was ist das Neues? Wir kennen ja bisher schon die Auslegung und Konkretisierung von Gesetzesbestimmungen. Ich meine, der wesentliche Unterschied liegt darin, daß der Rechtsanwender - insoweit gleichgültig, ob Verwaltung oder Gericht - bei der Auslegung die wesentlichen Wertungen vornimmt. In unserem Verfassungssystem ist es aber Aufgabe des Gesetzgebers, die wesentlichen und grundlegenden Wertungen vorzugeben und damit die Rechtsanwendung zukunftsorientiert zu steuern. Insofern würde das bewegliche System die Funktionenordnung des Grundgesetzes besser zum Ausdruck bringen. 
Herr SchmidtJortzig, Sie haben gefragt, was bringt die Figur des Rechtsverhältnisses, vor allem im Leistungsrecht? Ich meine, sie bringt zusammengefaßt - ich habe das ja schon ausführlicher dargestellt, und es ist auch bei der Münchener Tagung 1986 diskutiert worden - drei Dinge: Erstens bietet das Rechtsverhältnis eine übergreifende Hülle für die Beziehungen der Verwaltung zum Bürger, zunächst im bilateralen Verhältnis. Der Verwaltungsakt ist nur eine punktuelle Äußerung. Es gibt darüber hinaus aber einen vielfältigen, zusätzlichen Rechte- und Pflichtenkanon im Vorfeld und im Nachfeld einer Entscheidung. Es gibt daneben andere Handlungsformen, die die Beziehung Verwaltung - Bürger gestalten bzw. beeinflussen. Das Rechtsverhältnis bietet meiner Ansicht nach eine geeignete dogmatische Figur, diese verschiedenen Äußerungsformen sowie Rechte und Pflichten zu integrieren. Dies gilt zweitens nicht nur für das bilaterale Verhältnis, vielmehr bietet das Rechtsverhältnis vor allem die Möglichkeit, die Mehrseitigkeit und Komplexität der Beziehungen zu erfassen, also etwa auch den sog. Dritten im Verwaltungsrecht sowie weitere Betroffene bzw. Interessenten einzubeziehen. Zum dritten hat es vor allem einen Entwicklungsaspekt. Es ermöglicht die bessere Erkenntnis und Verfolgung von Rechtsentwicklungen in der Zeit. Das sind meiner Meinung nach die wesentlichen Vorteile der Rechtsfigur Rechtsverhältnis. Ich stehe daher dieser Figur durchaus positiv gegenüber.

Letzter Punkt - zum Kooperationsprinzip. Insoweit hat Herr Breuer gefragt - ich überspitze es jetzt mal etwas -, wollen wir die bewährten Ansprüche aufgeben? Natürlich will ich das nicht. Ich habe versucht, Vorteile und Nachteile von Ansprüchen zu schildern, genauso wie Vor- und Nachteile von Ermessen und habe - Sie erinnern sich vielleicht an die $\S \S 31$ und 33 SGB AT und die $\S \S 4$ Abs. 1 und 2 BSHG - für eine Kombination von Ansprüchen im Hinblick auf die Rahmenausgestaltung und Ermessen im Hinblick auf die Ausfüllung des Rechtsverhältnisses plädiert. Bei der Ausfüllung des gesetzlich vorgegebenen Rahmens, im Zusammenhang mit dem Ermessen der Verwaltung, also bei der Art und Weise der Leistungserbringung sollte nach meiner Auffassung eine Kooperation zwischen Verwaltung und Bürger stattfinden. Denn ich denke, es geht vor allen Dingen in den Bereichen, in denen staatliche Leistungen Voraussetzungen und Hilfen für die Grundrechtsverwirklichung darstellen, nicht an, daß der Staat einseitig die Leistung bestimmt. Insoweit ist eine Kooperation unbedingt erforderlich, um das Recht des Leistungsempfängers zur eigenverantwortlichen individuellen Lebensgestaltung besser $\mathrm{zu}$ wahren. Und ich könnte mir, Herr Sachs, in Anlehnung an Ihre Bemerkung zum Steuerberater und im Hinblick auf das amerikanische Modell der Mediation durchaus auch vorstellen, daß ein neutraler Vermittler, der sozusagen zwischen Verwaltung und Bürger steht, bei der Kooperation 
behilflich ist. Wir haben ähnliche Beispiele auch in unserem Rechtssy. stem, etwa im Sozialrecht, denken Sie an den Arzt oder den Sozialarbeiter. Ich glaube, darüber müßte man auch noch nachdenken, inwieweit dieses Modell zur Verbesserung des Verhältnisses Verwaltung Bürger und auch zur besseren Durchführung und Rechtsanwendung im Leistungsrecht geeignet sein kann.

Vorsitzender: Vielen Dank, Herr Hill. Das Wort hat Herr Hufen.

Hufen: Ich will diejenigen Punkte bevorzugt aufgreifen, die mir in der bisherigen Diskussion noch als zu kurz gekommen erscheinen. Herr Breuer, Herr Schmidt Jortzig, Herr Ress und Herr Häberle haben sozusagen Salz in die Wunden der Referenten gestreut im Hinblick auf wichtige Problemaspekte, die wir im Rahmen der uns zur Verfügung stehenden Zeit nicht behandeln konnten. Wenigstens stichwortweise: Keineswegs unwichtig sind die von mir als, instrumentell “ bezeichneten Aspekte wie Gesetzesaufbau, Verständlichkeit, Gesetzessprache usw. Auch die in hoffnungsvollem Himmelblau gehaltene „Checkliste“ der Bundesregierung für die Erarbeitung von Referentenentwürfen enthält sicherlich manchen wichtigen Teilaspekt. Das gilt auch für alle Vorschläge, die sich von einer "Schlußredaktion" eine Verbesserung der Gesetzesgestaltung erhoffen. Besonders schweren Herzens habe ich mich von dem von Herrn Schmidt-Jortzig angesprochenen Aspekt des Persönlichkeitsschutzes und der Möglichkeit, aber auch Grenzen der Sachaufklärung in den verschiedenen Verwaltungsverfahren getrennt. Auch hier zeigt sich jedenfalls eine wichtige Aufgabe des allgemeinen Verwaltungsrechts, die nicht in Spezialnormen des Datenschutzrechts abgeschoben werden sollte. Schmerzhaft auch das Auslassen der europäischen Dimension - in diesem Punkt nicht wegen der fehlenden Zeit, aber wegen fehlender europarechtlicher Sachkompetenz. Daher kann ich auf Herrn Häberles Frage, was wir in Bezug auf die europäische Dimension beizutragen hätten, nur ganz allgemein antworten. Ich meine, es ist hohe Zeit, daß sich die Besten der Gesetzesgestaltung auf nationaler Ebene, also Parlamentarier, Wissenschaftler, Verwaltungsfachleute usw. zusammensetzen und klären, was eine Art europäische Gesetzgebungslehre zur Qualität des Gemeinschaftsrechts beitragen kann. Hier sollten wir weder allein auf das europäische Parlament noch gar auf die instrumentelle Vernunft der europäischen Exekutive vertrauen.

Zum Gesetzgebungsverfahren, insbesondere zu meinem Vorschlag der Gesetzgebungskommission, ist in der Diskussion so viel gesagt worden, daß ich mich jetzt kurz fassen kann. Etwas betroffen hat mich hier der Einwand von Herrn Steiger gemacht, mein Vorschlag laufe auf eine Entpolitisierung hinaus. Bis hinein in die Einzelformulierungen 
wollte ich aber deutlich machen, daß es mir gerade nicht um eine solche Entpolitisierung geht. Es ging mir allerdings um die Versöhnung von Politik, Systematik und Qualität, um eine - meines Erachtens im Sinne der Geltungskraft der Gesetze sogar verfassungsrechtlich gebotene - Verbesserung von Qualität durch Verfahren. Geltungskraft von Gesetzen ist ja nicht nur eine Art ästhetisches Ideal sondern ihrerseits demokratisch und rechtsstaatlich geboten. Hinsichtlich der Zusammensetzung der Gesetzgebungskommissionen habe ich mir im Verlauf der Diskussion notiert: Vertreten müßten mindestens sein: Fraktionen, zuständiges Ministerium, Wissenschaft und wohl auch Verbände. Hier fühle ich mich durch das Modell bestätigt, das unser Schweizer Kollege Schweizer vorgestellt hat. In diesen Kommissionen scheinen mir genau die Kräfte vertreten, die auch ich vorschlagen würde. Im Hinblick auf den sachverständigen Rat, der in solchen Kommissionen vertreten sein müßte, würde ich zwar nicht sagen wie Herr Häberle: „möglichst wenige Staatsrechtslehrer“", aber auch nicht: „möglichst viele Staatsrechtslehrer". Es gehören aber doch wohl einige Staatsrechtslehrer als Moderatoren und eine Art Frühwarner hinein, damit wir nicht stets aufs neue gezwungen sind, Gesetze erst im nachhinein auf dem Prüfstand des Bundesverfassungsgerichts zu sehen, das bei uns anscheinend von manchen als eine Art „Verfassungs-TUV" für die Verkehrssicherheit von Gesetzen betrachtet wird.

Damit bin ich schon fast bei der Grundlagengesetzgebung angelangt. Bei allen Einwänden und bei aller Kritik habe ich mich doch gefreut, daß gerade diese Anregung in der Diskussion so breite Aufnahme gefunden hat. Ich begreife hier vieles von der vorgetragenen Skepsis, doch bin ich meinerseits den Skeptikern gegenüber skeptisch, denn es gibt ja längst das, was ich als Grundlagengesetzgebung bezeichnet habe - sie wird nur durch das falsche Staatsorgan, nämlich durch das Bundesverfassungsgericht formuliert. Und diese Art von „Grundlagengesetzgebung " ist - ungeachtet ihrer unzweifelhaften demokratischen Legitimation - jedenfalls für den demokratischen Prozeß noch weniger änderbar als die qualifizierte parlamentarische Grundlagengesetzgebung, die ich vorschlage. Verfassungsrechtsprechung überspringt mühelos die Legislaturperioden und hält sich auch nur mittelbar an das Mehrheitsprinzip. Hier ist die Verfassungsrechtsprechung in eine Luikke getreten, die der Gesetzgeber selbst wieder ausfüllen sollte. Herr Breuer hat in diesem Zusammenhang auf die korrigierende Wirkung von Aspekten wie Systemgerechtigkeit und Vertrauensschutz hingewiesen; doch geht dieser Hinweis leider doch wieder in die gleiche Richtung, denn es ist ja wieder das Bundesverfassungsgericht, das sagt, was das "System" und was das schützenswerte Vertrauen ist. Auch solche Grundlagenentscheidungen würde ich gern beim Gesetzgeber selbst sehen. So sehr mich also die vielen Einwände bewegen, insbe- 
sondere die von Herrn Sachs und Herrn Dittmann vorgetragenen, so sehr würde ich doch dazu auffordern, Möglichkeiten und Chancen des Instruments ,Grundlagengesetzgebung “ weiter zu verfolgen. Erinnern möchte ich auch daran, daß ich neben der ,großen“ von einer möglichen ,,kleinen “ Lösung gesprochen habe, nämlich Grundlagengesetzgebung ohne Verfassungsänderung, also z.B. durch entsprechende Modifikationen in den Geschäftsordnungen. Hier waren mir die Hinweise von Herrn Schmidt-Jortzig auf die Haushaltsgrundsätze und von Herrn Schmidt-Aßmann auf die Kodifikationsaufgaben im Bereich des allgemeinen Verwaltungsrechts besonders wertvoll.

Besonders gefreut hat mich, daß der Gedanke der Selbstregulierung auch in der Diskussion als wichtig und aktuell hervorgehoben wurde. Herr Hoffmann-Riem hat sogar von einer neuen Zauberformel gesprochen. Doch fände ich es sehr schade, wenn dies im Sinne einer modischen Zauberformel verstanden würde. Selbstregulierung und Selbstbestimmung sind ja eigentlich die ältesten und bewährtesten Formeln der Vorsorge überhaupt. Der Grundgedanke ist dabei auch von mehreren Diskussionsrednern hervorgehoben worden: Es geht sozusagen um eine gesetzliche Absicherung der Selbstregulierung und in gewissem Umfang auch um eine „Regulierung der Selbstregulierung“, wo wichtige gemeinschaftsbezogene Aufgaben wahrgenommen werden. Dankbar bin ich Herrn Schuppert für die Differenzierung Selbstverwaltung - Selbststeuerung - Selbstregulierung. Ich meine nur, diese drei Ebenen sind aufs engste miteinander verknüpft. Selbstregulierung etwa funktioniert unter dem Dach von ansonsten selbstverwalteten Bereichen - z.B. in den Gemeinden, Körperschafen, rechtlich verselbständigten Anstalten usw. - besonders gut. Die Selbstverwaltung kann hier besondere orts- und personennahe Kontrollformen ausprägen und die drei Ebenen können sich einander annähern.

Herr Haverkate hat in diesem Zusammenhang die Frage aufgeworfen, um wessen Autonomie es eigentlich gehe. Ich meine, das ist zum einen eine Frage der Größe der Organisation und es ist zum anderen eine Frage der Teilnahme an den jeweiligen Selbstregulierungsprozessen. Sie haben zu Recht kritisiert, daß ich mich hier in den Einzelheiten bedeckt gehalten habe. Das mußte ich, weil es einfach zu viele Ebenen, Größenordnungen, Gruppen usw. gibt, über die hier zu sprechen wäre. Sehr zustimmen kann ich in diesem Zusammenhang Herrn Isensee, der vom notwendigen Rahmen für die Selbstregulierung und von Verfahren für Kontrolle und Aufsicht gesprochen hat. Herr SchmidtJortzig hat zu Recht betont, daß Selbstregulierung nicht nur als Staatsentlastung verstanden werden darf - etwa in dem Sinne, daß eigentlich dem Staat zukommende öffentliche Aufgaben lediglich delegiert werden. Daneben geht es ja gerade um originär „private“ oder „gesellschaftliche“ Funktionen, die wegen ihrer Bedeutung in die Nä- 
he öffentlicher Aufgaben kommen und gleichwohl dezentral und vor Ort wahrgenommen werden. Die Klammer ist auch insofern die öffentliche Aufgabe, über die wir wohl insgesamt noch sehr viel zu sagen hätten.

Das Thema „Gleichheit" ist heute etwas kürzer gekommen als ich es erwartet hatte, kann aber gleichwohl den Bogen unserer Tagung schließen. Herrn Gramlich stimme ich im Hinblick auf den Zusammenhang von Gleichheit und Leistungssockel $\mathrm{zu}$, insbesondere was das $\mathrm{Zu}$ sammenwirken von Gleichheitssatz und Menschenwürde angeht. Gerade an der unteren Grenze menschlicher Leistungsfähigkeit gibt es auch menschenunwürdige Ungleichheit. Hier hört - das wollte ich deutlich sagen - die Freiheit zur Gesetzesgestaltung auf und es hat eine Gleichheit des Minimums zu herrschen, die ihre Kraft aus der Existenz des Menschenwürde-Prinzips bezieht. Sehr wichtig ist auch der von Herrn Haverkate hervorgehobene Aspekt der Gleichheit in der Zeit. Doch würde ich den Generationenvertrag nicht als Trug bezeichnen. Hier ist sowohl im Rentenrecht als auch im Umweltrecht ein ganz wichtiger Aspekt der Gleichheit, des Vertrauens, der Stetigkeit zwischen den Generationen. Um so mehr bedarf er der Absichenung durch generationenübergreifende Grundlagengesetzgebung und durch sichernde Verfahren. Für denjenigen, den der Staat in seine übergreifenden Leistungssysteme hineinholt, muß er die Leistungssysteme über die Grenzen der Generation und der Zeit hinweg verläßlich und stetig ausgestalten.

Herr Wallerath, in Sachen Kindergeld bin ich befangen. Dazu nur soviel: Ausgerechnet im Bereich des Familienlastenausgleichs lassen sich besonders drastische Beispiele für gesetzgeberische Querschläger, gleichheitswidrige Freigrenzen, Kumulationswirkungen usw. nachweisen.

Der Aspekt der Durchsetzbarkeit der verschiedenen heute vorgetragenen Reformvorschläge wäre sicherlich gesondert zu diskutieren. Er ist hier nur von Herrn Meyer angesprochen worden. Da die Vorschläge an den Kern des politischen Systems gehen, wird die Durchsetzbarkeit natürlich ein besonderes Problem sein. Herr Oppermann hat den Optimismus im Hinblick auf die Selbststeuerungsfähigkeit und das wache Bewußtsein des Volkes für die Qualität gesetzgeberischer Tätigkeit betont. Ich möchte es trotz aller vielleicht gegenläufigen Erfahrungen auch einmal mit Optimismus in bezug auf die Volksvertreter versuchen. Es klingt vielleicht naiv, aber ich gehe ganz einfach davon aus, daß auch die Parlamente von dem Interesse geleitet sind, gute Gesetze zu machen. Schon bestätigt hat sich mein Optimismus in bezug auf diese Diskussion. Ich bin Ihnen allen sehr dankbar für Kritik und Ergänzungen. Aus beidem habe ich viel gelernt - gerade was die internationalen und rechtsvergleichenden Aspekte anging. Im übrigen bitte ich um Fortsetzung des Gesprächs. Vielen Dank. 


\section{Vorsitzender: Vielen Dank, Herr Hufen. Das Wort hat Herr Muß- gnug.}

Mußgnug: Auch für mich ist einiges übriggeblieben, das ich gerne ansprechen möchte.

Herr Bachof hat auf eine Konsequenz aus meiner These XVI aufmerksam gemacht, die ich so nicht gesehen habe, die aber in der Tat aus ihr zu ziehen ist. Ich danke Herrn Bachof dafür, daß er meine Überlegungen zu Ende geführt hat.

Herr Wallerath hat die Verschonungsleistungen angesprochen, die ich aus sachlichen und aus Zeitgründen in meinem Referat nur erwähnt, aber nicht gründlicher durchleuchtet habe. Um so lieber greife ich seinen Hinweis auf, daß die Steuersubvention, die wichtigste Verschonungsleistung, daran krankt, daß sie sich nur bei den Einkommenstarken mit entsprechend hohen Steuerschulden in spürbaren finanziellen Vorteilen niederschlagen kann. Wer auf soziale Hilfe angewiesen ist, schuldet indessen so geringe Steuern, daß ihm Steuerverschonungen bestenfalls marginale Erleichterungen verschaffen. Die Steuersubvention taugt daher nur als Leistungssurrogat für die oberen Zehntausend. Für den Rest der Bevölkerung kommen auf dem Felde der Verschonungsleistungen nur die Gebührenermäßigungen und Gebührenbefreiungen in Betracht, die ihnen unter dem Motto „Schüler, Studenten, Rentner und Soldaten zahlen die Hälfte " gewährt werden. Sie finden ihre Rechtfertigung in einer altehrwürdigen sozialstaatlichen Tradition. Aber auch diese Tradition trägt nur die soziale Gestaltung der Eintrittspreise für die öffentlichen Schwimmbäder, Museen und Theater. Bei den weit höheren Gebühren der kommunalen Kindergärten, der Wasserversorgung, Abwasserbeseitigung etc. dagegen verbieten das Kostendeckungs- und Äquivalenzprinzip eine an sozialen Kriterien orientierte Tarifgestaltung. Denn man kann nicht für die gleiche Verwaltungsleistung unterschiedliche Gebühren fordern. Das Kostendekkungs- und das Äquivalenzprinzip zwingen vielmehr zur Gebührenbemessung nach der Regel „gleiche Leistung, gleicher Preis“, die keine sozial motivierten Abstriche duldet. Uber die Begründung des Verbots sozialer Differenzierungen bei den Verwaltungsgebühren und über die Voraussetzungen, unter denen es durchbrochen werden darf, werden wir jedoch noch intensiver nachdenken müssen. Es ist gut, daß Herr Wallerath darauf aufmerksam gemacht hat.

Was die Gesetzgebungs-Kommissionen angeht, so neige ich Herrn Steiger zu. Wie er, so sehe auch ich es als einen Sündenfall der Demokratie an, wenn sie unabhängige, dem Wählerwillen nicht verpflichtete Kommissionen in das Gesetzgebungsverfahren einschaltet, die mit dem Gewicht ihrer Voten die legislative Entscheidungsfreiheit der Parlamente schmälern. Dieses Bedenken richtet sich nicht gegen solche 
Kommissionen, die dem Gesetzgeber technische, natur- oder sozialwissenschaftliche Ratschläge erteilen, ebensowenig gegen die Kommissionen, die ihn bei der Formulierung seiner Vorschriften und bei ihrer Einpassung in das dogmatische System der Rechtsordnung beraten. Aber mit Kommissionen, die von Verfassungs wegen oder aufgrund zwingender gesetzlicher Vorschriften an der Gesetzgebung beteiligt werden und deswegen über kurz oder lang zu einer dem Parlament gleichrangigen oder gar überlegenen Konkurrenz erstarken, kann ich mich nicht anfreunden.

Das gilt erst recht für Herrn Steinbergs Vorschlag, das Gesetzgebungsverfahren dem jeweiligen Zustand der pluralistischen Gesellschaft anzugleichen, d.h. die Mitspracherechte der Repräsentanten partikulärer Interessen von den Gewerkschaften und Arbeitgeberverbänden bis hin zu den Kirchen dezidierter anzuerkennen. Diese Forderung zielt in ihrer Tendenz auf eine Verfälschung der alleinigen Repräsentation des Volkes durch das Parlament ab. Denn sie postuliert ein die Diagnosen der Soziologie und der Politikwissenschaft nachvollziehendes Verhalten des parlamentarischen Gesetzgebers. Der Gesetzgeber soll die Gesetze statt in eigener Verantwortung nach Maßgabe der Ansinnen gestalten, die von außen unter Berufung auf die Macht der Verbände an ihn herangetragen werden. Für die Staatsrechtslehre gibt es nach meiner Uberzeugung darauf nur eine Antwort: Anathema sit. Die Soziologie und die Politikwissenschaft können ermitteln, wie sich Verbände und Gruppen in das verfassungsrechtlich normierte Gesetzgebungsverfahren einmischen. Es steht ihnen auch frei, diese Einmischungen zu begrüßen. Aber sie gingen zu weit, würden sie verlangen, daß die Staatsrechtslehre ihre empirischen Befunde und theoretischen Hypothesen für sich zur normativen Richtschnur erhebt und auf jeden gesellschaftlichen Wandel sogleich mit einer entsprechenden Uminterpretation des Verfassungsrechts reagiert. Das Verfassungsrecht ist nach dem Grundsatz „ex factis ius non oritur" zu handhaben. Gehen wir statt dessen von der Regel „ex factis ius oritur" aus, so lösen wir das Verfassungsrecht auf. Fakten schaffen nur dann neues Verfassungsrecht, wenn sie vom Träger der verfassungsgebenden Gewalt gesetzt werden, also dann, wenn eine revolutionäre Bewegung sie auslöst. Das Grundgesetz gibt gottlob keinen Anlaß, derartige Bewegungen herbeizusehnen. Wir fahren daher besser, wenn wir die gesellschaftlichen Fakten dem Grundgesetz anpassen und uns strikt davor hüten, umgekehrt das GG den gesellschaftlichen Fakten anzugleichen. Deshalb verwahre ich mich dezidiert gegen jede Verbeugung der Staatsrechtslehre vor verfassungsrechtlich nicht ausdrücklich anerkannten pluralistischen Mechanismen. Das demokratische Verfassungsrecht beruht auf der Souveränität des Volkes in seiner Gesamtheit, nicht auf der Herrschaft oder auch nur Mitherrschaft einzelner Bevölkerungsgruppen. 
Gewiß, die gesellschaftlichen Gruppen tragen nachhaltig und sinnvoll zur Gesetzesgestaltung auf allen Gebieten und in besonderem Maße auf dem des Leistungsrechts bei. Aber der eigentliche Gesetzgeber muß das Parlament bleiben. Denn nur das Parlament wird vom Volk in seiner Gesamtheit beherrscht. Es mag sich von den Vertretern partikulärer Interessen beraten lassen. Es darf sein Amt als Gesetzgeber aber nicht an sie abtreten. Wie Friedrich der Große darauf gepocht hat, daß er und nicht Svarez der Gesetzgeber des ALR war, so müssen auch wir darauf achten, daß sich nicht neben dem Parlament der DGB, die Arbeitgeberverbände, die evangelische oder katholische Kirche und all die vielen anderen Verbände, Gruppen und Grüppchen zu clandestinen Mit-, Schatten- und Hintergrundgesetzgebern aufschwingen. Diese gesellschaftlichen Institutionen begrenzt das Grundgesetz auf die Einflußnahmen, die sie über die öffentliche Meinung auf die Gesetzesgestaltung nehmen können. Wir haben keinen Anlaß, dem Gesetzgeber mehr nahezulegen als eine gewissenhafte Prüfung ihrer Anregungen. Seine Gesetzgebungshoheit braucht und darf er nicht mit ihnen teilen.

Meiner These, der Haushaltsplan sei ein taugliches Instrument der Subventionssteuerung, ist entgegengehalten worden, der Haushaltsplan gebe den Subventionen keine präzisen Zweckbestimmungen vor. Dem möchte ich widersprechen. Der Haushaltsplan kann den Subventionen nicht nur genaue Ziele setzen; er tut das in aller Regel auch. Bewilligungen, die ohne nähere Konkretisierung Fonds für ,die Subventionierung notleidender Wirtschaftszweige " bereitstellen, kommen weder im Bundes- noch in den Landeshaushaltsplänen vor. Sie wären mit Art. $110 \mathrm{GG}$ und seinen landesrechtlichen Pendants unvereinbar. Wenn Art. 110 GG verlangt, alle Ausgaben in den Haushaltsplan einzustellen, so heißt das nicht, daß es mit einigen wenigen Globalansätzen getan wäre. So verfuhren die Regierungen in den Anfangszeiten der konstitutionellen Monarchie. Aber das haben sich die Landtage nicht bieten lassen. Sie haben in harten Kämpfen eine exakte Spezialisierung sämtlicher Haushaltsansätze durchgesetzt. Den Universitäten weisen die Haushaltspläne zwar nach wie vor Pauschalansätze für „Forschung und Lehre" zu, die sie nicht näher aufschlüsseln. Aber ihre Subventionstitel schlüsseln sie genauer auf. Bei ihnen warten sie mit trennscharfen $\mathrm{Zweckbindungen} \mathrm{auf.} \mathrm{Zu}$ ihnen treten die verwaltungsinternen, den Haushaltsausschüssen des Bundestags und der Landtage aber zur Prüfung zugänglichen Vergaberichtlinien, hinzu. Deshalb meine ich alles in allem, daß der Haushaltsplan sehr wohl eine tragfähige Grundlage für die Subventionsverteilung hergibt. Wenn er weniger bewilligt als in den Vorjahren, so führt das zwar zu Reibungen, die nicht ganz so abrupt auftreten würden, wenn die Subventionen samt und sonders gesetzlich geregelt wären und daher nur durch zeitraubende Gesetzesänderungen storniert werden könnten. Aber ich sehe den besonderen 
Vorzug der Subventionssteuerung durch den Haushaltsplan gerade darin, $d a b$ er die finanzpolitisch abträglichen langfristigen Bindungen des Gesetzesrechts vermeidet. Die Bindung der Subventionsverwaltung an ihre Verwaltungsakte bleibt davon unberührt. Sie sorgt für die Verläßlichkeit, die der Haushaltsplan nicht garantieren kann. Denn die einem Theater durch Verwaltungsakt zugesagte Dauerförderung läßt sich nicht kurzerhand aufkündigen, wenn der Haushaltsplan die für sie erforderlichen Mittel streicht. Sie ist, gleichgïltig was der Haushaltsplan über sie sagt, bis zu ihrem rechtlich einwandfreiem Widerruf zu leisten. Aber dabei muß es sein Bewenden finden. Es genügt, daß Rechtsansprüche auf langfristige Subventionsgewährung durch Verwaltungsakt begründet werden können. Ihre Begründung durch Gesetz ist zum einen nicht erforderlich und zum anderen haushaltspolitisch verfehlt. Deshalb gebührt der herkömmlichen Steuerung der Subventionen durch den Haushaltsplan m.E. nach wie vor der Vorzug vor ihrer Steuerung durch Gesetze.

Ich hätte noch auf einige weitere in der Diskussion angesprochene Punkte einzugehen. Aber ich will ihre Geduld nicht über Gebühr strapazieren. Darum nur noch ein Wort des Dankes an Sie alle für Ihr Interesse und für die Aufmerksamkeit, mit der Sie mir zugehört haben. Ich habe bei der Vorbereitung des Referats, heute morgen vor und nach meinem Vortrag und heute nachmittag in der Aussprache ein Übermaß an kollegialer Anteilnahme und Zuspruch erfahren. Daraus habe ich gelernt, daß ich zu kurz griffe, wenn ich nur für ihre Kollegialität dankte. Ich habe ihre Brïderlichkeit erlebt und genossen. Von Herrn Hill und Herrn Hufen weiß ich, daß es ihnen ebenso ergangen ist. Dafür wissen wir uns Ihnen verbunden. Es ist ein gutes Gefühl, einer wissenschaftlichen Vereinigung anzugehören, die neben der Freiheit und der Gleichheit ihrer Mitglieder auch die Brüderlichkeit hochhält und damit den rechten Rahmen für gemeinsames wissenschaftliches Arbeiten bietet, den Austrag wissenschaftlicher Kontroversen eingeschlossen. Bleiben wir dabei, was immer die Zukunft bringen mag.

\section{Beifall}

Vorsitzender: Meine Damen und Herren, gestatten Sie mir noch zwei Worte zum Schluß. Das erste ist ein Wort des Dankes noch ein$\mathrm{mal}$ an die Referenten dafür, daß sie sich die Mühe gemacht haben, die Referate auszuarbeiten, und daß sie dabei so gut kooperiert haben. Hinzuzufügen ist ein Wort des Dankes an die Diskussionsteilnehmer, die viele interessante Gesichtspunkte beigetragen haben und damit eigentlich den besten Dank an die Referenten abgestattet haben. Denn der beste Dank, den ein Referent bekommen kann, ist eine lebhafte und interessante Diskussion. Ich möchte Ihnen schließlich dafür dan- 
ken, daß Sie wenigstens kollektiv in der Lage waren, den zeitlichen Rahmen für die Diskussion einigermaßen einzuhalten.

Das zweite, was ich sagen möchte, ist, daß der Vorstand sich freut über die Annahme des Themas in der Diskussion. Ich habe es als Lob empfunden, daß ein Diskussionsteilnehmer gesagt hat, dieses Thema sei viel zu schade gewesen für den 2 . Tag, man hätte es an den 1 . Tag setzen müssen. Ich bin aber der Meinung, daß das Thema des ersten Tages nicht hätte diesem Thema weichen dürfen und daß wir gut daran tun, auch am zweiten Tag ein wichtiges Thema zur Aussprache zu stellen, was der guten Tradition der Vereinigung entspricht.

Damit möchte ich den wissenschaftlichen Teil unserer diesjährigen Tagung abschließen. 
